\title{
Serotonergic vulnerability : experimental studies in rats applying the method of acute tryptophan depletion
}

Citation for published version (APA):

Jans, L. A. W. (2008). Serotonergic vulnerability : experimental studies in rats applying the method of acute tryptophan depletion. [Doctoral Thesis, Maastricht University]. Universiteit Maastricht. https://doi.org/10.26481/dis.20080530lj

Document status and date:

Published: 01/01/2008

DOI:

10.26481/dis.20080530lj

Document Version:

Publisher's PDF, also known as Version of record

Please check the document version of this publication:

- A submitted manuscript is the version of the article upon submission and before peer-review. There can be important differences between the submitted version and the official published version of record.

People interested in the research are advised to contact the author for the final version of the publication, or visit the DOI to the publisher's website.

- The final author version and the galley proof are versions of the publication after peer review.

- The final published version features the final layout of the paper including the volume, issue and page numbers.

Link to publication

\footnotetext{
General rights rights.

- You may freely distribute the URL identifying the publication in the public portal. please follow below link for the End User Agreement:

www.umlib.nl/taverne-license

Take down policy

If you believe that this document breaches copyright please contact us at:

repository@maastrichtuniversity.nl

providing details and we will investigate your claim.
}

Copyright and moral rights for the publications made accessible in the public portal are retained by the authors and/or other copyright owners and it is a condition of accessing publications that users recognise and abide by the legal requirements associated with these

- Users may download and print one copy of any publication from the public portal for the purpose of private study or research.

- You may not further distribute the material or use it for any profit-making activity or commercial gain

If the publication is distributed under the terms of Article 25fa of the Dutch Copyright Act, indicated by the "Taverne" license above, 


\section{Serotonergic Vulnerability}

experimental studies in rats applying the method

of acute tryptophan depletion 
(C) Linda A.W. Jans, Maastricht, 2008

ISBN: 978-90-9022914-0

Cover design: Ramon Kool (www.mijnnaamisramon.nl)

Typesetting: Michał Sławiński

Printed in Poland 


\title{
Serotonergic Vulnerability
}

\author{
experimental studies in rats applying the method \\ of acute tryptophan depletion
}

\section{ProefsChrift}

ter verkrijging van de graad van doctor aan de Universiteit Maastricht

op gezag van de Rector Magnificus, Prof. Mr. G.P.M.F. Mols

volgens het besluit van het College van Decanen

in het openbaar te verdedigen

op vrijdag 30 mei 2008 om 12.00 uur

door

Linda A.W. Jans 


\section{Promotor}

Prof. Dr. W.J. Riedel

\section{Copromotor}

Dr. A. Blokland

\section{Beoordelingscommissie:}

Prof. J. Jolles (voorzitter)

Prof. W. van der Does (Universiteit Leiden)

Dr. C.J. Harmer (University of Oxford)

Prof. B.E. Leonard

Dr. J.H.H.J. Prickaerts 


\section{Contents}

$\begin{array}{lll}\text { Chapter } 1 \text { General introduction } & 7\end{array}$

$\begin{array}{ll}\text { ChAPTER } 2 \text { Serotonergic vulnerability and depression: assumptions, } & 13\end{array}$ experimental evidence and implications

$\begin{array}{lll}\text { ChAPTER } 3 & \text { Pharmacokinetics of acute tryptophan depletion using }\end{array}$ a gelatin based protein in male and female

$\begin{array}{lll}\text { ChAPTER } 4 & \text { Influence of sex and oestrous cycle on the effects of acute } & 81\end{array}$ tryptophan depletion induced by a gelatin-based mixture in adult Wistar rats

CHAPTER 5 The effects of acute tryptophan depletion on affective behaviour and cognition in Brown Norway and Sprague Dawley rats

ChAPTER 6 Influence of chronic mild stress on the behavioural effects of acute tryptophan depletion induced by a gelatin-based mixture

CHAPTER 7 The effects of acute tryptophan depletion in serotonin transporter knockout rats

Chapter 8 General discussion and conclusion

Summary

Samenvatting

APPENDix The effects of sex and oestrous cycle on object recognition memory

Dankwoord [Acknowledgements]

Publications 



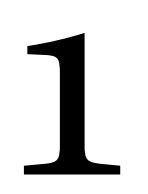

General introduction 


\section{General introduction}

Serotonin (5-hydroxytryptamine, 5-HT) is a monoamine neurotransmitter, together with the catecholamines dopamine, norepinephrine, and epinephrine. Since the discovery of serotonin in the nervous system by Twarog and Page in 1953, serotonin has been implicated in the regulation of almost all types of behaviour. This is not surprising, because the serotonergic system has a widespread distribution in the central nervous system (Steinbusch, 1981) and exerts a modulatory function on other neurotransmitter systems.

Serotonin is synthesized from the essential amino acid tryptophan (TRP). The level of TRP in blood plasma depends on the balance between the dietary intake of TRP and its removal from the plasma for protein synthesis. Most of the TRP in plasma is proteinbound, with only $5 \%$ available for transport into the central nervous system. Free TRP is taken up from the blood and transported into the brain across the blood-brain barrier by an active protein shuttle for which five other large neutral amino acids (LNAAs: valine, leucine, isoleucine, phenylalanine, tyrosine) also compete. The ratio of TRP and these other LNAAs (TRP/ $\Sigma$ LNAA ratio) is thought to be a more sensitive index of brain tryptophan availability than plasma TRP (Wurtman et al., 1980, Fernstrom, 1981), because it is this ratio that determines the amount of tryptophan that can enter the brain. Figure 1a shows that the consumption of both proteins and carbohydrates can influence the TRP/ $\Sigma$ LNAA ratio and thus the amount of TRP that can enter the brain.

Once in the brain, TRP is converted into 5-HT by a two-step process catalysed by the enzymes tryptophan hydroxylase and aromatic amino acid decarboxylase (Figure 1b). In the first step of the synthesis TRP is hydroxylated by the enzyme tryptophan hydroxylase into 5-hydroxytryptophan (5-HTP). Tryptophan hydroxylase is not fully saturated at normal brain TRP levels, therefore the availability of TRP is the limiting factor in the synthesis of 5-HT. Because of this, factors that influence brain TRP levels can influence the rate of 5-HT synthesis. 5-HTP is transported to the axonal nerve terminals where it is rapidly decarboxylated into 5 -HT by aromatic amino acid decarboxylase.

a

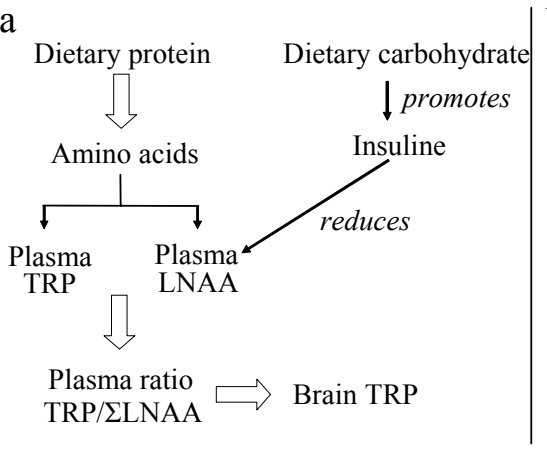

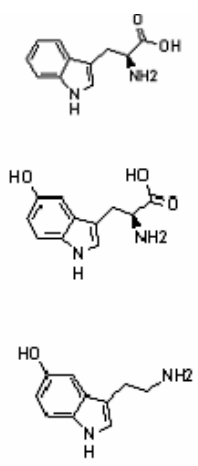

Tryptophan

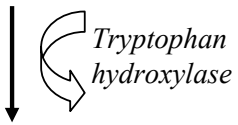

5-hydroxytryptophan

Aromatic L-amino y acid decarboxylase

Figure 1a. From food intake to brain tryptophan level and $1 \mathrm{~b}$. The synthesis of serotonin from tryptophan. 
Serotonin and the other monoamines have been implicated in depression since the discovery of the first antidepressants in the 1950s. The tricyclic antidepressant (TCA) imipramine (Kuhn, 1958) inhibits the synaptic reuptake of monoamine neurotransmitters, whereas the monoamine oxidase inhibitor (MAOI) iproniazine (Crane, 1957) inhibits monoamine oxydase, an enzyme that takes part in the inactivation of monoamine neurotransmitters after their release into the synapse. In this way, both drugs prolong the presence of monoamine neurotransmitters in the synapse and enhance monoamine neurotransmission, which has been associated with their antidepressant effects. In the following years, evidence suggesting a role of serotonin and the other monoamines in the aetiology of depression was found, which resulted in the hypothesis that low 5-HT levels and neurotransmission are associated with affective disorders (Coppen, 1967, Coppen, 1972). The original hypothesis that low serotonin has a direct role in depression has been through several modifications and low 5-HTergic neurotransmission is now thought to operate as a biological risk factor, that may play an important role in the triggering and maintenance of mood disorders (Maes and Meltzer, 1995). Recently, serotonergic functioning has been proposed as a vulnerability factor in the development of depression and other 5-HT related symptoms and disorders (Jans et al., 2007; see Chapter 2). According to this view, the serotonergic functioning of an individual determines the vulnerability of that individual to develop 5-HT related disorders.

Serotonergic vulnerability can be demonstrated by challenging the 5-HT system; vulnerable and non-vulnerable subjects will react differently to these manipulations. One way to challenge the serotonergic system is with acute TRP depletion, a non-invasive method that causes a transient reduction of central TRP and 5-HT levels. Because of these characteristics, the method can be applied in both humans and rats. We used the method of acute TRP depletion to measure serotonergic vulnerability. To induce acute TRP depletion, we used a gelatin-based protein that contains the entire range of amino acids (AAs) in the form of peptides, as found in regular food. Carbohydrates were added to the mixture to provide the rats with the necessary nutrients in a standardised manner. Carbohydrates are known to raise peripheral insulin levels, which increases protein synthesis and thus stimulates the uptake of branched amino acids such as leucine, isoleucine and valine into muscle tissue, changing the plasma ratio of AAs in favour of TRP (Figure 1a). However, due to the large amount of protein in the mixture it is unlikely that the level of TRP depletion is affected by the addition of carbohydrates, because the ingestion of protein counteracts the effects of the carbohydrates (Fernstrom and Fernstrom, 1995).

\section{Aim and outline of the thesis}

The aim of this thesis was to find evidence for the concept of serotonergic vulnerability in animal studies applying the method of acute TRP depletion. Rats were repeatedly treated with the gelatin-based protein-carbohydrate mixture and the effects of this method of 
acute TRP depletion on depression- and anxiety-related behaviour and cognition were evaluated by testing the rats in several behavioural tests.

First, the concept of serotonergic vulnerability is outlined (Chapter 2). A definition of serotonergic vulnerability is proposed and several factors that may cause serotonergic vulnerability are discussed. Methods to study serotonergic vulnerability are described and an overview is given of results of such experiments.

To further investigate the pharmacokinetic effects of acute TRP depletion, several experiments were carried out in males and females to investigate time and dose effects of acute TRP depletion in plasma amino acid levels. (Chapter 3 )

The following chapters describe experiments that were carried out to study serotonergic vulnerability using the method of acute TRP depletion in specific groups that were hypothesized to show signs of serotonergic vulnerability. Female rats are one of these groups, because in the human population depression is higher in women than in men and the female oestrous cycle is associated with fluctuations in mood. Therefore the effects of acute TRP depletion in male and female Wistar rats were studied. (Chapter 4)

It is known that genetic factors and a family history of depression are can increase the risk to develop depression. To test the hypothesis that different rat strains may differ in serotonergic vulnerability, Sprague Dawley and Brown Norway rats were treated with acute TRP depletion. (Chapter 5)

There is an obvious association between stress and depression. Depression is often preceded by stressful life events and stress increases the chance to develop depression. To investigate whether stress can increase serotonergic vulnerability, we studied the influence of exposure to chronic mild stress on the effects of acute TRP depletion. (Chapter 6)

During the last decade the serotonin transporter has been a major focus of attention in the genetic factors involved in depression. In humans, a form of a serotonin transporter polymorphism resulting in less transporter efficiency has been associated with an increased risk to develop depression. The effects of acute TRP depletion in homozygous and heterozygous serotonin transporter knockout rats and their wildtype littermates are described in Chapter 7.

\section{References}

Coppen, A., 1967. The biochemistry of affective disorders. Br J Psychiatry. 113, 1237-1264.

Coppen, A., 1972. Indoleamines and affective disorders. J Psychiatr Res. 9, 163-171.

Crane, G. E., 1957. Iproniazid (marsilid) phosphate, a therapeutic agent for mental disorders and debilitating diseases. Psychiatr Res Rep Am Psychiatr Assoc. 135, 142-152.

Fernstrom, J. D., 1981. Dietary precursors and brain neurotransmitter formation. Annu Rev Med. 32, 413-425. Fernstrom, M. H. and Fernstrom, J. D., 1995. Brain tryptophan concentrations and serotonin synthesis remain responsive to food consumption after the ingestion of sequential meals. Am J Clin Nutr. 61, 312-319.

Jans, L. A., Riedel, W. J., Markus, C. R. and Blokland, A., 2007. Serotonergic vulnerability and depression: assumptions, experimental evidence and implications. Mol Psychiatry. 12, 522-543. 
Kuhn, R., 1958. The treatment of depressive states with G 22355 (imipramine hydrochloride). Am J Psychiatry. $115,459-464$.

Maes, M. and Meltzer, H. Y., 1995. The Serotonin Hypothesis of Major Depression. In: Bloom, F. E. and Kupfer, D. J. (Eds.), Psychopharmacology: The Fourth Generation of Progress. Raven Press, Ltd., New York, pp. 933-944.

Steinbusch, H. W., 1981. Distribution of serotonin-immunoreactivity in the central nervous system of the ratcell bodies and terminals. Neuroscience. 6, 557-618.

Twarog, B. M. and Page, I. H., 1953. Serotonin content of some mammalian tissues and urine and a method for its determination. Am J Physiol. 175, 157-161.

Wurtman, R. J., Hefti, F. and Melamed, E., 1980. Precursor control of neurotransmitter synthesis. Pharmacol Rev. 32, 315-335. 



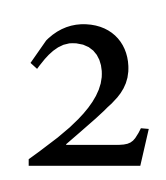

\section{Serotonergic vulnerability and depression: assumptions, experimental evidence and implications}

L. A. W. Jans, W. J. Riedel, C. R. Markus, A. Blokland

Molecular Psychiatry 2007, 12: 522-543 


\begin{abstract}
In recent years, the term serotonergic vulnerability (SV) has been used in scientific literature, but so far it has not been explicitly defined. This review article attempts to elucidate the SV concept. SV can be defined as increased sensitivity to natural or experimental alterations of the serotonergic system. Several factors that may disrupt the serotonergic system and hence contribute to SV are discussed, including genetic factors, female gender, personality characteristics, several types of stress and drug use. It is explained that SV can be demonstrated by means of manipulations of the serotonergic (5-HTergic) system, such as 5-HT challenges or acute tryptophan depletion (ATD). Results of 5-HT challenge studies and ATD studies are discussed in terms of their implications for the concept of SV. A model is proposed in which a combination of various factors that may compromise 5-HT functioning in one person can result in depression or other 5-HT related pathology. By manipulating 5-HT levels, in particular with ATD, vulnerable subjects may be identified before pathology initiates, providing the opportunity to take preventive action. Although it is not likely that this model applies to all cases of depression, or is able to identify all vulnerable subjects, the strength of the model is that it may enable identification of vulnerable subjects before the 5-HT related pathology occurs.
\end{abstract}




\section{Involvement of serotonin in depression}

Mood disorders are one of the most prevalent forms of mental illness (Nestler et al., 2002). According to the DSM-IV, the lifetime risk for major depressive disorder is between $10 \%$ and $25 \%$ for women and between $5 \%$ and $12 \%$ for men (APA, 1994). Depression has been studied intensively during the last few decades, but the psychological and neurobiological determinants of depression have not yet been precisely defined. Although several factors are known to contribute to the aetiology of depression, it is not clear how these factors cause depression, and why some subjects become depressed while others remain unaffected. In terms of biological factors in the aetiology of depression, there are several hypotheses. These include neurotransmitter dysfunctions (serotonin, 5-HT; dopamine, DA; norepinephrine, NE); dysregulations in hypothalamic-pituitaryadrenal (HPA) axis activity; and immune system imbalance. The aim of this article is not to discuss all of these hypotheses in detail, but to evaluate the role that serotonin may play within these hypothesized mechanisms.

It is widely accepted that diminished serotonergic (5-HTergic) function is involved in the onset and course of depression (Heninger et al., 1984, Heninger, 1995). The 5HTergic system is a large and complex system. Although nearly all cell bodies of 5-HTergic neurons are located in the raphe nuclei in the brain stem, the axons of these neurons innervate almost the entire brain. The actions of 5-HT are mediated by sixteen types and subtypes of receptors (Naughton et al., 2000). As the 5-HTergic system is assumed to be a modulatory system, the exact function of 5-HT is not easy to define (Stanford, 2001). However 5-HT is known to be involved in many physiological and behavioural processes, including mood, appetite, sleep, activity, suicide, sexual behaviour, and cognition; all of which are affected in depression (Leonard, 1997). Alterations in 5-HTergic function have been observed in many clinical conditions, including affective disorders, anxiety, obsessive-compulsive disorders, eating disorders, aggression, suicide, impulsive disorders, alcohol abuse, and premenstrual syndrome (Heninger, 1995, Jacobs and Fornal, 1995).

Several altered 5-HT system indices have been reported in depression, including decreased plasma tryptophan levels (Coppen et al., 1973, Cowen et al., 1989) and decreased levels of 5-hydroxyindolacetic acid (5-HIAA; metabolite of 5-HT) in cerebrospinal fluid (CSF) (Asberg et al., 1976a), suggesting decreased 5-HT metabolism in the central nervous system (CNS). Furthermore, brain imaging studies have reported a reduction in $5-\mathrm{HT}_{1 \mathrm{~A}}$ receptor binding, both pre- and postsynaptically, that failed to normalize after remission (Drevets et al., 1999, Sargent et al., 2000). Decreased availability of 5-HT reuptake sites in mid-brain and brainstem regions has also been found in patients with major depression (Malison et al., 1998). Evidence for functional serotonergic abnormalities comes from studies showing that depletion of tryptophan - and consequent lowering of brain 5-HTcan cause transient depressive symptoms in individuals that are vulnerable to depression, based on their personal or family history of depression (Ellenbogen et al., 1999, Klaassen et al., 1999, Moreno et al., 1999, Neumeister et al., 2004b). Furthermore, depressed and 
remitted patients show blunted neuroendocrine responses to drugs that stimulate 5-HT turnover, suggesting decreased 5-HT responsiveness (Flory et al., 1998, Kapitany et al., 1999, Bhagwagar et al., 2002). Some 5-HT abnormalities are also seen in remitted depressed patients or in subjects with a family history of depression, suggesting that either some dysfunction in 5-HT systems or an increased sensitivity of the 5-HT system is a trait abnormality in depression. It should be mentioned, however, that not all depressed patients show all these abnormalities in serotonergic functioning (van Praag, 2004).

The first monoamine theories of depression proposed that depression was caused by monoamine deficiency. By now, however, the model of a deficit in 5-HTergic neurotransmission being primary in the causation of depressive disorders, and predictive of therapeutic response to drugs enhancing 5-HTergic neurotransmission has become obsolete: not all depressed patients present with 5-HT abnormalities, not all patients benefit from drugs enhancing 5 -HTergic neurotransmission, and several drugs that are devoid of major effects on 5-HTergic neurotransmission are known to be effective antidepressants. The categorical view - low 5-HT is specific for depression - has gradually been replaced by a dimensional approach: low 5-HT explains in part the vulnerability to mood liability across diagnoses, rather than depression per se. Hence, the thinking has progressively evolved from one of an absolute deficit to a high-risk model: low 5-HTergic neurotransmission is now thought to operate as a biological risk factor, resulting from innate and/or environmental factors, neither sufficient nor necessary, yet when combined may play an important role in the triggering and maintenance of mood disorders (Maes and Meltzer, 1995). In other words, 5-HT can be considered as a vulnerability factor for developing depression.

\section{Serotonergic vulnerability}

In essence, serotonergic vulnerability (SV) means that the there is a vulnerability or sensitivity to alterations or dysregulations in the serotonergic system (based upon: Maes and Meltzer, 1995, van Praag, 1996, Aberg-Wistedt et al., 1998, Bhagwagar et al., 2002, Booij et al., 2002, Neumeister et al., 2002, Riedel et al., 2002b, Sobczak et al., 2002a, Sobczak et al., 2002b). Thus, the idea is that the 5-HTergic functioning of an individual determines the vulnerability of that individual to develop disorders that are related to 5-HT. This assumption implies that there are differences in 5-HT functioning between different individuals, and that the development of depression is associated with the presence of a priori abnormalities in the functioning of this system. Abnormalities in the serotonergic system could occur at one or more of several levels, including the availability of L-tryptophan (TRP), 5-HT synthesis, release, reuptake or metabolism, or at the level of pre- or postsynaptic receptors.

SV can be demonstrated by challenging the 5-HT system; vulnerable and nonvulnerable subjects will react differently to these manipulations. The 5-HT system can 
be challenged using tryptophan depletion or 5-HT challenges. In general terms, 5-HT challenge studies can show that the neuroendocrine response to a 5-HT related stimulus is blunted or enhanced in 5-HT vulnerable subjects as compared to non-vulnerable subjects. In acute tryptophan depletion (ATD), tryptophan - the precursor of 5-HT - is depleted, resulting in lower central 5-HT levels. ATD studies generally report the effects of lower 5-HT on behaviour (Klaassen et al., 1999, Riedel et al., 2002b).

The focus of this review is on the concept of serotonergic vulnerability. We advocate that serotonergic vulnerability is one answer to the question why some people become depressed, for example when exposed to stress, while others do not. In this article, possible causes of SV are discussed. Furthermore, it is discussed how SV can be studied and what results have been found in studies manipulating the 5-HTergic system. Is there enough evidence to justify the use of the SV concept? Apart from the scientific importance, more knowledge about SV may be relevant from a clinical point of view. When serotonergic vulnerability can be demonstrated in individuals, vulnerable subjects may be identified before they become ill. This may enable early intervention, perhaps minimizing the risk or preventing the occurrence of depression or other disorders (Moreno et al., 1999), hence decreasing personal suffering, social and occupational dysfunction, and health care expenditures. In addition, knowledge about the causes of depression may in time help to find the optimal treatment.

\section{Factors that may cause serotonergic vulnerability}

Any factor that has a long-lasting influence on the serotonergic system may make the system vulnerable. Several factors are known to be capable of causing abnormalities in 5 -HTergic function. Some of these factors are innate, some occur early in life, others can occur at any age.

\section{Innate factors}

\section{Family History}

Family studies show a familial aggregation of depression (Sullivan et al., 1996, Kendler et al., 1997, Sullivan et al., 2000). The presence of one depressed first-degree relative increases the relative risk for major depression by twofold (Sullivan et al., 2000). Although family history $(\mathrm{FH})$ is a risk factor for depression with high clinical relevance, it is not directly related to either genetic or environmental factors and can, therefore, not elucidate the mechanisms by which these factors may cause SV and/or depression.

It is interesting, however, that in many cases, subjects with a $\mathrm{FH}$ of depression also report other disorders in their family members, including affective psychosis, obsessive-compulsive phenomena, panic attacks, eating disorders, and alcoholism/substance 
abuse (Cadoret et al., 1996, Stallings et al., 1997, Michalak et al., 2002). Perhaps there is a general vulnerability factor involved in these disorders. Serotonergic functioning may be a good candidate, because 5-HT is involved in all these disorders (Heninger, 1995).

\section{Genetic factors}

The inheritability of liability to major depression in most twin studies ranges from 31 to $42 \%$ (Sullivan et al., 2000). Because depression is related to several altered serotonergic indices in the brain and CSF, numerous genes involved in the regulation of 5-HT synthesis, release, uptake and metabolism, or receptor activation, are candidate genes in association studies of depression. Genetics can affect 5-HTergic activity, given that heritability has been reported to account for approximately $35 \%$ of the variance in CSF 5-HIAA levels (Beck et al., 1984, Oxenstierna et al., 1986). Thus, alterations in the 5HTergic system that are associated with psychiatric disorders may be inheritable, and could represent heritable vulnerability factors for developing psychopathology.

5-HT transporter In the search for genetic factors related to depression, the serotonin transporter (5-HTT) has received particular attention, because it is the primary mode of action for selective serotonin reuptake inhibitors (SSRIs). The 5-HTT is involved in the reuptake of 5-HT from the synapse, returning it to the presynaptic neuron where it can be degraded or retained for release later. In this way, the 5-HTT determines the magnitude and duration of the 5-HT synaptic signal and thus plays an important role in the regulation of serotonergic neurotransmission. 5-HTT abnormalities are widely reported in depression (Mann et al., 2000, Neumeister et al., 2002). Both functional imaging (Malison et al., 1998) and postmortem brain studies (Mann et al., 2000) have reported fewer 5-HTT sites in the brain of depressed patients, indicating less 5-HTT binding. Since the binding to the 5-HTT and the 5-HT uptake capacity remain low after recovery, low 5HTT activity has been proposed as a trait marker for affective disorders (Lesch, 2001a).

The most important 5-HTT polymorphism in this perspective is the deletion/insertion polymorphism in the 5-HT transporter gene-linked promoter region (5-HTTLPR) (Heils et al., 1996, Lesch et al., 1996). Two 5-HTTLPR alleles have been identified: a 484-base pair denoted as short (s), and a 528-base pair denoted as long (l). The 1-variant is more active than the s-variant, resulting in higher 5-HTT expression and function (Heils et al., 1996, Lesch et al., 1996). As a result, the s/s and s/l genotypes are associated with $40 \%$ fewer 5 -HTT binding sites than the $1 / 1$ genotype (Mann et al., 2000). Consequently, the finding of fewer 5-HTT sites in depression can perhaps be explained by an association between the s-allele and major depression (Mann et al., 2000).

Regarding an association between 5-HTTLPR genotype and depression, results have been mixed. Some studies reported no association (Ohara et al., 1998, Mann et al., 2000, Minov et al., 2001), others found an association between the s-allele and depression (Collier et al., 1996, Lesch and Mossner, 1998, Neumeister et al., 2002, Joiner et 
al., 2003, Hoefgen et al., 2005), while others conclude that the l-allele is associated with depression (Moreno et al., 2002). However, most evidence seems to suggest an association between the s-allele of 5-HTTLPR and depression. The lower 5-HT uptake activity caused by the s-allele may result in increased levels of 5-HT in the vicinity of the serotonergic cell bodies and dendrites in the raphe complex. This increased extracellular 5-HT may bind to somatodendritic $5-\mathrm{HT}_{1 \mathrm{~A}}$ receptors, exerting negative feedback that leads to an overall decrease of 5-HT neurotransmission in subjects with the s-allele (Lesch, 2001b, Lesch, 2001a). Evidence for this mechanism comes from studies with 5HTT knockout mice $\left({ }^{-/}\right.$and $\left.{ }^{+/}\right)$that exhibit no $\left(^{(-)}\right.$) or lower $\left(^{+-}\right) 5$-HTT binding. These mice show reduced 5-HT tissue concentrations and increased extracellular concentrations of 5-HT in the striatum and probably other structures (for review see Murphy et al., 2001). The 1-allele of the 5-HTTLPR polymorphism is associated with better SSRI antidepressive effects than the s-allele (Moreno et al., 2002, Yu et al., 2002, Tsai et al., 2003). and with faster response to several SSRI's (Pollock et al., 2000, Durham et al., 2004). Combined treatment with a $5-\mathrm{HT}_{1 \mathrm{~A}}$ blocker to prevent negative feedback at the somatodendritic level compensated for the worse antidepressant effect of SSRIs in s/s and s/l genotypes (Smeraldi et al., 1998), suggesting higher $5-\mathrm{HT}_{1 \mathrm{~A}}$ negative feedback in s-allele genotypes.

5-HT ${ }_{1 \mathrm{~A}}$ receptor Human 5- $\mathrm{HT}_{1 \mathrm{~A}}$ receptors are expressed presynaptically on 5-HT cell bodies in the raphe (somatodendritic autoreceptors) and postsynaptically in other brain regions. Presynaptic 5- $\mathrm{HT}_{1 \mathrm{~A}}$ autoreceptors play a key role in the regulation of 5 -HT transmission, they reduce the firing rate of the 5-HT neuron by exerting negative feedback. Although several studies failed to find a clear association between polymorphisms in the $5-\mathrm{HT}_{1 \mathrm{~A}}$ receptor gene and depression (for review see Neumeister et al., 2004c), Lemonde et al. (2003) linked a common polymorphism in the human 5- $\mathrm{HT}_{1 \mathrm{~A}}$ promoter region (Wu and Comings, 1999) to depression and suicide. The homozygous G(-1019) genotype of this polymorphism may cause impaired repression of presynaptic $5-\mathrm{HT}_{1 \mathrm{~A}}$ autoreceptors, resulting in increased expression of these receptors. This may ultimately cause reduced 5-HT neurotransmission, perhaps predisposing individuals to depression and suicidal behaviour (Lemonde et al., 2003). Keeping in mind that the abnormalities in 5- $\mathrm{HT}_{1 \mathrm{~A}}$ receptor binding are not specific for depression (Neumeister et al., 2004a), this finding may reflect a general vulnerability factor for psychopathology, including affective and anxiety-related disorders.

Tryptophan hydroxylase 2 Tryptophan hydroxylase (TPH) is the rate-limiting enzyme for the synthesis of serotonin (Harvey et al., 2004). TPH catalyzes the oxygenation of tryptophan to 5-hydroxytryptophan, which is then decarboxylated to form 5-HT (Bellivier et al., 1998). Walther et al.(2003) discovered a new brain-specific TPH isoform, called TPH2. Biochemical studies in mice (Zhang et al., 2004) and human (Zhang et al., 2005) suggest that a TPH 2 polymorphism results in decreased 5-HT synthesis. Zhang 
et al.(2005) reported that in a group of elderly patients with a history of major depression, $10 \%$ carried the mutated gene variant encoding the poor producer of serotonin, compared with just $1.4 \%$ of the non-depressed controls. Furthermore, the controls carrying the mutant allele, although not diagnosed with depression, did report problems, such as generalized anxiety, mild depression, or family histories of alcohol abuse or mental illness. Zill et al.(2004) also found evidence to suggest that polymorphisms in the $\mathrm{TPH} 2$ gene represent risk factors in the development of major depression.

The mutation may help to predict treatment effectiveness, since depressed patients with the mutant TPH2 allele do not respond well to SSRIs (Cervo et al., 2005, Zhang et al., 2005). TPH2 represents an interesting candidate gene for affective disorders, but more research is needed in this area before more reliable conclusions can be drawn.

\section{Personality}

As was mentioned before, the heritability of liability to depression in most twin studies ranges from 31 to $42 \%$ (Sullivan et al., 2000). However, it is unclear whether depression itself is inherited or some personality traits that cause vulnerability for developing mood disorders. Personality traits appear to have a considerable heredity component (Loehlin et al., 1998) and it has been suggested that a certain type of personality or temperament represents a risk factor for developing major depression (Boyce et al., 1991, Kendler et al., 1993).

Depression has been associated with higher scores on neuroticism $(\mathrm{N})$ and the temperament dimension harm avoidance (HA), the tendency to respond to signals of adverse stimuli with behavioural inhibition (Brown et al., 1992, Joffe et al., 1993, Kendler et al., 1993, Duggan et al., 1995, Strakowski et al., 1995, Nelson et al., 1996, Richter et al., 2000, Hodgins and Ellenbogen, 2003, Kendler et al., 2004). Also, low self-directedness (the ability to regulate one's behaviour and commit to chosen goals; SD) and cooperativeness (the ability to identify with and accept other people; C) have been found in depressed patients (Hansenne and Ansseau, 1999, Richter et al., 2000), which may increase after treatment (Black and Sheline, 1997). SD and C have been associated with 5 -HTergic activity (Bond, 2001). The fact that antidepressant treatment also leads to increased SD scores (Tse and Bond, 2001) and decreased aggression and negative affect (Knutson et al., 1998) in healthy volunteers, might suggest that 5-HT is the causal factor (Bond, 2001). A reduction in HA has been reported in depressed patients after 5-HTergic antidepressant treatment (Chien and Dunner, 1996, Dunner et al., 1996), indicating that some personality change, mainly related to HA and N, is related to clinical improvement (Bond, 2001).

Higher scores on HA may be related to lower central serotonergic turnover or low central basal 5-HT levels (Nelson et al., 1996, Hansenne et al., 1997, Peirson et al., 1999), lower 5- $\mathrm{HT}_{2 \mathrm{~A}}$ receptor binding in the cortex (Moresco et al., 2002) and lower platelet 
$5-\mathrm{HT}_{2 \mathrm{~A}}$ receptor number (Nelson et al., 1996). Low brain 5-HT turnover, indicated by low CSF 5-HIAA, is characteristic for a subgroup of depressed subjects, who have a history of serious suicide attempts (Asberg et al., 1976b). Low CSF 5-HIAA is associated with increased impulsivity and impaired control of aggressive behaviours (Linnoila et al., 1983, van Praag et al., 1987) and with impulsive aggression and suicidal behaviour (for review see Asberg, 1997). Studies with non-human primates have shown that CNS 5-HT functioning is trait-like, with low CSF 5-HIAA being stable over time and across settings (Higley et al., 1991, Higley et al., 1993, Higley and Linnoila, 1997). In non-human primates, low CSF 5-HIAA is associated with impaired impulse control, less competent social behaviour and impulsive and unrestrained aggression (Higley and Linnoila, 1997).

In conclusion, personality factors may be involved in SV, but it is far from clear how personality factors may cause SV and whether the personality factors cause serotonergic abnormalities or vice versa.

\section{Gender}

Epidemiological studies have shown that major depression is more common in females than in males (for review see Piccinelli and Wilkinson, 2000). This is found in several countries and ethnic groups (Weissman et al., 1996). Artefactual factors, including more help-seeking and illness behaviour in women, may enhance the female prevalence to some extent, but the gender difference in depression appears to be genuine (Piccinelli and Wilkinson, 2000). The gender difference in the prevalence of depression begins around puberty and persists until midlife. During puberty, women enter their reproductive years (Kessler et al., 1993), while at the same time the frequency of traumatic events increases and social roles are changing (Nolen-Hoeksema, 2001). All these factors may be involved in the gender difference in prevalence of depression.

Besides the prevalence of depression, there are also gender differences in the presentation of the disorder. Men commonly have classical neurovegetative symptoms of depression, such as decreased appetite and insomnia and have higher incidence of comorbid alcohol and substance abuse. Women on the other hand are more likely to present with sleep disturbance, psychomotor retardation, somatization, comorbid psychiatric disorders, mostly anxiety and eating disorders, and atypical symptoms such as increased appetite and weight gain (for review see Kornstein, 2003). There are several possible causes of these sex differences in depression, to which 5-HT may be directly or indirectly related. Sex differences in 5-HT system and sex hormones are discussed in this section, whereas sex differences in stress exposure and stress responsivity will be discussed later.

5-HT differences between males and females Reports of sex differences related to the 5-HTergic system come from animal and human studies. Female rats exhibit increased 5-HT activity in the dorsal raphe nuclei (Dominguez et al., 2003), higher 
5-HT levels in the brain stem and limbic forebrain (Carlsson and Carlsson, 1988), higher 5-HT synthesis (Haleem et al., 1990) and turnover (Rosencrans, 1970). The average firing activity of 5-HT neurons has also been found to be higher in males than in cycling females (Klink et al., 2002).

Human CSF studies suggest that the rate of brain 5-HT metabolism is higher in females than in males (Young et al., 1980, Agren et al., 1986) while 5-HT 2 receptor binding capacity in some brain regions (Biver et al., 1996) and whole brain 5-HT synthesis (Nishizawa et al., 1997) are lower in women than in men. Women also appear to have lower 5-HTT binding than men (Mann et al., 2000). Possibly, sex differences in 5-HT are related to higher SV in females.

There is some data indicating that the decrease in 5-HT transporter availability observed in depression (Malison et al., 1998) is sex dependent. Staley et al. (2006) reported an overall decrease of transporter availability in depressed patients. However, this decrease was explained by a substantial decrease in women, with hardly any decrease in men.

Sex hormones Oestrogen may play a neuromodulatory role on several neurotransmitter systems, including the serotonergic system (Osterlund and Hurd, 2001). It has been shown, for example, that 5-HT concentrations fluctuate throughout the rodent oestrous cycle (Gundlah et al., 1998, Maswood et al., 1999). Oestrogen has been reported to increase TPH production in non-human primates (Bethea et al., 2000). Furthermore, oestrogen can alter the expression of genes involved in the serotonergic system and can enhance serotonergic activity (Weigel, 1996, Fink et al., 1998, Joffe and Cohen, 1998, Sumner and Fink, 1998, McEwen and Alves, 1999). This raises the possibility that oestrogen may alter the risk for depression through its effect on serotonergic function (Weigel, 1996, Fink et al., 1998, Joffe and Cohen, 1998, Sumner and Fink, 1998, McEwen and Alves, 1999).

Oestrogen acts on the central nervous system through two different oestrogen receptors, the oestrogen receptor $\alpha$ (ER- $\alpha$ ), and the oestrogen receptor $\beta$ (ER- $\beta$ ). ER $\alpha$ may be involved in automatic and reproductive functions, emotional expression and mood regulation, since this receptor subtype is predominantly expressed in hypothalamus and amygdala (Ostlund et al., 2003). ER $\beta$ is highly expressed in hippocampus and thalamus, suggesting a role in cognition and memory. Compared to wildtype littermates, female ER $\beta$ knockout mice have been found to have significantly lower 5-HT and dopamine content in several brain regions, including reduced 5-HT in the hippocampus and a trend towards decreased 5-HT content in the dorsal raphe nucleus (Imwalle et al., 2005). On a behavioural level, these knockout mice showed increased anxiety.

The effects of oestrogen appear to have protective effects in some women, while conferring an added risk for mood disorders in others (Joffe and Cohen, 1998). Oestrogen levels vary along the oestrous cycle, perhaps transiently increasing SV in some women. This may be related, for example, to symptoms of premenstrual syndrome (Rubinow et al., 1998). 


\section{Environmental factors}

\section{Stress}

Depression is likely to result from a combination of innate and environmental factors that each modify the risk of an individual to become depressed. Stress is one of the most potent environmental factors (Markus, 2003). Stress is a difficult concept to define. It consists of a threatening of homeostasis to which the organism reacts with adaptive responses. There is a psychological aspect to stress, in which predictability, control, and coping are involved; and a biological aspect, consisting of the activation of specific brain and neuroendocrine circuits (Lopez et al., 1999). There is an obvious connection between depression and stress. Depression is often preceded by stressors (van Praag, 2004) and chances to develop a depressive episode are increased five or six fold after stressful life events (Connor and Leonard, 1998).

The response to stress varies vastly across individuals (Kofman, 2002); stress responsivity is the result of complex interactions between genetic susceptibility and environmental stress (Huizink et al., 2004). Various types of situations can be perceived as stressful. In general, typical stressful events include ending personal relationships, job loss, moving to another town, and long-lasting situations including financial problems and problems at work. There are some individual differences in exactly what situations are stressful. A situation that is perceived as stressful activates the stress system and results in several physiological changes. In medical students, for example, academic examinations increased cortisol levels only in students who perceived stress (Malarkey et al., 1995). The biological changes caused by stress are probably an adaptive response, serving to sustain well-being (Anisman and Merali, 2003, Markus, 2003). Stressors challenge the capacity of an individual to cope. A person may adapt to the stressor by responding in a way that reduces the impact of the stressor (Prickaerts and Steckler, 2005). If this coping fails, various events can result in a long-lasting state of distress, which is reflected in abnormal HPA axis activity and altered limbic function, increasing the risk of developing depression (de Kloet et al., 2005a). When the stress-state is long-lasting and cortisol levels remain high, negative consequences may occur.

Stress and depression Depressed patients show higher levels of circulating stress hormones (Sachar et al., 1973, Holsboer, 2000, van Praag, 2004) and abnormalities in various hormonal challenge tests (van Praag, 2004), indicating HPA axis hyperactivity that appears to be depression-related rather than stress-related. This HPA overactivity is a consistent finding, although it is not found in all patients (van Praag, 2004).

During stress, activity of the brain 5-HT system and HPA activity rises. Serotonin can modulate the HPA axis, 5-HT overdrive increases corticotrophin-releasing factor (CRF) and corticosteroid release (van Praag, 2004). Increased cortisol levels initially 
cause higher CNS 5-HT turnover by increasing tryptophan availability and stimulation of tryptophan hydroxylase activity (Davis et al., 1995, Maccari et al., 2003) and increased responsivity of the $5 \mathrm{HT}_{1 \mathrm{~A}}$ receptor system (Meijer and de Kloet, 1994, Young et al., 1994). However, when cortisol/corticosterone levels remain high, 5-HT turnover and 5-HT ${ }_{1 \mathrm{~A}}$ sensitivity and mRNA expression will be reduced (van Praag, 2004).

Given that high cortisol levels initially cause higher CNS 5-HT turnover, hypothetically, during continuous or frequent exposure to stress, availability of brain TRP and serotonin may diminish and vulnerability to pathology may increase (Anisman et al., 1993, Markus, 2003). Stress-induced depletion of brain serotonin has been shown in animal research (for review see Markus, 2003). As serotonin enhances the negative feedback control of cortisol on the release of CRF and adrenocorticotrophic hormone (ACTH), reduced tryptophan availability and 5-HT depletion may reduce this feedback control, causing increased cortisol concentrations in the blood (Markus, 2003, Porter et al., 2004), perhaps by reducing activation of 5- $\mathrm{HT}_{1 \mathrm{~A}}$ receptors in the hippocampus (Porter et al., 2004).

There is evidence to indicate that impaired glucocorticoid receptors (GR)-mediated feedback may be involved in the pathophysiology of depression (Holsboer, 2000, Pariante et al., 2001). The changes in expression and function of GR and mineralocorticoid receptors (MR) in the hippocampus may be mediated by the increased 5HT release that is evoked by exposure to stress (Semont et al., 1999, Lai et al., 2003, Robertson et al., 2005). Furthermore, chronic stress and glucocorticoids induce neural atrophy in limbic structures, mainly the hippocampus, and reduce cell proliferation and neurogenesis in the hippocampus (Watanabe et al., 1992, Sapolsky, 1996, Gould et al., 1997, Magarinos et al., 1997, McEwen and Magarinos, 1997, Gould and Tanapat, 1999, Malberg and Duman, 2003). These changes have been related to the development of depression, including the cognitive symptoms of this disorder (McEwen, 2004). Antidepressants can increase GR function and expression (Pariante et al., 2001) and normalization of the HPA axis could be important for clinical improvement and prediction of relapse (Holsboer, 2000).

Altered HPA axis feedback inhibition may be a trait marker for vulnerability to depression, since reduced HPA axis suppression by dexamethasone has also been shown in first-degree relatives of depressed patients (Modell et al., 1998). In healthy individuals with family history of depression, the combined dex/CRF test showed cortisol responses that were intermediate between depressed individuals and healthy controls (Modell et al., 1998), indicating that this family history is accompanied by subtle changes in HPA axis functioning, resulting in increased risk of developing depression.

In conclusion, stress causes $\mathrm{CRF}$ and corticosteroid overdrive, in time resulting in decreased 5-HT turnover and 5- $\mathrm{HT}_{1 \mathrm{~A}}$ responsivity. In this way inability to cope with a chronic stressor (McEwen, 1999) or exposure to a single acute life event can cause changes in HPA axis activity and corticosteroid action (de Kloet et al., 2005b), imposing a risk for depression and other diseases (de Kloet et al., 2005a). 
Prenatal stress Exposure of a pregnant woman to physical and/or psychological stress (prenatal stress; PS) can have structural, behavioural and pharmacological effects on the offspring (Kofman, 2002, Maccari et al., 2003, Huizink et al., 2004). A large body of evidence relates stress-induced disturbances in the maternal HPA axis activity to impaired development. In humans, paternal death, malnutrition or drug use during pregnancy, and familial or marital problems can predispose individuals to the development of affective and anxiety disorders in adulthood (for review see Kofman, 2002, Maccari et al., 2003, Morley-Fletcher et al., 2003). It has been reported, for example, that the prevalence of depression was increased in children prenatally exposed to the earthquake in Tangshan, China, in 1976 (Watson et al., 1999).

In rat studies, PS has been reported to result in developmental abnormalities that may have long-term detrimental consequences for brain functioning and may lead to increased susceptibility to psychopathology, including depression, in adulthood (Weinstock, 1997, Van den Hove et al., 2006). Prenatal stressors such as repeated saline injections, daily restraint stress, or crowding (for review see Kofman, 2002, Maccari et al., 2003) have been associated with several deficits in the offspring, such as reduced birth weight, increased infant morbidity, locomotor and cognitive retardation, circadian abnormalities and sleep disturbances, alterations in sexual or social behaviour, and learning deficits (Maccari et al., 1995, Huizink et al., 2004). Rat PS offspring show enhanced response to stress (Hayashi et al., 1998, Kofman, 2002, Maccari et al., 2003, MorleyFletcher et al., 2003, Huizink et al., 2004) and higher behavioural emotionality in several stressful situations (Deminiere et al., 1992, Maccari et al., 1995, Poltyrev and Weinstock, 1997, Vallee et al., 1997, Dugovic et al., 1999, Morley-Fletcher et al., 2003). Adult PS offspring show many characteristics similar to those seen in depressed humans (Bhatnagar et al., 2005) including HPA dysregulations and anhedonic behaviours (Carroll et al., 1976, Mortola et al., 1987). Abnormalities in brain neurotransmitter systems have also been reported, most importantly low central 5-HT activity in adult offspring after high maternal and fetal 5-HT (Hayashi et al., 1998).

The mechanisms accounting for the impact of PS on postnatal life are not yet fully understood. Investigations on the putative mechanisms involved have focused mainly on the HPA axis. The generally held hypothesis is that PS leads to activation of the maternal HPA axis and elevated plasma levels of glucocorticoids in the pregnant animal, which influences fetal brain development. This results in downregulated glucocorticoid receptors in the fetal hippocampus, altered receptor sensitivity, and neurotoxic effects on hippocampal cells, finally causing decreased negative feedback in the PS offspring (Kofman, 2002, Maccari et al., 2003, Huizink et al., 2004).

Since glucocorticoids may play a role in brain development, PS may result in alterations of other biochemical systems in the brain, including 5-HT (Huizink et al., 2004). The 5-HTergic system develops early in the mammalian brain and is widespread, therefore it can influence the maturation of many other cells in the brain (Gaspar et al., 2003). In addition to influencing the development of target regions, 5-HT also has a neg- 
ative feedback effect on the developing fetal 5-HT neurons (Whitaker-Azmitia, 2005). As 5-HT neurons develop, 5-HT levels increase until a point is reached at which the growth is curtailed through a negative feedback mechanism (Whitaker-Azmitia, 2005). When 5-HT levels are high early in development, when the blood-brain barrier is not fully formed yet, 5-HT can enter the brain of a developing fetus and thus cause loss of serotonin terminals through negative feedback. In this way, increased 5-HTergic activity during development causes loss of 5-HT terminals in the adult (WhitakerAzmitia, 2005). Several drug treatment studies have shown this negative feedback of 5-HT on development of 5-HTergic neurons (Shemer et al., 1988, Shemer et al., 1991, Akbari et al., 1992, Huether et al., 1992, Whitaker-Azmitia et al., 1994, Feenstra et al., 1996, Cabrera-Vera et al., 1997, Cabrera-Vera and Battaglia, 1998, Owesson et al., 2002, Yan, 2002, Koprich et al., 2003). Alterations in 5-HTT function (Slotkin et al., 1996) and hypothalamic 5-HT levels (Muneoka et al., 1997) may be in part responsible for altered HPA axis activity in adult PS offspring (Owen et al., 2005). PS may lead to an altered set-point of the HPA axis and 5-HT system, increasing susceptibility to later (depressive) disorders (Huizink et al., 2004).

Early life experiences Aversive or stressful early life experiences, such as childhood neglect, childhood sexual or physical abuse, exposure to war, or parental loss, are important environmental factors contributing to the development of psychiatric disorders, including depression, anxiety, impulsive behaviour and substance abuse in adulthood (Heim and Nemeroff, 1999, Heim and Nemeroff, 2001, Vazquez et al., 2002, Heim et al., 2004). Alterations in mother-infant interactions also have major influences on development and subsequent functioning of the HPA axis (Meaney, 2001, Gunnar and Donzella, 2002).

Human children, as well as rodent pups, are characterized by a stress hypo-responsive period, developing gradually during the first year of life (Sapolsky and Meaney, 1986, de Kloet et al., 2005b). Healthy newborn infants react to stressors with an adrenocortical response (Gunnar, 1998), but the HPA axis of a 12-18 months old child does not respond to mild stressors (Ramsay and Lewis, 1994, Gunnar et al., 1996), although the child does show a behavioural response to such a stressor. More severe stress, however, will cause an acute rise in corticosterone levels during the stress-hyporesponsive period (Huot et al., 2002).

The effects of early life experiences depend on their nature. Rodents exposed to the mild stress of short periods of neonatal handling show decreased HPA responsivity to stress in adulthood (Meaney et al., 1996), although a sex difference in this effect has been reported, with an increase in the ability to cope with stressful stimuli in males and a decrease in females after neonatal handling (Papaioannou et al., 2002). The more severe stress of maternal deprivation, on the other hand, causes behavioural abnormalities resembling symptoms of depression and anxiety in adulthood (Huizink et al., 2004, 
Ruedi-Bettschen et al., 2004, Ruedi-Bettschen et al., 2005). these negative effects may be more marked in males than in females (Ruedi-Bettschen et al., 2004).

In rodents, early-life stress induces serotonergic dysfunctioning and persistent changes in HPA responsiveness and CRF expression (Heim et al., 2004, de Kloet et al., 2005a, de Kloet et al., 2005b). Adverse early life experiences appear to interact with chronic stress in adulthood to alter physiology and behaviour (Bhatnagar and Meaney, 1995). The release of corticosterone in response to mild stress is heightened and prolonged in adult male rats that were maternally deprived as pups, indicating impaired glucocorticoid-mediated feedback sensitivity (Huot et al., 2004) that may results from down-regulation of hippocampal GR (Sutanto et al., 1996).

Another long-term effect of stressful experiences during development, is that they can permanently affect neurogenesis (Karten et al., 2005). Inhibition of adult neurogenesis in the dentate gyrus might play a role in depressive illness (Sapolsky, 2004), since several antidepressant treatments increase neurogenesis with a delay that parallels clinical improvement (Malberg et al., 2000, Malberg and Duman, 2003). Early adverse experience inhibits structural plasticity via hypersensitivity to glucocorticoids and diminishes the ability of the hippocampus to respond to stress in adulthood (Mirescu et al., 2004).

\section{Immune system and cytokines}

Psychological, physical, and systemic stressors, the latter including infection, chronic inflammation and tissue injury, have been reported to influence cytokine production (Leonard and Song, 1999, Watkins et al., 1999, Anisman et al., 2002, Anisman et al., 2003, Capuron and Dantzer, 2003). Cytokines are the signalling molecules of the immune system, and may also act to signal the CNS about the presence of an immunological challenge. They can be divided into two general categories, i.e. anti-inflammatory cytokines and proinflammatory cytokines, the latter including interleukin (IL)-1, IL-6, interferongamma (IFN- $\gamma$ ), and tumour necrosis factor-alpha (TNF- $\alpha$ ) (Schiepers et al., 2005).

Dysregulated activity of the immune system in depression, with increased proinflammatory activity, has repeatedly been demonstrated (Kronfol et al., 1983, Irwin and Gillin, 1987, Maes, 1995, Maes, 1999, Nunes et al., 2002). In addition, inflammatory diseases are typically associated with depressed mood (Yirmiya, 2000, Wright et al., 2005). Administration of proinflammatory cytokines (e.g. in cancer or hepatitis $\mathrm{C}$ therapy) has been found to induce depressive symptoms. Several studies in healthy volunteers have suggested that increased concentrations of IL-6, but also of TNF- $\alpha$ and IL-1 receptor antagonist (IL-1Ra) may cause depressed mood (Reichenberg et al., 2001, Strike et al., 2004, Wright et al., 2005). The increase of several proinflammatory cytokines appear to correlate with the severity of depressive symptom (Maes, 1995, Maes, 1999, Yirmiya, 2000, Bonaccorso et al., 2001, Wright et al., 2005). The "cytokine theory of depression" implies that proinflammatory cytokines, acting as neuromodulators, represent the key 
factor in the (central) mediation of the behavioural, neuroendocrine, and neurochemical features of depressive disorders (Yirmiya et al., 1999, Schiepers et al., 2005).

Proinflammatory cytokines increase 5-HT turnover, which may lead to depletion of 5-HT in combination with several other mechanisms that lower 5-HT (Maes, 1999, Schiepers et al., 2005). First, proinflammatory cytokines may induce tryptophan depletion by reducing food intake (Plata-Salaman, 1998, Reichenberg et al., 2001). A second possibility is that they set off depressive symptoms by modulating the activity of the HPA axis (Capuron and Dantzer, 2003, Schiepers et al., 2005). Proinflammatory cytokines may disturb the negative feedback inhibition of corticosteroids on the HPA axis, causing HPA axis hyperactivity (for review see Schiepers et al., 2005). Thirdly, cytokines may induce depressive symptoms by downregulating the synthesis of serotonin. Several cytokines, including IL-1, IL-2, IL-6, and INFs reduce TRP availability by activating the TRP-metabolizing enzyme indoleamine 2,3-dioxygenase (IDO), the rate-limiting enzyme in the TRP-kynurenine pathway that converts L-TRP to N-formylkynurenine (Wichers and Maes, 2004). In this way, there is less TRP available for serotonin synthesis, which may lead to depletion of serum TRP and reduction of 5-HT synthesis (Heyes et al., 1992, Stone and Darlington, 2002). Along with the cytokine-induced stimulation of IDO, the production of certain metabolites of the IDOmediated kynurenine pathway increases, including 3-hydroxy-kynurenine (3OH-KYN) and quinolinic acid (QUIN). These are neurotoxic substances and may cause hippocampal volume loss, loss of glucocorticoid receptors and increased HPA activity (Maes et al., 2002, Wichers and Maes, 2004). Furthermore, proinflammatory cytokines also stimulate the utilization of TRP and other peripheral amino acids for synthesis of positive acute-phase proteins (APPs) (Kubera and Maes, 2000, Stone and Darlington, 2002). Moreover, it has been suggested that proinflammatory cytokines result in reduced extracellular 5-HT levels (Maes et al., 2001, Bonaccorso et al., 2002a, Bonaccorso et al., 2002b, Capuron and Dantzer, 2003) based on the finding that several proinflammatory cytokines have been shown to upregulate 5-HTT expression (Ramamoorthy et al., 1995, Morikawa et al., 1998, Mossner et al., 1998). Ultimately, neurotrophic factors such as brain derived neurotrophic factor (BDNF) may be affected. The activation of proinflammatory cytokines and/or inhibition of anti-inflammatory may be involved in depression by means of processes related to neuroplasticity (McDonald et al., 2003, Hayley et al., 2005). It is possible that cytokines contribute to the pathogenesis of depression through their actions on 5-HT and BDNF, which co-regulate each other (Mattson et al., 2004, Hayley et al., 2005).

Stressors, including cytokine challenges, can proactively influence the response to later challenges. Neuronal systems may sensitize, so that later exposure results in exaggerated neurochemical changes (Anisman et al., 2003). Cytokine administration increases the response to stressors or further cytokine exposure (Tilders et al., 1993, Schmidt et al., 1995, Tilders and Schmidt, 1999, Hayley et al., 2002, Anisman et al., 2003). It is possible that exposure to stress, including the activation of the inflammatory immune system, may result in greater vulnerability to stressor-related pathology (for review see Connor and Leonard, 1998, Hayley et al., 2005). 
Preexisting vulnerability may also affect the outcome of acute immune challenge (Simmons and Broderick, 2005). For example, some reports showed that pretreatment depression scores and past psychiatric history were predictive for the occurrence of depression-like changes over the course of chronic cytokine therapy (Valentine et al., 1998, Capuron and Ravaud, 1999, Capuron and Dantzer, 2003).

\section{Drug use}

Hypothetically, any drug that influences the serotonergic system may cause that system to become vulnerable. Some popular drugs that may influence the 5-HTergic system are discussed.

MDMA $\pm 3,4$-methylenedioxymethamphetamine (MDMA) is a popular recreational drug taken for its acute effects, which include euphoria, increased sociability and energy (Verheyden et al., 2002). Acutely, MDMA causes the release of stored 5-HT from nerve terminals, prevents reuptake of 5-HT from the synaptic cleft, and inhibits tryptophan hydroxylase, thereby inhibiting the synthesis of replacement 5-HT (McKenna and Peroutka, 1990). These acute effects are followed by a temporary attenuation of central 5-HT (Schmidt, 1987).

There is evidence to indicate that MDMA has neurotoxic effects on the serotonergic system in animals (Ricaurte et al., 2000) and humans (Semple et al., 1999, Reneman et al., 2001a), mainly characterized by a decreased number of serotonin transporters (Reneman et al., 2001a, Reneman et al., 2001b). Animal studies have indicated that MDMA administration results in long-term attenuation of brain 5-HT and 5-HIAA as well as attenuated tryptophan hydroxylase activity and reductions in the density of 5-HT uptake sites (for review see Curran and Verheyden, 2003) and there is evidence to indicate that recovery may remain incomplete for several years (Scheffel et al., 1998, Hatzidimitriou et al., 1999). In human studies the decreased 5-HTT binding is generally reported to be at least partly reversible (Gerra et al., 2000, Reneman et al., 2001a, Reneman et al., 2001b, Thomasius et al., 2003). However, it should be mentioned that the recovery of SERT densities does not necessarily guarantee normal functioning (de Win et al., 2004). Studies on the functional consequences of MDMA induced 5-HT neurotoxicity show converging evidence of memory impairments (Reneman et al., 2000). There are several reports indicating that current and former heavy MDMA use results in negative effects on mood and depression, results are mixed (Gerra et al., 1998, Gamma et al., 2000, Gamma et al., 2001, MacInnes et al., 2001, Morgan et al., 2002, Thomasius et al., 2003, de Win et al., 2004, Guillot and Greenway, 2006).

Alcohol Alcohol dependence and depression co-occur commonly in clinical populations (Powell et al., 1982, Hesselbrock et al., 1985). Presumably, a deficit in serotonergic transmission is involved in the aetiology and maintenance of alcoholism and 5-HT may 
mediate ethanol intake (for review see LeMarquand et al., 1994b, LeMarquand et al., 1994a). Distinguishing the effects of long-term alcohol intake from putative premorbid 5-HT dysfunction is a problem (LeMarquand et al., 1994a). Alcohol can damage the nervous system, either directly or indirectly through damage to other organs (OscarBerman et al., 1997). Chronic alcohol intake may have neurotoxic effects on the 5-HT system (Halliday et al., 1993) that may result in loss of central 5-HTergic function and negative mood states (Heinz et al., 1998).

Overall evidence suggests that acute ethanol facilitates 5-HTergic neurotransmission (for review see LeMarquand et al., 1994a), although there is some evidence that alcohol may have a biphasic effect on the serotonergic system, with an initial facilitation of 5-HTergic activity followed by a decrease several hours later (Badawy and Evans, 1976, Morland et al., 1985). Animal studies suggest that acute and chronic ethanol result in transient increases in 5-HT levels and functioning, but withdrawal of chronic ethanol causes a decrease in 5-HT and 5-HIAA levels and serotonergic functioning (for review see LeMarquand et al., 1994b). Low CSF 5-HIAA and low plasma TRP availability have been reported in alcoholics, suggesting lowered central 5-HT neurotransmission (for review see LeMarquand et al., 1994a) and it has been demonstrated that heavy drinkers can experience mood symptoms as a consequence of their heavy drinking (Vaillant et al., 1983).

Heinz et al.(1998) found a significant reduction in the availability of brainstem 5-HTT in alcoholics after 3-5 weeks of withdrawal compared to healthy controls, that was correlated with ratings of depression and anxiety during the withdrawal. The reduction in raphe 5-HTT also correlated with lifetime alcohol consumption, suggested that this reduction in transporter density may be caused by the cumulative toxic effects of ethanol consumption (Heinz et al., 1998).

Cannabis There is evidence to indicate that heavy or problematic cannabis users have an increased chance of developing depression (for review see Degenhardt et al., 2003). One hypothesis to explain this increased risk is that large doses of the primary psychoactive ingredient of cannabis, delta-9-tetrahydrocannabinol (THC) affect 5-HT and other neurotransmitters (Degenhardt et al., 2003). THC acts upon the cannabinoid system, a neuromodulatory system in the brain that is involved in regulating some of the same physiological processes as the 5-HTergic system. Acutely, THC has been reported to suppress 5-HT neurotransmission in the hippocampus by inhibiting 5-HT release (Egashira et al., 2002). Long-term cannabinoid administration can affect the response to a single challenge of a $5-\mathrm{HT}_{1 \mathrm{~A}}$ and $5-\mathrm{HT}_{2 \mathrm{~A}}$ receptor agonist. Twelve days of pretreatment with a cannabinoid receptor agonist resulted in an apparent upregulation of $5-\mathrm{HT}_{2 \mathrm{~A}}$ receptor activity and a down-regulation of $5-\mathrm{HT}_{1 \mathrm{~A}}$ receptor activity (Hill et al., 2006). The effects of THC on 5-HTergic functioning and receptor activity resemble the changes seen in depressed patients. 
Cocaine Cocaine binds to all three monoamine transporters, and acutely inhibits the reuptake of monoaminergic neurotransmitters into presynaptic neurons (Reith et al., 1983, Ritz et al., 1990). This causes an initial increase in extracellular neurotransmitter concentrations, which leads to compensatory decreases in cell firing and neurotransmitter synthesis (for review see Levy et al., 1994). During cocaine withdrawal, symptoms of depression are common (Gawin and Kleber, 1986). Repeated exposure to cocaine may alter functioning of monoamine neurotransmitter systems. Cocaine appears to result in subsensitive postsynaptic $5-\mathrm{HT}_{1 \mathrm{~A}}$ receptors and supersensitive 5- $\mathrm{HT}_{2}$ receptors (Levy et al., 1994, Baumann and Rothman, 1995, Baumann and Rothman, 1998).

\section{Biopsychological interactions}

It is likely that interactions between innate (genetics, gender, personality, prenatal stress) and environmental factors (postnatal stress, drug use) determine the vulnerability to develop depression. Figure 1 presents an overview of the factors that may contribute to SV.

Evidence appears to suggest that the 5-HTTLPR s-allele increases sensitivity to the depressogenic effects of environmental insults ranging from stress to MDMA use and neurochemical challenges such as ATD. The s-allele may predispose for a more reactive arousal system. The s-allele appears to predispose towards increased anxiety and exerts a negative influence on the capacity to cope with stress (for review see Hariri and Holmes, 2006). It has been shown that carriers of the s-allele have an elevated risk of depression in the context of environmental adversity (Caspi et al., 2003, Kendler et al., 2004, Kendler et al., 2005). Furthermore, in rhesus macaques, which have the same 5-HTTLPR length variations as humans, the s-allele is associated with decreased serotonergic function, indicated by lower CSF 5-HIAA concentrations, only in monkeys reared in stressful conditions (Bennett et al., 2002). In addition, s-allele carriers showed increased activation of the amygdala in response to fearful or threatening stimuli (Hariri et al., 2002, Hariri et al., 2005, Heinz et al., 2005). In terms of interactions between genes and MDMA, Roiser et al.(2005) reported that 5-HTTLPR genotype mediates emotional processing in ecstasy users, as only ecstasy users carrying the s-allele showed abnormal emotional processing. Interestingly, the abnormalities in emotional processing were similar to those reported in healthy volunteers after ATD (Rubinsztein et al., 2001).

The 1-allele of the 5-HTTLPR may account for a certain flexibility in the 5-HTergic system, or the possibility to react and adapt to changes that are imposed on the system. First, alcoholics carrying the s-allele showed no difference in 5-HTT availability, whereas 1/l genotype alcoholics show a reduction in raphe 5-HTT availability (Little et al., 1998, Heinz et al., 2000). Second, the $1 / 1$ genotype is associated with an initially low response to alcohol (Schuckit et al., 1999). Third, 1-allele carriers have better antidepressant response to SSRI treatment than s-allele carriers (Yu et al., 2002). Subjects carrying the s-allele appear to respond less to these environmental factors. 
Personality factors may also determine how an individual interacts with the environment. An association exists between 5-HTTLPR genotype and some personality factors, given that carriers of the s-allele are more likely to demonstrate anxiety-related personality traits, including neuroticism and harm avoidance, than $1 / 1$ genotypes (Lesch et al., 1996, Mazzanti et al., 1998, Greenberg et al., 2000, Van Gestel et al., 2002). It is unclear whether personality can directly cause SV. For example, it is also possible that certain personality traits simply co-occur with SV or depression, or that they represent the state of SV. Neuroticism scores, however, appear to predict future depression and 55\% of the genetic risk of depression appears to be shared with neuroticism (Kendler et al., 1993). Personality characteristics are known to interact with other factors, because they influence the interpretation of events, the ability to cope with stress and the experienced level of cognitive control over a stressful situation. To make matters even more complex, individuals with a genetic risk for depression are not only more susceptible to the depressive episode-triggering effects of an adverse event, but may also be more likely to expose themselves to such an adverse event (Kendler et al., 1999).

Several types of stressors, for example psychological stress and the systemic stress caused by proinflammatory cytokine activation, may result in HPA axis overactivity, decreased 5-HT turnover and reduced 5-HTergic functioning. Prenatal stress and adverse early life events may lead to an altered set-point of the HPA axis and 5-HT system, influencing the response to later stressors and hence increase vulnerability to psychopathology. Stress reactivity in adulthood is influenced by genetic background and early life experiences. Genetic background can modulate the response to adversity in early life as well as in adulthood (de Kloet et al., 2005a). Adversity early in life may also influence personality.

Sex hormones or sex differences in 5-HTergic activity and the 5-HTergic system may be directly responsible for higher SV in women. Sex differences in exposure and response to stress may also affect SV. Women are more likely than men to develop depression following a stressful life event early in life (Weiss et al., 1999) and their HPA axis is more susceptible to PS-induced programming (Weinstock et al., 1992, McCormick et al., 1995, Szuran et al., 2000). Women have a lower mean rate of 5-HT synthesis compared to men, while men and women appear to have similar stores of brain 5-HT (Nishizawa et al., 1997). Thus, in times of increased 5-HT utilization, a lower rate of synthesis in women may cause 5-HT levels to decline more in women than in men, possibly increasing vulnerability to depression (Nishizawa et al., 1997). Some types of stressful events may be more common in women than in men. The rates of childhood sexual abuse, for example, are higher in girls than in boys, and as a result, as much as 35\% of the gender difference in adult depression could be explained by this higher incidence of childhood abuse of girls compared to boys (Cutler and Nolen-Hoeksema, 1991). Furthermore, there are some indications that women may experience more chronic stress in everyday life than men (Nolen-Hoeksema, 2001, Matud, 2004).

Some studies found an association between the s-allele and stress only in women (Grabe et al., 2005). The effects of adverse life experiences are mediated by personality 
characteristics, attributional style and coping (Brewin, 1996, Hanninen and Aro, 1996). Several authors have suggested the possibility that women appraise some threatening events as more stressful than men (Miller and Kirsch, 1987, Ptacek et al., 1992). It has also been reported that for women, life events appear to be less controllable and more negative (Matud, 2004). There is evidence to indicate that there is a sex difference in response to stress. In rats, exposure to an acute stressful event can facilitate learning in males, but impairs performance in female rats (Wood et al., 2001, Shors and Miesegaes, 2002). Furthermore, exposure to an elevated plus-maze, a rodent anxiety test, leads to decreased 5-HTergic activity in the dorsal raphe nuclei in female rats, but to decreased 5-HTergic activity in the medial raphe nuclei in males (Dominguez et al., 2003). There is also data to indicate that male rats may adapt better to stress than females (Kennett et al., 1986). Furthermore, the female HPA axis may be more reactive to stress, possibly due to sex hormones (Weiss et al., 1999). In terms of coping styles, women have been reported to use more emotion-focused coping than men, while men more often use rational and problem-focused coping (Matud, 2004). Women appear to be more likely than men to respond to stress with rumination - focusing inward on feelings of distress and personal concerns rather than taking action to relieve their distress (Nolen-Hoeksema, 2001).

Gender may also interact with drug use. Subjective MDMA response (Liechti et al., 2001), the effects of MDMA on 5-HTT densities (Reneman et al., 2001a) and reductions in CSF 5-HIAA concentrations caused by MDMA (McCann et al., 1994) have been reported to be stronger in women than in men.
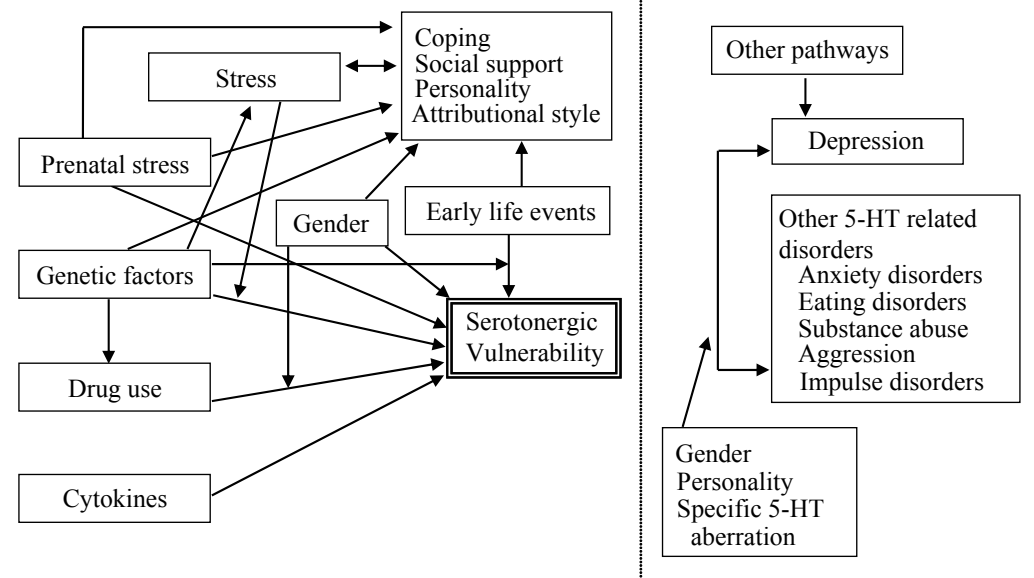

Figure 1. The aetiology of SV and depression. The factors that may cause SV and possible interactions between these factors are depicted on the left. On the right are the possible pathological outcomes of SV. As the figure shows, the nature of the outcome may depend on personality variables and the gender of the individual, as well as on the location of the 5-HT aberration. 


\section{Possible pathological outcomes of SV}

In terms of the pathology in which the SV finally becomes manifest, there may be several factors involved. First, it is possible that the location of the vulnerability-causing factor within the 5-HT system plays a role. There is some evidence to indicate that abnormalities in the 5- $\mathrm{HT}_{1 \mathrm{~B}}$ receptor are related to substance abuse, impulsive aggression and motor impulsivity (Ramboz et al., 1996, Brunner and Hen, 1997) while disturbances in $5-\mathrm{HT}_{1 \mathrm{~A}}$ neurotransmission have been associated with less reactivity and higher anxiety (Lesch and Mossner, 1999, Zhuang et al., 1999) and 5-HTT abnormalities with depression (Malison et al., 1998). Gender may also be involved in forms of manifestation of SV, with substance abuse, aggression and impulsivity being more common in men while anxiety and depression are more common in women. Furthermore, personality traits appear to be involved, since mood lowering after ATD tends to occur in subjects with mean baseline depression scores at the upper end of the normal range (Ellenbogen et al., 1999, Bell et al., 2001). Furthermore, TRP depletion produces a marked rise in the ratings of aggression during provocation in subjects with high trait aggression, but has little effect in subjects with low-trait aggression (for review see Young and Leyton, 2002).

\section{Experimental manipulations of 5-HT in relation to SV factors}

\section{Challenge studies}

Serotonergic challenge tests are used to measure serotonergic responsivity in vivo. These tests involve the administration of a 5-HTergic probe and the subsequent assessment of one or more anterior pituitary hormones, such as cortisol, ACTH, growth hormone and prolactin (Flory et al., 1998, Kapitany et al., 1999). The secretion of prolactin is regulated by serotonergic mechanisms in the brain (Gala, 1990, Van de Kar et al., 1996). Therefore, increased plasma prolactin can be interpreted as an index of enhanced brain serotonin function (MacIndoe and Turkington, 1973, Cowen and Charig, 1987) and hypersensitivity of the serotonergic system (Clemens et al., 1980, Delgado et al., 1989). Neuroendocrine responses to 5-HT agonists are an indication of postsynaptic receptor sensitivity, with relatively high hormonal responses being indicative of receptor hypersensitivity while relatively low hormonal responses suggest receptor hyposensitivity (Riedel et al., 2002a).

Many substances with different sites of action have been used in serotonergic challenge studies, including L-tryptophan (Charney et al., 1982), fenfluramine (Siever et al., 1984, Asnis et al., 1988, Maes et al., 1991, O’Keane and Dinan, 1991, Lichtenberg et al., 1992), buspirone (Meltzer et al., 1983), meta-chlorophenylpiperazine ( $m$-CPP) 
(Charney et al., 1987) and several serotonergic reuptake inhibitors (Laakmann et al., 1984, Golden et al., 1992, Reist et al., 1996).

Administration of d-fenfluramine results in a dose-dependent rise in prolactin levels (Kavoussi et al., 1998), which has been used as an index of central 5-HT responsivity (Quattrone et al., 1983, Newman et al., 1998, Sher et al., 2003). The prolactin response to fenfluramine in depression has been studied extensively, with mixed results (for review see Kavoussi et al., 1998). Studies that compare prolactin response to fenfluramine in depressed patients before and after antidepressant treatment have yielded mixed results (Kasper et al., 1990, O’Keane et al., 1992, Shapira et al., 1993).

Citalopram is a highly selective 5 -HT reuptake inhibitor that produces dose-related increases in prolactin and cortisol in normal subjects (Seifritz et al., 1996, Attenburrow et al., 2001). Intravenous challenge with citalopram has been reported to result in a blunted prolactin response in depressed patients compared to healthy controls (Heninger et al., 1984, O'Keane and Dinan, 1991), while cortisol secretion was reported not to differ between groups (Kapitany et al., 1999). Bhagwagar et al.(2002) showed that the prolactin response to citalopram was blunted similarly in both acutely depressed and recovered drug-free euthymic subjects. The cortisol responses, however, were blunted in the acutely depressed patients, but not in the recovered subjects. These data support the notion that some aspects of impaired 5-HT neurotransmission, such as the blunted 5-HT-mediated prolactin release, may be trait markers of vulnerability to depression, since they persist into clinical remission. However, it could be a consequence of having been depressed or treatment with antidepressants, rather than a marker of vulnerability (Bhagwagar et al., 2002).

Studies measuring hormonal responses to L-TRP infusion generally demonstrate attenuated prolactin and growth hormone responses in patients with major depression, indicating an impairment in postsynaptic $5-\mathrm{HT}_{1 \mathrm{~A}}$ receptor function (for review see Porter et al., 2003).

Nutrients can influence 5-HT synthesis, with carbohydrate ingestion generally increasing 5-HT synthesis, while protein ingestion has been reported to decrease 5-HT synthesis or not to change it (Fernstrom and Wurtman, 1971, Fernstrom, 1985, Fernstrom, 1990). The amount of TRP available to the brain can be increased with alphalactalbumin (LAC), a whey protein with high TRP content (Heine et al., 1996, Markus et al., 2002), leading to enhanced 5-HT synthesis. While TRP availability to the brain influences 5-HT synthesis (Fernstrom, 1985, Fernstrom, 1990), extracellular 5-HT levels reflect the neuronal activity of release and reuptake of the neurotransmitter (Kalen et al., 1988). LAC ingestion not only affects 5-HT synthesis, but also its release. Long-term LAC diet was reported to elevate extracellular 5-HT and may induce beneficial effects on mood (Orosco et al., 2004).

In humans, LAC has been reported to increase the plasma TRP/LNAA ratio by $43-48 \%$ in subjects with high and low stress vulnerability (Markus et al., 2000b, Markus et al., 2002). This increase in plasma TRP-LNAA ratio is considered to be an indirect in- 
dex of elevated brain TRP and 5-HT concentrations (Markus et al., 2002). However, LAC had a positive effect on mood (Markus et al., 2000a) and cognitive performance (Markus et al., 2002) only in the group of high stress-vulnerable subjects. These results may suggest that high stress-vulnerability is related to poor 5-HTergic functioning, in a way that the stress-vulnerable subjects appear to need more 5-HT than they have, in order to keep up performance under stress conditions. The LAC intake may compensate for this deficiency by enhancing brain 5-HT function.

In short, a blunted neuroendocrine response to serotonergic agonists has been found in depressed patients (Heninger et al., 1984, Siever et al., 1984, O'Keane and Dinan, 1991, Mann et al., 1995). The consensus is that 5-HT neurotransmission is impaired in unmedicated depressed patients, but it is unclear whether this abnormality persists following clinical recovery (Bhagwagar et al., 2002). Results are mixed and it is difficult to distinguish possible trait markers of vulnerability to depression from abnormalities that occur as a result of having been depressed.

Blunted prolactin responses to fenfluramine have been reported in euthymic men and women with a personal history of depression, indicating persistent disturbances of serotonergic activity in these subjects (Flory et al., 1998). Heavy drinkers also show bunted prolactin responses to fenfluramine challenge compared to healthy controls, suggesting impaired central serotonergic neurotransmission in heavy drinkers (Balldin et al., 1994). During withdrawal from chronic cocaine use, hormone responses to some specific 5-HT challenges are altered (for review see Baumann and Rothman, 1998, Levy et al., 1994). Furthermore, healthy 5 -HTTLPR $1 / 1$ individuals show significantly greater prolactin responses than s/s individuals after challenge with the tricyclic antidepressant clomipramine (Whale et al., 2000) or the SSRI citalopram (Smith et al., 2004). Thus, it appears that heavy drinking, withdrawal from cocaine use and 5-HTTLPR genotype are associated with altered hormonal responses to 5-HT challenges, which may indicate SV.

\section{Acute tryptophan depletion}

Serotonin is synthesized from its amino acid precursor tryptophan (TRP), which is taken up from the blood. Most of the TRP in plasma is protein-bound, with only $5 \%$ being left free and available for transport into the CNS. This free TRP is transported into the brain across the blood-brain barrier by an active transport system for which TRP competes with five other large neutral amino acids (LNAAs; valine, leucine, isoleucine, phenylalanine, tyrosine) (Fernstrom and Wurtman, 1972). Once in the brain, TRP is converted into 5-HT. The availability of free plasma TRP is a limiting factor in the synthesis of serotonin. Therefore, ATD can be used to study the effects of lower 5-HT. In humans, an amino-acid based mixture is used for ATD, whereas in rats a protein-mixture is used (Lieben et al., 2004). ATD lowers plasma TRP (Young et al., 1985) and alters 5-HT synthesis, metabolism, and release (Stancampiano et al., 1997). Brain 5-HT levels are temporarily lowered (Biggio et al., 1974, Moja et al., 1989) and there is a decrease in brain 5-HT synthesis (Nishizawa et 
al., 1997), CSF 5-HT (Bel and Artigas, 1996) and 5-HIAA concentrations (Stancampiano et al., 1997, Carpenter et al., 1998, Williams et al., 1999). Nishizawa et al.(1997) studied the effects of ATD on 5-HT synthesis and found that the rates of 5-HT synthesis were reduced by ATD by a factor of about 9.5 in men and a factor of about 40 in women. Apparently, the effect of ATD on 5-HT synthesis is larger in women than in men.

In rats, ATD can cause changes in cognitive functions and depression- and anxiety-like behaviour (Blokland et al., 2002). In humans, ATD has cognitive effects and can cause mild, transient mood effects. Although ATD causes approximately the same decrease in TRP levels in all subjects, not all subjects experience symptoms like mood lowering following ATD. Mood lowering in response to ATD demonstrates individual vulnerability of the serotonergic system (Delgado et al., 1994, Aberg-Wistedt et al., 1998, Booij et al., 2002, Riedel et al., 2002b, Sobczak et al., 2002a, Sobczak et al., 2002b).

In currently depressed untreated patients, ATD does not cause any mood-lowering (for review see Maes and Meltzer, 1995, Bell et al., 2001, Young and Leyton, 2002). However, ATD can cause mood changes in subjects with a personal history of mood disorders (Young and Leyton, 2002). Remitted depressed patients can experience lowered mood after ATD, especially when they had more than one depressive episode (Booij et al., 2002) and/or were treated with SSRIs or MAOIs (Van der Does, 2001a, Young and Leyton, 2002). Duration of treatment and/or remission may also play a role (for review see Bell et al., 2001, Van der Does, 2001a). Patients with a history of self-injury or suicidal activity are also more likely to report mood-lowering effects after ATD (for review see Booij et al., 2002, Young and Leyton, 2002, Van der Does, 2001a).

Of the healthy subjects, some report mood lowering after ATD, while others do not. Female gender (Ellenbogen et al., 1996, Smith et al., 1997) and a positive family history for affective illness (Benkelfat et al., 1994, Klaassen et al., 1999) are associated with mood effects on ATD. Higher baseline depression score also increase chances of ATD-induced mood lowering (for review see Bell et al., 2001, Van der Does, 2001a). MDMA use may also influence the effects of ATD, as Taffe et al.(2003) demonstrated that monkeys exposed to a short-course, high-dose repeated regimen of MDMA showed no observable effects of the MDMA under unchallenged conditions 1 year later, but did show alterations in electrophysiological and behavioural sensitivity to ATD.

The extent of TRP depletion is not consistent across studies, which may explain some mixed results and negative findings. There is evidence to indicate that a threshold exists that needs to be exceeded before behavioural effects occur (Spillmann et al., 2001, Van der Does, 2001b). Van der Does (2001b) reviewed several ATD studies and suggests that the threshold for possible mood effects to occur lies somewhere around a $60 \%$ reduction of free plasma TRP. In a study comparing high and low dose ATD in remitted depressed patients, Booij et al.(2005a) reported impaired processing of positive information in all and return of depressive symptoms in some of the participants in the high depletion group (80-90\% depletion of plasma TRP levels). Participants in the low depletion group (40-50\% depletion) did not show effects on mood or impaired processing of positive information. 


\section{Proposed model and conclusions}

There appear to be various factors that can disrupt 5-HT functioning in any person. The factors that may cause SV have one common final result: a change in 5-HTergic activity, mostly reduced 5-HT indices or reduced 5-HTergic activity. The proposed model is one in which each factor results in some disturbance in the 5-HTergic system, making the system more vulnerable. Depression is hypothesized to result from the combination of several factors in one person. As long as the number of vulnerability factors is limited, the disturbances in the 5-HTergic system can be compensated for and there are no overt signs to indicate the vulnerability. However, when several vulnerability factors occur in one individual, a threshold is reached where the system can no longer compensate and depression or other 5-HT related disorders occur. This may be similar to the threshold hypothesis stated by Van der Does (2001b), which claims that a certain level of TRP depletion is required in order for mood changes to occur after ATD. Some 5-HT challenge and ATD studies appear to confirm the model and the threshold hypothesis. Both models state that the 5-HT system requires a significant amount of challenging for symptoms of depression or other 5-HT related disorders to occur.

This model may be able to provide an explanation for the issue why one person becomes depressed after, for example, a stressful life event, while other individuals may appear unaffected. In individuals with an existing SV -probably caused by genetics and/ or early life events- such a stressor may cause depression, but in subjects without this pre-existing vulnerability the stressor will not cause depression. However, this stressor may influence 5-HTergic functioning in this person, resulting in increased vulnerability to develop depression in reaction to further adversity. In other words, a stressor may cause depression in one subject, and SV in another. In this way, the stressor can have very different effects in different individuals, depending on their 5-HTergic functioning when encountering the stressor.

The aetiology of both depression and SV are complex, and both can be caused by various factors. In depressed patients, it is often difficult to pinpoint the possible causes of the depression. Although the same is true for SV, the main advantage of the concept of SV is that SV can be demonstrated in individuals before behavioural and emotional symptoms occur. The amount of adversity or compromising of the 5-HT system that is needed to make the system vulnerable probably varies per individual, but with 5-HT manipulations vulnerable subjects can be identified at a point in time where disorders may be prevented. 5-HT manipulation studies can indicate whether a person is close to the threshold where the system can no longer compensate for the compromising factors. This is important because SV will not necessarily lead to pathology, symptoms will only occur if adversity continues to affect the 5-HTergic system. Identifying vulnerable subjects before 5-HT related pathology occurs provides the opportunity to take preventive action. In these vulnerable subjects, pathology may be prevented by improving coping skills or by increasing TRP intake in times of stress (Markus et al., 2000a). 
A mood response to ATD appears to be the best way to identify subjects with SV, because this mood response indicated that the 5-HTergic system lacks the ability to compensate for the transient decrease in TRP and 5-HT. ATD has already been described as a way to identify a subgroup of patients with a specific serotonergic 'vulnerability'(Aberg-Wistedt et al., 1998) and as a suitable model of vulnerability to depression (Booij et al., 2005b). ATD causes mood lowering in some populations, but results are generally mixed, and ATD does not cause mood lowering in currently depressed patients. These findings suggest that decreased serotonergic activity is not the limiting factor in the severity of depression in untreated major depression (Maes and Meltzer, 1995). Also, it is not the primary or sole cause of affective disorders.(Bell et al., 2001) This is consistent with the hypothesis of diminished serotonergic activity as a vulnerability factor in depression (Maes and Meltzer, 1995).

It may also be important to identify SV patients, because if they do become depressed, 5-HT being a causal factor may have consequences for treatment outcome. The s-allele of the 5-HTTLPR, the described 5- $\mathrm{HT}_{1 \mathrm{~A}}$ polymorphism and $\mathrm{TPH} 2$ are all associated with lower responsiveness to SSRI treatment. Although it may appear logical to use treatment targeting the 5-HT system when 5-HT is a causal factor in the pathology, this may not work because in these patients the $5-\mathrm{HT}$ system is not responsive and flexible enough to react to the treatment and benefit from it.

\section{Limitations of the model}

It is important to keep in mind that depression is a complex and heterogeneous disorder, both on phenotypical and biological levels. Depression is not likely to result from a single gene or a single external event, but is caused by the complex interactions between an individual and its environment. The specific symptoms of depression, both the subjective feelings and complaints and the physiological indices, are different in different patients. Obviously, this complicates research, because it may not always be valid to compare one group of depressed patients with another.

It is only logical to assume that this model does not explain all cases of depression. It is not likely that all depressed patients share this aetiology of factors causing SV and later developing depression. It is known that other neurotransmitters are involved in depression as well, and these may be causal in depression, either on their own or in combination with 5-HT. Apart from SV, there are other paths leading to depression.

Another limitation is that although SV can be demonstrated before depression occurs, it is not possible to determine whether depressed patients had SV before their depression occurred. In depressed patients, ATD does not cause further mood lowering (Bell et al., 2001). and if mood changes are reported in remitted patients after ATD, this may indicate an acquired vulnerability of the system as a result of the depression instead of representing a causal mechanism. In other words, the changes in 5-HTergic functioning may be secondary. 
Furthermore, it cannot be excluded that there are vulnerable subjects that do not show vulnerable responses to challenges. For example, if a person does not report mood lowering after ATD, this may not necessarily mean that this person has no vulnerability to develop depression. These false negatives cannot be excluded. In addition, the mood response to ATD is an indication of SV at a given moment in time. SV can occur later in life as a result of for example stress or drug use. If the circumstances of an individual change, so may the 5-HTergic functioning of that individual. In short, normal responses to 5-HT challenges do not guarantee that an individual cannot develop a 5-HT-related pathology.

It may be difficult to find evidence against the model in human studies because there are always factors to explain mixed results and negative findings, such as level of 5-HT depletion, heterogeneity of the disorder, or not correcting for possible genetic SV, PS, stressful life events early or later in life or other factor that may influence SV. It should be mentioned though that evidence against the model has been found in an ATD study in Parkinson's disease (PD) patients (Leentjens et al., 2006). This study found no support for SV in PD patients, although these patients generally have reduced 5-HT activity and an increased risk of depression. These results may debilitate the model, although there may be several possible explanations for the negative findings.

\section{Conclusions}

In conclusion, there is evidence to indicate that there are various factors that may interfere with 5-HTergic functioning. The proposed model is one in which each factor disrupts the 5-HT system, until a threshold is reached where the system can no longer compensate and pathology occurs. In this way, a combination of the factors described may result in depression or other 5-HT related disorders. The aetiology of depression and SV are complex, but the concept of SV offers an opportunity to identify individuals that are vulnerable to developing depression and/or other 5-HT related disorders. This may enable preventive actions in these individuals and may give an indication of what treatment to choose if these people do become depressed. However, it is unlikely that this model applies to all cases of depression, and 5-HT challenges may not be able to identify all vulnerable subjects.

\section{References}

Aberg-Wistedt, A., Hasselmark, L., Stain-Malmgren, R., Aperia, B., Kjellman, B. F. and Mathe, A. A., 1998. Serotonergic 'vulnerability' in affective disorder: a study of the tryptophan depletion test and relationships between peripheral and central serotonin indexes in citalopram-responders. Acta Psychiatr Scand. 97, 374-380. 
Agren, H., Mefford, I. N., Rudorfer, M. V., Linnoila, M. and Potter, W. Z., 1986. Interacting neurotransmitter systems. A non-experimental approach to the 5HIAA-HVA correlation in human CSF. J Psychiatr Res. 20, 175-193.

Akbari, H. M., Kramer, H. K., Whitaker-Azmitia, P. M., Spear, L. P. and Azmitia, E. C., 1992. Prenatal cocaine exposure disrupts the development of the serotonergic system. Brain Res. 572, 57-63.

Anisman, H., Hayley, S., Turrin, N. and Merali, Z., 2002. Cytokines as a stressor: implications for depressive illness. Int J Neuropsychopharmacol. 5, 357-373.

Anisman, H. and Merali, Z., 2003. Cytokines, stress and depressive illness: brain-immune interactions. Ann Med. 35, 2-11.

Anisman, H., Merali, Z. and Hayley, S., 2003. Sensitization associated with stressors and cytokine treatments. Brain Behav Immun. 17, 86-93.

Anisman, H., Zalcman, S. and Zacharko, R. M., 1993. The impact of stressors on immune and central neurotransmitter activity: bidirectional communication. Rev Neurosci. 4, 147-180.

Asberg, M., 1997. Neurotransmitters and suicidal behavior. The evidence from cerebrospinal fluid studies. Ann N Y Acad Sci. 836, 158-181.

Asberg, M., Thoren, P., Traskman, L., Bertilsson, L. and Ringberger, V., 1976a. “Serotonin depression”--a biochemical subgroup within the affective disorders? Science. 191, 478-480.

Asberg, M., Traskman, L. and Thoren, P., 1976b. 5-HIAA in the cerebrospinal fluid. A biochemical suicide predictor? Arch Gen Psychiatry. 33, 1193-1197.

Asnis, G. M., Eisenberg, J., van Praag, H. M., Lemus, C. Z., Friedman, J. M. and Miller, A. H., 1988. The neuroendocrine response to fenfluramine in depressives and normal controls. Biol Psychiatry. 24, 117-120.

Association, A. P., 1994. Diagnostic and Statistical Manual of Mental Disorders. American Psychiatric Association, Washington, DC.

Attenburrow, M. J., Mitter, P. R., Whale, R., Terao, T. and Cowen, P. J., 2001. Low-dose citalopram as a 5-HT neuroendocrine probe. Psychopharmacology (Berl). 155, 323-326.

Badawy, A. A. and Evans, M., 1976. The role of free serum tryptophan in the biphasic effect of acute ethanol administration on the concentrations of rat brain tryptophan, 5-hydroxytryptamine and 5-hydroxyindol-3-ylacetic acid. Biochem J. 160, 315-324.

Balldin, J., Berggren, U., Engel, J. and Eriksson, M., 1994. Neuroendocrine evidence for reduced serotonergic neurotransmission during heavy drinking. Alcohol Clin Exp Res. 18, 822-825.

Baumann, M. H. and Rothman, R. B., 1995. Repeated cocaine administration reduces 5-HT1A-mediated prolactin secretion in rats. Neurosci Lett. 193, 9-12.

Baumann, M. H. and Rothman, R. B., 1998. Alterations in serotonergic responsiveness during cocaine withdrawal in rats: similarities to major depression in humans. Biol Psychiatry. 44, 578-591.

Beck, O., Borg, S., Edman, G., Fyro, B., Oxenstierna, G. and Sedvall, G., 1984. 5-hydroxytryptophol in human cerebrospinal fluid: conjugation, concentration gradient, relationship to 5-hydroxyindoleacetic acid, and influence of hereditary factors. J Neurochem. 43, 58-61.

Bel, N. and Artigas, F., 1996. Reduction of serotonergic function in rat brain by tryptophan depletion: effects in control and fluvoxamine-treated rats. J Neurochem. 67, 669-676.

Bell, C., Abrams, J. and Nutt, D., 2001. Tryptophan depletion and its implications for psychiatry. Br J Psychiatry. 178, 399-405.

Bellivier, F., Leboyer, M., Courtet, P., Buresi, C., Beaufils, B., Samolyk, D., Allilaire, J. F., Feingold, J., Mallet, J. and Malafosse, A., 1998. Association between the tryptophan hydroxylase gene and manic-depressive illness. Arch Gen Psychiatry. 55, 33-37.

Benkelfat, C., Ellenbogen, M. A., Dean, P., Palmour, R. M. and Young, S. N., 1994. Mood-lowering effect of tryptophan depletion. Enhanced susceptibility in young men at genetic risk for major affective disorders. Arch Gen Psychiatry. 51, 687-697.

Bennett, A. J., Lesch, K. P., Heils, A., Long, J. C., Lorenz, J. G., Shoaf, S. E., Champoux, M., Suomi, S. J., Linnoila, M. V. and Higley, J. D., 2002. Early experience and serotonin transporter gene variation interact to influence primate CNS function. Mol Psychiatry. 7, 118-122. 
Bethea, C. L., Gundlah, C. and Mirkes, S. J., 2000. Ovarian steroid action in the serotonin neural system of macaques. Novartis Found Symp. 230, 112-130; discussion 130-113.

Bhagwagar, Z., Whale, R. and Cowen, P. J., 2002. State and trait abnormalities in serotonin function in major depression. Br J Psychiatry. 180, 24-28.

Bhatnagar, S., Lee, T. M. and Vining, C., 2005. Prenatal stress differentially affects habituation of corticosterone responses to repeated stress in adult male and female rats. Horm Behav. 47, 430-438.

Bhatnagar, S. and Meaney, M. J., 1995. Hypothalamic-pituitary-adrenal function in chronic intermittently cold-stressed neonatally handled and non handled rats. J Neuroendocrinol. 7, 97-108.

Biggio, G., Fadda, F., Fanni, P., Tagliamonte, A. and Gessa, G. L., 1974. Rapid depletion of serum tryptophan, brain tryptophan, serotonin and 5-hydroxyindoleacetic acid by a tryptophan-free diet. Life Sci. 14, 1321-1329.

Biver, F., Lotstra, F., Monclus, M., Wikler, D., Damhaut, P., Mendlewicz, J. and Goldman, S., 1996. Sex difference in 5HT2 receptor in the living human brain. Neurosci Lett. 204, 25-28.

Black, K. J. and Sheline, Y. I., 1997. Personality disorder scores improve with effective pharmacotherapy of depression. J Affect Disord. 43, 11-18.

Blokland, A., Lieben, C. and Deutz, N. E., 2002. Anxiogenic and depressive-like effects, but no cognitive deficits, after repeated moderate tryptophan depletion in the rat. J Psychopharmacol. 16, 39-49.

Bonaccorso, S., Marino, V., Biondi, M., Grimaldi, F., Ippoliti, F. and Maes, M., 2002a. Depression induced by treatment with interferon-alpha in patients affected by hepatitis C virus. J Affect Disord. 72, 237-241.

Bonaccorso, S., Marino, V., Puzella, A., Pasquini, M., Biondi, M., Artini, M., Almerighi, C., Verkerk, R., Meltzer, H. and Maes, M., 2002b. Increased depressive ratings in patients with hepatitis $\mathrm{C}$ receiving interferon-alpha-based immunotherapy are related to interferon-alpha-induced changes in the serotonergic system. J Clin Psychopharmacol. 22, 86-90.

Bonaccorso, S., Puzella, A., Marino, V., Pasquini, M., Biondi, M., Artini, M., Almerighi, C., Levrero, M., Egyed, B., Bosmans, E., Meltzer, H. Y. and Maes, M., 2001. Immunotherapy with interferon-alpha in patients affected by chronic hepatitis $\mathrm{C}$ induces an intercorrelated stimulation of the cytokine network and an increase in depressive and anxiety symptoms. Psychiatry Res. 105, 45-55.

Bond, A. J., 2001. Neurotransmitters, temperament and social functioning. Eur Neuropsychopharmacol. 11, 261-274.

Booij, L., Van der Does, A. J., Haffmans, P. M., Riedel, W. J., Fekkes, D. and Blom, M. J., 2005a. The effects of high-dose and low-dose tryptophan depletion on mood and cognitive functions of remitted depressed patients. J Psychopharmacol. 19, 267-275.

Booij, L., van der Does, A. J., Haffmans, P. M., Spinhoven, P. and McNally, R. J., 2005b. Acute tryptophan depletion as a model of depressive relapse: behavioural specificity and ethical considerations. Br J Psychiatry. $187,148-154$.

Booij, L., Van der Does, W., Benkelfat, C., Bremner, J. D., Cowen, P. J., Fava, M., Gillin, C., Leyton, M., Moore, P., Smith, K. A. and Van der Kloot, W. A., 2002. Predictors of mood response to acute tryptophan depletion. A reanalysis. Neuropsychopharmacology. 27, 852-861.

Boyce, P., Parker, G., Barnett, B., Cooney, M. and Smith, F., 1991. Personality as a vulnerability factor to depression. Br J Psychiatry. 159, 106-114.

Brewin, C. R., 1996. Cognitive processing of adverse experiences. International-Review of Psychiatry. 8, 333339.

Brown, S. L., Svrakic, D. M., Przybeck, T. R. and Cloninger, C. R., 1992. The relationship of personality to mood and anxiety states: a dimensional approach. J Psychiatr Res. 26, 197-211.

Brunner, D. and Hen, R., 1997. Insights into the neurobiology of impulsive behavior from serotonin receptor knockout mice. Ann N Y Acad Sci. 836, 81-105.

Cabrera-Vera, T. M. and Battaglia, G., 1998. Prenatal exposure to fluoxetine (Prozac) produces site-specific and age-dependent alterations in brain serotonin transporters in rat progeny: evidence from autoradiographic studies. J Pharmacol Exp Ther. 286, 1474-1481. 
Cabrera-Vera, T. M., Garcia, F., Pinto, W. and Battaglia, G., 1997. Effect of prenatal fluoxetine (Prozac) exposure on brain serotonin neurons in prepubescent and adult male rat offspring. J Pharmacol Exp Ther. 280, 138-145.

Cadoret, R. J., Winokur, G., Langbehn, D., Troughton, E., Yates, W. R. and Stewart, M. A., 1996. Depression spectrum disease, I: The role of gene-environment interaction. Am J Psychiatry. 153, 892-899.

Capuron, L. and Dantzer, R., 2003. Cytokines and depression: the need for a new paradigm. Brain Behav Immun. 17 Suppl 1, S119-124.

Capuron, L. and Ravaud, A., 1999. Prediction of the depressive effects of interferon alfa therapy by the patient's initial affective state. N Engl J Med. 340, 1370.

Carlsson, M. and Carlsson, A., 1988. A regional study of sex differences in rat brain serotonin. Prog Neuropsychopharmacol Biol Psychiatry. 12, 53-61.

Carpenter, L. L., Anderson, G. M., Pelton, G. H., Gudin, J. A., Kirwin, P. D., Price, L. H., Heninger, G. R. and McDougle, C. J., 1998. Tryptophan depletion during continuous CSF sampling in healthy human subjects. Neuropsychopharmacology. 19, 26-35.

Carroll, B. J., Curtis, G. C. and Mendels, J., 1976. Neuroendocrine regulation in depression. II. Discrimination of depressed from nondepressed patients. Arch Gen Psychiatry. 33, 1051-1058.

Caspi, A., Sugden, K., Moffitt, T. E., Taylor, A., Craig, I. W., Harrington, H., McClay, J., Mill, J., Martin, J., Braithwaite, A. and Poulton, R., 2003. Influence of life stress on depression: moderation by a polymorphism in the 5-HTT gene. Science. 301, 386-389.

Cervo, L., Canetta, A., Calcagno, E., Burbassi, S., Sacchetti, G., Caccia, S., Fracasso, C., Albani, D., Forloni, G. and Invernizzi, R. W., 2005. Genotype-dependent activity of tryptophan hydroxylase-2 determines the response to citalopram in a mouse model of depression. J Neurosci. 25, 8165-8172.

Charney, D. S., Heninger, G. R., Reinhard, J. F., Jr., Sternberg, D. E. and Hafstead, K. M., 1982. The effect of IV L-tryptophan on prolactin, growth hormone, and mood in healthy subjects. Psychopharmacology (Berl). 78, 38-43.

Charney, D. S., Woods, S. W., Goodman, W. K. and Heninger, G. R., 1987. Serotonin function in anxiety. II. Effects of the serotonin agonist MCPP in panic disorder patients and healthy subjects. Psychopharmacology (Berl). 92, 14-24.

Chien, A. J. and Dunner, D. L., 1996. The Tridimensional Personality Questionnaire in depression: state versus trait issues. J Psychiatr Res. 30, 21-27.

Clemens, J. A., Bennett, D. R. and Fuller, R. W., 1980. The effect of a tryptophan-free diet on prolactin and corticosterone release by serotonergic stimuli. Horm Metab Res. 12, 35-38.

Collier, D. A., Stober, G., Li, T., Heils, A., Catalano, M., Di Bella, D., Arranz, M. J., Murray, R. M., Vallada, H. P., Bengel, D., Muller, C. R., Roberts, G. W., Smeraldi, E., Kirov, G., Sham, P. and Lesch, K. P., 1996. A novel functional polymorphism within the promoter of the serotonin transporter gene: possible role in susceptibility to affective disorders. Mol Psychiatry. 1, 453-460.

Connor, T. J. and Leonard, B. E., 1998. Depression, stress and immunological activation: the role of cytokines in depressive disorders. Life Sci. 62, 583-606.

Coppen, A., Eccleston, E., Craft, I. and Bye, P., 1973. Letter: Total and free plasma-tryptophan concentration and oral contraception. Lancet. 2, 1498.

Cowen, P. J. and Charig, E. M., 1987. Neuroendocrine responses to intravenous tryptophan in major depression. Arch Gen Psychiatry. 44, 958-966.

Cowen, P. J., Parry-Billings, M. and Newsholme, E. A., 1989. Decreased plasma tryptophan levels in major depression. J Affect Disord. 16, 27-31.

Curran, H. V. and Verheyden, S. L., 2003. Altered response to tryptophan supplementation after long-term abstention from MDMA (ecstasy) is highly correlated with human memory function. Psychopharmacology (Berl). 169, 91-103.

Cutler, S. and Nolen-Hoeksema, S., 1991. Accounting for sex differences in depression through female victimization: Childhood sexual abuse. Sex Roles. 24, 425-438. 
Davis, S., Heal, D. J. and Stanford, S. C., 1995. Long-lasting effects of an acute stress on the neurochemistry and function of 5-hydroxytryptaminergic neurones in the mouse brain. Psychopharmacology (Berl). $118,267-272$.

de Kloet, E. R., Joels, M. and Holsboer, F., 2005a. Stress and the brain: from adaptation to disease. Nat Rev Neurosci. 6, 463-475.

de Kloet, E. R., Sibug, R. M., Helmerhorst, F. M. and Schmidt, M., 2005b. Stress, genes and the mechanism of programming the brain for later life. Neurosci Biobehav Rev. 29, 271-281.

de Win, M. M., Reneman, L., Reitsma, J. B., den Heeten, G. J., Booij, J. and van den Brink, W., 2004. Mood disorders and serotonin transporter density in ecstasy users--the influence of long-term abstention, dose, and gender. Psychopharmacology (Berl). 173, 376-382.

Degenhardt, L., Hall, W. and Lynskey, M., 2003. Exploring the association between cannabis use and depression. Addiction. 98, 1493-1504.

Delgado, P. L., Charney, D. S., Price, L. H., Landis, H. and Heninger, G. R., 1989. Neuroendocrine and behavioral effects of dietary tryptophan restriction in healthy subjects. Life Sci. 45, 2323-2332.

Delgado, P. L., Price, L. H., Miller, H. L., Salomon, R. M., Aghajanian, G. K., Heninger, G. R. and Charney, D. S., 1994. Serotonin and the neurobiology of depression. Effects of tryptophan depletion in drug-free depressed patients. Arch Gen Psychiatry. 51, 865-874.

Deminiere, J. M., Piazza, P. V., Guegan, G., Abrous, N., Maccari, S., Le Moal, M. and Simon, H., 1992. Increased locomotor response to novelty and propensity to intravenous amphetamine self-administration in adult offspring of stressed mothers. Brain Res. 586, 135-139.

Dominguez, R., Cruz-Morales, S. E., Carvalho, M. C., Xavier, M. and Brandao, M. L., 2003. Sex differences in serotonergic activity in dorsal and median raphe nucleus. Physiol Behav. 80, 203-210.

Drevets, W. C., Frank, E., Price, J. C., Kupfer, D. J., Holt, D., Greer, P. J., Huang, Y., Gautier, C. and Mathis, C., 1999. PET imaging of serotonin 1A receptor binding in depression. Biol Psychiatry. 46, 1375-1387.

Duggan, C., Sham, P., Lee, A., Minne, C. and Murray, R., 1995. Neuroticism: a vulnerability marker for depression evidence from a family study. J Affect Disord. 35, 139-143.

Dugovic, C., Maccari, S., Weibel, L., Turek, F. W. and Van Reeth, O., 1999. High corticosterone levels in prenatally stressed rats predict persistent paradoxical sleep alterations. J Neurosci. 19, 8656-8664.

Dunner, D. L., Schmaling, K. B., Hendrickson, H., Becker, J., Lehman, A. and Bea, C., 1996. Cognitive therapy versus fluoxetine in the treatment of dysthymic disorder. Depression. 4, 34-41.

Durham, L. K., Webb, S. M., Milos, P. M., Clary, C. M. and Seymour, A. B., 2004. The serotonin transporter polymorphism, 5HTTLPR, is associated with a faster response time to sertraline in an elderly population with major depressive disorder. Psychopharmacology (Berl). 174, 525-529.

Egashira, N., Mishima, K., Katsurabayashi, S., Yoshitake, T., Matsumoto, Y., Ishida, J., Yamaguchi, M., Iwasaki, K. and Fujiwara, M., 2002. Involvement of 5-hydroxytryptamine neuronal system in Delta(9)-tetrahydrocannabinol-induced impairment of spatial memory. Eur J Pharmacol. 445, 221-229.

Ellenbogen, M. A., Young, S. N., Dean, P., Palmour, R. M. and Benkelfat, C., 1996. Mood response to acute tryptophan depletion in healthy volunteers: sex differences and temporal stability. Neuropsychopharmacology. 15, 465-474.

Ellenbogen, M. A., Young, S. N., Dean, P., Palmour, R. M. and Benkelfat, C., 1999. Acute tryptophan depletion in healthy young women with a family history of major affective disorder. Psychol Med. 29, 35-46.

Feenstra, M. G., van Galen, H., Te Riele, P. J., Botterblom, M. H. and Mirmiran, M., 1996. Decreased hypothalamic serotonin levels in adult rats treated neonatally with clomipramine. Pharmacol Biochem Behav. $55,647-652$.

Fernstrom, J. D., 1985. Dietary effects on brain serotonin synthesis: relationship to appetite regulation. Am J Clin Nutr. 42, 1072-1082.

Fernstrom, J. D., 1990. Aromatic amino acids and monoamine synthesis in the central nervous system: influence of the diet. J Nutr Biochem. 1, 508-517.

Fernstrom, J. D. and Wurtman, R. J., 1971. Brain serotonin content: increase following ingestion of carbohydrate diet. Science. 174, 1023-1025. 
Fernstrom, J. D. and Wurtman, R. J., 1972. Brain serotonin content: physiological regulation by plasma neutral amino acids. Science. 178, 414-416.

Fink, G., Sumner, B. E., McQueen, J. K., Wilson, H. and Rosie, R., 1998. Sex steroid control of mood, mental state and memory. Clin Exp Pharmacol Physiol. 25, 764-775.

Flory, J. D., Mann, J. J., Manuck, S. B. and Muldoon, M. F., 1998. Recovery from major depression is not associated with normalization of serotonergic function. Biol Psychiatry. 43, 320-326.

Gala, R. R., 1990. The physiology and mechanisms of the stress-induced changes in prolactin secretion in the rat. Life Sci. 46, 1407-1420.

Gamma, A., Buck, A., Berthold, T. and Vollenweider, F. X., 2001. No difference in brain activation during cognitive performance between ecstasy (3,4-methylenedioxymethamphetamine) users and control subjects: a [H2(15)O]-positron emission tomography study. J Clin Psychopharmacol. 21, 66-71.

Gamma, A., Frei, E., Lehmann, D., Pascual-Marqui, R. D., Hell, D. and Vollenweider, F. X., 2000. Mood state and brain electric activity in ecstasy users. Neuroreport. 11, 157-162.

Gaspar, P., Cases, O. and Maroteaux, L., 2003. The developmental role of serotonin: news from mouse molecular genetics. Nat Rev Neurosci. 4, 1002-1012.

Gawin, F. H. and Kleber, H. D., 1986. Abstinence symptomatology and psychiatric diagnosis in cocaine abusers. Clinical observations. Arch Gen Psychiatry. 43, 107-113.

Gerra, G., Zaimovic, A., Ferri, M., Zambelli, U., Timpano, M., Neri, E., Marzocchi, G. F., Delsignore, R. and Brambilla, F., 2000. Long-lasting effects of $\left({ }^{+/}\right) 3$,4-methylenedioxymethamphetamine (ecstasy) on serotonin system function in humans. Biol Psychiatry. 47, 127-136.

Gerra, G., Zaimovic, A., Giucastro, G., Maestri, D., Monica, C., Sartori, R., Caccavari, R. and Delsignore, R., 1998. Serotonergic function after $\left({ }^{+/}\right) 3,4$-methylene-dioxymethamphetamine ('Ecstasy') in humans. Int Clin Psychopharmacol. 13, 1-9.

Golden, R. N., Ekstrom, D., Brown, T. M., Ruegg, R., Evans, D. L., Haggerty, J. J., Jr., Garbutt, J. C., Pedersen, C. A., Mason, G. A., Browne, J. and et al., 1992. Neuroendocrine effects of intravenous clomipramine in depressed patients and healthy subjects. Am J Psychiatry. 149, 1168-1175.

Gould, E., McEwen, B. S., Tanapat, P., Galea, L. A. and Fuchs, E., 1997. Neurogenesis in the dentate gyrus of the adult tree shrew is regulated by psychosocial stress and NMDA receptor activation. J Neurosci. 17, 2492-2498.

Gould, E. and Tanapat, P., 1999. Stress and hippocampal neurogenesis. Biol Psychiatry. 46, 1472-1479.

Grabe, H. J., Lange, M., Wolff, B., Volzke, H., Lucht, M., Freyberger, H. J., John, U. and Cascorbi, I., 2005. Mental and physical distress is modulated by a polymorphism in the 5-HT transporter gene interacting with social stressors and chronic disease burden. Mol Psychiatry. 10, 220-224.

Greenberg, B. D., Li, Q., Lucas, F. R., Hu, S., Sirota, L. A., Benjamin, J., Lesch, K. P., Hamer, D. and Murphy, D. L., 2000. Association between the serotonin transporter promoter polymorphism and personality traits in a primarily female population sample. Am J Med Genet. 96, 202-216.

Guillot, C. and Greenway, D., 2006. Recreational ecstasy use and depression. J Psychopharmacol. 20, 411-416.

Gundlah, C., Simon, L. D. and Auerbach, S. B., 1998. Differences in hypothalamic serotonin between estrous phases and gender: an in vivo microdialysis study. Brain Res. 785, 91-96.

Gunnar, M. R., 1998. Quality of early care and buffering of neuroendocrine stress reactions: potential effects on the developing human brain. Prev Med. 27, 208-211.

Gunnar, M. R., Brodersen, L., Krueger, K. and Rigatuso, J., 1996. Dampening of adrenocortical responses during infancy: normative changes and individual differences. Child Dev. 67, 877-889.

Gunnar, M. R. and Donzella, B., 2002. Social regulation of the cortisol levels in early human development. Psychoneuroendocrinology. 27, 199-220.

Haleem, D. J., Kennett, G. A. and Curzon, G., 1990. Hippocampal 5-hydroxytryptamine synthesis is greater in female rats than in males and more decreased by the 5-HT1A agonist 8-OH-DPAT. J Neural Transm Gen Sect. 79, 93-101.

Halliday, G., Ellis, J., Heard, R., Caine, D. and Harper, C., 1993. Brainstem serotonergic neurons in chronic alcoholics with and without the memory impairment of Korsakoff's psychosis. J Neuropathol Exp Neurol. 52, 567-579. 
Hanninen, V. and Aro, H., 1996. Sex differences in coping and depression among young adults. Soc Sci Med. 43, 1453-1460.

Hansenne, M. and Ansseau, M., 1999. Harm avoidance and serotonin. Biol Psychol. 51, 77-81.

Hansenne, M., Pitchot, W., Moreno, A. G., Reggers, J., Machurot, P. Y. and Ansseau, M., 1997. Harm avoidance dimension of the Tridimensional Personality Questionnaire and serotonin-1A activity in depressed patients. Biol Psychiatry. 42, 959-961.

Hariri, A. R., Drabant, E. M., Munoz, K. E., Kolachana, B. S., Mattay, V. S., Egan, M. F. and Weinberger, D. R., 2005. A susceptibility gene for affective disorders and the response of the human amygdala. Arch Gen Psychiatry. 62, 146-152.

Hariri, A. R. and Holmes, A., 2006. Genetics of emotional regulation: the role of the serotonin transporter in neural function. Trends Cogn Sci. 10, 182-191.

Hariri, A. R., Mattay, V. S., Tessitore, A., Kolachana, B., Fera, F., Goldman, D., Egan, M. F. and Weinberger, D. R., 2002. Serotonin transporter genetic variation and the response of the human amygdala. Science. 297, 400-403.

Harvey, M., Shink, E., Tremblay, M., Gagne, B., Raymond, C., Labbe, M., Walther, D. J., Bader, M. and Barden, N., 2004. Support for the involvement of TPH2 gene in affective disorders. Mol Psychiatry. 9, 980-981.

Hatzidimitriou, G., McCann, U. D. and Ricaurte, G. A., 1999. Altered serotonin innervation patterns in the forebrain of monkeys treated with $(+/-) 3,4$-methylenedioxymethamphetamine seven years previously: factors influencing abnormal recovery. J Neurosci. 19, 5096-5107.

Hayashi, A., Nagaoka, M., Yamada, K., Ichitani, Y., Miake, Y. and Okado, N., 1998. Maternal stress induces synaptic loss and developmental disabilities of offspring. Int J Dev Neurosci. 16, 209-216.

Hayley, S., Kelly, O. and Anisman, H., 2002. Murine tumor necrosis factor-alpha sensitizes plasma corticosterone activity and the manifestation of shock: modulation by histamine. J Neuroimmunol. 131, 60-69.

Hayley, S., Poulter, M. O., Merali, Z. and Anisman, H., 2005. The pathogenesis of clinical depression: stressorand cytokine-induced alterations of neuroplasticity. Neuroscience. 135, 659-678.

Heils, A., Teufel, A., Petri, S., Stober, G., Riederer, P., Bengel, D. and Lesch, K. P., 1996. Allelic variation of human serotonin transporter gene expression. J Neurochem. 66, 2621-2624.

Heim, C. and Nemeroff, C. B., 1999. The impact of early adverse experiences on brain systems involved in the pathophysiology of anxiety and affective disorders. Biol Psychiatry. 46, 1509-1522.

Heim, C. and Nemeroff, C. B., 2001. The role of childhood trauma in the neurobiology of mood and anxiety disorders: preclinical and clinical studies. Biol Psychiatry. 49, 1023-1039.

Heim, C., Plotsky, P. M. and Nemeroff, C. B., 2004. Importance of studying the contributions of early adverse experience to neurobiological findings in depression. Neuropsychopharmacology. 29, 641-648.

Heine, W., Radke, M., Wutzke, K. D., Peters, E. and Kundt, G., 1996. alpha-Lactalbumin-enriched low-protein infant formulas: a comparison to breast milk feeding. Acta Paediatr. 85, 1024-1028.

Heinz, A., Braus, D. F., Smolka, M. N., Wrase, J., Puls, I., Hermann, D., Klein, S., Grusser, S. M., Flor, H., Schumann, G., Mann, K. and Buchel, C., 2005. Amygdala-prefrontal coupling depends on a genetic variation of the serotonin transporter. Nat Neurosci. 8, 20-21.

Heinz, A., Jones, D. W., Mazzanti, C., Goldman, D., Ragan, P., Hommer, D., Linnoila, M. and Weinberger, D. R., 2000. A relationship between serotonin transporter genotype and in vivo protein expression and alcohol neurotoxicity. Biol Psychiatry. 47, 643-649.

Heinz, A., Ragan, P., Jones, D. W., Hommer, D., Williams, W., Knable, M. B., Gorey, J. G., Doty, L., Geyer, C., Lee, K. S., Coppola, R., Weinberger, D. R. and Linnoila, M., 1998. Reduced central serotonin transporters in alcoholism. Am J Psychiatry. 155, 1544-1549.

Heninger, G. R., 1995. Indoleamines: The Role of Serotonin in Clinical Disorders. In: Bloom, F. E. and Kupfer, D. J. (Eds.), Psychopharmacology: The Fourth Generation of Progress. Raven Press, Ltd., New York, pp. 471-482.

Heninger, G. R., Charney, D. S. and Sternberg, D. E., 1984. Serotonergic function in depression. Prolactin response to intravenous tryptophan in depressed patients and healthy subjects. Arch Gen Psychiatry. 41, 398-402. 
Hesselbrock, M. N., Meyer, R. E. and Keener, J. J., 1985. Psychopathology in hospitalized alcoholics. Arch Gen Psychiatry. 42, 1050-1055.

Heyes, M. P., Saito, K., Crowley, J. S., Davis, L. E., Demitrack, M. A., Der, M., Dilling, L. A., Elia, J., Kruesi, M. J., Lackner, A. and et al., 1992. Quinolinic acid and kynurenine pathway metabolism in inflammatory and non-inflammatory neurological disease. Brain. 115 ( Pt 5), 1249-1273.

Higley, J. D. and Linnoila, M., 1997. Low central nervous system serotonergic activity is traitlike and correlates with impulsive behavior. A nonhuman primate model investigating genetic and environmental influences on neurotransmission. Ann N Y Acad Sci. 836, 39-56.

Higley, J. D., Suomi, S. J. and Linnoila, M., 1991. CSF monoamine metabolite concentrations vary according to age, rearing, and sex, and are influenced by the stressor of social separation in rhesus monkeys. Psychopharmacology (Berl). 103, 551-556.

Higley, J. D., Thompson, W. W., Champoux, M., Goldman, D., Hasert, M. F., Kraemer, G. W., Scanlan, J. M., Suomi, S. J. and Linnoila, M., 1993. Paternal and maternal genetic and environmental contributions to cerebrospinal fluid monoamine metabolites in rhesus monkeys (Macaca mulatta). Arch Gen Psychiatry. $50,615-623$.

Hill, M. N., Sun, J. C., Tse, M. T. and Gorzalka, B. B., 2006. Altered responsiveness of serotonin receptor subtypes following long-term cannabinoid treatment. Int J Neuropsychopharmacol. 9, 277-286.

Hodgins, S. and Ellenbogen, M., 2003. Neuroticism and depression. Br J Psychiatry. 182, 79-80; author reply 80.

Hoefgen, B., Schulze, T. G., Ohlraun, S., von Widdern, O., Hofels, S., Gross, M., Heidmann, V., Kovalenko, S., Eckermann, A., Kolsch, H., Metten, M., Zobel, A., Becker, T., Nothen, M. M., Propping, P., Heun, R., Maier, W. and Rietschel, M., 2005. The power of sample size and homogenous sampling: association between the 5-HTTLPR serotonin transporter polymorphism and major depressive disorder. Biol Psychiatry. 57, 247-251.

Holsboer, F., 2000. The corticosteroid receptor hypothesis of depression. Neuropsychopharmacology. 23, 477501.

Huether, G., Thomke, F. and Adler, L., 1992. Administration of tryptophan-enriched diets to pregnant rats retards the development of the serotonergic system in their offspring. Brain Res Dev Brain Res. 68, 175-181.

Huizink, A. C., Mulder, E. J. and Buitelaar, J. K., 2004. Prenatal stress and risk for psychopathology: specific effects or induction of general susceptibility? Psychol Bull. 130, 115-142.

Huot, R. L., Gonzalez, M. E., Ladd, C. O., Thrivikraman, K. V. and Plotsky, P. M., 2004. Foster litters prevent hypothalamic-pituitary-adrenal axis sensitization mediated by neonatal maternal separation. Psychoneuroendocrinology. 29, 279-289.

Huot, R. L., Plotsky, P. M., Lenox, R. H. and McNamara, R. K., 2002. Neonatal maternal separation reduces hippocampal mossy fiber density in adult Long Evans rats. Brain Res. 950, 52-63.

Imwalle, D. B., Gustafsson, J. A. and Rissman, E. F., 2005. Lack of functional estrogen receptor beta influences anxiety behavior and serotonin content in female mice. Physiol Behav. 84, 157-163.

Irwin, M. and Gillin, J. C., 1987. Impaired natural killer cell activity among depressed patients. Psychiatry Res. 20, 181-182.

Jacobs, B. L. and Fornal, C. A., 1995. Serotonin and Behavior. In: Bloom, F. E. and Kupfer, D. J. (Eds.), Psychopharmacology: The Fourth Generation of Progress. Raven Press, Ltd., New York, pp. 461-469.

Joffe, H. and Cohen, L. S., 1998. Estrogen, serotonin, and mood disturbance: where is the therapeutic bridge? Biol Psychiatry. 44, 798-811.

Joffe, R. T., Bagby, R. M., Levitt, A. J., Regan, J. J. and Parker, J. D., 1993. The Tridimensional Personality Questionnaire in major depression. Am J Psychiatry. 150, 959-960.

Joiner, T. E., Jr., Johnson, F., Soderstrom, K. and Brown, J. S., 2003. Is there an association between serotonin transporter gene polymorphism and family history of depression? J Affect Disord. 77, 273-275.

Kalen, P., Strecker, R. E., Rosengren, E. and Bjorklund, A., 1988. Endogenous release of neuronal serotonin and 5-hydroxyindoleacetic acid in the caudate-putamen of the rat as revealed by intracerebral dialysis 
coupled to high-performance liquid chromatography with fluorimetric detection. J Neurochem. 51, 1422-1435.

Kapitany, T., Schindl, M., Schindler, S. D., Hesselmann, B., Fureder, T., Barnas, C., Sieghart, W. and Kasper, S., 1999. The citalopram challenge test in patients with major depression and in healthy controls. Psychiatry Res. 88, 75-88.

Karten, Y. J., Olariu, A. and Cameron, H. A., 2005. Stress in early life inhibits neurogenesis in adulthood. Trends Neurosci. 28, 171-172.

Kasper, S., Vieira, A., Schmidt, R. and Richter, P., 1990. Multiple hormone responses to stimulation with dlfenfluramine in patients with major depression before and after antidepressive treatment. Pharmacopsychiatry. 23, 76-84.

Kavoussi, R. J., Kramer, J., Hauger, R. L. and Coccaro, E. F., 1998. Prolactin response to D-fenfluramine in outpatients with major depression. Psychiatry Res. 79, 199-205.

Kendler, K. S., Davis, C. G. and Kessler, R. C., 1997. The familial aggregation of common psychiatric and substance use disorders in the National Comorbidity Survey: a family history study. Br J Psychiatry. 170, 541-548.

Kendler, K. S., Karkowski, L. M. and Prescott, C. A., 1999. Causal relationship between stressful life events and the onset of major depression. Am J Psychiatry. 156, 837-841.

Kendler, K. S., Kuhn, J. and Prescott, C. A., 2004. The interrelationship of neuroticism, sex, and stressful life events in the prediction of episodes of major depression. Am J Psychiatry. 161, 631-636.

Kendler, K. S., Kuhn, J. W., Vittum, J., Prescott, C. A. and Riley, B., 2005. The interaction of stressful life events and a serotonin transporter polymorphism in the prediction of episodes of major depression: a replication. Arch Gen Psychiatry. 62, 529-535.

Kendler, K. S., Neale, M. C., Kessler, R. C., Heath, A. C. and Eaves, L. J., 1993. A longitudinal twin study of personality and major depression in women. Arch Gen Psychiatry. 50, 853-862.

Kennett, G. A., Chaouloff, F., Marcou, M. and Curzon, G., 1986. Female rats are more vulnerable than males in an animal model of depression: the possible role of serotonin. Brain Res. 382, 416-421.

Kessler, R. C., McGonagle, K. A., Swartz, M., Blazer, D. G. and Nelson, C. B., 1993. Sex and depression in the National Comorbidity Survey. I: Lifetime prevalence, chronicity and recurrence. J Affect Disord. 29, 85-96.

Klaassen, T., Riedel, W. J., van Someren, A., Deutz, N. E., Honig, A. and van Praag, H. M., 1999. Mood effects of 24-hour tryptophan depletion in healthy first-degree relatives of patients with affective disorders. Biol Psychiatry. 46, 489-497.

Klink, R., Robichaud, M. and Debonnel, G., 2002. Gender and gonadal status modulation of dorsal raphe nucleus serotonergic neurons. Part I: effects of gender and pregnancy. Neuropharmacology. 43, 11191128 .

Knutson, B., Wolkowitz, O. M., Cole, S. W., Chan, T., Moore, E. A., Johnson, R. C., Terpstra, J., Turner, R. A. and Reus, V. I., 1998. Selective alteration of personality and social behavior by serotonergic intervention. Am J Psychiatry. 155, 373-379.

Kofman, O., 2002. The role of prenatal stress in the etiology of developmental behavioural disorders. Neurosci Biobehav Rev. 26, 457-470.

Koprich, J. B., Chen, E. Y., Kanaan, N. M., Campbell, N. G., Kordower, J. H. and Lipton, J. W., 2003. Prenatal 3,4-methylenedioxymethamphetamine (ecstasy) alters exploratory behavior, reduces monoamine metabolism, and increases forebrain tyrosine hydroxylase fiber density of juvenile rats. Neurotoxicol Teratol. 25, 509-517.

Kornstein, S. G., 2003. Gender, Depression, and Antidepressant Treatment. Primary Psychiatry. 10, 58-61.

Kronfol, Z., Silva, J., Jr., Greden, J., Dembinski, S., Gardner, R. and Carroll, B., 1983. Impaired lymphocyte function in depressive illness. Life Sci. 33, 241-247.

Kubera, M. and Maes, M., 2000. Serotonin-immune interactions in major depression. In: Patterson, P. H. et al. (Eds.), Neuroimmune Interactions in Neurologic and Psychiatric Disorders. Springer Verlag, New York, pp. 79-88. 
Laakmann, G., Gugath, M., Kuss, H. J. and Zygan, K., 1984. Comparison of growth hormone and prolactin stimulation induced by chlorimipramine and desimipramine in man in connection with chlorimipramine metabolism. Psychopharmacology (Berl). 82, 62-67.

Lai, M., McCormick, J. A., Chapman, K. E., Kelly, P. A., Seckl, J. R. and Yau, J. L., 2003. Differential regulation of corticosteroid receptors by monoamine neurotransmitters and antidepressant drugs in primary hippocampal culture. Neuroscience. 118, 975-984.

Leentjens, A. F., Scholtissen, B., Vreeling, F. W. and Verhey, F. R., 2006. The serotonergic hypothesis for depression in Parkinson's disease: an experimental approach. Neuropsychopharmacology. 31, 1009-1015.

LeMarquand, D., Pihl, R. O. and Benkelfat, C., 1994a. Serotonin and alcohol intake, abuse, and dependence: clinical evidence. Biol Psychiatry. 36, 326-337.

LeMarquand, D., Pihl, R. O. and Benkelfat, C., 1994b. Serotonin and alcohol intake, abuse, and dependence: findings of animal studies. Biol Psychiatry. 36, 395-421.

Lemonde, S., Turecki, G., Bakish, D., Du, L., Hrdina, P. D., Bown, C. D., Sequeira, A., Kushwaha, N., Morris, S. J., Basak, A., Ou, X. M. and Albert, P. R., 2003. Impaired repression at a 5-hydroxytryptamine 1A receptor gene polymorphism associated with major depression and suicide. J Neurosci. 23, 8788-8799.

Leonard, B. E., 1997. Fundamentals of Psychopharmacology. Wiley \& Sons, New York.

Leonard, B. E. and Song, C., 1999. Stress, depression, and the role of cytokines. Adv Exp Med Biol. 461, 251-265.

Lesch, K. P., 2001a. Serotonergic gene expression and depression: implications for developing novel antidepressants. J Affect Disord. 62, 57-76.

Lesch, K. P., 2001b. Variation of serotonergic gene expression: neurodevelopment and the complexity of response to psychopharmacologic drugs. Eur Neuropsychopharmacol. 11, 457-474.

Lesch, K. P., Bengel, D., Heils, A., Sabol, S. Z., Greenberg, B. D., Petri, S., Benjamin, J., Muller, C. R., Hamer, D. H. and Murphy, D. L., 1996. Association of anxiety-related traits with a polymorphism in the serotonin transporter gene regulatory region. Science. 274, 1527-1531.

Lesch, K. P. and Mossner, R., 1998. Genetically driven variation in serotonin uptake: is there a link to affective spectrum, neurodevelopmental, and neurodegenerative disorders? Biol Psychiatry. 44, 179-192.

Lesch, K. P. and Mossner, R., 1999. Knockout Corner: 5-HT(1A) receptor inactivation: anxiety or depression as a murine experience. Int J Neuropsychopharmcol. 2, 327-331.

Levy, A. D., Baumann, M. H. and Van de Kar, L. D., 1994. Monoaminergic regulation of neuroendocrine function and its modification by cocaine. Front Neuroendocrinol. 15, 85-156.

Lichtenberg, P., Shapira, B., Gillon, D., Kindler, S., Cooper, T. B., Newman, M. E. and Lerer, B., 1992. Hormone responses to fenfluramine and placebo challenge in endogenous depression. Psychiatry Res. 43, 137-146.

Lieben, C. K., Blokland, A., Westerink, B. and Deutz, N. E., 2004. Acute tryptophan and serotonin depletion using an optimized tryptophan-free protein-carbohydrate mixture in the adult rat. Neurochem Int. 44, 9-16.

Liechti, M. E., Gamma, A. and Vollenweider, F. X., 2001. Gender differences in the subjective effects of MDMA. Psychopharmacology (Berl). 154, 161-168.

Linnoila, M., Virkkunen, M., Scheinin, M., Nuutila, A., Rimon, R. and Goodwin, F. K., 1983. Low cerebrospinal fluid 5-hydroxyindoleacetic acid concentration differentiates impulsive from nonimpulsive violent behavior. Life Sci. 33, 2609-2614.

Little, K. Y., McLaughlin, D. P., Zhang, L., Livermore, C. S., Dalack, G. W., McFinton, P. R., DelProposto, Z. S., Hill, E., Cassin, B. J., Watson, S. J. and Cook, E. H., 1998. Cocaine, ethanol, and genotype effects on human midbrain serotonin transporter binding sites and mRNA levels. Am J Psychiatry. 155, 207-213.

Loehlin, J. C., McCrae, R. R., Costa, P. T. J. and John, O. P., 1998. Heritables of common and measure-specific components of the Big Five personality factors. Journal of Research in Personality. 32, 431-453.

Lopez, J. F., Akil, H. and Watson, S. J., 1999. Neural circuits mediating stress. Biol Psychiatry. 46, 1461-1471.

Maccari, S., Darnaudery, M., Morley-Fletcher, S., Zuena, A. R., Cinque, C. and Van Reeth, O., 2003. Prenatal stress and long-term consequences: implications of glucocorticoid hormones. Neurosci Biobehav Rev. 27, 119-127.

Maccari, S., Piazza, P. V., Kabbaj, M., Barbazanges, A., Simon, H. and Le Moal, M., 1995. Adoption reverses the long-term impairment in glucocorticoid feedback induced by prenatal stress. J Neurosci. 15, 110-116. 
MacIndoe, J. H. and Turkington, R. W., 1973. Stimulation of human prolactin secretion by intravenous infusion of L-tryptophan. J Clin Invest. 52, 1972-1978.

MacInnes, N., Handley, S. L. and Harding, G. F., 2001. Former chronic methylenedioxymethamphetamine (MDMA or ecstasy) users report mild depressive symptoms. J Psychopharmacol. 15, 181-186.

Maes, M., 1995. Evidence for an immune response in major depression: a review and hypothesis. Prog Neuropsychopharmacol Biol Psychiatry. 19, 11-38.

Maes, M., 1999. Major depression and activation of the inflammatory response system. Adv Exp Med Biol. 461, 25-46.

Maes, M., Capuron, L., Ravaud, A., Gualde, N., Bosmans, E., Egyed, B., Dantzer, R. and Neveu, P. J., 2001. Lowered serum dipeptidyl peptidase IV activity is associated with depressive symptoms and cytokine production in cancer patients receiving interleukin-2-based immunotherapy. Neuropsychopharmacology. 24, 130-140.

Maes, M., D’Hondt, P., Suy, E., Minner, B., Vandervorst, C. and Raus, J., 1991. HPA-axis hormones and prolactin responses to dextro-fenfluramine in depressed patients and healthy controls. Prog Neuropsychopharmacol Biol Psychiatry. 15, 781-790.

Maes, M. and Meltzer, H. Y., 1995. The Serotonin Hypothesis of Major Depression. In: Bloom, F. E. and Kupfer, D. J. (Eds.), Psychopharmacology: The Fourth Generation of Progress. Raven Press, Ltd., New York, pp. 933-944.

Maes, M., Verkerk, R., Bonaccorso, S., Ombelet, W., Bosmans, E. and Scharpe, S., 2002. Depressive and anxiety symptoms in the early puerperium are related to increased degradation of tryptophan into kynurenine, a phenomenon which is related to immune activation. Life Sci. 71, 1837-1848.

Magarinos, A. M., Verdugo, J. M. and McEwen, B. S., 1997. Chronic stress alters synaptic terminal structure in hippocampus. Proc Natl Acad Sci U S A. 94, 14002-14008.

Malarkey, W. B., Pearl, D. K., Demers, L. M., Kiecolt-Glaser, J. K. and Glaser, R., 1995. Influence of academic stress and season on 24-hour mean concentrations of ACTH, cortisol, and beta-endorphin. Psychoneuroendocrinology. 20, 499-508.

Malberg, J. E. and Duman, R. S., 2003. Cell proliferation in adult hippocampus is decreased by inescapable stress: reversal by fluoxetine treatment. Neuropsychopharmacology. 28, 1562-1571.

Malberg, J. E., Eisch, A. J., Nestler, E. J. and Duman, R. S., 2000. Chronic antidepressant treatment increases neurogenesis in adult rat hippocampus. J Neurosci. 20, 9104-9110.

Malison, R. T., Price, L. H., Berman, R., van Dyck, C. H., Pelton, G. H., Carpenter, L., Sanacora, G., Owens, M. J., Nemeroff, C. B., Rajeevan, N., Baldwin, R. M., Seibyl, J. P., Innis, R. B. and Charney, D. S., 1998. Reduced brain serotonin transporter availability in major depression as measured by [123I]-2 betacarbomethoxy-3 beta-(4-iodophenyl)tropane and single photon emission computed tomography. Biol Psychiatry. 44, 1090-1098.

Mann, J. J., Huang, Y. Y., Underwood, M. D., Kassir, S. A., Oppenheim, S., Kelly, T. M., Dwork, A. J. and Arango, V., 2000. A serotonin transporter gene promoter polymorphism (5-HTTLPR) and prefrontal cortical binding in major depression and suicide. Arch Gen Psychiatry. 57, 729-738.

Mann, J. J., McBride, P. A., Malone, K. M., DeMeo, M. and Keilp, J., 1995. Blunted serotonergic responsivity in depressed inpatients. Neuropsychopharmacology. 13, 53-64.

Markus, C. R., 2003. Interactions between stress, food and mood. In: Watson, D. a. D., F (Ed.), Performance functional foods. Woodhead Publishing, Cambridge, pp. 5-20.

Markus, C. R., Olivier, B. and de Haan, E. H., 2002. Whey protein rich in alpha-lactalbumin increases the ratio of plasma tryptophan to the sum of the other large neutral amino acids and improves cognitive performance in stress-vulnerable subjects. Am J Clin Nutr. 75, 1051-1056.

Markus, C. R., Olivier, B., Panhuysen, G. E., Van Der Gugten, J., Alles, M. S., Tuiten, A., Westenberg, H. G., Fekkes, D., Koppeschaar, H. F. and de Haan, E. E., 2000a. The bovine protein alpha-lactalbumin increases the plasma ratio of tryptophan to the other large neutral amino acids, and in vulnerable subjects raises brain serotonin activity, reduces cortisol concentration, and improves mood under stress. Am J Clin Nutr. 71, 1536-1544. 
Markus, R., Panhuysen, G., Tuiten, A. and Koppeschaar, H., 2000b. Effects of food on cortisol and mood in vulnerable subjects under controllable and uncontrollable stress. Physiol Behav. 70, 333-342.

Maswood, S., Truitt, W., Hotema, M., Caldarola-Pastuszka, M. and Uphouse, L., 1999. Estrous cycle modulation of extracellular serotonin in mediobasal hypothalamus: role of the serotonin transporter and terminal autoreceptors. Brain Res. 831, 146-154.

Mattson, M. P., Maudsley, S. and Martin, B., 2004. BDNF and 5-HT: a dynamic duo in age-related neuronal plasticity and neurodegenerative disorders. Trends Neurosci. 27, 589-594.

Matud, M. P., 2004. Gender differencesin stress and coping styles. Personality and Individual Differences. 37, 1401-1415.

Mazzanti, C. M., Lappalainen, J., Long, J. C., Bengel, D., Naukkarinen, H., Eggert, M., Virkkunen, M., Linnoila, M. and Goldman, D., 1998. Role of the serotonin transporter promoter polymorphism in anxiety-related traits. Arch Gen Psychiatry. 55, 936-940.

McCann, U. D., Ridenour, A., Shaham, Y. and Ricaurte, G. A., 1994. Serotonin neurotoxicity after $\left({ }^{+/}\right) 3,4-$ methylenedioxymethamphetamine (MDMA; "Ecstasy"): a controlled study in humans. Neuropsychopharmacology. 10, 129-138.

McCormick, C. M., Smythe, J. W., Sharma, S. and Meaney, M. J., 1995. Sex-specific effects of prenatal stress on hypothalamic-pituitary-adrenal responses to stress and brain glucocorticoid receptor density in adult rats. Brain Res Dev Brain Res. 84, 55-61.

McDonald, W. M., Richard, I. H. and DeLong, M. R., 2003. Prevalence, etiology, and treatment of depression in Parkinson's disease. Biol Psychiatry. 54, 363-375.

McEwen, B. S., 1999. Stress and hippocampal plasticity. Annu Rev Neurosci. 22, 105-122.

McEwen, B. S., 2004. Protection and damage from acute and chronic stress: allostasis and allostatic overload and relevance to the pathophysiology of psychiatric disorders. Ann N Y Acad Sci. 1032, 1-7.

McEwen, B. S. and Alves, S. E., 1999. Estrogen actions in the central nervous system. Endocr Rev. 20, 279-307.

McEwen, B. S. and Magarinos, A. M., 1997. Stress effects on morphology and function of the hippocampus. Ann N Y Acad Sci. 821, 271-284.

McKenna, D. J. and Peroutka, S. J., 1990. Neurochemistry and neurotoxicity of 3,4-methylenedioxymethamphetamine (MDMA, “ecstasy”). J Neurochem. 54, 14-22.

Meaney, M. J., 2001. Maternal care, gene expression, and the transmission of individual differences in stress reactivity across generations. Annu Rev Neurosci. 24, 1161-1192.

Meaney, M. J., Diorio, J., Francis, D., Widdowson, J., LaPlante, P., Caldji, C., Sharma, S., Seckl, J. R. and Plotsky, P. M., 1996. Early environmental regulation of forebrain glucocorticoid receptor gene expression: implications for adrenocortical responses to stress. Dev Neurosci. 18, 49-72.

Meijer, O. C. and de Kloet, E. R., 1994. Corticosterone suppresses the expression of 5-HT1A receptor mRNA in rat dentate gyrus. Eur J Pharmacol. 266, 255-261.

Meltzer, H. Y., Flemming, R. and Robertson, A., 1983. The effect of buspirone on prolactin and growth hormone secretion in man. Arch Gen Psychiatry. 40, 1099-1102.

Michalak, E. E., Wilkinson, C., Hood, K. and Dowrick, C., 2002. Seasonal and nonseasonal depression: how do they differ? Symptom profile, clinical and family history in a general population sample. J Affect Disord. 69, 185-192.

Miller, S. M. and Kirsch, N., 1987. Sex differences in cognitive coping with stress. In: Barnett, R. C. et al. (Eds.), Gender \& Stress. The Free Press, New York, pp. 278-307.

Minov, C., Baghai, T. C., Schule, C., Zwanzger, P., Schwarz, M. J., Zill, P., Rupprecht, R. and Bondy, B., 2001. Serotonin-2A-receptor and -transporter polymorphisms: lack of association in patients with major depression. Neurosci Lett. 303, 119-122.

Mirescu, C., Peters, J. D. and Gould, E., 2004. Early life experience alters response of adult neurogenesis to stress. Nat Neurosci. 7, 841-846.

Modell, S., Lauer, C. J., Schreiber, W., Huber, J., Krieg, J. C. and Holsboer, F., 1998. Hormonal response pattern in the combined DEX-CRH test is stable over time in subjects at high familial risk for affective disorders. Neuropsychopharmacology. 18, 253-262. 
Moja, E. A., Cipolla, P., Castoldi, D. and Tofanetti, O., 1989. Dose-response decrease in plasma tryptophan and in brain tryptophan and serotonin after tryptophan-free amino acid mixtures in rats. Life Sci. 44, 971-976.

Moreno, F. A., Gelenberg, A. J., Heninger, G. R., Potter, R. L., McKnight, K. M., Allen, J., Phillips, A. P. and Delgado, P. L., 1999. Tryptophan depletion and depressive vulnerability. Biol Psychiatry. 46, 498-505.

Moreno, F. A., Rowe, D. C., Kaiser, B., Chase, D., Michaels, T., Gelernter, J. and Delgado, P. L., 2002. Association between a serotonin transporter promoter region polymorphism and mood response during tryptophan depletion. Mol Psychiatry. 7, 213-216.

Moresco, F. M., Dieci, M., Vita, A., Messa, C., Gobbo, C., Galli, L., Rizzo, G., Panzacchi, A., De Peri, L., Invernizzi, G. and Fazio, F., 2002. In vivo serotonin 5HT(2A) receptor binding and personality traits in healthy subjects: a positron emission tomography study. Neuroimage. 17, 1470-1478.

Morgan, M. J., McFie, L., Fleetwood, H. and Robinson, J. A., 2002. Ecstasy (MDMA): are the psychological problems associated with its use reversed by prolonged abstinence? Psychopharmacology (Berl). 159, 294-303.

Morikawa, O., Sakai, N., Obara, H. and Saito, N., 1998. Effects of interferon-alpha, interferon-gamma and cAMP on the transcriptional regulation of the serotonin transporter. Eur J Pharmacol. 349, 317-324.

Morland, J., Stowell, L. and Gjerde, H., 1985. Ethanol increases rat liver tryptophan oxygenase: evidence for corticosterone mediation. Alcohol. 2, 255-259.

Morley-Fletcher, S., Darnaudery, M., Koehl, M., Casolini, P., Van Reeth, O. and Maccari, S., 2003. Prenatal stress in rats predicts immobility behavior in the forced swim test. Effects of a chronic treatment with tianeptine. Brain Res. 989, 246-251.

Mortola, J. F., Liu, J. H., Gillin, J. C., Rasmussen, D. D. and Yen, S. S., 1987. Pulsatile rhythms of adrenocorticotropin $(\mathrm{ACTH})$ and cortisol in women with endogenous depression: evidence for increased ACTH pulse frequency. J Clin Endocrinol Metab. 65, 962-968.

Mossner, R., Heils, A., Stober, G., Okladnova, O., Daniel, S. and Lesch, K. P., 1998. Enhancement of serotonin transporter function by tumor necrosis factor alpha but not by interleukin-6. Neurochem Int. 33, 251-254.

Muneoka, K., Mikuni, M., Ogawa, T., Kitera, K., Kamei, K., Takigawa, M. and Takahashi, K., 1997. Prenatal dexamethasone exposure alters brain monoamine metabolism and adrenocortical response in rat offspring. Am J Physiol. 273, R1669-1675.

Murphy, D. L., Li, Q., Engel, S., Wichems, C., Andrews, A., Lesch, K. P. and Uhl, G., 2001. Genetic perspectives on the serotonin transporter. Brain Res Bull. 56, 487-494.

Naughton, M., Mulrooney, J. B. and Leonard, B. E., 2000. A review of the role of serotonin receptors in psychiatric disorders. Hum Psychopharmacol. 15, 397-415.

Nelson, E. C., Cloninger, C. R., Przybeck, T. R. and Csernansky, J. G., 1996. Platelet serotonergic markers and Tridimensional Personality Questionnaire measures in a clinical sample. Biol Psychiatry. 40, 271-278.

Nestler, E. J., Gould, E., Manji, H., Buncan, M., Duman, R. S., Greshenfeld, H. K., Hen, R., Koester, S., Lederhendler, I., Meaney, M., Robbins, T., Winsky, L. and Zalcman, S., 2002. Preclinical models: status of basic research in depression. Biol Psychiatry. 52, 503-528.

Neumeister, A., Bain, E., Nugent, A. C., Carson, R. E., Bonne, O., Luckenbaugh, D. A., Eckelman, W., Herscovitch, P., Charney, D. S. and Drevets, W. C., 2004a. Reduced serotonin type 1A receptor binding in panic disorder. J Neurosci. 24, 589-591.

Neumeister, A., Konstantinidis, A., Stastny, J., Schwarz, M. J., Vitouch, O., Willeit, M., Praschak-Rieder, N., Zach, J., de Zwaan, M., Bondy, B., Ackenheil, M. and Kasper, S., 2002. Association between serotonin transporter gene promoter polymorphism (5HTTLPR) and behavioral responses to tryptophan depletion in healthy women with and without family history of depression. Arch Gen Psychiatry. 59, 613-620.

Neumeister, A., Nugent, A. C., Waldeck, T., Geraci, M., Schwarz, M., Bonne, O., Bain, E. E., Luckenbaugh, D. A., Herscovitch, P., Charney, D. S. and Drevets, W. C., 2004b. Neural and behavioral responses to tryptophan depletion in unmedicated patients with remitted major depressive disorder and controls. Arch Gen Psychiatry. 61, 765-773. 
Neumeister, A., Young, T. and Stastny, J., 2004c. Implications of genetic research on the role of the serotonin in depression: emphasis on the serotonin type $1 \mathrm{~A}$ receptor and the serotonin transporter. Psychopharmacology (Berl). 174, 512-524.

Newman, M. E., Shapira, B. and Lerer, B., 1998. Evaluation of central serotonergic function in affective and related disorders by the fenfluramine challenge test: a critical review. Int J Neuropsychopharmcol. 1, 49-69.

Nishizawa, S., Benkelfat, C., Young, S. N., Leyton, M., Mzengeza, S., de Montigny, C., Blier, P. and Diksic, M., 1997. Differences between males and females in rates of serotonin synthesis in human brain. Proc Natl Acad Sci U S A. 94, 5308-5313.

Nolen-Hoeksema, S., 2001. Gender Differences in Depression. American Psychological Society. 10, 173 - 176.

Nunes, S. O., Reiche, E. M., Morimoto, H. K., Matsuo, T., Itano, E. N., Xavier, E. C., Yamashita, C. M., Vieira, V. R., Menoli, A. V., Silva, S. S., Costa, F. B., Reiche, F. V., Silva, F. L. and Kaminami, M. S., 2002. Immune and hormonal activity in adults suffering from depression. Braz J Med Biol Res. 35, 581-587.

Ohara, K., Nagai, M., Tsukamoto, T., Tani, K. and Suzuki, Y., 1998. Functional polymorphism in the serotonin transporter promoter at the SLC6A4 locus and mood disorders. Biol Psychiatry. 44, 550-554.

O'Keane, V. and Dinan, T. G., 1991. Prolactin and cortisol responses to d-fenfluramine in major depression: evidence for diminished responsivity of central serotonergic function. Am J Psychiatry. 148, 1009-1015.

O’Keane, V., McLoughlin, D. and Dinan, T. G., 1992. D-fenfluramine-induced prolactin and cortisol release in major depression: response to treatment. J Affect Disord. 26, 143-150.

Orosco, M., Rouch, C., Beslot, F., Feurte, S., Regnault, A. and Dauge, V., 2004. Alpha-lactalbumin-enriched diets enhance serotonin release and induce anxiolytic and rewarding effects in the rat. Behav Brain Res. 148, 1-10.

Oscar-Berman, M., Shagrin, B., Evert, D. L. and Epstein, C., 1997. Impairments of brain and behavior: the neurological effects of alcohol. Alcohol Health Res World. 21, 65-75.

Osterlund, M. K. and Hurd, Y. L., 2001. Estrogen receptors in the human forebrain and the relation to neuropsychiatric disorders. Prog Neurobiol. 64, 251-267.

Ostlund, H., Keller, E. and Hurd, Y. L., 2003. Estrogen receptor gene expression in relation to neuropsychiatric disorders. Ann N Y Acad Sci. 1007, 54-63.

Owen, D., Andrews, M. H. and Matthews, S. G., 2005. Maternal adversity, glucocorticoids and programming of neuroendocrine function and behaviour. Neurosci Biobehav Rev. 29, 209-226.

Owesson, C. A., Hopwood, S. E., Callado, L. F., Seif, I., McLaughlin, D. P. and Stamford, J. A., 2002. Altered presynaptic function in monoaminergic neurons of monoamine oxidase-A knockout mice. Eur J Neurosci. $15,1516-1522$.

Oxenstierna, G., Edman, G., Iselius, L., Oreland, L., Ross, S. B. and Sedvall, G., 1986. Concentrations of monoamine metabolites in the cerebrospinal fluid of twins and unrelated individuals--a genetic study. J Psychiatr Res. 20, 19-29.

Papaioannou, A., Gerozissis, K., Prokopiou, A., Bolaris, S. and Stylianopoulou, F., 2002. Sex differences in the effects of neonatal handling on the animal's response to stress and the vulnerability for depressive behaviour. Behav Brain Res. 129, 131-139.

Pariante, C. M., Makoff, A., Lovestone, S., Feroli, S., Heyden, A., Miller, A. H. and Kerwin, R. W., 2001. Antidepressants enhance glucocorticoid receptor function in vitro by modulating the membrane steroid transporters. Br J Pharmacol. 134, 1335-1343.

Peirson, A. R., Heuchert, J. W., Thomala, L., Berk, M., Plein, H. and Cloninger, C. R., 1999. Relationship between serotonin and the temperament and character inventory. Psychiatry Res. 89, 29-37.

Piccinelli, M. and Wilkinson, G., 2000. Gender differences in depression. Critical review. Br J Psychiatry. 177, 486-492.

Plata-Salaman, C. R., 1998. Cytokines and anorexia: a brief overview. Semin Oncol. 25, 64-72.

Pollock, B. G., Ferrell, R. E., Mulsant, B. H., Mazumdar, S., Miller, M., Sweet, R. A., Davis, S., Kirshner, M. A., Houck, P. R., Stack, J. A., Reynolds, C. F. and Kupfer, D. J., 2000. Allelic variation in the serotonin transporter promoter affects onset of paroxetine treatment response in late-life depression. Neuropsychopharmacology. 23, 587-590. 
Poltyrev, T. and Weinstock, M., 1997. Effect of prenatal stress on opioid component of exploration in different experimental situations. Pharmacol Biochem Behav. 58, 387-393.

Porter, R. J., Gallagher, P., Watson, S., Smith, M. S. and Young, A. H., 2003. Elevated prolactin responses to Ltryptophan infusion in medication-free depressed patients. Psychopharmacology (Berl). 169, 77-83.

Porter, R. J., Gallagher, P., Watson, S. and Young, A. H., 2004. Corticosteroid-serotonin interactions in depression: a review of the human evidence. Psychopharmacology (Berl). 173, 1-17.

Powell, B. J., Penick, E. C., Othmer, E., Bingham, S. F. and Rice, A. S., 1982. Prevalence of additional psychiatric syndromes among male alcoholics. J Clin Psychiatry. 43, 404-407.

Prickaerts, J. and Steckler, T., 2005. Effects of glucocorticoids on emotion and cognitive processes in animals. In: Steckler, T. et al. (Eds.), Handbook of Stress and the Brain, vol.15. Elsevier, Amsterdam/London, pp. 359-385.

Ptacek, J. T., Smith, R. E. and Zanas, J., 1992. Gender, appraisal, and coping: A longitudinal analysis. Journal of Personality. 60, 747-770.

Quattrone, A., Tedeschi, G., Aguglia, U., Scopacasa, F., Direnzo, G. F. and Annunziato, L., 1983. Prolactin secretion in man: a useful tool to evaluate the activity of drugs on central 5-hydroxytryptaminergic neurones. Studies with fenfluramine. Br J Clin Pharmacol. 16, 471-475.

Ramamoorthy, S., Ramamoorthy, J. D., Prasad, P. D., Bhat, G. K., Mahesh, V. B., Leibach, F. H. and Ganapathy, V., 1995. Regulation of the human serotonin transporter by interleukin-1 beta. Biochem Biophys Res Commun. 216, 560-567.

Ramboz, S., Saudou, F., Amara, D. A., Belzung, C., Segu, L., Misslin, R., Buhot, M. C. and Hen, R., 1996. 5 HT1B receptor knock out--behavioral consequences. Behav Brain Res. 73, 305-312.

Ramsay, D. S. and Lewis, M., 1994. Developmental change in infant cortisol and behavioral response to inoculation. Child Dev. 65, 1491-1502.

Reichenberg, A., Yirmiya, R., Schuld, A., Kraus, T., Haack, M., Morag, A. and Pollmacher, T., 2001. Cytokineassociated emotional and cognitive disturbances in humans. Arch Gen Psychiatry. 58, 445-452.

Reist, C., Helmeste, D., Albers, L., Chhay, H. and Tang, S. W., 1996. Serotonin indices and impulsivity in normal volunteers. Psychiatry Res. 60, 177-184.

Reith, M. E., Sershen, H., Allen, D. L. and Lajtha, A., 1983. A portion of [3H]cocaine binding in brain is associated with serotonergic neurons. Mol Pharmacol. 23, 600-606.

Reneman, L., Booij, J., de Bruin, K., Reitsma, J. B., de Wolff, F. A., Gunning, W. B., den Heeten, G. J. and van den Brink, W., 2001a. Effects of dose, sex, and long-term abstention from use on toxic effects of MDMA (ecstasy) on brain serotonin neurons. Lancet. 358, 1864-1869.

Reneman, L., Booij, J., Schmand, B., van den Brink, W. and Gunning, B., 2000. Memory disturbances in "Ecstasy" users are correlated with an altered brain serotonin neurotransmission. Psychopharmacology (Berl). 148, 322-324.

Reneman, L., Lavalaye, J., Schmand, B., de Wolff, F. A., van den Brink, W., den Heeten, G. J. and Booij, J., 2001b. Cortical serotonin transporter density and verbal memory in individuals who stopped using 3,4methylenedioxymethamphetamine (MDMA or "ecstasy"): preliminary findings. Arch Gen Psychiatry. 58, 901-906.

Ricaurte, G. A., Yuan, J. and McCann, U. D., 2000. $\left({ }^{+/}\right)$3,4-Methylenedioxymethamphetamine ('Ecstasy')-induced serotonin neurotoxicity: studies in animals. Neuropsychobiology. 42, 5-10.

Richter, J., Eisemann, M. and Richter, G., 2000. Temperament and character during the course of unipolar depression among inpatients. Eur Arch Psychiatry Clin Neurosci. 250, 40-47.

Riedel, W. J., Klaassen, T., Griez, E., Honig, A., Menheere, P. P. and van Praag, H. M., 2002a. Dissociable hormonal, cognitive and mood responses to neuroendocrine challenge: evidence for receptor-specific serotonergic dysregulation in depressed mood. Neuropsychopharmacology. 26, 358-367.

Riedel, W. J., Klaassen, T. and Schmitt, J. A., 2002b. Tryptophan, mood, and cognitive function. Brain Behav Immun. 16, 581-589.

Ritz, M. C., Cone, E. J. and Kuhar, M. J., 1990. Cocaine inhibition of ligand binding at dopamine, norepinephrine and serotonin transporters: a structure-activity study. Life Sci. 46, 635-645. 
Robertson, D. A., Beattie, J. E., Reid, I. C. and Balfour, D. J., 2005. Regulation of corticosteroid receptors in the rat brain: the role of serotonin and stress. Eur J Neurosci. 21, 1511-1520.

Roiser, J. P., Cook, L. J., Cooper, J. D., Rubinsztein, D. C. and Sahakian, B. J., 2005. Association of a functional polymorphism in the serotonin transporter gene with abnormal emotional processing in ecstasy users. Am J Psychiatry. 162, 609-612.

Rosencrans, J. A., 1970. Differences in brain area 5-hydroxytryptamine turnover and rearing behavior in rats and mice of both sexes. European Journal of Pharmacology. 9, 379-382.

Rubinow, D. R., Schmidt, P. J. and Roca, C. A., 1998. Estrogen-serotonin interactions: implications for affective regulation. Biol Psychiatry. 44, 839-850.

Rubinsztein, J. S., Rogers, R. D., Riedel, W. J., Mehta, M. A., Robbins, T. W. and Sahakian, B. J., 2001. Acute dietary tryptophan depletion impairs maintenance of "affective set" and delayed visual recognition in healthy volunteers. Psychopharmacology (Berl). 154, 319-326.

Ruedi-Bettschen, D., Feldon, J. and Pryce, C. R., 2004. The impaired coping induced by early deprivation is reversed by chronic fluoxetine treatment in adult fischer rats. Behav Pharmacol. 15, 413-421.

Ruedi-Bettschen, D., Pedersen, E. M., Feldon, J. and Pryce, C. R., 2005. Early deprivation under specific conditions leads to reduced interest in reward in adulthood in Wistar rats. Behav Brain Res. 156, 297-310.

Sachar, E. J., Hellman, L., Roffwarg, H. P., Halpern, F. S., Fukushima, D. K. and Gallagher, T. F., 1973. Disrupted 24-hour patterns of cortisol secretion in psychotic depression. Arch Gen Psychiatry. 28, 19-24.

Sapolsky, R. M., 1996. Why stress is bad for your brain. Science. 273, 749-750.

Sapolsky, R. M., 2004. Is impaired neurogenesis relevant to the affective symptoms of depression? Biol Psychiatry. 56, 137-139.

Sapolsky, R. M. and Meaney, M. J., 1986. Maturation of the adrenocortical stress response: neuroendocrine control mechanisms and the stress hyporesponsive period. Brain Res. 396, 64-76.

Sargent, P. A., Kjaer, K. H., Bench, C. J., Rabiner, E. A., Messa, C., Meyer, J., Gunn, R. N., Grasby, P. M. and Cowen, P. J., 2000. Brain serotonin1A receptor binding measured by positron emission tomography with [11C]WAY-100635: effects of depression and antidepressant treatment. Arch Gen Psychiatry. 57, 174-180.

Scheffel, U., Szabo, Z., Mathews, W. B., Finley, P. A., Dannals, R. F., Ravert, H. T., Szabo, K., Yuan, J. and Ricaurte, G. A., 1998. In vivo detection of short- and long-term MDMA neurotoxicity--a positron emission tomography study in the living baboon brain. Synapse. 29, 183-192.

Schiepers, O. J., Wichers, M. C. and Maes, M., 2005. Cytokines and major depression. Prog Neuropsychopharmacol Biol Psychiatry. 29, 201-217.

Schmidt, C. J., 1987. Neurotoxicity of the psychedelic amphetamine, methylenedioxymethamphetamine. J Pharmacol Exp Ther. 240, 1-7.

Schmidt, E. D., Janszen, A. W., Wouterlood, F. G. and Tilders, F. J., 1995. Interleukin-1-induced long-lasting changes in hypothalamic corticotropin-releasing hormone $(\mathrm{CRH})$--neurons and hyperresponsiveness of the hypothalamus-pituitary-adrenal axis. J Neurosci. 15, 7417-7426.

Schuckit, M. A., Mazzanti, C., Smith, T. L., Ahmed, U., Radel, M., Iwata, N. and Goldman, D., 1999. Selective genotyping for the role of 5-HT2A, 5-HT2C, and GABA alpha 6 receptors and the serotonin transporter in the level of response to alcohol: a pilot study. Biol Psychiatry. 45, 647-651.

Seifritz, E., Baumann, P., Muller, M. J., Annen, O., Amey, M., Hemmeter, U., Hatzinger, M., Chardon, F. and Holsboer-Trachsler, E., 1996. Neuroendocrine effects of a 20-mg citalopram infusion in healthy males. A placebo-controlled evaluation of citalopram as 5-HT function probe. Neuropsychopharmacology. 14, 253-263.

Semont, A., Fache, M., Ouafik, L., Hery, M., Faudon, M. and Hery, F., 1999. Effect of serotonin inhibition on glucocorticoid and mineralocorticoid expression in various brain structures. Neuroendocrinology. 69, 121-128.

Semple, D. M., Ebmeier, K. P., Glabus, M. F., O’Carroll, R. E. and Johnstone, E. C., 1999. Reduced in vivo binding to the serotonin transporter in the cerebral cortex of MDMA ('ecstasy') users. Br J Psychiatry. 175, 63-69.

Shapira, B., Cohen, J., Newman, M. E. and Lerer, B., 1993. Prolactin response to fenfluramine and placebo challenge following maintenance pharmacotherapy withdrawal in remitted depressed patients. Biol Psychiatry. 33, 531-535. 
Shemer, A., Whitaker-Azmitia, P. M. and Azmitia, E. C., 1988. Effects of prenatal 5-methoxytryptamine and parachlorophenylalanine on serotonergic uptake and behavior in the neonatal rat. Pharmacol Biochem Behav. 30, 847-851.

Shemer, A. V., Azmitia, E. C. and Whitaker-Azmitia, P. M., 1991. Dose-related effects of prenatal 5-methoxytryptamine (5-MT) on development of serotonin terminal density and behavior. Brain Res Dev Brain Res. 59, 59-63.

Sher, L., Oquendo, M. A., Li, S., Ellis, S., Brodsky, B. S., Malone, K. M., Cooper, T. B. and Mann, J. J., 2003. Prolactin response to fenfluramine administration in patients with unipolar and bipolar depression and healthy controls. Psychoneuroendocrinology. 28, 559-573.

Shors, T. J. and Miesegaes, G., 2002. Testosterone in utero and at birth dictates how stressful experience will affect learning in adulthood. Proc Natl Acad Sci U S A. 99, 13955-13960.

Siever, L. J., Murphy, D. L., Slater, S., de la Vega, E. and Lipper, S., 1984. Plasma prolactin changes following fenfluramine in depressed patients compared to controls: an evaluation of central serotonergic responsivity in depression. Life Sci. 34, 1029-1039.

Simmons, D. A. and Broderick, P. A., 2005. Cytokines, stressors, and clinical depression: augmented adaptation responses underlie depression pathogenesis. Prog Neuropsychopharmacol Biol Psychiatry. 29, 793-807.

Slotkin, T. A., Barnes, G. A., McCook, E. C. and Seidler, F. J., 1996. Programming of brainstem serotonin transporter development by prenatal glucocorticoids. Brain Res Dev Brain Res. 93, 155-161.

Smeraldi, E., Zanardi, R., Benedetti, F., Di Bella, D., Perez, J. and Catalano, M., 1998. Polymorphism within the promoter of the serotonin transporter gene and antidepressant efficacy of fluvoxamine. Mol Psychiatry. 3, 508-511.

Smith, G. S., Lotrich, F. E., Malhotra, A. K., Lee, A. T., Ma, Y., Kramer, E., Gregersen, P. K., Eidelberg, D. and Pollock, B. G., 2004. Effects of serotonin transporter promoter polymorphisms on serotonin function. Neuropsychopharmacology. 29, 2226-2234.

Smith, K. A., Fairburn, C. G. and Cowen, P. J., 1997. Relapse of depression after rapid depletion of tryptophan. Lancet. 349, 915-919.

Sobczak, S., Honig, A., Nicolson, N. A. and Riedel, W. J., 2002a. Effects of acute tryptophan depletion on mood and cortisol release in first-degree relatives of type I and type II bipolar patients and healthy matched controls. Neuropsychopharmacology. 27, 834-842.

Sobczak, S., Riedel, W. J., Booij, I., Aan Het Rot, M., Deutz, N. E. and Honig, A., 2002b. Cognition following acute tryptophan depletion: difference between first-degree relatives of bipolar disorder patients and matched healthy control volunteers. Psychol Med. 32, 503-515.

Spillmann, M. K., Van der Does, A. J., Rankin, M. A., Vuolo, R. D., Alpert, J. E., Nierenberg, A. A., Rosenbaum, J. F., Hayden, D., Schoenfeld, D. and Fava, M., 2001. Tryptophan depletion in SSRI-recovered depressed outpatients. Psychopharmacology (Berl). 155, 123-127.

Staley, J. K., Sanacora, G., Tamagnan, G., Maciejewski, P. K., Malison, R. T., Berman, R. M., Vythilingam, M., Kugaya, A., Baldwin, R. M., Seibyl, J. P., Charney, D. and Innis, R. B., 2006. Sex differences in diencephalon serotonin transporter availability in major depression. Biol Psychiatry. 59, 40-47.

Stallings, M. C., Cherny, S. S., Young, S. E., Miles, D. R., Hewitt, J. K. and Fulker, D. W., 1997. The familial aggregation of depressive symptoms, antisocial behavior, and alcohol abuse. Am J Med Genet. 74, 183-191.

Stancampiano, R., Melis, F., Sarais, L., Cocco, S., Cugusi, C. and Fadda, F., 1997. Acute administration of a tryptophan-free amino acid mixture decreases 5-HT release in rat hippocampus in vivo. Am J Physiol. 272, R991-994.

Stanford, S. C., 2001. 5-Hydroxytryptamine. In: Webster, R. A. (Ed.), Neurotransmitters, Drugs and Brain Function. John Wiley \& Sons Ltd, pp. 187-209.

Stone, T. W. and Darlington, L. G., 2002. Endogenous kynurenines as targets for drug discovery and development. Nat Rev Drug Discov. 1, 609-620.

Strakowski, S. M., Dunayevich, E., Keck, P. E., Jr. and McElroy, S. L., 1995. Affective state dependence of the Tridimensional Personality Questionnaire. Psychiatry Res. 57, 209-214. 
Strike, P. C., Wardle, J. and Steptoe, A., 2004. Mild acute inflammatory stimulation induces transient negative mood. J Psychosom Res. 57, 189-194.

Sullivan, P. F., Neale, M. C. and Kendler, K. S., 2000. Genetic epidemiology of major depression: review and meta-analysis. Am J Psychiatry. 157, 1552-1562.

Sullivan, P. F., Wells, J. E., Joyce, P. R., Bushnell, J. A., Mulder, R. T. and Oakley-Browne, M. A., 1996. Family history of depression in clinic and community samples. J Affect Disord. 40, 159-168.

Sumner, B. E. and Fink, G., 1998. Testosterone as well as estrogen increases serotonin2A receptor mRNA and binding site densities in the male rat brain. Brain Res Mol Brain Res. 59, 205-214.

Sutanto, W., Rosenfeld, P., de Kloet, E. R. and Levine, S., 1996. Long-term effects of neonatal maternal deprivation and ACTH on hippocampal mineralocorticoid and glucocorticoid receptors. Brain Res Dev Brain Res. 92, 156-163.

Szuran, T. F., Pliska, V., Pokorny, J. and Welzl, H., 2000. Prenatal stress in rats: effects on plasma corticosterone, hippocampal glucocorticoid receptors, and maze performance. Physiol Behav. 71, 353-362.

Taffe, M. A., Huitron-Resendiz, S., Schroeder, R., Parsons, L. H., Henriksen, S. J. and Gold, L. H., 2003. MDMA exposure alters cognitive and electrophysiological sensitivity to rapid tryptophan depletion in rhesus monkeys. Pharmacol Biochem Behav. 76, 141-152.

Thomasius, R., Petersen, K., Buchert, R., Andresen, B., Zapletalova, P., Wartberg, L., Nebeling, B. and Schmoldt, A., 2003. Mood, cognition and serotonin transporter availability in current and former ecstasy (MDMA) users. Psychopharmacology (Berl). 167, 85-96.

Tilders, F. J. and Schmidt, E. D., 1999. Cross-sensitization between immune and non-immune stressors. A role in the etiology of depression? Adv Exp Med Biol. 461, 179-197.

Tilders, F. J., Schmidt, E. D. and de Goeij, D. C., 1993. Phenotypic plasticity of CRF neurons during stress. Ann N Y Acad Sci. 697, 39-52.

Tsai, S. J., Wang, Y. C., Hong, C. J. and Chiu, H. J., 2003. Association study of oestrogen receptor alpha gene polymorphism and suicidal behaviours in major depressive disorder. Psychiatr Genet. 13, 19-22.

Tse, W. S. and Bond, A. J., 2001. Serotonergic involvement in the psychosocial dimension of personality. J Psychopharmacol. 15, 195-198.

Vaillant, G. E., Clark, W., Cyrus, C., Milofsky, E. S., Kopp, J., Wulsin, V. W. and Mogielnicki, N. P., 1983. Prospective study of alcoholism treatment. Eight-year follow-up. Am J Med. 75, 455-463.

Valentine, A. D., Meyers, C. A., Kling, M. A., Richelson, E. and Hauser, P., 1998. Mood and cognitive side effects of interferon-alpha therapy. Semin Oncol. 25, 39-47.

Vallee, M., Mayo, W., Dellu, F., Le Moal, M., Simon, H. and Maccari, S., 1997. Prenatal stress induces high anxiety and postnatal handling induces low anxiety in adult offspring: correlation with stress-induced corticosterone secretion. J Neurosci. 17, 2626-2636.

Van de Kar, L. D., Rittenhouse, P. A., Li, Q. and Levy, A. D., 1996. Serotonergic regulation of renin and prolactin secretion. Behav Brain Res. 73, 203-208.

Van den Hove, D. L., Steinbusch, H. W., Scheepens, A., Van de Berg, W. D., Kooiman, L. A., Boosten, B. J., Prickaerts, J. and Blanco, C. E., 2006. Prenatal stress and neonatal rat brain development. Neuroscience. 137, 145-155.

Van der Does, A. J., 2001a. The effects of tryptophan depletion on mood and psychiatric symptoms. J Affect Disord. 64, 107-119.

Van der Does, A. J., 2001b. The mood-lowering effect of tryptophan depletion: possible explanation for discrepant findings. Arch Gen Psychiatry. 58, 200-202.

Van Gestel, S., Forsgren, T., Claes, S., Del-Favero, J., Van Duijn, C. M., Sluijs, S., Nilsson, L. G., Adolfsson, R. and Van Broeckhoven, C., 2002. Epistatic effect of genes from the dopamine and serotonin systems on the temperament traits of novelty seeking and harm avoidance. Mol Psychiatry. 7, 448-450.

van Praag, H. M., 1996. Faulty cortisol/serotonin interplay. Psychopathological and biological characterisation of a new, hypothetical depression subtype (SeCA depression). Psychiatry Res. 65, 143-157.

van Praag, H. M., 2004. Can stress cause depression? Prog Neuropsychopharmacol Biol Psychiatry. 28, 891-907. 
van Praag, H. M., Kahn, R. S., Asnis, G. M., Wetzler, S., Brown, S. L., Bleich, A. and Korn, M. L., 1987. Denosologization of biological psychiatry or the specificity of 5-HT disturbances in psychiatric disorders. J Affect Disord. 13, 1-8.

Vazquez, D. M., Eskandari, R., Zimmer, C. A., Levine, S. and Lopez, J. F., 2002. Brain 5-HT receptor system in the stressed infant rat: implications for vulnerability to substance abuse. Psychoneuroendocrinology. 27, 245-272.

Verheyden, S. L., Hadfield, J., Calin, T. and Curran, H. V., 2002. Sub-acute effects of MDMA (+/-3,4-methylenedioxymethamphetamine, "ecstasy") on mood: evidence of gender differences. Psychopharmacology (Berl). 161, 23-31.

Walther, D. J., Peter, J. U., Bashammakh, S., Hortnagl, H., Voits, M., Fink, H. and Bader, M., 2003. Synthesis of serotonin by a second tryptophan hydroxylase isoform. Science. 299, 76.

Watanabe, Y., Gould, E. and McEwen, B. S., 1992. Stress induces atrophy of apical dendrites of hippocampal CA3 pyramidal neurons. Brain Res. 588, 341-345.

Watkins, L. R., Nguyen, K. T., Lee, J. E. and Maier, S. F., 1999. Dynamic regulation of proinflammatory cytokines. Adv Exp Med Biol. 461, 153-178.

Watson, J. B., Mednick, S. A., Huttunen, M. and Wang, X., 1999. Prenatal teratogens and the development of adult mental illness. Dev Psychopathol. 11, 457-466.

Weigel, N. L., 1996. Steroid hormone receptors and their regulation by phosphorylation. Biochem J. 319 ( Pt 3), 657-667.

Weinstock, M., 1997. Does prenatal stress impair coping and regulation of hypothalamic-pituitary-adrenal axis? Neurosci Biobehav Rev. 21, 1-10.

Weinstock, M., Matlina, E., Maor, G. I., Rosen, H. and McEwen, B. S., 1992. Prenatal stress selectively alters the reactivity of the hypothalamic-pituitary adrenal system in the female rat. Brain Res. 595, 195-200.

Weiss, E. L., Longhurst, J. G. and Mazure, C. M., 1999. Childhood sexual abuse as a risk factor for depression in women: psychosocial and neurobiological correlates. Am J Psychiatry. 156, 816-828.

Weissman, M. M., Bland, R. C., Canino, G. J., Faravelli, C., Greenwald, S., Hwu, H. G., Joyce, P. R., Karam, E. G., Lee, C. K., Lellouch, J., Lepine, J. P., Newman, S. C., Rubio-Stipec, M., Wells, J. E., Wickramaratne, P. J., Wittchen, H. and Yeh, E. K., 1996. Cross-national epidemiology of major depression and bipolar disorder. Jama. 276, 293-299.

Whale, R., Quested, D. J., Laver, D., Harrison, P. J. and Cowen, P. J., 2000. Serotonin transporter (5-HTT) promoter genotype may influence the prolactin response to clomipramine. Psychopharmacology (Berl). 150, 120-122.

Whitaker-Azmitia, P. M., 2005. Behavioral and cellular consequences of increasing serotonergic activity during brain development: a role in autism? Int J Dev Neurosci. 23, 75-83.

Whitaker-Azmitia, P. M., Zhang, X. and Clarke, C., 1994. Effects of gestational exposure to monoamine oxidase inhibitors in rats: preliminary behavioral and neurochemical studies. Neuropsychopharmacology. 11, 125-132.

Wichers, M. C. and Maes, M., 2004. The role of indoleamine 2,3-dioxygenase (IDO) in the pathophysiology of interferon-alpha-induced depression. J Psychiatry Neurosci. 29, 11-17.

Williams, W. A., Shoaf, S. E., Hommer, D., Rawlings, R. and Linnoila, M., 1999. Effects of acute tryptophan depletion on plasma and cerebrospinal fluid tryptophan and 5-hydroxyindoleacetic acid in normal volunteers. J Neurochem. 72, 1641-1647.

Wood, G. E., Beylin, A. V. and Shors, T. J., 2001. The contribution of adrenal and reproductive hormones to the opposing effects of stress on trace conditioning in males versus females. Behav Neurosci. 115, 175-187.

Wright, C. E., Strike, P. C., Brydon, L. and Steptoe, A., 2005. Acute inflammation and negative mood: mediation by cytokine activation. Brain Behav Immun. 19, 345-350.

Wu, S. and Comings, D. E., 1999. A common C-1018G polymorphism in the human 5-HT1A receptor gene. Psychiatr Genet. 9, 105-106.

Yan, Q. S., 2002. Reduced serotonin release and serotonin uptake sites in the rat nucleus accumbens and striatum after prenatal cocaine exposure. Brain Res. 929, 59-69.

Yirmiya, R., 2000. Depression in medical illness: the role of the immune system. West J Med. 173, 333-336. 
Yirmiya, R., Weidenfeld, J., Pollak, Y., Morag, M., Morag, A., Avitsur, R., Barak, O., Reichenberg, A., Cohen, E., Shavit, Y. and Ovadia, H., 1999. Cytokines, "depression due to a general medical condition," and antidepressant drugs. Adv Exp Med Biol. 461, 283-316.

Young, A. H., Goodwin, G. M., Dick, H. and Fink, G., 1994. Effects of glucocorticoids on 5-HT1A presynaptic function in the mouse. Psychopharmacology (Berl). 114, 360-364.

Young, S. N., Gauthier, S., Anderson, G. M. and Purdy, W. C., 1980. Tryptophan, 5-hydroxyindolacetic acid and indoleacetic acid in human cerebrospinal fluid: interrelationship and the influence of age, sex, epilepsy and anticonvulsant drugs. J Neurol Neurosurg Psychiatry. 43, 438-445.

Young, S. N. and Leyton, M., 2002. The role of serotonin in human mood and social interaction. Insight from altered tryptophan levels. Pharmacol Biochem Behav. 71, 857-865.

Young, S. N., Smith, S. E., Pihl, R. O. and Ervin, F. R., 1985. Tryptophan depletion causes a rapid lowering of mood in normal males. Psychopharmacology (Berl). 87, 173-177.

Yu, Y. W., Tsai, S. J., Chen, T. J., Lin, C. H. and Hong, C. J., 2002. Association study of the serotonin transporter promoter polymorphism and symptomatology and antidepressant response in major depressive disorders. Mol Psychiatry. 7, 1115-1119.

Zhang, X., Beaulieu, J. M., Sotnikova, T. D., Gainetdinov, R. R. and Caron, M. G., 2004. Tryptophan hydroxylase-2 controls brain serotonin synthesis. Science. 305, 217.

Zhang, X., Gainetdinov, R. R., Beaulieu, J. M., Sotnikova, T. D., Burch, L. H., Williams, R. B., Schwartz, D. A., Krishnan, K. R. and Caron, M. G., 2005. Loss-of-function mutation in tryptophan hydroxylase-2 identified in unipolar major depression. Neuron. 45, 11-16.

Zhuang, X., Gross, C., Santarelli, L., Compan, V., Trillat, A. C. and Hen, R., 1999. Altered emotional states in knockout mice lacking 5-HT1A or 5-HT1B receptors. Neuropsychopharmacology. 21, 52S-60S.

Zill, P., Baghai, T. C., Zwanzger, P., Schule, C., Eser, D., Rupprecht, R., Moller, H. J., Bondy, B. and Ackenheil, M., 2004. SNP and haplotype analysis of a novel tryptophan hydroxylase isoform (TPH2) gene provide evidence for association with major depression. Mol Psychiatry. 9, 1030-1036. 



\section{Pharmacokinetics of acute tryptophan depletion using a gelatin based protein in male and female Wistar rats}

L. A. W. Jans, C. K. J. Lieben, L. T. Smits, A. Blokland Submitted for publication 


\begin{abstract}
The essential amino acid tryptophan is the precursor of the neurotransmitter serotonin. By depleting the body of tryptophan, brain tryptophan and serotonin levels are temporarily reduced, making tryptophan depletion a useful tool to study the relationship between serotonin and behaviour. In this paper, several experiments are described in which dose and treatment effects of acute tryptophan depletion using a gelatin-based protein-carbohydrate mixture are studied in male and female Wistar rats. It is concluded that two or three doses of tryptophan depleting mixture resulted in $65-70 \%$ depletion after two to four hours in males. Object recognition was impaired two, four, and six hours after the first of two doses acute tryptophan depletion, suggesting that the central effects occurred rapidly and continued until at least six hours after the first of two doses, in spite of decreasing treatment effects on plasma TRP levels at that time point. The number of doses a rat received appeared to affect the duration of the depletion more than the level of depletion, as the doses are staggered over a longer period of time. Effects of acute tryptophan depletion were similar in males and females. In females, treatment effects after four consecutive days of treatment were similar to treatment effects after one day of treatment. The method of acute tryptophan depletion described here can be used to study the relationship between serotonin and behaviour by temporarily lowering brain tryptophan in male and female rats.
\end{abstract}




\section{Introduction}

The neurotransmitter serotonin (5-hydroxytryptamine, 5-HT) plays a prominent role in various aspects of behaviour and is known to be involved in numerous psychiatric diseases (Maes and Meltzer, 1995). Serotonin is synthesized from its amino acid precursor tryptophan (TRP), which is taken up from the blood. The level of TRP in plasma depends on the balance between the dietary intake of TRP and its removal from the plasma by protein synthesis and enzymatic degradation. Most of the TRP in plasma is proteinbound, with only 5\% available for transport into the CNS. Free TRP is transported into the brain across the blood-brain barrier by an active protein shuttle for which five other large neutral amino acids (LNAAs: valine, leucine, isoleucine, phenylalanine, tyrosine) also compete. The ratio of TRP and these other LNAAs (TRP/ $\Sigma$ LNAA ratio) is thought to be a more sensitive index of brain tryptophan availability (Wurtman et al., 1980, Fernstrom, 1981), because it is this ratio that determines how much tryptophan can enter the brain. Once in the brain, TRP is converted into 5-HT by a two-step process catalysed by the enzymes tryptophan hydroxylase and aromatic amino acid decarboxylase.

Tryptophan hydroxylase is not fully saturated at normal brain TRP levels, hence the availability of TRP is the limiting factor in the synthesis of 5-HT. Because of this, factors that influence brain TRP levels can influence the rate of 5-HT synthesis. In the method of acute tryptophan depletion (ATD) brain 5-HT is lowered by depleting the body of TRP. Subjects ingest an amino acid load in the form of a drink. The mixture does not contain TRP, but does contain high levels of the other amino acids, resulting in a lowering of plasma TRP and the TRP/ $\Sigma$ LNAA ratio, thus restricting the entry of TRP into the brain. Due to its reversible and non-intrusive effects, the method of ATD can be used in animals and humans.

ATD lowers plasma TRP (Young et al., 1985) for several hours via increased competition for transport across the blood-brain barrier (Fernstrom, 1981) and increased protein synthesis in the liver (Moja et al., 1991). Brain 5-HT levels are temporarily lowered (Biggio et al., 1974, Moja et al., 1989) and there is a decrease in brain 5-HT synthesis (Nishizawa et al., 1997) and concentrations of 5-HT (Bel and Artigas, 1996) and its metabolite 5-HIAA (Stancampiano et al., 1997, Carpenter et al., 1998, Williams et al., 1999). The ATD method has been shown to affect various aspects of behaviour (Reilly et al., 1997, Moore et al., 2000, Booij et al., 2003). Impaired memory performance after ATD has been shown consistently in human (Park et al., 1994, Riedel et al., 1999) and animal studies (Lieben et al., 2004b).

Sex may affect several outcome measures of ATD. (Nishizawa et al., 1997) studied the effects of ATD on 5-HT synthesis and found that the rates of 5-HT synthesis were reduced by ATD by a factor of about 9.5 in men and a factor of about 40 in women. Apparently, the effect of ATD on 5-HT synthesis is larger in women than in men. Several previous ATD studies in which gender effects were considered showed that mood effects 
are larger in females than in males (Ellenbogen et al., 1996, Smith et al., 1997, Booij et al., 2002). In a mega-analysis, Sambeth et al. (2007) found that the effects of ATD on verbal memory were larger in females than in males on both the immediate and delayed recall scores, despite similar levels of depletion in males and females.

Previous studies in our lab have shown that ATD in male rats results in a temporary lowering of plasma TRP levels and TRP, 5-HT and 5-HIAA levels in several brain regions (Lieben et al., 2004a). In females, a temporary lowering of plasma and brain TRP has been reported that was independent of the female oestrous cycle phase (Jans et al., 2007). Furthermore, reliable effects of ATD on memory four hours after treatment have been found in male (Lieben et al., 2004b, Jans et al., 2007) and female rats (Jans et al., 2007). In this paper, we describe several experiments that were done to further characterize the pharmacokinetic effects of ATD, using a gelatin based mixture, in male and female rats. In separate experiments we investigated time and dose effects of ATD in males; time effects of acute TRP depletion and suppletion in females; the effects of repeated ATD in females; the influence of female oestrous cycle phase on the effects of ATD on plasma amino acid (AA) levels; and the effect of ATD on object recognition memory in males.

\section{Materials and methods}

\section{Experiments}

A total of 5 experiments are described in this paper. In experiment 1 time and TRP- time and dose effects were studied in male rats. In experiment 2 time and TRP+ dose effects were studied in female rats. In experiment 3 the effects of repeated ATD were studied in female rats. In experiment 4 the influence of oestrous cycle phase on the effects of ATD were investigated. In experiment 5 the effects of ATD on object recognition in males are measured 6 hours after treatment.

\section{Animals}

In all experiments, subjects were 4-month-old Wistar rats, male or female (Charles River, the Netherlands). In experiment 2 and 3 the rats were housed individually, while in experiments 1 and 4 they were housed per two. In all experiments, the rats were housed in standard Macrolon cages on sawdust bedding in an air-conditioned room $\left( \pm 21^{\circ} \mathrm{C}\right)$. The animals had free access to food and water. They were kept under a reversed 12/12$\mathrm{h}$ light/dark cycle. The lights were on from $06.00-18.00 \mathrm{~h}$. A radio, which was playing softly, provided background noise. All experimental procedures were approved by the local ethical committee of the Maastricht University for animal experiments and met governmental guidelines. 


\section{Drugs and chemicals}

The Gelatin hydrolysate (Solugel) was obtained from PB Gelatins (Tessenderlo, Belgium). Glucodry 210 was obtained from the Amylumgroup (Koog aan de Zaan, The Netherlands). L-tryptophan was obtained from Sigma (Zwijndrecht, The Netherlands). Kaliumchloride $(\mathrm{KCl})$, calciumchloride-dihydrate $\left(\mathrm{CaCl}_{2} \cdot 2 \mathrm{H}_{2} \mathrm{O}\right)$ and 5-sulfosalicylic acid dihydrate were purchased from Merck (Darmstadt, Germany).

\section{Treatment}

During a period of two weeks preceding the experiment, the rats were handled and habituated to oral injections with normal tap water $(10 \mathrm{ml} / \mathrm{kg})$. On experimental days, the rats were fasted $14 \mathrm{~h}$ prior treatment until the testing period was completed. This was done to minimize the availability of TRP from food which would counteract the effects of the acute treatment. The rats were orally treated with a protein-carbohydrate mixture containing TRP (TRP+ group, $0.28 \%$ TRP of the total protein) or one lacking TRP (TRP-group), or with saline (experiment 1 ). The composition of the nutritional mixture is shown in Table 1.

Table 1. Composition of the protein-carbohydrate mixture.

\begin{tabular}{|c|c|c|}
\hline Protein $\left(\right.$ Solugel ${ }^{\circledR}$ ) in $100 \mathrm{ml}$ water & & $100 \mathrm{~g}$ \\
\hline Alanine & 8.4 & \\
\hline Arginine & 7.7 & \\
\hline Aspartic Acid/Asparagine & 4.5 & \\
\hline Glutamic Acid/Glutamine & 10.0 & \\
\hline Glycine & 23.3 & \\
\hline Histidine & 0.9 & \\
\hline Hydroxylysine & 1.5 & \\
\hline Hydroxyproline & 12.3 & \\
\hline Isoleucine & 1.2 & \\
\hline Leucine & 2.6 & \\
\hline Lysine & 3.3 & \\
\hline Methionine & 0.9 & \\
\hline Phenylalanine & 1.6 & \\
\hline Proline & 13.7 & \\
\hline Serine & 3.4 & \\
\hline Threonine & 1.9 & \\
\hline Tryptophan & 0.0 & \\
\hline Tyrosine & 0.6 & \\
\hline Valine & 2.2 & \\
\hline Carbohydrate (Glucodry 210) in $80 \mathrm{ml}$ water & & 50 \\
\hline $\mathrm{KCL}$ & & 0.094 \\
\hline $\mathrm{CaCl}_{2} \cdot 2 \mathrm{H}_{2} \mathrm{O}$ & & 2.32 \\
\hline L-tryptophan (TRP- group) & & 0 \\
\hline L-tryptophan (TRP+ group) & & 0.28 \\
\hline
\end{tabular}


In each experiment, one dose contained $4.0 \mathrm{~g}$ Solugel $\mathrm{C} / \mathrm{kg}$ and $2.0 \mathrm{~g}$ Glucodry $/ \mathrm{kg}$ of the body weight and was given in a volume of $10 \mathrm{ml} / \mathrm{kg}$ between 8.30 and $12.30 \mathrm{~h}$. Blood samples were taken at baseline (10 or 20 minutes before treatment) and at several time points after treatment. Specific treatment conditions and mean TRP values of each experiment are shown in table 2.

\section{Biochemistry}

For the determination of plasma amino acid levels blood samples were taken at resting values and repeated at several points in time. Blood sampling was done via a tailincision method (Fluttert et al., 2000). Promptly after collection of blood in a sodium heparin tubes (Microvette ${ }^{\varpi}$ CB 300, Sarstedt, Germany), the samples were kept on ice. After centrifugation of the blood samples (at $4^{\circ} \mathrm{C}$ for $15 \mathrm{~min}$ at $3000 \mathrm{~g}$ in a Hettich EBA 12 centrifuge), plasma was deproteinised with cups containing dry 5-sulfosalicylic acid (6 $\mathrm{mg} / 100 \mu \mathrm{l}$ plasma) and the protein was spun down. Samples were frozen in liquid nitrogen and stored at $-80^{\circ} \mathrm{C}$. Before analysis, samples were thawed at $4^{\circ} \mathrm{C}$, vortex-mixed vigorously and centrifuged at 50,000 $\mathrm{g}$ in a Hereaus Model Biofuge Stratos for $10 \mathrm{~min}$ at $4^{\circ} \mathrm{C}$. From the clear supernatant $20 \mu \mathrm{l}$ was mixed with $1960 \mu \mathrm{l}$ water and $20 \mu \mathrm{l}$ norvaline and stored in the cooled $\left(7^{\circ} \mathrm{C}\right)$ sample compartment until analysis. In addition to total plasma TRP, the concentrations of several other amino acids were determined with a fully automated high-performance liquid chromatography (HPLC) system after precolumn derivatization with ophthaldialdehyde (OPA) (van Eijk et al., 1993). OPA-AA derivates were quantified with fluorescence detection. The concentrations of the total plasma amino acids were expressed as $\mu \mathrm{mol} / \mathrm{l}$.

\section{Behaviour}

The object recognition test was performed to measure the effects of acute tryptophan depletion on cognition and was performed as described in detail elsewhere (Ennaceur and Delacour, 1988, Prickaerts et al., 2002). The apparatus consisted of a circular arena, $83 \mathrm{~cm}$ in diameter. Half of the $40-\mathrm{cm}$-high wall was made of grey polyvinyl chloride, the other half of transparent polyvinyl chloride. The light intensity (20 Lux) was equal in the different parts of the apparatus. We used four different sets of objects that could not be displaced by a rat. Each object was available in triplicate. The different objects were: 1) a cone consisted of a grey polyvinyl chloride base (maximal diameter $18 \mathrm{~cm}$ ) with collar on top made of brass (total height $16 \mathrm{~cm}$ ), 2) a standard 11 transparent glass bottle (diameter $10 \mathrm{~cm}$, height $22 \mathrm{~cm})$ filled with water, 3$)$ a massive metal cube $(10 \times 5 \times 7.5 \mathrm{~cm})$ with two holes (diameter $1.9 \mathrm{~cm}$ ), and 4) a massive aluminium cube with a tapering top $(13 \times 8 \times 8 \mathrm{~cm})$.

In the week preceding testing, the animals were adapted to the procedure, i.e., they were allowed to explore the apparatus (without any objects) twice for $3 \mathrm{~min}$. In the fol- 
lowing days, the rats were trained until a stable discrimination performance was shown. A testing session comprised two trials. The duration of each trial was $3 \mathrm{~min}$. Two objects were placed in a symmetrical position about $10 \mathrm{~cm}$ away from the grey wall. A rat was always placed in the apparatus facing the wall at the middle of the front (transparent) segment. During the first trial the apparatus contained two identical objects. After the first exploration period the rat was put back in its home cage. One hour later the rat was put back in the apparatus for the second trial, but now with dissimilar objects, a familiar one and a new one. The duration of exploring each object in trial 1 and trial 2 was recorded manually with a personal computer. Exploration was defined as directing the nose to the object at a distance of no more than $2 \mathrm{~cm}$ and/or touching the object with the nose. Sitting on the object was not considered as exploratory behaviour. In order to avoid the presence of olfactory trails, the objects were always thoroughly cleaned. Moreover, each object was available in triplicate so that none of the two objects from the first trial had to be used as the familiar object in the second trial. In addition, all combinations and locations of objects were used in a balanced manner to reduce potential biases due to preferences for particular locations or objects. After the rats were familiarized to the procedures of the task and had stable baseline $d 2$ values, testing with treatment began.

\section{Results}

\section{Biochemistry}

The mean concentrations of plasma amino acids were determined for each treatment and time condition separately. The extent of reduction (expressed in absolute values and in percentage decline from resting values) was calculated for total plasma TRP concentrations and for the TRP/ $\Sigma$ LNAA ratio in experiments 1,2 , and 3 . In experiment 4 , values of all plasma AAs were calculated. Extreme values were excluded from statistical analysis. Differences in plasma amino acid concentrations were analysed with Generalized Linear Models (GLM), with main factor 'treatment' and repeated measure factor 'time'. When appropriate, post-hoc Bonferroni analyses were performed to further characterize the effects of treatment. In experiment 4, AA levels at T4 were compared using T-tests. Differences were regarded as statistically significant if $\mathrm{p}<0.05$. An overview of the treatment effects on plasma TRP values of all experiments is shown in Table 2.

\section{Behaviour}

The basic measures in the object recognition test were the times spent by rats exploring an object during trial 1 and trial 2. The discrimination index $d 2$ ((exploration new object trial 2 - exploration familiar object trial 2)/total exploration time during trial 2) was calculated for each treatment condition (see Rutten et al., 2007). $d 2$ is a relative index 
of discrimination between new and familiar object, because it corrects for total exploration time in trial 2 (see Şık et al., 2003). Effects of treatment, time, and interactions were analysed with univariate ANOVA.

\section{Experiment 1: time and TRP- dose effects in males}

This experiment consisted of four treatment conditions, with 6 male rats per group. The rats were treated either with 1 dose of TRP- (1TRP-), 3 doses of TRP- with 60 minute intervals (3TRP-), one dose of TRP+ or one dose of saline. Blood samples were taken at baseline (T0) and again 2 (T2), 4 (T4), and 6 (T6) hours after baseline blood samples.

Table 2. Overview of the effects of different treatment- and test conditions on the absolute TRP values in the different experiments

\begin{tabular}{|c|c|c|c|c|c|c|c|}
\hline \multirow{2}{*}{$\operatorname{Exp}$} & \multicolumn{3}{|c|}{ Treatment groups } & \multicolumn{4}{|c|}{ Time (h): plasma tryptophan levels } \\
\hline & Treat & Sex & $\mathbf{n}$ & T0 & $\mathrm{T} 2$ & T4 & T6 \\
\hline \multirow{8}{*}{1} & & & & 112.69 & 118.75 & 120.97 & 113.28 \\
\hline & TRP+ & M & 6 & $(3.87)$ & $(4.43)$ & $(2.74)$ & $(3.46)$ \\
\hline & & & & 118.03 & $67.88^{+++,}, \mathrm{xxx}$ & $88.30^{+++,} \mathrm{xxx}$ & 111.08 \\
\hline & TTRP- & M & 6 & $(5.24)$ & $(6.75)$ & $(7.60)$ & $(6.44)$ \\
\hline & & & & 125.91 & $52.75^{+++, x x x}$ & $49.03^{+++,} \mathrm{xxx}$ & $69.51^{+++,} \mathrm{xxx}$ \\
\hline & 3TRP- & M & 6 & $(3.17)$ & $(7.85)$ & $(15.39)$ & $(11.95)$ \\
\hline & & & & 133.50 & 127.35 & 135.39 & 118.41 \\
\hline & Saline & M & 6 & $(4.77)$ & $(6.28)$ & $(6.34)$ & $(4.43)$ \\
\hline \multirow{6}{*}{2} & TRP+ & F & 4 & 110.04 & 113.44 & 88.43 & 128.58 \\
\hline & $1 \mathrm{RP}+$ & $\mathrm{F}$ & 4 & $(4.78)$ & $(5.83)$ & $(3.51)$ & $(9.61)$ \\
\hline & TRP & $\mathrm{F}$ & 8 & 112.38 & $32.90^{+++}$ & $54.59^{+++}$ & $100.05+$ \\
\hline & $1 \mathrm{KP}-$ & $\mathrm{F}$ & 8 & $(6.59)$ & $(1.94)$ & $(4.14)$ & $(2.49)$ \\
\hline & $\mathrm{TRP}_{++}$ & F & 4 & 105.16 & $217.28^{+++}$ & $135.34^{+++}$ & 104.91 \\
\hline & IRP++ & $\mathrm{F}$ & 4 & $(7.18)$ & $(12.10)$ & $(6.28)$ & $(8.33)$ \\
\hline \multirow{4}{*}{3} & & & & 117.35 & 106.21 & 100.11 & \\
\hline & $\mathrm{TRP}+$ & $\mathrm{F}$ & 3 & (12.31) & $(4.40)$ & $(8.74)$ & \\
\hline & & & & 107.54 & $34.40^{+++}$ & $38.54^{+++}$ & \\
\hline & TRP- & $\mathrm{F}$ & 7 & $(3.95)$ & $(2.55)$ & $(2.90)$ & \\
\hline
\end{tabular}

Mean (SEM). Abbreviations: Exp = experiment; $M=$ male; $F=$ female; $n=$ number of animals per treatment group. Time effect ${ }^{*} p<0.05 ;{ }^{* *} p<0.001$; difference from TRP+ $+p<0.05 ;+++p<0.001$; difference from saline $x x x p<0.001$.

The Time $\times$ Treatment interaction was significant for both TRP levels $[\mathrm{F}(9,54)=14.31$, $\mathrm{p}<0.001]$ and for the TRP $/ \Sigma$ LNAA ratio $[\mathrm{F}(9,45)=21.51, \mathrm{p}<0.001]$. Both TRPlevels [Time: $\mathrm{F}(3,54)=27.07, \mathrm{p}<0.001]$ and the TRP $/ \Sigma$ LNAA ratio [Time: $\mathrm{F}(3,45)=37.31, \mathrm{p}<0.001]$ changed over the 6 hours. There was a treatment effect for TRP levels $[\mathrm{F}(3,18)=17.27$, $\mathrm{p}<0.001]$ and the TRP $/ \Sigma$ LNAA ratio $[\mathrm{F}(3,15)=22.24, \mathrm{p}<0.001]$. In terms of TRP levels, post-hoc analysis showed that saline was different from both TRP- conditions. TRP+ differed from only 3TRP-. There was no significant difference between the two TRP- conditions. Separate analyses for each treatment condition indicated that there was a significant time effect on TRP levels in both TRP- conditions [1TRP-: $F(3,15)=21.65, \mathrm{p}<0.001$; 
3TRP-: $\mathrm{F}(3,9)=22.11, \mathrm{p}<0.001]$, but not in the TRP+ and the saline condition. In terms of the TRP/ $\Sigma$ LNAA ratio, post-hoc analysis showed that the 3TRP- condition was different from all other treatment conditions. There were no significant differences between other treatment conditions. Separate analyses for each treatment condition showed that there was a significant time effect on the TRP/ $\Sigma$ LNAA ratio in both TRP-conditions and in the saline condition [1TRP-: $\mathrm{F}(3,12)=20.01$, $\mathrm{p}<0.001 ; 3 \mathrm{TRP}-\mathrm{F}(3,9)=54.74, \mathrm{p}<0.001$; Saline: $\mathrm{F}(3,12)=6.12, \mathrm{p}<0.01$ ], but not in the TRP+ condition. Treatment effects on the TRP/ $\Sigma$ LNAA ratio are shown in Figure 1.

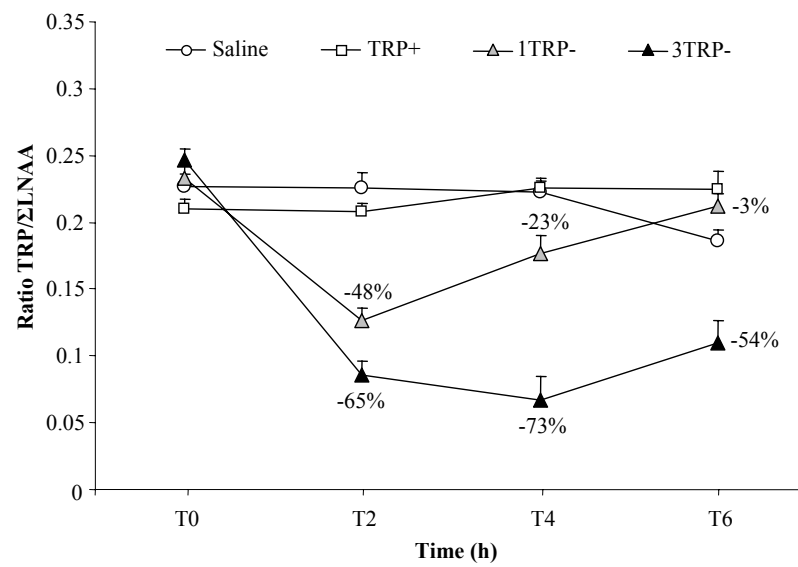

Figure 1. Experiment 1: time and TRP- dose effects in males. The effects of treatment on the ratio plasma TRP/ ILNAA (mean values and SEM). Percentages indicate the difference from baseline levels in the TRP-conditions.

\section{Experiment 2: time and TRP+ dose effects in females}

In this experiment, 8 female rats were treated with TRP- on one day and with TRP+ $(\mathrm{n}=4)$ or TRP $++(\mathrm{n}=4)$ on another day. They received 2 doses with 90 minutes interval. The TRP++ mixture contained $2.8 \%$ of TRP, which is ten times the amount of TRP that is used for the normal TRP+ mixture. Blood samples were taken at baseline and 2, 4, and 6 hours after the first injection (T2, T4, and T6 respectively).

There was a Time $\times$ Treatment interaction for both TRP levels $[F(6,27)=37.21$, $\mathrm{p}<0.001]$ and the TRP $/ \Sigma \mathrm{LNAA}$ ratio $[\mathrm{F}(6,24)=30.75, \mathrm{p}<0.001]$. There was a time effect on TRP levels $[\mathrm{F}(3,27)=8.61, \mathrm{p}<0.001]$ and on the TRP $/ \Sigma \mathrm{LNAA}$ ratio $[\mathrm{F}(3,24)=15.37, \mathrm{p}<0.001]$ and a treatment effect on TRP levels $[\mathrm{F}(2,9)=126.02, \mathrm{p}<0.001]$ and on the TRP $/ \Sigma L N A A$ ratio $[\mathrm{F}(2,8)=15,77, \mathrm{p}<0.01]$. In terms of TRP levels, post-hoc analysis revealed that all treatment groups were significantly different, whereas post-hoc analysis of the TRP/ $L$ LNAA ratio showed that TRP++ was significantly different from TRP- and TRP+, while TRP- and $\mathrm{TRP}+$ did not differ significantly. Separate analyses for each treatment condition revealed 
that there was a time effect in all treatment conditions on TRP levels [TRP-: $\mathrm{F}(3,9)=84.80$, $\mathrm{p}<0.001 ; \mathrm{TRP}+\mathrm{F}(3,9)=6.60, \mathrm{p}<0.05 ; \mathrm{TRP}++\mathrm{F}(3,9)=27.94]$ and on the TRP/ $/ L N A A$ ratio[TRP-: $\mathrm{F}(3,6)=52.29, \mathrm{p}<0.001 ; \mathrm{TRP}+\mathrm{F}(3,9)=4.48, \mathrm{p}<0.05 ; \mathrm{TRP}++: \mathrm{F}(3,9)=40.43$, $\mathrm{p}<0.001]$. Treatment effects on the TRP/ $\Sigma$ LNAA ratio are shown in Figure 2.

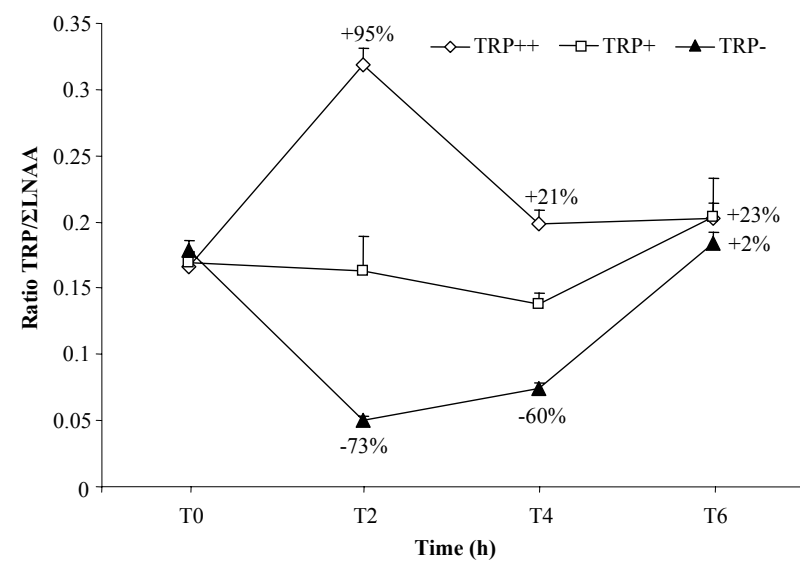

Figure 2. Experiment 2: time and TRP+ dose effects in females. The effects of treatment on the ratio plasma TRP/ ¿LNAA (mean values and SEM). Percentages indicate the difference from baseline levels in the TRP depletion and TRP suppletion condition.

\section{Experiment 3: effects of repeated treatment}

Female rats were treated on four consecutive days with TRP- $(n=7)$ first and one week later with TRP+ $(\mathrm{n}=3)$. The rats were injected with two doses on each day, with 90 minutes interval. They had access to normal food in the afternoon of each day. In the evening, food was taken away again (14 hours before treatment the next day). On the fourth day, blood samples were taken at baseline, and 2 (T2) and 4 (T4) hours after the first injection.

After four consecutive days of administration of TRP- or TRP+, with blood samples being taken on the fourth day, Time $\times$ Treatment interaction effects were found on TRP $[\mathrm{F}(2,14)=35.54, \mathrm{p}<0.001]$ and the $\mathrm{TRP} / \Sigma \mathrm{LNAA}$ ratio $[\mathrm{F}(2,12)=23.78, \mathrm{p}<0.001]$. There was a timeeffecton $\operatorname{TRP}[\mathrm{F}(2,14)=77.39, \mathrm{p}<0.001]$ and on the TRP $/ \Sigma \operatorname{LNAA}$ ratio $[\mathrm{F}(2,12)=189.34$, $\mathrm{p}<0.001]$. The time effect on the TRP/ $\Sigma$ LNAA was significant for both treatment condition $[\mathrm{TRP}+\mathrm{F}(2,4)=14.68$, $\mathrm{p}<0.05$; TRP-: $\mathrm{F}(2,8)=565.03$, $\mathrm{p}<0.001]$, but there was a time effect on TRP only in the TRP- condition $[\mathrm{F}(2,10)=222.55, \mathrm{p}<0.001]$. There were treatment effects on TRP $[\mathrm{F}(1,7)=61.49, \mathrm{p}<0.001]$ and the TRP $/ \Sigma$ LNAA ratio $[\mathrm{F}(1,6)=99.13, \mathrm{p}<0.001]$. Treatment effects on the TRP/ $\Sigma$ LNAA ratio are shown in Figure 3.

When comparing the TRP- after four consecutive treatment days with the TRPcondition of one day administration that was taken earlier in the same animals (experi- 


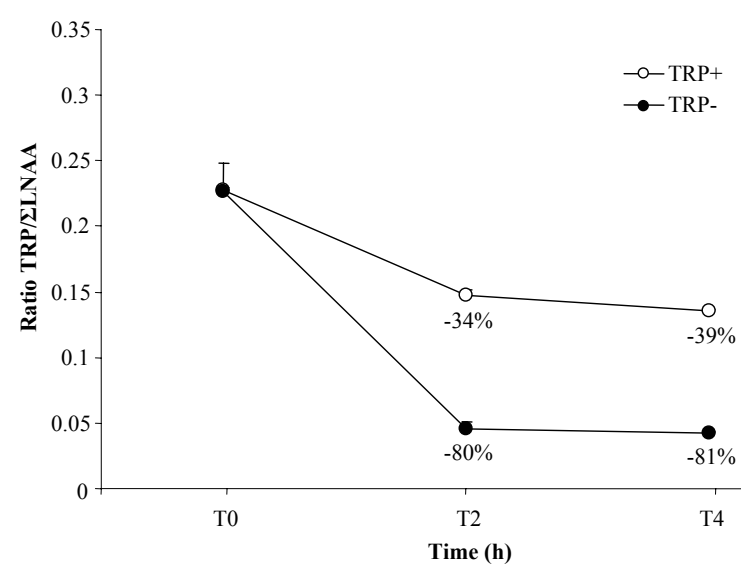

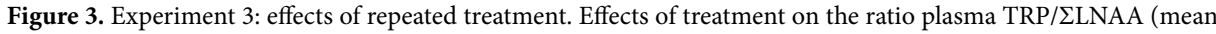
values and SEM). Percentages indicate difference from baseline levels.

ment 2), an interaction effect was not found for TRP [Time $\times$ Treatment: $F(2,16)=2.66$, $n s]$, but this interaction was significant for the TRP/ $L$ LNAA ratio $[\mathrm{F}(2,12)=14.80$, $\mathrm{p}<0.001]$. There was a time effect for $\operatorname{TRP}[\mathrm{F}(2,16)=279.22, \mathrm{p}<0.001]$ and the TRP/ $\Sigma$ LNAA ratio $[\mathrm{F}(2,12)=304.23, \mathrm{p}<0.001]$. Treatment effects were not found, neither for $\operatorname{TRP}[\mathrm{F}(1,8)=0.29, \mathrm{~ns}]$ nor for the TRP/ $/ \mathrm{LNAA}$ ratio $[\mathrm{F}(1,6)=0.78, \mathrm{~ns}]$.

When comparing the TRP+ after four consecutive treatment days with the $\mathrm{TRP}+$ condition of one day administration that was taken earlier in the same animals (experiment 2), an interaction effect was not found for TRP [Time $\times$ Treatment: $\mathrm{F}(2,8)=3.52$, ns] , but this interaction was marginally significant for the TRP/ $\Sigma$ LNAA ratio $[\mathrm{F}(2,8)=4.23, \mathrm{p}=0.056]$. There was a time effect for $\operatorname{TRP}[\mathrm{F}(2,8)=10.18, \mathrm{p}<0.05]$ and the $\mathrm{TRP} / \Sigma \mathrm{LNAA}$ ratio $[\mathrm{F}(2,8)=10.78, \mathrm{p}<0.05]$. Treatment effects were not found, neither for TRP $[\mathrm{F}(1,4)=0.1, \mathrm{~ns}]$ nor for the TRP $/ \Sigma \mathrm{LNAA}$ ratio $[\mathrm{F}(1,4)=0.23$, ns $]$.

\section{Experiment 4: time effects in females, taking in account oestrous cycle phase}

Male $(\mathrm{n}=24)$ and Female rats $(\mathrm{n}=48)$ were treated with TRP- on one day and with $\mathrm{TRP}+$ on another day. They received two doses with 90 minutes interval. Blood samples were taken at baseline (T0) and 4 hours after the first injection (T4). Female oestrous cycle was determined by means of vaginal smears (see (Jans et al., 2007). Females were characterized as either pro-oestrus/oestrus (pro/oes) or as met-oestrus/di-oestrus (met/ di). There were six groups in this experiment: TRP- male; TRP- pro/oes; TRP- met/di; $\mathrm{TRP}+$ male; TRP+ pro/oes; TRP+ met/di. Treatment effects on plasma and brain TRP and the plasma TRP/ $\Sigma$ LNAA ratio have been reported previously (Jans et al., 2007). Treatment effects on all plasma AA values are shown in Table 3. 
Table 3. Time, Treatment and group effect on plasma AA levels.

\begin{tabular}{|c|c|c|c|c|c|}
\hline $\mathbf{A A}$ & Group & TRP+ & TRP- & TRP+ & TRP- \\
\hline GLU & $1^{+++2,3}$ & $89.54(4.78)$ & $84.14(3.35)$ & $101.69(4.55)$ & $103.41(8.38)$ \\
\hline \multirow[t]{2}{*}{ ddd, eee } & 2 & $70.02(3.35)$ & $62.23(2.16)$ & $75.22(1.31)$ & 75.35 (2.69) \\
\hline & 3 & $65.00(4.71)$ & $66.77(3.40)$ & $79.50(6.63)$ & $87.25(7.40)$ \\
\hline ASN & $1^{+++2,3 x}$ & $73.87(1.38)$ & $68.08(1.17)$ & $35.77(0.97)$ & $34.47(1.17)$ \\
\hline bbb, ddd, & $2^{x}$ & $54.63(1.31)$ & $52.37(1.14)$ & $32.75(1.12)$ & $28.41(1.08)^{\star *}$ \\
\hline eee, fff & 3 & $61.38(2.42)$ & $58.14(2.70)$ & $31.98(1.55)$ & $29.41(2.15)$ \\
\hline SER & 1 & $275.74(5.92)$ & $275.26(8.91)$ & $408.37(14.05)$ & $379.55(13.21)$ \\
\hline bbb, ccc, & 2 & $251.60(5.36)$ & $259.24(6.67)$ & 442.95 (11.26) & $398.61(10.37)^{* *}$ \\
\hline ddd & 3 & $254.65(7.95)$ & $263.17(8.37)$ & $424.76(18.47)$ & $408.58(21.70)$ \\
\hline GLN & $1^{+++3}$ & $883.39(20.85)$ & $899.92(16.62)$ & 721.65 (15.17) & $725.45(17.48)$ \\
\hline \multirow[t]{2}{*}{ ddd, eee } & $2^{++3 x x}$ & $876.72(16.26)$ & $819.26(17.76)$ & $724.78(15.16)$ & $658.73(16.42)^{\star *}$ \\
\hline & 3 & $789.88(28.09)$ & $796.89(24.50)$ & $639.78(18.86)$ & $613.10(26.36)$ \\
\hline HIS & 1 & $76.75(1.95)$ & $74.54(2.14)$ & $66.10(2.46)$ & $60.44(1.97)$ \\
\hline \multirow{2}{*}{$\begin{array}{r}\text { b, cc, ddd, } \\
\text { eee, fff }\end{array}$} & $\begin{array}{l}2^{+++} \\
1 \mathrm{xxx}\end{array}$ & $72.16(1.14)$ & $68.63(1.04)$ & $57.61(1.61)$ & $49.51(1.62)^{\star *}$ \\
\hline & $3^{++1}$ & $68.94(2.64)$ & $68.52(2.75)$ & $61.98(3.22)$ & $53.22(2.92)$ \\
\hline \multirow{3}{*}{$\begin{array}{l}\text { GLY } \\
\text { b, ccc } \\
\text { ddd, eee, ff }\end{array}$} & $1^{+++2,3}$ & 411.13 (11.09) & 419.09 (17.68) & $1634.18(56.73)$ & $1464.50(59.58)^{\star}$ \\
\hline & 2 & $273.86(7.73)$ & $282.58(9.57)$ & $1370.91(49.01)$ & $1240.99(34.86)^{*}$ \\
\hline & 3 & $297.54(15.35)$ & $288.43(12.71)$ & $1409.90(76.87)$ & $1246.84(86.32)$ \\
\hline \multirow{3}{*}{$\begin{array}{r}\text { THR } \\
\text { bbb, ddd, } \\
\text { eee, f } \\
\end{array}$} & $1^{+++2,3}$ & $286.86(6.64)$ & $276.14(7.75)$ & $253.78(7.20)$ & $251.53(7.64)$ \\
\hline & $2^{x}$ & $229.17(7.76)$ & $212.54(6.32)$ & $233.36(6.20)$ & $214.54(6.32) *$ \\
\hline & 3 & $236.28(12.87)$ & $219.26(11.19)$ & $231.17(10.41)$ & $214.55(8.93)$ \\
\hline \multirow{3}{*}{$\begin{array}{l}\text { CIT } \\
\text { bb, ddd }\end{array}$} & 1 & $81.30(2.68)$ & $77.77(2.69)$ & $99.75(3.41)$ & $99.98(3.03)$ \\
\hline & 2 & $71.39(1.77)$ & $70.58(1.98)$ & $103.50(3.57)$ & $100.10(3.21)$ \\
\hline & 3 & $71.65(2.70)$ & $72.60(2.73)$ & $94.45(4.60)$ & $95.50(6.07)$ \\
\hline \multirow{3}{*}{$\begin{array}{l}\text { ARG } \\
\text { ddd, eee }\end{array}$} & $1^{+++2}$ & $151.19(4.60)$ & $144.97(4.00)$ & $230.37(8.40)$ & $239.52(6.74)$ \\
\hline & 2 & $129.02(2.95)$ & $129.69(3.96)$ & $214.90(6.12)$ & $209.13(7.60)$ \\
\hline & 3 & $148.78(12.24)$ & $146.06(6.03)$ & $213.70(8.02)$ & $215.99(13.93)$ \\
\hline \multirow{3}{*}{$\begin{array}{l}\text { ALA } \\
\text { bb, cc, ddd } \\
\text { eee, fff }\end{array}$} & $1^{+++2,3}$ & $350.21(9.81)$ & $324.19(6.96)$ & $529.99(18.06)$ & $493.18(22.06)$ \\
\hline & 2 & $298.53(6.44)$ & $293.88(7.18)$ & $465.32(16.24)$ & $394.39(10.63)^{\star *}$ \\
\hline & $3^{x}$ & $322.54(16.64)$ & $290.86(8.02)$ & $461.55(19.60)$ & $385.46(23.99) *$ \\
\hline \multirow{3}{*}{$\begin{array}{l}\text { TAU } \\
\text { ddd, fff }\end{array}$} & $1^{\mathrm{xx}}$ & $269.64(10.75)$ & $227.91(10.24)$ & $213.14(11.63)$ & $175.79(8.75)^{*}$ \\
\hline & $2^{x}$ & $268.75(12.41)$ & $237.85(9.46)$ & $216.46(10.42)$ & $195.71(8.48)$ \\
\hline & 3 & $299.12(38.44)$ & $243.89(16.10)$ & $223.25(21.80)$ & $195.59(23.91)$ \\
\hline \multirow{3}{*}{$\begin{array}{r}\text { TYR } \\
\text { bbb, ddd, } \\
\text { eee }\end{array}$} & $1^{+++2,3}$ & $62.12(1.72)$ & $59.95(1.30)$ & $34.61(1.02)$ & $39.06(1.26)^{\star *}$ \\
\hline & 2 & $49.34(1.47)$ & $46.75(0.88)$ & $35.49(1.85)$ & $32.48(1.33)$ \\
\hline & 3 & $48.67(1.94)$ & $51.48(2.84)$ & $29.93(1.39)$ & $30.76(2.09)$ \\
\hline \multirow{3}{*}{$\begin{array}{l}\text { VAL } \\
\text { bbb, ddd } \\
\text { eee } \\
\end{array}$} & $1^{+++2,3}$ & $200.88(5.56)$ & $196.85(7.25)$ & $274.17(6.40)$ & $277.10(6.51)$ \\
\hline & 2 & $177.00(5.02)$ & $172.32(5.16)$ & $224.84(3.65)$ & $227.61(5.05)$ \\
\hline & 3 & $173.13(9.98)$ & $167.35(7.87)$ & $227.26(3.66)$ & $224.33(10.47)$ \\
\hline \multirow{3}{*}{$\begin{array}{l}\text { MET } \\
\qquad \begin{array}{l}\text { a, bbb, d } \\
\text { ff }\end{array}\end{array}$} & $1^{x}$ & $54.61(1.16)$ & $51.46(1.58)$ & $50.15(1.29)$ & $45.56(1.79) *$ \\
\hline & 2 & $46.52(1.29)$ & $49.64(1.61)$ & $52.59(1.27)$ & $47.61(1.39) *$ \\
\hline & $3^{x}$ & $52.43(3.27)$ & $45.03(1.79)$ & $49.42(1.93)$ & $43.01(2.20)^{*}$ \\
\hline \multirow{3}{*}{$\begin{array}{l}\text { ILE } \\
\text { ddd, eee }\end{array}$} & $1^{+++2,3}$ & $108.65(2.85)$ & $108.87(4.77)$ & $94.59(2.46)$ & $93.71(1.69)$ \\
\hline & 2 & $94.83(2.60)$ & $93.76(2.98)$ & $82.01(1.92)$ & $84.92(1.68)$ \\
\hline & 3 & $91.26(4.79)$ & $94.13(4.01)$ & $78.67(2.52)$ & $81.67(3.92)$ \\
\hline \multirow{3}{*}{$\begin{array}{l}\text { PHE } \\
\text { ddd, eee }\end{array}$} & $1^{+++2,3}$ & $72.23(1.25)$ & $69.12(1.26)$ & $79.70(1.69)$ & $81.32(1.12)$ \\
\hline & 2 & $59.08(0.83)$ & $57.28(0.77)$ & $68.55(1.13)$ & $66.87(1.05)$ \\
\hline & 3 & $56.75(1.94)$ & $57.34(1.59)$ & $65.23(1.74)$ & $67.48(2.76)$ \\
\hline \multirow{3}{*}{$\begin{array}{l}\text { TRP } \\
\text { ccc, ddd, } \\
\text { eee, fff }\end{array}$} & $\begin{array}{l}1^{+++2,3} \\
\operatorname{xxx}\end{array}$ & $99.51(3.29)$ & $90.72(2.11)$ & $93.70(2.26)$ & $35.45(1.21)^{\star * *}$ \\
\hline & $2^{x x x}$ & $121.81(2.51)$ & $122.45(1.95)$ & $121.27(2.22)$ & $61.72(2.95)^{* * *}$ \\
\hline & $3^{\mathrm{xxx}}$ & $122.46(5.09)$ & $117.89(3.98)$ & $116.32(2.93)$ & $56.71(5.52) * * *$ \\
\hline \multirow{3}{*}{$\begin{array}{l}\text { LEU } \\
\text { ddd, eee }\end{array}$} & $1^{+++2,3}$ & $156.97(3.94)$ & $153.61(5.08)$ & $176.04(4.82)$ & $178.48(4.81)$ \\
\hline & 2 & $136.77(3.18)$ & $139.32(3.32)$ & $149.97(3.66)$ & $159.08(3.60)$ \\
\hline & 3 & $140.53(6.09)$ & $140.97(4.80)$ & $159.32(4.90)$ & $158.04(7.02)$ \\
\hline \multirow{3}{*}{$\begin{array}{l}\text { ORN } \\
\text { bbb, ccc } \\
\text { ddd }\end{array}$} & $1^{+++2,3}$ & $59.48(1.69)$ & $56.21(3.40)$ & $150.61(5.63)$ & $143.97(3.50)$ \\
\hline & 2 & $32.37(1.17)$ & $33.00(1.08)$ & $72.87(2.62)$ & $72.74(2.79)$ \\
\hline & 3 & $33.61(2.60)$ & $34.25(2.15)$ & 80.87 (6.99) & $76.63(6.40)$ \\
\hline
\end{tabular}




\begin{tabular}{|c|c|c|c|c|c|c|c|c|c|}
\hline AA & Group & T0 & TRP+ & TO & TRP- & T4 & TRP+ & T4 & TRP- \\
\hline LYS & $1^{+++2,3 x}$ & \multicolumn{2}{|c|}{$446.23(8.82)$} & \multicolumn{2}{|c|}{420.74 (12.87) } & \multicolumn{2}{|c|}{466.07 (8.98) } & \multicolumn{2}{|c|}{$445.17(10.15)$} \\
\hline \multirow[t]{2}{*}{ ddd, eee } & $2^{x}$ & \multicolumn{2}{|c|}{$460.71(15.30)$} & \multicolumn{2}{|c|}{$550.74(20.66)$} & \multicolumn{2}{|c|}{$538.43(15.20)$} & \multicolumn{2}{|c|}{$586.12(24.20)$} \\
\hline & 3 & \multicolumn{2}{|c|}{$574.68(55.21)$} & \multicolumn{2}{|c|}{$543.05(16.13)$} & \multicolumn{2}{|c|}{$634.06(33.88)$} & 560.48 & (22.72) \\
\hline
\end{tabular}

Data shown: mean (SEM). Group 1: male, 2: female pro/oes, 3: female met/di. Abbreviations: treat: treatment, GLU: glutamate, ASN: asparagine, SER: serine, GLN: glutamine, HIS: histidine, GLY: glycine, THR: threonine, CIT: citrulline, ARG: arginine, ALA: alanine, TAU: taurine, TYR: tyrosine, VAL: valine, MET: methionine, ILE: isoleucine, PHE: phenylalanine, LEU: leucine, ORN: ornithine, LYS: lysine. Time $\times$ Group $\times$ Treatment interaction: $a p<0.05$; Time $\times$ Group interaction: $b p<0.05 ; b b p<0.01 ; b b b p<0.001$; Time $\times$ Treatment interaction: $c c$ $p<0.01$; ccc $p<0.001$; Time: $d p<0.05$; ddd $p<0.001$; Group: eee $p<0.001$ with ${ }^{+++}$posthoc Bonferroni $p<0.001$; Treatment: $f p<0.05$; ff $p<0.01$; fff $p<0.001$; Treatment effect on T4: ${ }^{*} p<0.05$; ${ }^{* *} p<0.01 ;{ }^{* * *} p<0.001$; Treatment effect within group: ${ }^{x} p<0.05 ;{ }^{x x} p<0.01 ;{ }^{x x x} p<0.001$.

A Time $\times$ Group $\times$ Treatment interaction was found for methionine $[\mathrm{F}(2,131)=3.59$, $\mathrm{p}<0.05]$. A Time $\times$ Group interaction was found for asparagine $[\mathrm{F}(2,132)=45.07, \mathrm{p}<0.001]$, serine $[\mathrm{F}(2,133)=11.07, \mathrm{p}<0.001]$, histidine $[\mathrm{F}(2,133)=4.76, \mathrm{p}<0.05]$, glycine $[\mathrm{F}(2$, $133)=3.15, \mathrm{p}<0.05]$, threonine $[\mathrm{F}(2,132)=17.07, \mathrm{p}<0.001]$, citrulline $[\mathrm{F}(2,132)=7.62$, $\mathrm{p}<0.01]$, alanine $[\mathrm{F}(2,131)=6.51, \mathrm{p}<0.01]$, tyrosine $[\mathrm{F}(2,132)=14.95, \mathrm{p}<0.001]$, valine $[\mathrm{F}(2,132)=9.48, \mathrm{p}<0.001]$, methionine $[\mathrm{F}(2,131)=10.85, \mathrm{p}<0.001]$, and ornithine $[\mathrm{F}(2,124)=90.62, \mathrm{p}<0.001]$. A Time $\times$ Treatment interaction was found for serine $[\mathrm{F}(1$, $133)=16.52, \mathrm{p}<0.001]$, histidine $[\mathrm{F}(1,133)=8.52, \mathrm{p}<0.01]$, glycine $[\mathrm{F}(1,133)=14.46$, $\mathrm{p}<0.001]$, alanine $[\mathrm{F}(1,131)=7.04, \mathrm{p}<0.01]$, and $\mathrm{TRP}[\mathrm{F}(1,132)=328.85, \mathrm{p}<0.001]$.

All plasma AA levels changed over time. Levels of glutamate, serine, glycine, citrulline, arginine, alanine, valine, phenylalanine, leucine, ornithine and lysine increased over time, whereas levels of asparagine, glutamine, histidine, threonine, taurine, tyrosine, methionine, isoleucine, and TRP decreased over time. A treatment effect was found on asparagine $[\mathrm{F}(1,131)=58.69, \mathrm{p}<0.001]$, histidine $[\mathrm{F}(1,133)=12.11, \mathrm{p}<0.01]$, glycine $[\mathrm{F}(1,133)=7.83, \mathrm{p}<0.01]$, threonine $[\mathrm{F}(1,132)=5.46, \mathrm{p}<0.05]$, alanine $[\mathrm{F}(1,131)=14.45$, $\mathrm{p}<0.001]$, taurine $[\mathrm{F}(1,132)=16.19, \mathrm{p}<0.001]$, methionine $[\mathrm{F}(1,131)=9.85, \mathrm{p}<0.01]$, and on $\operatorname{TRP}[\mathrm{F}(1,132)=337.86, \mathrm{p}<0.001]$. In males there was a treatment effect on asparagine, taurine, methionine, TRP, and lysine. In females pro/oes there was a treatment effect on asparagine, glutamine, histidine, threonine, taurine, TRP, and lysine. In females met/di there was a treatment effect on alanine, methionine, and TRP. At T4 there was a treatment effect in males on levels of glycine, taurine, tyrosine, methionine and TRP; at this time point glycine, taurine, methionine and TRP levels were lower in the TRP-condition compared to the TRP+ condition, whereas tyrosine levels were higher in the TRP- condition. In females pro/oes there was a treatment effect at $\mathrm{T} 4$ on levels of asparagine, serine, glutamine, histidine, glycine, threonine, alanine, methionine, and TRP. All of these AAs were lower after TRP- treatment compared to TRP+ treatment. In females met/di levels of alanine, methionine, and TRP were lower at T4 in the TRP- compared to the TRP+condition. 


\section{Experiment 5: effects of ATD on object recognition memory}

Male rats $(n=24)$ were treated with TRP- and TRP+ on different days. They received two doses with 90 minutes interval and were tested in the object recognition test. There was a one-hour interval between the two trials of the test, trial 1 was 2,4 , or 6 hours after the first treatment on different testing days. There was a treatment effect on $d 2[\mathrm{~F}(1,137)=88.73, \mathrm{p}<0.001]$. There was no effect of Time or a Time $\times$ Treatment interaction effect. TRP- treated rats had a lower discrimination index $d 2$ compared to TRP+ treated rats (Figure 4). The treatment effect was significant at all time points [T2: $\mathrm{F}(1,45)=23.42, \mathrm{p}<0.001 ; \mathrm{T} 4: \mathrm{F}(1,45)=35.14, \mathrm{p}<0.001 ; \mathrm{T} 6: \mathrm{F}(1,45)=30.42, \mathrm{p}<0.001]$.

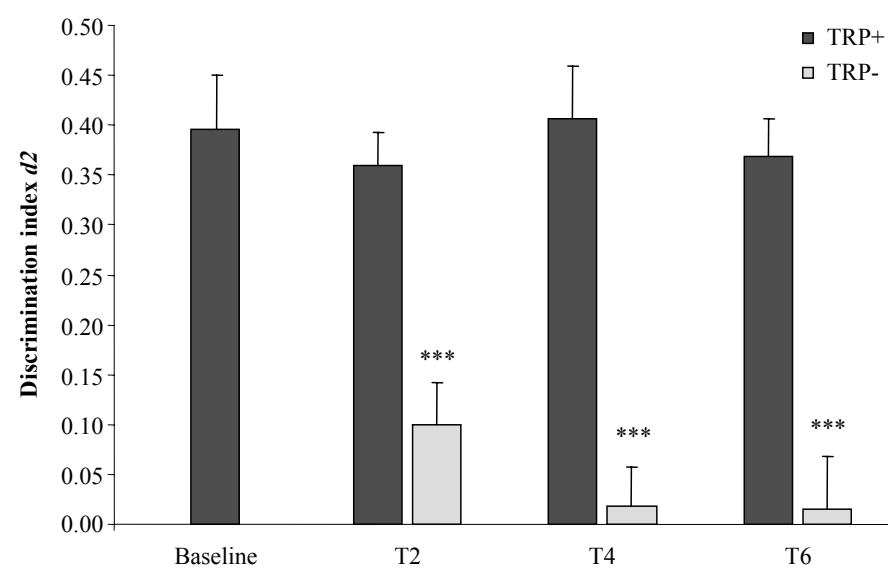

Figure 4. Experiment 5: effects of ATD on object recognition memory. Effects of treatment on discrimination index $d 2$ (mean values and SEM). Treatment effect ${ }^{* * *} \mathrm{p}<0.001$ compared to TRP+.

\section{Discussion}

In adult male and female Wistar rats, acute tryptophan depletion resulted in a transient lowering of plasma TRP and the TRP/ $L$ LNAA ratio. The exact characteristics of the depletion seemed to depend on the number of doses, or the amount of the TRP- mixture, the rat receives. It appeared that the number of dosages the male rats received in experiment 1 influenced both the duration of the depletion and its intensity. After three doses of TRP- the depletion was maximal at T4, four hours after the first treatment. With two doses the depletion was maximal at T2, two hours after the first treatment. After one dose of TRP- depletion was maximal at T2, two hours after the treatment. However, it is possible that maximal depletion had been achieved before the T2 blood sampling and that amino acid levels were already rising to return to baseline levels at T2. Rats in other 
treatment conditions by that time had already received a second dose, causing a further drop in TRP levels. Therefore it may not be valid to compare TRP and TRP/ $L$ LNAA ratio values at T2 between one dose TRP- and conditions in which rats received more than one dose.

As the level of plasma depletion is about $70 \%$ with 2 and 3 doses, this level may represent the highest level of depletion that can be achieved using the method of acute tryptophan depletion. Therefore it may be concluded that the number of doses mainly affected the duration of the depletion. This is of course at least partly explained by the fact that the rats received their TRP- injections staggered over a longer period of time. Nevertheless, the maximal plasma TRP depletion appeared to be about $70 \%$ and in this experiment more doses of TRP- did not result in lower TRP levels, but in longer duration of the TRP depletion.

Treatment effects on TRP and the TRP/ $\Sigma$ LNAA ratio in females appeared to be similar to those in males. Compared to a study in which males were treated with two doses ATD (Lieben et al., 2004b), females showed similar levels of depletion at T2, but less depletion than males at T4 and T6. It is striking that at T6, the female TRP/ 2 LNAA ratio was back at baseline levels, while the male ratio still showed a treatment effect, with $49 \%$ depletion. TRP levels showed the same effect, with $11 \%$ depletion they were almost back to baseline levels in females at T6, but in males they were still 30\% lower than baseline levels (Lieben et al., 2004b). It is also interesting to not that in females the $\mathrm{TRP} / \Sigma$ LNAA ratio returned to baseline levels faster than plasma TRP levels, whereas the opposite occurred in males. At T6, plasma TRP depletion was less than depletion of the TRP/ $\Sigma$ LNAA ratio (Lieben et al., 2004b).

ATD resulted in significant impairment of object recognition when this is measured 2, 4, or 6 hours after the first of two ATD doses. Previously, reliable memory effects have been found four hours after the first treatment when rats are treated with two doses (Lieben et al., 2004b). Although maximal depletion and return to baseline in females appeared to occur faster than in males, ATD impaired object recognition memory in females four hours after treatment (Jans et al., 2007). Experiment 5 of this study showed that already at T2 there is a significant impairment of object recognition memory, suggesting central depletion effects at this time point. This experiment also showed that object recognition memory in males is still impaired 6 hours after ATD treatment, in spite of decreasing treatment effects on plasma TRP levels, suggesting that maximal treatment effects in the brain occur at a later time point than maximal plasma TRP depletion. This was also found in a study in which rats were tested in the object recognition test after one dose of ATD (Rutten et al., 2007). This study further showed that $50 \%$ reduction of plasma TRP levels is sufficient to impair object recognition in rats (Rutten et al., 2007). It can be concluded that ATD impaired object recognition memory and that this effect is both rapid and long lasting.

From experiment 1 it may be concluded that TRP+ treatment is a better control condition than saline, because the TRP/ $\Sigma$ LNAA ratio decreased over time in the saline 
condition but was stable over time in the TRP+ condition. This may be explained by the fact that the TRP+ condition has nutritional value whereas saline does not. Therefore, in the saline condition amino acid levels may drop over time as a result of lack of food intake, as the animals were deprived of normal food for 14 hours before treatment and during the treatment period. Ideally, the control condition entails the same experiences for the rat as the treatment condition, but with as little change in amino acid levels as possible. It is assumed that the experience of oral injection with TRP- or TRP+ is the same, because the mixtures are exactly the same except for the presence of a small amount of TRP. In experiment 1 plasma TRP levels were stable over time in both the $\mathrm{TRP}+$ and the saline condition, suggesting treatment may affect the other LNAAs. However, in a similar experiment with male rats Lieben et al. (Lieben et al., 2004a) reported that TRP levels and the TRP/ $L$ LNAA ratio decreased over time after saline, TRP+ and TRP- treatment. In females, experiment 2 of this study showed a time effect in the TRP+ condition, plasma TRP and the TRP/ $L$ LNAA ratio dropped a bit over six hours, both were especially low at T4. These effects, however, were not replicated in experiment 4 , where TRP levels were stable over time in the TRP+ condition in males and both groups of females. The TRP/ $L$ LNAA ratio did decrease over time (Jans et al., 2007) again suggesting treatment effects on other LNAAs.

It is important to note that the TRP+ control condition of this protein-carbohydrate mixture does not result in an increase in TRP levels, whereas this increase has been reported in TRP+ rats when using an amino acid mixture that is often used in human ATD studies (Blokland et al., 2004). This is an important advantage of the proteincarbohydrate mixture over the amino acid mixture in rats. It should be noted though, that TRP+ treatment increased the levels of numerous AAs (serine, glycine, arginine, ornithine) in males in a previous study (Lieben et al., 2004a).

Experiment 4 of this study indicates that in males and females, ATD affected not only TRP and the TRP/ $\Sigma$ LNAA ratio, but also the levels of other AAs (table 3 ). In this experiment, all plasma AA levels changed over time. Levels of glutamate, serine, glycine, citrulline, arginine, alanine, valine, phenylalanine, leucine, ornithine and lysine increased over time, whereas levels of asparagine, glutamine, histidine, threonine, taurine, tyrosine, methionine, isoleucine, and TRP decreased over time. The decrease in tyrosine could be especially important because tyrosine is the precursor of the neurotransmitters dopamine and norepinephrine. Changes in the levels of these neurotransmitters may affect behaviour and the effects of ATD on behaviour. A previous study in males reported a decrease of plasma and brain tyrosine levels over time after $\mathrm{TRP}+$ and TRP- treatment, but no effects on dopamine and DOPAC concentrations in the brain (Lieben et al., 2004a).

Treatment effects at T4 are important because this is the time point of behavioural testing in rat ATD studies (Blokland et al., 2002, Lieben et al., 2004b, Jans et al., 2007). In experiment 4 , TRP- males showed lower glycine, taurine, methionine and TRP at T4 compared to TRP+ males whereas tyrosine was higher in TRP- males. In TRP- females 
pro/oes levels of asparagine, serine, glutamine, histidine, glycine, threonine, alanine, methionine, and TRP were lower at T4 after TRP- treatment compared to TRP+ treatment. In females met/di there was a treatment effect at T4 on levels of alanine, methionine, and TRP, all were lower after TRP- compared to TRP+ treatment. Thus, although female oestrous cycle phase did not influence the effects of ATD on TRP, it did influence the effects of ATD on other AAs. It should be noted though, that treatment effects at T4 on AAs other than TRP were relatively small. Differences between TRP values in TRP+ and TRP- at T4 were 50-60\%, whereas differences in other AAs did not exceed 20\%. Keeping in mind that a large amount of AA values have been compared here, it might not be wise to draw strong conclusions from the small differences, as they might be based on coincidence rather than on true effects.

Suppletion of TRP, as in the TRP++ condition in experiment 2 , caused a fast increase of both TRP levels and the TRP/ $/$ LNAA ratio that is most pronounced 2 hours after the first injection. Six hours after the first injection, TRP levels are back to baseline levels, while the TRP/ $\Sigma$ LNAA ratio is at that time point still somewhat higher than baseline levels.

It could be argued that repeated treatment with the TRP- diet might affect the level of depletion (e.g. adaptation to diet). However, we observed that repeated exposure to ATD does not affect the depletion effects. When comparing TRP- treatment on one day with treatment on four consecutive days, there was no significant difference in TRP levels or TRP/ $\Sigma$ LNAA ratio. In the TRP+ condition the TRP/ $\Sigma$ LNAA ratio decreased over time on the fourth day of treatment, but there was no difference when comparing one day of TRP+ treatment with treatment on four consecutive days. The effects of ATD are transient, TRP levels return to baseline several hours after treatment on the day that the rat is treated, even when the rats do not have access to food. When the rats were treated on four consecutive days, baseline levels and treatment effects on the fourth day were similar to the effects of one-day treatment.

In conclusion, the method of acute tryptophan depletion can be used to temporarily lower peripheral tryptophan levels and consequently affect 5-HT levels. A protocol with two injections with 90 minutes interval or one with three injections with 60 minutes interval resulted in depletion of peripheral TRP levels of about $65-70 \%$ two to four hours after the first treatment. Object recognition was impaired two, four, and six hours after the first of two doses ATD, suggesting that the central effects of ATD occurred rapidly and continued until at least 6 hours after the first of two doses, in spite of decreasing treatment effects on plasma TRP levels at that time point. The number of doses the rat receives appears to mainly affect the duration of the depletion as the doses are staggered over a longer period of time. Treatment effects appear to be similar in male and female Wistar rats, although females may return to baseline levels faster than males. Female oestrous cycle phase did not influence the pharmacokinetic effects of ATD on plasma TRP and the TRP/ $\Sigma$ LNAA ratio. Treatment effects after one day of treatment were not different from treatment effects after four consecutive days of treatment. TRP+ appeared to be an appropriate control condition. 


\section{References}

Bel, N. and Artigas, F., 1996. Reduction of serotonergic function in rat brain by tryptophan depletion: effects in control and fluvoxamine-treated rats. J Neurochem. 67, 669-676.

Biggio, G., Fadda, F., Fanni, P., Tagliamonte, A. and Gessa, G. L., 1974. Rapid depletion of serum tryptophan, brain tryptophan, serotonin and 5-hydroxyindoleacetic acid by a tryptophan-free diet. Life Sci. 14, 1321-1329.

Blokland, A., Lieben, C. and Deutz, N. E., 2002. Anxiogenic and depressive-like effects, but no cognitive deficits, after repeated moderate tryptophan depletion in the rat. J Psychopharmacol. 16, 39-49.

Blokland, A., Lieben, C., Deutz, N. E. P. and Schmitt, J., 2004. Acute tryptophan depletion: comparing the effects of an amino acid mixture with a gelatin-based protein in man and rat. Current Topics in Nutraceutical Research. 2, 161-169.

Booij, L., Van der Does, A. J. and Riedel, W. J., 2003. Monoamine depletion in psychiatric and healthy populations: review. Mol Psychiatry. 8, 951-973.

Booij, L., Van der Does, W., Benkelfat, C., Bremner, J. D., Cowen, P. J., Fava, M., Gillin, C., Leyton, M., Moore, P., Smith, K. A. and Van der Kloot, W. A., 2002. Predictors of mood response to acute tryptophan depletion. A reanalysis. Neuropsychopharmacology. 27, 852-861.

Carpenter, L. L., Anderson, G. M., Pelton, G. H., Gudin, J. A., Kirwin, P. D., Price, L. H., Heninger, G. R. and McDougle, C. J., 1998. Tryptophan depletion during continuous CSF sampling in healthy human subjects. Neuropsychopharmacology. 19, 26-35.

Ellenbogen, M. A., Young, S. N., Dean, P., Palmour, R. M. and Benkelfat, C., 1996. Mood response to acute tryptophan depletion in healthy volunteers: sex differences and temporal stability. Neuropsychopharmacology. 15, 465-474.

Ennaceur, A. and Delacour, J., 1988. A new one-trial test for neurobiological studies of memory in rats. 1: Behavioral data. Behav Brain Res. 31, 47-59.

Fernstrom, J. D., 1981. Dietary precursors and brain neurotransmitter formation. Annu Rev Med. 32, 413-425.

Fluttert, M., Dalm, S. and Oitzl, M. S., 2000. A refined method for sequential blood sampling by tail incision in rats. Lab Anim. 34, 372-378.

Jans, L. A., Lieben, C. K. and Blokland, A., 2007. Influence of sex and estrous cycle on the effects of acute tryptophan depletion induced by a gelatin-based mixture in adult Wistar rats. Neuroscience. 147, 304-317.

Lieben, C. K., Blokland, A., Westerink, B. and Deutz, N. E., 2004a. Acute tryptophan and serotonin depletion using an optimized tryptophan-free protein-carbohydrate mixture in the adult rat. Neurochem Int. 44, 9-16.

Lieben, C. K., van Oorsouw, K., Deutz, N. E. and Blokland, A., 2004b. Acute tryptophan depletion induced by a gelatin-based mixture impairs object memory but not affective behavior and spatial learning in the rat. Behav Brain Res. 151, 53-64.

Maes, M. and Meltzer, H. Y., 1995. The Serotonin Hypothesis of Major Depression. In: Bloom, F. E. and Kupfer, D. J. (Eds.), Psychopharmacology: The Fourth Generation of Progress. Raven Press, Ltd., New York, pp. 933-944.

Moja, E. A., Cipolla, P., Castoldi, D. and Tofanetti, O., 1989. Dose-response decrease in plasma tryptophan and in brain tryptophan and serotonin after tryptophan-free amino acid mixtures in rats. Life Sci. 44, 971-976.

Moja, E. A., Restani, P., Corsini, E., Stacchezzini, M. C., Assereto, R. and Galli, C. L., 1991. Cycloheximide blocks the fall of plasma and tissue tryptophan levels after tryptophan-free amino acid mixtures. Life Sci. 49, 1121-1128.

Moore, P., Landolt, H. P., Seifritz, E., Clark, C., Bhatti, T., Kelsoe, J., Rapaport, M. and Gillin, J. C., 2000. Clinical and physiological consequences of rapid tryptophan depletion. Neuropsychopharmacology. 23, 601-622.

Nishizawa, S., Benkelfat, C., Young, S. N., Leyton, M., Mzengeza, S., de Montigny, C., Blier, P. and Diksic, M., 1997. Differences between males and females in rates of serotonin synthesis in human brain. Proc Natl Acad Sci U S A. 94, 5308-5313. 
Park, S. B., Coull, J. T., McShane, R. H., Young, A. H., Sahakian, B. J., Robbins, T. W. and Cowen, P. J., 1994. Tryptophan depletion in normal volunteers produces selective impairments in learning and memory. Neuropharmacology. 33, 575-588.

Prickaerts, J., van Staveren, W. C., Şık, A., Markerink-van Ittersum, M., Niewohner, U., van der Staay, F. J., Blokland, A. and de Vente, J., 2002. Effects of two selective phosphodiesterase type 5 inhibitors, sildenafil and vardenafil, on object recognition memory and hippocampal cyclic GMP levels in the rat. Neuroscience. 113, 351-361.

Reilly, J. G., McTavish, S. F. and Young, A. H., 1997. Rapid depletion of plasma tryptophan: a review of studies and experimental methodology. J Psychopharmacol. 11, 381-392.

Riedel, W. J., Klaassen, T., Deutz, N. E., van Someren, A. and van Praag, H. M., 1999. Tryptophan depletion in normal volunteers produces selective impairment in memory consolidation. Psychopharmacology (Berl). 141, 362-369.

Rutten, K., Lieben, C., Smits, L. and Blokland, A., 2007. The PDE4 inhibitor rolipram reverses object memory impairment induced by acute tryptophan depletion in the rat. Psychopharmacology (Berl). 192, 275-282.

Sambeth, A., Blokland, A., Harmer, C. J., Kilkens, T. O., Nathan, P. J., Porter, R. J., Schmitt, J. A., Scholtissen, B., Sobczak, S., Young, A. H. and Riedel, W. J., 2007. Sex differences in the effect of acute tryptophan depletion on declarative episodic memory: a pooled analysis of nine studies. Neurosci Biobehav Rev. 31, 516-529.

Şı, A., van Nieuwehuyzen, P., Prickaerts, J. and Blokland, A., 2003. Performance of different mouse strains in an object recognition task. Behav Brain Res. 147, 49-54.

Smith, K. A., Fairburn, C. G. and Cowen, P. J., 1997. Relapse of depression after rapid depletion of tryptophan. Lancet. 349, 915-919.

Stancampiano, R., Melis, F., Sarais, L., Cocco, S., Cugusi, C. and Fadda, F., 1997. Acute administration of a tryptophan-free amino acid mixture decreases 5-HT release in rat hippocampus in vivo. Am J Physiol. 272, R991-994.

van Eijk, H. M., Rooyakkers, D. R. and Deutz, N. E., 1993. Rapid routine determination of amino acids in plasma by high-performance liquid chromatography with a 2-3 microns Spherisorb ODS II column. J Chromatogr. 620, 143-148.

Williams, W. A., Shoaf, S. E., Hommer, D., Rawlings, R. and Linnoila, M., 1999. Effects of acute tryptophan depletion on plasma and cerebrospinal fluid tryptophan and 5-hydroxyindoleacetic acid in normal volunteers. J Neurochem. 72, 1641-1647.

Wurtman, R. J., Hefti, F. and Melamed, E., 1980. Precursor control of neurotransmitter synthesis. Pharmacol Rev. 32, 315-335.

Young, S. N., Smith, S. E., Pihl, R. O. and Ervin, F. R., 1985. Tryptophan depletion causes a rapid lowering of mood in normal males. Psychopharmacology (Berl). 87, 173-177. 



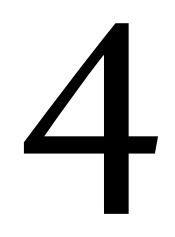

Influence of sex and oestrous cycle on the effects of acute tryptophan depletion induced by a gelatin-based mixture in adult Wistar rats

L. A. W. Jans, C. K. J. Lieben, A. Blokland

Neuroscience 2007, 147: 304-317 


\section{Abstract}

Women are more vulnerable to develop depression and anxiety disorders than men. This may be related to higher serotonergic vulnerability in women. Serotonergic vulnerability entails that differences between people in the regulation of serotonin determine the vulnerability of an individual to develop depression or other serotonin-related disorders. The aim of the present experiment was to evaluate whether male and female Wistar rats differ in serotonergic vulnerability. Here, a stronger behavioural response to acute tryptophan (TRP) depletion was assumed to reflect serotonergic vulnerability. Twenty-four male and 48 female rats were repeatedly subjected to treatment with a gelatine-based protein-carbohydrate mixture, either with or without L-tryptophan. Female oestrous cycle phase was determined by means of vaginal smears and the females were divided into two groups based on their oestrous cycle phase: pro-oestrus/oestrus and met-oestrus/di-oestrus. Blood samples showed stronger TRP depletion in males than females. There was no effect of oestrous cycle on plasma TRP concentrations. In contrast, treatment effects on some brain TRP concentrations were influenced by oestrous cycle phase, females in pro-oestrus/ oestrus showed the strongest response to TRP depletion. In the open field test and home cage emergence test, females in pro-oestrus/oestrus also showed the strongest behavioural response to acute TRP depletion. In general, females showed more activity than males in anxiety-related situations and this effect appeared to be enhanced by TRP depletion. In the social interaction test, passive body contact in males and females in pro-oestrus/oestrus was decreased after TRP depletion whereas it was increased in females in met/di. Acute TRP depletion affected object recognition, but did not affect behaviour in the forced swim test and a reaction time task. It is concluded that sex and oestrous cycle phase can influence the behavioural response to TRP depletion, and that females in pro-oestrus/oestrus show the strongest behavioural response to acute TRP depletion. 


\section{Introduction}

The neurotransmitter serotonin (5-Hydroxytryptamine, 5-HT) is known to be involved in many physiological and behavioural processes, including mood, appetite, sleep, activity, suicide, sexual behaviour and cognition. Alterations in 5-HTergic function have been observed in numerous clinical conditions, including affective disorders, anxiety, obsessive-compulsive disorders, eating disorders, aggression, suicide, impulsive disorders, alcohol abuse, and premenstrual syndrome (Heninger, 1995, Jacobs and Fornal, 1995). Serotonergic functioning is thought to operate as a vulnerability factor for depression and other 5-HT-related disorders. The idea is that the 5-HTergic functioning of an individual determines the vulnerability of that individual to develop 5-HT related disorders. Individuals with vulnerability of the serotonergic system (serotonergic vulnerability; SV) are vulnerable to alterations or dysregulations in the serotonergic system (Jans et al., In press). SV can be demonstrated by challenging the 5-HT system; vulnerable and non-vulnerable subjects will react differently to these manipulations. This implies that there are differences in 5-HT functioning between different individuals, and that the development of depression, anxiety or other 5 -HT related disorders is associated with the presence of a priori abnormalities in the functioning of this system.

Epidemiological studies have shown that major depression is more common in females than in males (for review see Piccinelli and Wilkinson, 2000). This has been found in several countries and ethnic groups (Weissman et al., 1996). Artefactual factors, including more help-seeking and illness behaviour in women, may enhance the female prevalence to some extent, but the gender difference in depression appears to be genuine (Piccinelli and Wilkinson, 2000). The gender difference in the prevalence of depression begins around puberty and persists until midlife.

There are several possible causes for this female preponderance. One possibility lies in the 5-HT differences between males and females. Reports of sex differences related to the 5-HTergic system come from animal and human studies. Female rats exhibit increased 5-HT activity (expressed as the quotient between 5-hydroxyindolacetic acid (5-HIAA) and 5-HT concentrations) in the dorsal raphe nucleus but not in the median raphe nucleus (Dominguez et al., 2003). Higher levels in females of tryptophan (TRP), 5-HT, 5-HIAA and 5-HIAA/5-HT have been found in several brain structures and the sex difference in the brain 5-HT system appears to be a general phenomenon rather than being restricted to a specific region (Carlsson and Carlsson, 1988). Brain 5-HT synthesis rate has also been found to be higher in female rats compared to males in several structures (Rosencrans, 1970, Watts and Stanley, 1984, Carlsson and Carlsson, 1988, Haleem et al., 1990), suggesting higher presynaptic capacity in the 5-HTergic system of females (Carlsson and Carlsson, 1988).Human cerebrospinal fluid studies suggest that the rate of brain 5-HT metabolism is higher in females than in males (Asberg et al., 1973, Young et al., 1980, Agren et al., 1986) 
whereas whole brain 5-HT synthesis (Nishizawa et al., 1997) have been reported to be lower in women than in men. Women also appear to have a diffuse reduction of 5-HTT binding sites in the prefrontal cortex compared to men (Mann et al., 2000).

Putative neuromodulatory effects of oestrogen are a second possible cause of higher SV in women than men. Oestrogen may play a neuromodulatory role on several neurotransmitter systems, including the serotonergic system (Osterlund and Hurd, 2001). It has been shown, for example, that 5-HT concentrations fluctuate throughout the rodent oestrous cycle (Gundlah et al., 1998, Maswood et al., 1999). Oestrogen has been reported to increase the production of tryptophan hydroxylase, the rate-limiting enzyme for the synthesis of 5-HT, in non-human primates (Bethea et al., 2000). Furthermore, oestrogen can alter the expression of genes involved in the serotonergic system and can enhance serotonergic activity (Weigel, 1996, Fink et al., 1998, Joffe and Cohen, 1998, Sumner and Fink, 1998, McEwen and Alves, 1999).

In this experiment, we wanted to test the hypothesis that SV is higher in females than in males. We used acute tryptophan depletion (ATD), using a gelatin-based TRP free protein-carbohydrate mixture, to challenge the 5-HT system. In ATD, L-tryptophan -the essential amino acid that is the precursor of 5-HT- is depleted, resulting in lower central 5-HT levels. The method of ATD has been frequently used as a tool to reduce systemic TRP levels and consequently central 5-HT concentrations (Biggio et al., 1974, Gessa et al., 1974, Moja et al., 1989, Fernstrom and Wurtman, 1997). ATD is a non-intrusive and reversible method that can be applied to investigate the role of 5-HT in behavioural functions (e.g., anxiety, sleep, aggression, memory, impulsivity) in humans as well as in animals (Young, 1996, Moore et al., 2000, Bell et al., 2001). The TRP lacking amino acid mixture has been shown to reduce plasma TRP levels and tissue 5-HT levels in overall brain tissue and more selective brain structures (e.g., the hippocampus) in the rat (Biggio et al., 1974, Gessa et al., 1974, Moja et al., 1989, Brown et al., 1998). TRP depletion also lowered the extracellular levels of 5-HT in the hippocampus (Stancampiano et al., 1997). Previous studies in our lab using a gelatin-based-carbohydrate mixture showed a robust reduction in plasma TRP (about 70\%) and central tissue 5-HT (about 40-45\%) concentrations in male Wistar rats (Lieben et al., 2004a). In male rats, this ATD method has been reported to impair object memory, but not affective behaviour (Lieben et al., 2004b).

In healthy human volunteers, ATD generally results in memory impairments, whereas other effects of ATD, such as effects on mood, are only found in vulnerable subjects (Riedel et al., 1999, Schmitt et al., 2000, Riedel et al., 2002). Sex has been reported to affect several outcome measures of ATD. (Nishizawa et al., 1997) studied the effects of ATD on human 5-HT synthesis and found that the rates of 5-HT synthesis were reduced by ATD by a factor of about 9.5 in men and a factor of about 40 in women. Several previous ATD studies in which gender effects were considered showed that mood effects are larger in women than in men (Ellenbogen et al., 1996, 
Smith et al., 1997, Booij et al., 2002). In a mega-analysis, Sambeth et al. (in press) found that the effects of ATD on verbal memory were larger in women than in men on both the immediate and delayed recall scores, despite similar levels of plasma TRP depletion in males and females.

In the present study, the effects of ATD on affective and cognitive behaviour were examined in adult male and female Wistar rats. All animals were tested in behavioural tests of anxiety-related behaviour (open field test, home cage emergence test, social interaction test), depression-related behaviour (forced swim test) and cognition (object recognition test, reaction time task). The object recognition test measures the ability of the animal to discriminate between a novel and a familiar object after a specific time interval. In the reaction time task, the number of premature responses is of special interest because these premature responses are assumed to reflect motor impulsivity (Blokland et al., 2005). 5-HT is known to be involved in impulsive behaviour, but whether lowered central 5-HT level is involved in motor impulsivity as reflected by premature responses is unknown. The magnitude of TRP depletion was determined by measuring plasma and brain amino acid concentrations.

In order to investigate the effects of the female oestrous cycle on behaviour and the behavioural response to ATD, the group of females were subdivided in females in the pro-oestrus/oestrus phase (pro/oes; characterized by higher levels of oestradiol and progesterone) and females in the met-oestrus/di-oestrus phase (met/di; characterized by lower levels of oestradiol and progesterone) of the oestrous cycle. This resulted in a total of three different experimental groups: males, females in pro/oes, and females in met/di. Females were hypothesized to have higher SV than males, and therefore we hypothesized that one or both groups of females would show stronger behavioural responses to the ATD treatment, e.g. higher indices of anxiety- or depression-related behaviours, on one or more behavioural tests.

\section{Materials and methods}

\section{Animals}

All experimental procedures were approved by the local ethical committee of the Maastricht University for animal experiments and met governmental guidelines. Subjects were twenty-four 4-month-old male Wistar rats weighing between 330 and $390 \mathrm{~g}$ at arrival and 48 female Wistar rats of the same age, weighing between 160 and $235 \mathrm{~g}$ at their arrival (Charles River, the Netherlands). The total number of 72 rats was divided into two groups that were tested separately, with each group consisting of 12 males and 24 females. All rats were housed two per cage in standard Macrolon cages on sawdust bedding in an air-conditioned room $\left( \pm 21^{\circ} \mathrm{C}\right)$. Only during training and testing in the object recognition test and the Skinnerbox test, the rats were housed individually. 
The animals always had free access to water. They were kept under a reversed 12/12$\mathrm{h}$ light/dark cycle. The lights were on from 17.00-05.00 h. A radio, which was playing softly, provided background noise.

\section{Oestrous cycle}

To determine the oestrous cycle phase of each female, vaginal smears were taken between 7.00 and 10.00 am on all testing days. A plastic smear loop was inserted in the vaginal opening, gently rotated and withdrawn. The smear loop was immediately rolled onto a glass slide and allowed to air dry. Slides were examined under a light microscope for the presence of nucleated epithelial cells, cornified epithelial cells, leukocytes, and mucus. Oestrous cycle stage was determined using the following criteria: 1) prooestrus: predominantly nucleated epithelial cells; 2) oestrus: predominantly cornified epithelial cells; 3 ) met-oestrus: cornified epithelial cells and leukocytes; 4) di-oestrus: predominantly leukocytes, some nucleated epithelial cells and mucus (Singletary et al., 2005). Female sex steroids vary with oestrous cycle phase. Plasma oestradiol levels peak during pro-oestrus and decrease during oestrus and met-oestrus, whereas the highest plasma progesterone levels have been observed during pro-oestrus and oestrus with lower levels during met-oestrus and di-oestrus (Butcher et al., 1974). Based on these plasma levels of sex steroids, we subdivided the group of females into two groups based on oestrous cycle phase. Females in pro-oestrus and oestrus formed one group, and the other group consisted of females in met-oestrus and di-oestrus. Similar subdivisions of cycling females have been made in other studies measuring behaviour and oestrous cycle (Contreras et al., 2000).

\section{Drugs and chemicals}

The Gelatin hydrolysate (Solugel P') was obtained from PB Gelatins (Tessenderlo, Belgium). Glucodry 210 was obtained from the Amylumgroup (Koog aan de Zaan, The Netherlands). Kaliumchloride $(\mathrm{KCl})$, calciumchloride-dihydrate $\left(\mathrm{CaCl}_{2} \cdot 2 \mathrm{H}_{2} \mathrm{O}\right)$ and 5-sulfosalicylic acid dihydrate were purchased from Merck (Darmstadt, Germany). Tryptophan was obtained from Sigma (Zwijndrecht, The Netherlands).

\section{Treatment}

During a period of two weeks preceding the experiment, the rats were handled and habituated to oral injections with normal tap water (up to $10 \mathrm{ml} / \mathrm{kg}$ ). The females were also habituated to the procedure for taking vaginal smears. On testing days the rats were treated with a protein-carbohydrate mixture containing TRP (TRP+ group, $0.28 \%$ TRP of the total protein) or lacking TRP (TRP- group). The rats received two doses of $10 \mathrm{ml} / \mathrm{kg}$ with a 90 -minute interval. Each administration contained $4.0 \mathrm{~g}$ 
Solugel P/kg and 2.0 g Glucodry $210 / \mathrm{kg}$ of the body weight. The composition of the nutritional mixture is shown in Table 1.

Table 1: Composition of the treatment mixture.

\begin{tabular}{lrr}
\hline Protein (Solugel $^{\mathbf{}}$ ) in $\mathbf{1 0 0 ~} \mathbf{~ m l}$ water & 100 g \\
\hline Alanine & 8.4 & \\
Arginine & 7.7 & \\
Aspartic Acid/Asparagine & 4.5 & \\
Glutamic Acid/Glutamine & 10.0 & \\
Glycine & 23.3 & \\
Histidine & 0.9 & \\
Hydroxylysine & 1.5 & \\
Hydroxyproline & 12.3 \\
Isoleucine & 1.2 & \\
Leucine & 2.6 & \\
Lysine & 3.3 & \\
Methionine & 0.9 & \\
Phenylalanine & 1.6 & \\
Proline & 13.7 & \\
Serine & 3.4 & \\
Threonine & 1.9 & \\
Tryptophan & 0.0 & \\
Tyrosine & 0.6 & \\
Valine & 2.2 & 0.094 \\
Carbohydrate (Glucodry 210) in 80 ml water & & 2.32 \\
KCL & & 0 \\
CaCl-2H ${ }_{2} \mathrm{O}$ & & 0.28 \\
L-tryptophan (TRP- group) & & \\
L-tryptophan (TRP+group) & & \\
\hline
\end{tabular}

The rats were fasted from $15 \mathrm{~h}$ prior to treatment until the testing period was completed. This was done to minimize the availability of TRP from food. Behavioural testing was conducted $4 \mathrm{~h}$ after the first oral administration. At the end of each testing day, the animals had ad libitum access to food for at least $3 \mathrm{~h}$. An overview of the order of testing and the number of times the rats were treated with the mixture is given in Table 2. Males were randomly assigned to treatment with TRP+ or TRP- for each test separately. Females were first divided into the two oestrous cycle groups and were then randomly assigned one of the two treatment conditions. In this way, on tests where the rats were treated either with TRP- or with TRP+, the treatment condition for each rat varied between tests, but not within one test. This was the case for the open field test, home cage emergence test, social interaction test and forced swim test. In the object recognition test and the reaction time task, where all rats were treated with both TRP+ and TRP- on different days. There were always at least three days between the different behavioural tests, in which the rats were undisturbed and food was provided ad libitum. 
Table 2: Order of the different behavioural experiments and the number of days treatment was given for each of the separate testing groups.

\begin{tabular}{|c|c|c|c|c|c|}
\hline \multicolumn{3}{|c|}{$\begin{array}{c}\text { Testing group } 1 \\
12 \text { males, } 24 \text { females }\end{array}$} & \multicolumn{3}{|c|}{$\begin{array}{c}\text { Testing group } 2 \\
12 \text { males, } 24 \text { females }\end{array}$} \\
\hline Week & Test & Treatment & Week & Test & Treatment \\
\hline 1,2 & Handling & 1 & 1,2 & Handling & 1 \\
\hline 3 & Blood sampling 1 & 1 & 3 & Blood sampling 1 & 1 \\
\hline $\begin{array}{c}4 \\
\text { Day 3-4 }\end{array}$ & Open field test & $2^{*}$ & $\begin{array}{c}4 \\
\text { Day 2-3 }\end{array}$ & Open field test & $2^{*}$ \\
\hline $\begin{array}{c}5 \\
\text { Day 3-4 }\end{array}$ & $\begin{array}{l}\text { Home cage emer- } \\
\text { gence test }\end{array}$ & $2^{*}$ & $\begin{array}{c}5 \\
\text { Day } 2-3\end{array}$ & $\begin{array}{l}\text { Home cage emer- } \\
\text { gence test }\end{array}$ & $2^{*}$ \\
\hline $\begin{array}{c}6 \\
\text { Day } 1,5\end{array}$ & Social interaction test & $2^{*}$ & $\begin{array}{c}6 \\
\text { Day } 1,5\end{array}$ & Social interaction test & $2^{*}$ \\
\hline $\begin{array}{c}7 \\
\text { Day 3-4 }\end{array}$ & Forced swim test & $2^{*}$ & $\begin{array}{c}7 \\
\text { Day 5-6 }\end{array}$ & Forced swim test & $2^{*}$ \\
\hline $8,9,10$ & $\begin{array}{l}\text { Object recognition } \\
\text { test }\end{array}$ & $2 \#$ & $\begin{array}{c}8,9,10 \\
11,12,13\end{array}$ & Skinnerbox task & $2 \#$ \\
\hline 11,12 & $\begin{array}{l}\text { Blood sampling } 2 \text { and } \\
\text { decapitation }\end{array}$ & 1 & 14,15 & $\begin{array}{l}\text { Blood sampling } 2 \text { and } \\
\text { decapitation }\end{array}$ & 1 \\
\hline
\end{tabular}

${ }^{*}$ Rats were treated with either TRP+ or TRP- and received the same treatment condition on both testing days.

"Rats were treated with both TRP+ and TRP- on different testing days.

\section{Biochemistry}

For the determination of plasma amino acid levels blood samples were taken at resting values (T0; i.e., $10 \mathrm{~min}$ before the first oral administration) and repeated at $4 \mathrm{~h}$ after the first administration (T4). Blood sampling was done via a tail-incision method (Fluttert et al., 2000). Promptly after collection of blood in a sodium heparin tubes (Microvette ${ }^{\oplus}$ CB 300 , Sarstedt, Germany), the samples were kept on ice. After centrifugation of the blood samples (at $4^{\circ} \mathrm{C}$ for $15 \mathrm{~min}$ at $3000 \mathrm{~g}$ in a Hettich EBA 12 centrifuge), plasma was deproteinised with cups containing dry 5 -sulfosalicylic acid ( $17 \mu \mathrm{l}$ of a $5 \mathrm{mg} / 10 \mathrm{ml}$ milliQ water solution with $100 \mu \mathrm{l}$ plasma) and the protein was spun down. Samples were frozen in liquid nitrogen and stored at $-80^{\circ} \mathrm{C}$. For brain samples of the frontal cortex and hippocampus, rats were decapitated four hours after the first administration of treatment and the heads were immersed in liquid nitrogen for $6 \mathrm{~s}$. Brain structures were rapidly dissected and then stored at $-80^{\circ} \mathrm{C}$. Before analysis, the frozen brain structures were transferred to a vial containing $0.3 \mathrm{~g}$ of glass beads $(1.0 \mathrm{~mm}$ diameter $)$ and $400 \mu \mathrm{l}$ of an ice-cold 10\% 5-sulfosalicylic acid solution. The tissue samples were homogenized in a mini-bead beater at high speed for $30 \mathrm{~s}$. They were frozen in liquid nitrogen and stored at $-80^{\circ} \mathrm{C}$ until further processing.

Before analysis, samples were thawed at $4^{\circ} \mathrm{C}$, vortex-mixed vigorously and centrifuged at 50,000 g in a Hereaus Model Biofuge Stratos for $10 \mathrm{~min}$ at $4^{\circ} \mathrm{C}$. From the clear supernatant $20 \mu \mathrm{l}$ was mixed with $1960 \mu \mathrm{l}$ water and $20 \mu \mathrm{l}$ norvaline and stored in the cooled $\left(7^{\circ} \mathrm{C}\right)$ sample compartment until analysis. Plasma and brain amino acid concentrations were determined with a fully automated high-performance liquid chromatog- 
raphy (HPLC) system after precolumn derivatization with o-phthaldialdehyde (OPA) (van Eijk et al., 1993). OPA-AA derivates were quantified with fluorescence detection. The concentrations of the total plasma amino acids were expressed as $\mu \mathrm{mol} / \mathrm{l}$, brain concentrations as $\mathrm{ng} / \mathrm{mg}$.

\section{Behaviour}

Open field test The open field test was conducted in a square, clear Plexiglas box $(100 \times 100 \times 40 \mathrm{~cm})$, with an open top and a dark floor. The arena of the open field was subdivided in 'corner' (four squares each $16 \times 16 \mathrm{~cm}$ ), 'wall' (four rectangles each $16 \times 64 \mathrm{~cm}$ ) and 'center' (one square $64 \times 64 \mathrm{~cm}$ ) zones. Testing was carried out in dimmed white light. A camera was installed above the center of the field. Immediately after a rat was placed in the center of the open field, the movements and position of the animals were recorded and registered automatically by a computerized system (EthoVision, Noldus Information Technology, The Netherlands). Reported are the time spent in the center and the corner zones of the open field and the total distance moved. Testing was carried out on two consecutive days, with one 5-minute trial a day for all rats. The floor of the open field was cleaned with a damp sponge after each session to prevent transmission of olfactory cues. Open field behaviour was tested between $13.00 \mathrm{~h}$ and 16.30 h. Data of the two trials were aggregated to enhance reliability (Ossenkopp and Mazmanian, 1985). These aggregated data strongly correlate with definitions of anxiety in other models, such as the plus maze and the light dark box (Blokland et al., 1992, Prickaerts et al., 1996, van der Staay and Blokland, 1996).

Home cage emergence test In the home cage emergence test the home cage was placed in an arena and the lid of the home cage was removed (Prickaerts et al., 1996). During the testing of one rat, its cage mate was placed in another cage for the duration of the trial. A grid was placed over the edge of the cage to make it easier for the rats to leave the home cage. Testing was carried out in dimmed white light. A stopwatch was used to measure the latency to leave the cage. The experimenter measured the time it took for the rat to climb out of its cage into the arena. A criterion was set to determine the escape time. Time was stopped and the trial ended when all four paws of the rat were over the edge of the cage. If the rat did not emerge from its home cage within $600 \mathrm{~s}$, the trial was ended, the home cage was closed again and the rat was given a score of 600 . The grid was cleaned between trials with a damp sponge to prevent transmission of olfactory cues. This test was carrier out on two consecutive days.

Social interaction test In the social interaction test (File and Hyde, 1978, File and Seth, 2003), two rats were placed in closed part of the open field, $50 \times 50 \times 40 \mathrm{~cm}$ with two black and two transparent walls. The two animals that were tested together were weight matched and of the same sex, and had received the same treatment (both TRP- or 
both TRP+). The animals were placed in the test area at the same time and spend $10 \mathrm{~min}$ utes together, which were videotaped for later offline analysis by an observer who was blind to the treatment and oestrous cycle phase of the rats, whereas the sex of a rat could be inferred from its size. Per interaction duo, total time of social interaction was measured, subdivided into active social interaction and passive body contact. Active social interaction comprises sniffing, grooming, exploring, following, biting, etc the other rat. During passive body contact, the rats touch each other but do not explore, i.e. sitting or lying together. In order to increase the number of observations, all rats were tested twice with at least 5 days between the two trials. They received the same treatment on both trials, but were exposed to a different unfamiliar testing partner on each trial.

Forced swim test Three cylindrical transparent plastic tanks $(40 \mathrm{~cm}$ tall $\times 17 \mathrm{~cm} \mathrm{di-}$ ameter), filled to a depth of $30 \mathrm{~cm}$ with $22( \pm 1)^{\circ} \mathrm{C}$ water, were used in the forced swim test. Testing was carried out over two consecutive days. When the animals were placed in the water, their movements were videotaped in 5-min test trials for off-line measurement of the duration of immobility by an observer who was blind to the treatment and oestrous cycle phase of the rats. The behavioural variable 'immobility' was defined as follows: making no movements or only making those movements that were necessary to keep the nose above the water. It was allowed for the rats to move their forepaws or support themselves by pressing their paws against the wall of the cylinder. Active climbing and swimming along the wall were not scored as immobility.

Object recognition test The object recognition test was performed as described in detail elsewhere (Ennaceur and Delacour, 1988, Prickaerts et al., 2002). During training and testing, the rats were housed individually. The apparatus consisted of a circular arena, $83 \mathrm{~cm}$ in diameter. Half of the $40-\mathrm{cm}$-high wall was made of grey polyvinyl chloride, the other half of transparent polyvinyl chloride. Testing was carried out in dimmed white light. We used four different sets of objects that could not be displaced by a rat. Each object was available in triplicate. The different objects were: 1) a cone consisted of a grey polyvinyl chloride base (maximal diameter $18 \mathrm{~cm}$ ) with collar on top made of brass (total height $16 \mathrm{~cm}$ ), 2) a standard 11 transparent glass bottle (diameter $10 \mathrm{~cm}$, height $22 \mathrm{~cm}$ ) filled with water, 3$)$ a massive metal cube $(10 \times 5 \times 7.5 \mathrm{~cm})$ with two holes (diameter $1.9 \mathrm{~cm})$, and 4$)$ a massive aluminium cube with a tapering top $(13 \times 8 \times 8 \mathrm{~cm})$.

In the week preceding testing, the animals were adapted to the procedure, i.e., they were allowed to explore the apparatus (without any objects) twice for $3 \mathrm{~min}$. In the following days, the rats were tested until a stable discrimination performance was shown. A testing session comprised two trials. The duration of each trial was $3 \mathrm{~min}$. Two objects were placed in a symmetrical position about $10 \mathrm{~cm}$ away from the grey wall. A rat was always placed in the apparatus facing the wall at the middle of the front (transparent) segment. During the first trial the apparatus contained two identical objects. After the first exploration period the rat was put back in its home cage. One hour later the rat was 
put back in the apparatus for the second trial, but now with dissimilar objects, a familiar one and a new one. The duration of exploring each object in both trials was recorded manually with a personal computer. Exploration was defined as directing the nose to the object at a distance of no more than $2 \mathrm{~cm}$ and/or touching the object with the nose. Sitting on the object was not considered as exploratory behaviour. In order to avoid the presence of olfactory trails, the objects were always thoroughly cleaned. Moreover, each object was available in triplicate so that none of the two objects from the first trial had to be used as the familiar object in the second trial. In addition, all combinations and locations of objects were used in a balanced manner to reduce potential biases due to preferences for particular locations or objects.

After the rats were familiarized to the procedures of the task, testing with treatment began. The first trial was given $4 \mathrm{~h}$ after the first oral administration. The delay interval of one hour was preferable since during this time, we expected the plasma TRP levels to remain at low level. The basic measures were the total exploration time of both objects during trial 1 and trial 2,e1 and $e 2$, respectively. Rats that explored less than $10 \mathrm{~s}$ in any of the trials or explored only one of the objects were removed from analysis to avoid possible erroneous conclusions. A discrimination index $d 2(d 2=$ (exploration new object - exploration familiar object)/total exploration time during test trial) were calculated.

Reaction time task During the period of training and testing in the Skinnerboxes, the rats were housed individually and were given 10-12 g standard laboratory chow (Hopefarms, NL) per day and ad libitum food from Friday afternoon to Sunday afternoon. This schedule reduced their weight to about $90 \%$ of their free feeding weight during the week.

The apparatus consisted of ten identical operant chambers (inner dimensions: $40 \times 30 \times 33 \mathrm{~cm}$ ) which were equipped with two retractable levers, and cue lights just above the levers. A food tray $(5 \times 5 \mathrm{~cm}$ and $2.5 \mathrm{~cm}$ above the grid floor), which was positioned equidistant between the two levers, could be accessed by pushing a hinged panel. The levers ( $4 \mathrm{~cm}$ wide) projected $2 \mathrm{~cm}$ into the conditioning chamber and were located $6 \mathrm{~cm}$ from both sides of the food tray and $12 \mathrm{~cm}$ above the grid floor. A house light and a loudspeaker were fixed in the ceiling of the conditioning chamber. The operanda and manipulanda in the chambers were controlled by a personal computer and the data were stored on disk at the end of a session.

In this experiment we used a choice reaction time task, that has been described in detail elsewhere (Blokland, 1998). The rats were first trained to push the hinged panel of the magazine to make the right or left lever available. Whenever a lever was inserted into the chamber the cue light above the lever was switched on. A $45 \mathrm{mg}$ food reward (Bioserve) was given when a rat pressed the lever. After the rats had acquired this stage of training the rats had to push the panel for a longer duration until one of the levers were made accessible. First, a randomly chosen duration of $0.5-1.0 \mathrm{~s}$ (steps of $0.1 \mathrm{~s}$ ) was used. This variable period was called the hold duration. An auditory stimulus signalled the end of the hold duration. A high tone $(10 \mathrm{kHz} ; 80 \mathrm{~dB})$ predicted insertion 
of the left lever and a low tone $(2.5 \mathrm{kHz} ; 80 \mathrm{~dB})$ predicted the insertion of the right lever. The insertion of the lever took about $2 \mathrm{~s}$ but was active as soon as it was set in motion. Pressing the lever resulted in a food reward. The tone was switched off when the rat withdrew its nose from the food tray. When a rat did not succeed in pushing the panel for the entire hold duration, the same interval was started again upon pushing the panel. After the rats showed a steady performance during this stage they were required to push the panel for a randomly chosen duration of $0.6-1.5 \mathrm{~s}$ (steps of $0.1 \mathrm{~s}$ ). These hold durations were used during all further testing. The inter-trial interval was $10 \mathrm{~s}$. Subsequently, the rats were subjected to a reinforcement schedule in which $50 \%$ (at random) of the responses were reinforced. This was done to increase the response vigour of rats in this task (see Blokland, 1998). A session lasted $40 \mathrm{~min}$ or when a rat had completed 80 trials. The reinforcement was given independent of the reaction time. After the rats showed a stable performance (i.e., equivalent amount of premature responses per trial, stable performance on the measure reaction time) on 5 successive sessions treatment testing started.

The following parameters were used to evaluate the performance of the rats in this test: 1) premature responses (number of times the rats retracted their nose from the magazine before the tone was presented). Since the rats did not always completed the total of 60 trials per session the proportion of premature responses was calculated; 2) reaction time (time between onset of tone and retraction of nose from magazine); 3) motor time (time between retraction from magazine and lever press); and 4) percentage of correct responses. Since the data of the reaction time, motor time, and percentage of correct responses were not normally distributed all data were transformed logarithmically. All rats were tested in both treatment conditions on different days.

\section{Statistical analysis}

Data of the two separate testing groups were combined for the plasma and brain amino acid concentrations, the open field test, home cage emergence test, social interaction test and forced swim test. Because there were differences between the two groups on most of these behavioural tests [testing group effects, for example open field test $F(3,55)=7.31, \mathrm{p}<0.01$; home cage emergence test $\mathrm{F}(1,56)=4.57, \mathrm{p}<0.05]$, $\mathrm{z}$-scores of each group were calculated and used for statistical testing. This was done for all behavioural tests with data from two separate testing groups, i.e. open field test, home cage emergence test, social interaction test and forces swimming test. For all variables, treatment effects were analysed using parametric statistics (ANOVA). Data of the open field test, home cage emergence test and forced swim test were aggregated over the two trials to enhance reliability (Ossenkopp and Mazmanian, 1985). The mean scores over the two testing days were used in statistical analysis, as was done in comparable studies(Blokland et al., 2002, Lieben et al., 2004b). Data from the two trials of the social interaction test were treated as independent observations 
because the testing partner differed on the two trials. Plasma amino acid concentrations were analysed with repeated measures ANOVA to include the time factor. To further characterize the differences between groups, post-hoc Bonferroni t-test $(\mathrm{p}<0.05)$ was used. When there were no differences between the two groups of females, data of all females were pooled together. In order to test our specific hypotheses, we also analysed the effects of treatment on behaviour in each experimental group separately.

\section{Results}

\section{Biochemistry}

For each separate testing group of 12 males and 24 females, plasma amino acid concentrations and the ratio of TRP over the sum of the other large neutral amino acids (TRP/ $\Sigma$ LNAA ratio) were calculated in the beginning and at the end of the study, i.e. before and after the period of behavioural testing. There was no difference in plasma TRP/ $\Sigma$ LNAA ratio between the two blood sampling measurements (before and after the period of behavioural testing), or between the two separate testing groups of 36 rats. Therefore, data from all four blood sampling measurements (both testing groups and both measurements) were pooled together. Figure 1 shows the plasma TRP/ $/$ LNAA ratio and brain TRP concentrations.

Plasma TRP levels decreased over the four hours [Time: $F(1,132)=355.96$, $\mathrm{p}<0.001]$. There was a treatment effect $[\mathrm{F}(1,132)=337.86, \mathrm{p}<0.001]$ and a interaction effect [Time $\times$ Treatment: $F(1,132)=328.85, \mathrm{p}<0.001]$ indicating that TRP levels decreased much more in the TRP- condition compared to the TRP+ condition. There was an effect of experimental group $[\mathrm{F}(2,132)=112,95, \mathrm{p}<0.001]$. Post-hoc analysis showed that the males differed from both groups of females [both $\mathrm{p}<0.001$ ], with both groups of females showing higher TRP levels than the males.

The plasma TRP/ $\Sigma$ LNAA ratio also decreased over time $[\mathrm{F}(1,130)=355.92$, $\mathrm{p}<0.001]$. There also was an effect of treatment $[\mathrm{F}(1,130)=262,24, \mathrm{p}<0.001]$, and an interaction effect was found for Time $\times$ Treatment $[\mathrm{F}(1,130)=199,52, \mathrm{p}<0.001]$, indicating that the decrease of the plasma TRP/ $L$ LNAA ratio was much stronger in the TRP- condition compared to the TRP+ condition. There also was an effect of experimental group $[\mathrm{F}(2,130)=242,67, \mathrm{p}<0.001]$; post-hoc analysis showed that both groups of females had higher plasma TRP/ $\Sigma$ LNAA ratio levels than the males [both $\mathrm{p}<0.001$ ].

Brain TRP concentrations were lower after TRP- treatment than after TRP+ treatment in both the frontal cortex [Treatment: $\mathrm{F}(1,60)=18.01, \mathrm{p}<0.001$ ] and the hippocampus [Treatment: $\mathrm{F}(1,63)=6.641, \mathrm{p}<0.05$ ]. An effect of experimental group on TRP concentrations was only found in the frontal cortex $[\mathrm{F}(2,60)=5.00, \mathrm{p}<0.01]$; post-hoc analysis indicated that the females in pro-oestrus/oestrus had higher TRP 

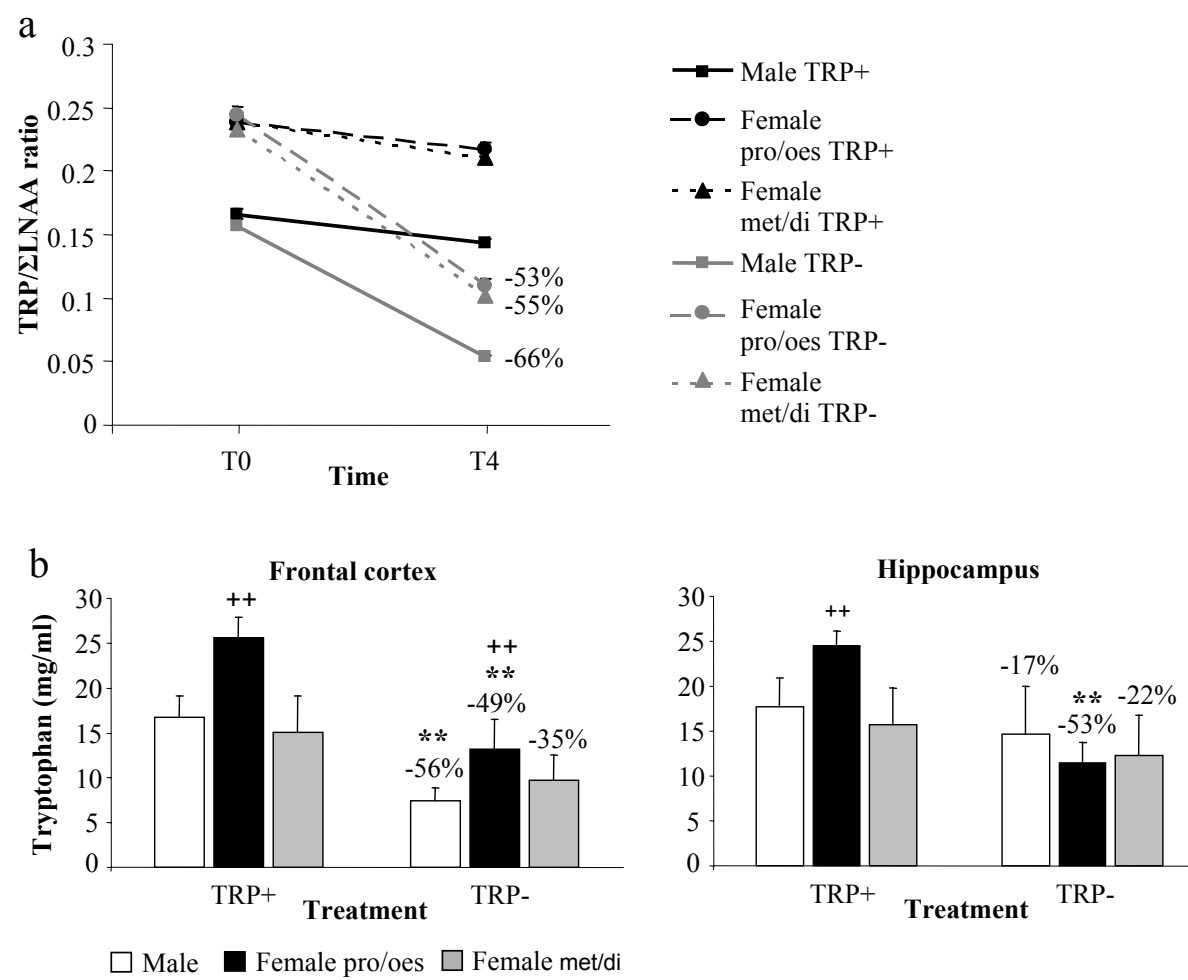

Figure 1. Effects of treatment with TRP+ or TRP- on biochemistry measures. 1a shows the plasma TRP/ $\Sigma$ LNAA ratio of all groups at baseline (T0) and four hours after the first administration of the mixture (T4). 1b shows the effects of the treatment on TRP concentrations in the frontal cortex and hippocampus at T4. Bars represent mean and standard error. Percentages indicate difference from baseline (1a) or from TRP+ condition (1b). ${ }^{\star \star}$ Treatment effect $\mathrm{p}<0.01{ }^{++}$ Experimental group effect $\mathrm{p}<0.01$.

concentrations in the frontal cortex than the males and the females in met-oestrus/di-oestrus [both $\mathrm{p}<0.05$ ]. When treatment effects were analysed within each experimental group separately, it was found that treatment effects in the frontal cortex TRP levels were significant in males $[\mathrm{F}(1,20)=10.98, \mathrm{p}<0.01]$ and females in pro/oes $[\mathrm{F}(1,24)=9.43, \mathrm{p}<0.01]$ but not in females in met/di. Hippocampal TRP levels were only significant decreased after TRP- treatment in females in pro/oes $[\mathrm{F}(1,26)=21.63, \mathrm{p}<0.001]$.

In general, there were no considerable effects on concentrations of other amino acids in the brain (data not shown). Remarkably, however, there was an effect of treatment, experimental group and a Treatment $\times$ Experimental group interaction on tyrosine (TYR) concentrations in both the frontal cortex [Treatment: $\mathrm{F}(1,50)=11.16$, $\mathrm{p}<0.01$; Experimental group: $\mathrm{F}(2,50)=62.65, \mathrm{p}<0.001$; Treatment $\times$ Experimental group: $\mathrm{F}(2,50)=14.31, \mathrm{p}<0.001]$ and the hippocampus [Treatment: $\mathrm{F}(1,57)=4.25, \mathrm{p}<0.05$; Exper- 
imental group: $\mathrm{F}(2,57)=25.67, \mathrm{p}<0.001$; Treatment $\times$ Experimental group: $\mathrm{F}(2,57)=5.93$, $\mathrm{p}<0.01]$. In both structures, post-hoc analysis showed that TYR concentrations in females in pro/oes were higher than in males and females in met/di [both $\mathrm{p}<0.001$ ]. When treatment effects were analysed within each experimental group, a treatment effect in the frontal cortex was found only in females in pro/oes $[\mathrm{F}(1,21)=1966, \mathrm{p}<0.001]$, whereas in the hippocampus a treatment effect was found in both groups of females, but not in males [females in pro/oes: $\mathrm{F}(1,26)=9.29, \mathrm{p}<0.01$; females in met/di: $\mathrm{F}(1,13)=13.07, \mathrm{p}<0.01$ ]. Interestingly, in females in pro/oes hippocampal TYR concentrations were lower in the TRP- condition than in the TRP+ condition, whereas in females in met/di they were higher in the TRP- compared to the TRP+ condition (Figure 2). It should be noted that no treatment effect on plasma TYR was found. Plasma TYR levels decreased over the four hours $[\mathrm{F}(1,132)=422.08, \mathrm{p}<0.001$, and there was an effect of experimental group on plasma TYR levels $[\mathrm{F}(2,132)=31.81, \mathrm{p}<0.001]$. Post-hoc testing showed that males had higher plasma TYR concentrations than both groups of females [both $\mathrm{p}<0.001$ ].
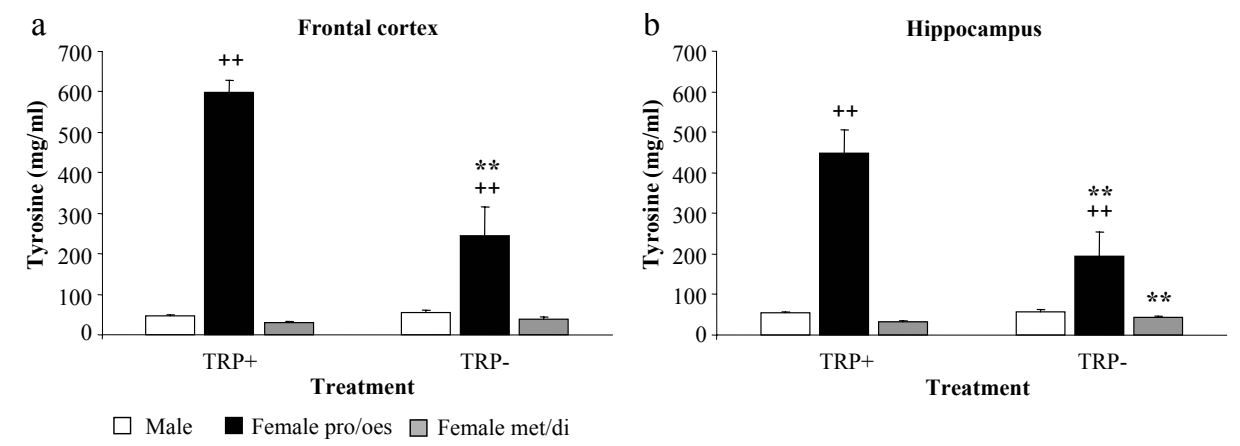

Figure 2. Effects of treatment with TRP+ or TRP- on brain tyrosine concentrations at T4 in the frontal cortex (2a) and hippocampus (2b). Bars represent mean and standard error. ${ }^{* *}$ Treatment effect $\mathrm{p}<0.01$; ${ }^{++}$Experimental group effect $\mathrm{p}<0.01$.

\section{Behavioural Tests}

Open field test Z-scores of the distance moved and time spent in corners data of the open field test are depicted in Figure 3. There was an effect of experimental group on the distance moved $[\mathrm{F}(2,55)=13.54, \mathrm{p}<0.001]$; post-hoc analysis revealed that the males had moved a shorter distance than both groups of females [both $\mathrm{p}<0.01$ ] indicating higher anxiety in males compared to females. There was no treatment effect or interaction effect on distance moved. All groups of rats (treatment and experimental groups) spent an equal amount of time in the center of the open field. On time spent in the corners of the open field, there was an effect of experimental group $[\mathrm{F}(2,53)=5.43, \mathrm{p}<0.01]$, post- 
hoc analysis showed that the males spent more time in the corners than both groups of females again indicating higher anxiety in males [males vs. females in pro/oes $\mathrm{p}<0.05$; males vs. females in met/di $\mathrm{p}<0.01]$. There also was Treatment $\times$ Experimental group interaction effect on time spent in the corners $[\mathrm{F}(2,53)=4.00, \mathrm{p}<0.05]$. There were no treatment effects.

When treatment effects were analysed within each experimental group, there was a treatment effect only in the females in pro-oestrus/oestrus. In the TRP- condition they showed a higher distance moved $[\mathrm{F}(1,22)=6.29, \mathrm{p}<0.05]$ and spent less time in the corners of the open field $[\mathrm{F}(1,22)=6.03, \mathrm{p}<0.05]$ compared to the female in pro/oes TRP+ controls, indicating lower anxiety in these females in the TRP-condition. As there were no differences between the two oestrous cycle groups of females, data of all females were pooled together. Compared to females, males showed a shorter distance moved [Sex: $\mathrm{F}(1,56)=27.29, \mathrm{p}<0.001]$, spent less time in the center $[\operatorname{Sex}: \mathrm{F}(1,56)=4.28, \mathrm{p}<0.05]$ and spent more time in the corners of the open field [Sex: $F(1,55)=10.79, p<0.01]$. After pooling the data of the female rats a Treatment $\times$ Sex interaction effect on the time spent in the corners $[\mathrm{F}(1,55)=6.21, \mathrm{p}<0.05]$; females in the TRP- condition spent less time in the corners than TRP+ females, while the opposite pattern, with more time spent in the corners in the TRP- condition, was observed in the males.

a

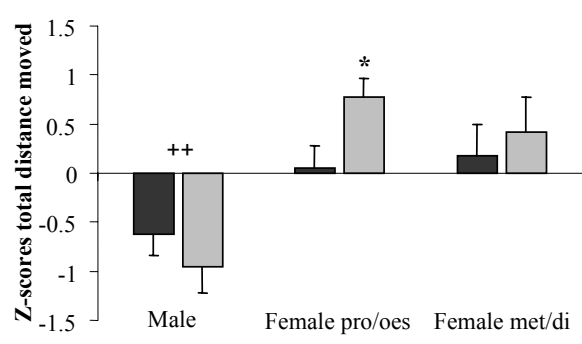

b

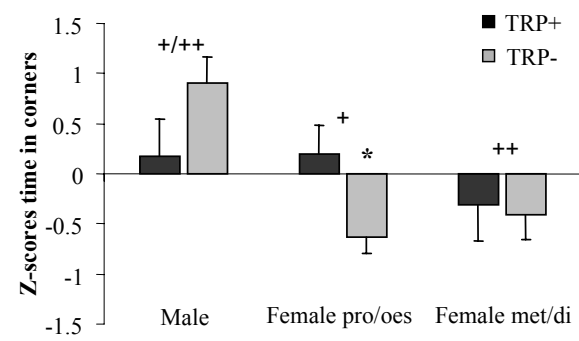

Figure 3. The open field test. Z-scores of the mean over two trials of total distance moved (3a) and the time spent in the corners of the open field (3b) are shown for each experimental group and treatment condition. Bars represent mean \pm standard error. Treatment effect ${ }^{\star} \mathrm{p}<0.05$; Experimental group effect ${ }^{+} \mathrm{p}<0.05 ;{ }^{++} \mathrm{p}<0.01$.

Home cage emergence test Z-scores of the escape latency data of the home cage emergence test are depicted in Figure 4 . There was no Treatment $\times$ Experimental group interaction effect on mean escape time and there were no main effects of treatment or experimental group. When treatment effects were analysed within each experimental group, a treatment effect on escape time was found only in the females in pro-oestrus/ oestrus $[\mathrm{F}(1,20)=5.73, \mathrm{p}<0.05]$; they emerged from the home cage faster in the TRPcondition than in the TRP+ condition indicating lower anxiety in the TRP-condition. As there were no differences between the two oestrous cycle groups of females, data 
of all females were pooled together. There was a Sex $\times$ Treatment interaction effect on mean escape time $[\mathrm{F}(1,54)=4.86, \mathrm{p}<0.05]$, indicating that females emerged from the home cage faster in the TRP- condition than in the TRP+ condition, while the opposite pattern was observed in males. There were no main effects of treatment or experimental group.

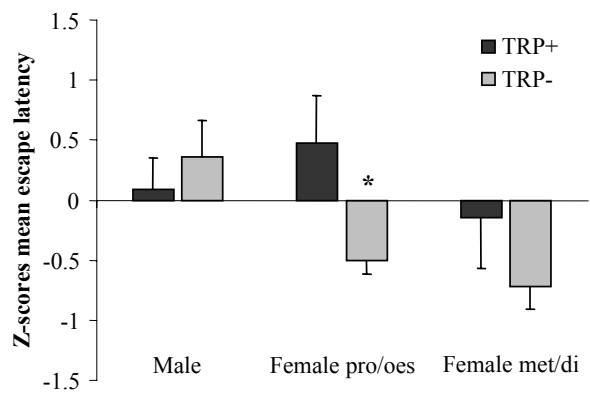

Figure 4. Home cage emergence test. Z-scores of the mean escape latency over two trials per experimental group and treatment condition. Bars represent mean \pm standard error. ${ }^{*}$ Treatment effect $\mathrm{p}<0.05$.

Social interaction test Z-scores of the duration of passive body contact and of percentage of active social interaction are shown in Figure 5. There were no effects of treatment, experimental group or interaction effects on total duration of social interaction and on the duration of active social interaction. After TRP- treatment, the duration of passive body contact was shorter than after TRP+ treatment [Treatment: $F(1,44)=6.00, \mathrm{p}<0.02$ ] and the percentage of active social interaction was higher [Treatment: $F(1,44)=4.72$, $\mathrm{p}<0.05]$. There also was an effect of experimental group on the duration of passive body contact $[\mathrm{F}(2,44)=8.52, \mathrm{p}<0.001]$ and the percentage of active social interaction
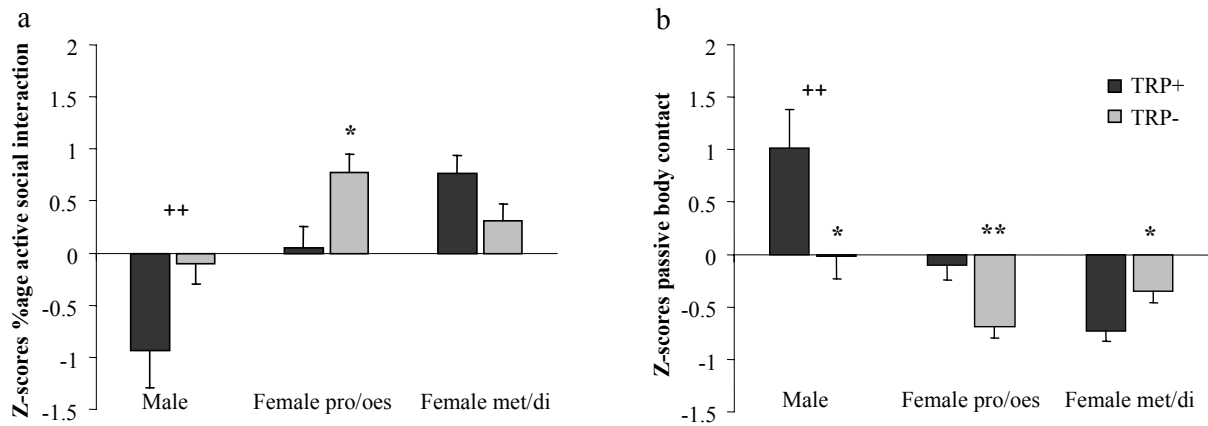

Figure 5. Social interaction test. Z-scores of percentage active social interaction of the total social interaction (5a) and the duration of passive body contact (5b) are shown for all experimental groups and treatment conditions. Bars represent mean \pm standard error. Treatment effect ${ }^{\star} \mathrm{p}<0.05 ;{ }^{\star *} \mathrm{p}<0.01$; Experimental group effect ${ }^{++} \mathrm{p}<0.01$. 
$[\mathrm{F}(2,44)=9.14, \mathrm{p}<0.001]$, post-hoc analysis indicated that the males showed more passive body contact and spent a smaller percentage of their total social interaction being involved in active social interaction than both groups of females [all $\mathrm{p}<0.01$ ] indicating higher activity in the females.

When treatment effects were analysed within each experimental group, treatment effects were found on the duration of passive body contact in all experimental groups [males: $\mathrm{F}(1,20)=5.16, \mathrm{p}<0.05$; females in pro/oes: $\mathrm{F}(1,13)=10.41, \mathrm{p}<0.01$; females in met/di: $F(1,9)=6.75, p<0.05]$. The direction of the effect, however, was not the same in all experimental groups. Males and females in pro/oes showed less passive body contact in the TRP- condition than in the TRP+ condition, whereas females in met/di showed more passive body contact in the TRP- condition than in the TRP+ condition. A treatment effect on the percentage of active social interaction was found only in females in pro/oes $[F(1,13)=7.78, p<0.05]$, these females showed a larger percentage of active social interaction in the TRP- condition.

Forced swim test Z-scores of the immobility data of the forced swim test are depicted in Figure 6 . There was no Treatment $\times$ Experimental group interaction effect on mean duration of immobility behaviour. There was no main effect of treatment, but the main effect of Experimental group on immobility was significant $[\mathrm{F}(2,60)=64.52, \mathrm{p}<0.001]$; post-hoc analysis showed that the males showed more immobility than both groups of females [both $\mathrm{p}<0.001]$. When treatment effects were analysed within each experimental group, no treatment effects were found. There were no differences between the two oestrous cycle groups of females. When data of all females were pooled together, there was no Sex $\times$ Treatment interaction effect and no treatment effect. Males showed more immobility than females [Sex: $\mathrm{F}(1,61)=130.10, \mathrm{p}<0.001]$. There was no main effect of Treatment.

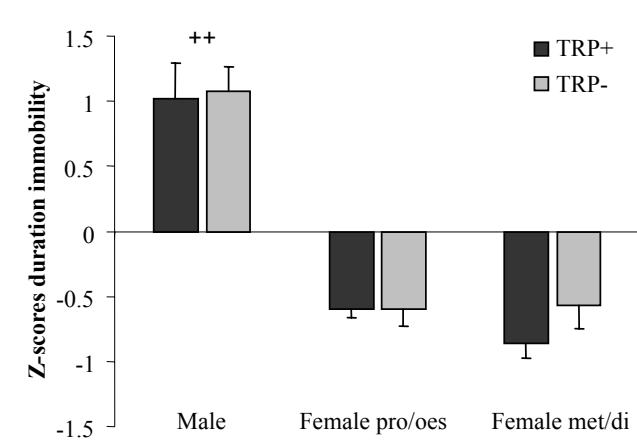

Figure 6. Forced swim test. Z-scores of the mean duration of immobility over two trials for each experimental group and treatment condition. Bars represent mean \pm standard error. Experimental group effect ${ }^{++} \mathrm{p}<0.01$ 
Object recognition test The effects of treatment and experimental group on the performance in the object recognition test are summarized in Table 3. Treatment did not affect the exploration time in trial 1 or trial 2. A clear treatment effect was found on the discrimination index $(d 2)[\mathrm{F}(1,66)=12.87, \mathrm{p}<0.01]$, rats treated with TRP- did not discriminate between the novel and the known object in trial 2 after a one hour interval. In contrast, the rats treated with TRP+ showed a high preference to investigate the novel object. When treatment effects were analysed within each experimental group, there was a treatment effect on $d 2$ only in the females in pro/oes. There were no differences between the two oestrous cycle groups of females. When data of all females were pooled together, females showed more exploration in trial 2 [Sex: $F(1,67)=5.16$, $\mathrm{p}<0.05]$. Scores $d 1$, and $d 2$ were higher in the TRP+ condition than in the TRP- condition $[\mathrm{F}(1,67)=11.55, \mathrm{p}<0.01$ and $\mathrm{F}(1,67)=13.04, \mathrm{p}<0.01$, respectively $]$.

Table 3. Effects of treatment and experimental group on the measures of the object recognition test.

\begin{tabular}{ccccc}
\hline \multirow{2}{*}{$\begin{array}{c}\text { Outcome } \\
\text { measure }\end{array}$} & $\begin{array}{c}\text { Treatment } \\
\text { condition }\end{array}$ & Male & $\begin{array}{c}\text { Females in } \\
\text { pro/oes }\end{array}$ & $\begin{array}{c}\text { Females in } \\
\text { met/di }\end{array}$ \\
\cline { 3 - 5 } & TRP+ & $260.5(39.9)$ & $241.2(23.8)$ & $240.2(8.6)$ \\
\multirow{2}{*}{$e 1$} & TRP- & $206.4(18.2)$ & $258.2(27.5)$ & $232.3(16.6)$ \\
& TRP+ & $310.4(32.4)^{+}$ & $395.1(30.5)^{+}$ & $339.6(28.4)$ \\
$e 2$ & TRP- & $294.6(21.6)^{+}$ & $373.1(35.0)^{+}$ & $320.7(16.9)$ \\
& TRP+ & $81.6(37.0)$ & $172.9(39.9)$ & $108.4(28.5)$ \\
\multirow{2}{*}{$d 1^{* *}$} & TRP- & $28.4(28.7)$ & $35.9(29.3)$ & $28.5(28.4)$ \\
& TRP+ & $0.31(0.10)$ & $0.41(0.09)$ & $0.34(0.09)$ \\
\multirow{2}{*}{$d 2^{* *}$} & TRP- & $0.10(0.09)$ & $0.10(0.08)$ & $0.10(0.09)$ \\
\hline
\end{tabular}

Values are mean \pm S.E. Males and females in pro/oes $n=12$, females in met $/$ di $n=11$. Treatment effect ${ }^{*} p<0.05$; ${ }^{* *} p<0.01$; Experimental group effect ${ }^{+} p<0.05$.

Reaction time task Data of the Skinnerbox reaction time task are shown in table 4. There was an effect of experimental group on reaction time $[\mathrm{F}(2,68)=10.39, \mathrm{p}<0.001]$ and on motor time $[\mathrm{F}(2,68)=6.87, \mathrm{p}<0.01]$, post-hoc analysis showed that males had faster reaction time than both groups of females and males had faster motor time than females in pro/oes [all $\mathrm{p}<0.01$ ]. There were no effects of Treatment $\times$ Experimental group or treatment. There were no differences between the groups on premature responses or the percentage of correct responses (All F values $<2.11$, ns). Analyzing treatment effects within each experimental group revealed no significant effects. There were no differences between the two oestrous cycle groups of females. When data of all females were pooled together, males were found to have shorter reaction time $[\mathrm{F}(1,69)=20.98, \mathrm{p}<0.001]$ and motor time $[\mathrm{F}(1,69)=12.78, \mathrm{p}<0.01]$. 
Table 4. Effects of treatment and experimental group on the measures of the Skinnerbox reaction time task.

\begin{tabular}{ccccc}
\hline \multirow{2}{*}{$\begin{array}{c}\text { Outcome } \\
\text { measure }\end{array}$} & $\begin{array}{c}\text { Treatment } \\
\text { condition }\end{array}$ & Male & $\begin{array}{c}\text { Females in } \\
\text { pro/oes }\end{array}$ & $\begin{array}{c}\text { Females in } \\
\text { met/di }\end{array}$ \\
\cline { 3 - 5 } & & $0.33(0.02)^{+}$ & $0.42(0.02)^{+}$ & $0.40(0.03)^{+}$ \\
\multirow{2}{*}{ Reaction Time } & TRP+ & $0.34(0.02)^{+}$ & $0.41(0.02)^{+}$ & $0.45(0.02)^{+}$ \\
& TRP- & $0.66(0.02)^{+}$ & $0.83(0.05)^{+}$ & $0.81(0.04)$ \\
Motor Time & TRP+ & $0.70(0.03)^{+}$ & $0.82(0.05)^{+}$ & $0.76(0.04)$ \\
& TRP- & $0.37(0.06)$ & $0.33(0.06)$ & $0.30(0.03)$ \\
Premature & TRP+ & $0.44(0.07)$ & $0.29(0.03)$ & $0.47(0.08)$ \\
responses & TRP- & $95.73(1.52)$ & $94.06(1.21)$ & $94.75(1.25)$ \\
Percentage & TRP+ & $97.50(1.21)$ & $94.27(1.08)$ & $96.25(0.85)$ \\
Correct & TRP- & $9.25)$ &
\end{tabular}

Values are mean \pm S.E. Males $n=12$; females in pro/oes TRP- $n=12$ and $T R P+n=16$; females in met $/$ di $n=10$. Experimental group effect ${ }^{+} p<0.05$.

\section{Discussion}

In the present study, the effects of acute TRP depletion using a gelatin-based proteincarbohydrate mixture were examined in adult male and female Wistar rats. The females were subdivided based on oestrous cycle phase in females in pro/oes and females in met/ di. The rats were tested in animal behavioural tests of anxiety- and depression- related behaviour and cognition to investigate whether the rats' sex and the female oestrous cycle influenced the behavioural response to ATD.

The biochemical data showed strong depletion of plasma TRP levels in the TRP- condition in both males and females, and TRP concentrations in frontal cortex and hippocampus were also lower after TRP- treatment than after TRP+ treatment. Although plasma TRP/ $\Sigma$ LNAA levels were decreased to a similar extent in all experimental groups, this was not the case for brain TRP levels. In the hippocampus, females in pro/oes showed higher overall TRP concentrations than males and females in met/di. The treatment effect in the frontal cortex was significant in males and females in pro/oes, in the hippocampus the treatment effect was only found in females in pro/oes. Thus, although TRP- treatment significantly lowered plasma TRP and TRP/ $\Sigma$ LNAA concentrations in all experimental groups, the difference in brain TRP concentrations between TRP- and TRP+ treated rats at T4 was not significant in all experimental groups. A significant difference in both brain structures was found only in females in pro/oes. In females in met/di this difference was not significant in either of these brain structures. The finding that a significant treatment effect in plasma does not necessarily result in a significant treatment effect in hippocampus and frontal cortex in the rat is important to note. It may imply that caution is needed 
in interpreting findings of studies that report only effects of ATD on plasma amino acid concentrations.

Females in pro/oes appeared to show the strongest behavioural response to ATD on both the open field test and the home cage emergence test. In both tests, females in pro/oes were the only experimental group in which a treatment effect was found. This is strikingly similar to the brain TRP concentrations, in which females in pro/oes were the only experimental group with treatment differences in TRP concentrations in both frontal cortex and hippocampus.

It should be noted, however, that this treatment effect that was found to be most pronounced in females in pro/oes, was not in the direction that had been hypothesized. ATD was hypothesized to increase anxiety, which was to result in less distance moved, less time spent in the center and more time spent in the corners of the open field and a longer escape latency on the home cage emergence test. This pattern of behavioural responses was seen in males only, but there it was not significant. In females in general and mainly the females in pro/oes where significant effects were found, the opposite pattern was reported, with more distance moved, more time spent in the center and less time spent in the corners of the open field and a shorter escape latency in the home cage emergence test. This is difficult to explain. One possible explanation is that ATD had a different effect on males and females, resulting in increased fear and anxiety in males and decreased fear and anxiety in females. However, another possible explanation for these unexpected findings may be that males and females reacted differently to fear and anxiety. Most behavioural tests that were used in the present study, including the open field test and the home cage emergence test, have been validated with adult males (van der Staay et al., 1990, Schoemaker and Smits, 1994, Prickaerts et al., 1996, Palanza, 2001). These tests have also been done with females and there are studies in literature to indicate that females become more active in case of fear or anxiety, while males do not (Johnston and File, 1991, Fernandes et al., 1999, Palanza, 2001). This complicates the interpretation of the behavioural data and consequently the effects of treatment in the females. In the present study, the females were in general more active in these specific anxiety tests than the males and the response to TRP- treatment was in an opposite direction in males vs. females.

Besides the higher level of activity of females in the open field test, females also showed less passive body contact in the social interaction test. Interpretation of the results of the social interaction in males and females is complicated by the possibility that the social investigation of same-sex partners serves different functions in males and females (Johnston and File, 1991). Furthermore, females showed less immobility in the forced swim test, again indicating higher activity in females. Other studies comparing males and females on the forced swim test show mixed results (Dalla et al., 2005, Lifschytz et al., 2006).

Not all sex effects reported in the present study, however, are necessarily genuine. For example, the sex effect that was found in the forced swim test may be at least partly 
explained by the size difference between the sexes. As the males were bigger, they were able to rest on their tail more easily and support themselves by spreading their paws across the walls of the cylindrical tanks. Therefore, it may have been easier for the males to show immobility behaviour than for the females. The size of the rats may have been a factor in other tests as well, because larger animals may tend to be less inclined to show active behaviours. However, in the present experiment animal size did not affect the distance moved within each sex in the open field test, the duration of immobility in the forced swim test, and the extent of TRP depletion after TRP- treatment (data not shown), but we cannot exclude that differences in body weight attributed to the reported sex differences. The effects of body size and sex could not be studied separately because all males had higher body weight than the females. Overall, the sex differences that were found give the impression that the females were more active in anxiety- related situations compared to the males, which appears to be in line with several other reports.

Females in pro/oes showed higher TYR concentrations in the frontal cortex and hippocampus compared to both other experimental groups. Furthermore, they had lower brain TYR concentrations in the TRP- condition compared to the TRP+ condition. Females in met/di, however, had significantly higher hippocampal TYR concentrations in the TRP-compared to the TRP+ condition. These TYR differences were not found in plasma concentrations. TYR is the precursor of the catecholamines dopamine, norepinephrine and epinephrine. It is known that variations in dopamine and norepinephrine systems occur during the oestrous cycle (Selmanoff et al., 1976). Because some catecholamine neurotransmitter systems may also be involved in depression and anxiety, changes in TYR may also influence anxiety- and depression- related behaviour. However, this pattern with females in pro/oes showing an opposite reaction compared to the females in met/di does not correspond to the results found in most of the behavioural tests, where females in pro/oes showed the strongest behavioural responses whereas females in met/di did no show any change in behaviour after treatment. Furthermore, there were no behavioural differences between females in pro/oes and females in met/di in the TRP+ condition, although these groups of females did show differences in brain TYR concentrations in this treatment condition. Therefore, it is not likely that the differences in brain TYR levels are responsible for the treatment effect we found after ATD.

One exception may be the social interaction test, in which the most striking finding was that males and females in pro/oes showed less passive body contact in TRPcondition, whereas females in met/di showed the more passive body contact in the TRPcondition compared to the TRP+ condition. This appears to correspond with the brain TYR levels, because the groups of females showed opposite behavioural responses.

There were no treatment effects on the forced swim test, indicating that ATD does not affect immobility in this test. Furthermore, no effects of treatment were found in the reaction time task. 5-HT is known to be involved in impulsive behaviour in general and there are reports of an involvement of $5-\mathrm{HT}_{2 \mathrm{~A} / \mathrm{C}}$ receptors in motor impulsivity (Blokland et al., 2005). However, in this task the number of premature responses was not affected 
by ATD. It can be concluded that involvement of 5-HT on motor impulsivity does not occur on the level of general availability of TRP and 5-HT.

In the object recognition test, an overall treatment effect was found. Further testing indicated that this treatment effect on the discrimination index $d 2$ was significant only in females in pro/oes, but it seems likely that with a larger number of rats the treatment effect would be significant in all groups. There was no Sex $\times$ Treatment interaction effect. These results correspond with findings in humans, where ATD has been reported to cause general memory effects in healthy subjects (Riedel et al., 1999, Schmitt et al., 2000, Riedel et al., 2002). In an recent mega-analysis, however, it was found that women are more sensitive to effects of ATD on memory (Sambeth et al., In press). This is a subtle effect that is only found with a very large number of observations. Therefore it is likely that a Sex $\times$ Treatment interaction effect, if it were present, could not be detected in this study due to the relatively small number of observations. Furthermore, the object recognition test may not be sensitive enough to detect subtle effects.

This study has several possible shortcomings and limitations. First, the effects of ATD on brain 5-HT concentrations were not measured in this study. In a previous study in our laboratory, using the same TRP- treatment in adult male Wistar rats, a comparable reduction in plasma TRP and plasma TRP/ $L$ LNAA ratio levels was observed. This peripheral TRP depletion was associated with a $40 \%$ reduction in TRP and 5-HT concentrations in the different brain structures (Lieben et al., 2004a). Since the decrease in plasma TRP levels in both studies was comparable, we assume that the decrease in central tissue levels of 5-HT is also comparable. For the females, however, no comparison data was available.

Secondly, the same group of rats were frequently subjected to the treatment, although the treatment condition varied between tests. The tests used in this study required multiple testing trials to obtain valid indices of anxiety and depression. Therefore it is important to note that there were no differences in the treatment effect on the plasma TRP/ $\Sigma$ LNAA ratio when comparing the data of the blood sampling at the beginning and at the end of the study. Apparently, the treatment effect after the second exposure to the treatment was the same as after the thirteenth exposure. We therefore assume that the treatment has had comparable biochemical effects throughout the entire study.

Thirdly, the repeated testing of the rats in the successive tests (Table 2) might have affected the performance from one test to the other. Because all rats were subjected to the same series of tests, we may assume that the effects of repeated testing were similar in all groups. Furthermore, there were always at least three days between tests during which the rats were left undisturbed and provided with food ad libitum. However, it cannot be excluded that this successive testing could have interfered with treatment effects. This can only be tested if naïve rats are used for each individual test.

Another shortcoming may be that the females may have been exposed to higher levels of stress throughout the study because of the vaginal smears that were taken on every testing day. Although there may not have been a direct effect of the stress during 
the vaginal smears on the test performance because the smears were taken at least four and a half hours before testing, the presumed higher levels of stress in females may nevertheless have influenced the results. Sex differences in exposure and response to stress may also affect SV. It is known that in humans, for example, women are more likely than men to develop depression following exposure to stress early in life (Weiss et al., 1999) or prenatally (Weinstock et al., 1992). In rats, there is evidence to indicate that males may adapt and respond better to stress than females (Kennett et al., 1986, Shors and Miesegaes, 2002). Furthermore, the female hypothalamic-pituitary-adrenal axis may be more reactive to stress, possibly due to sex hormones (Weiss et al., 1999). It has also been shown that after exposure to an elevated plus-maze, a rodent anxiety test, 5-HTergic activity was decreased in the dorsal raphe nuclei in female rats whereas 5-HTergic activity was decreased in the medial raphe nuclei in males (Dominguez et al., 2003).

In the present study, vaginal cytology was used to determine the oestrous cycle phase of the females and there were no blood samples taken to verify the oestrous cycle phase by measuring blood hormone levels. Vaginal smears are a reliable method of determining oestrous cycle phase, but inferring hormone levels from vaginal smears may not be as reliable. Taking blood samples to determine hormone levels was not an option in this study. Due to the practical limitations caused by the necessity of determining oestrous cycle phase before administration of the treatment was to start, vaginal smears were the best option. Practical reasons were also important in subdividing the females into the groups pro/oes and met/di. We made a rough discrimination based on the beginning of the cycle when oestradiol and progesterone levels are higher, and the end of the cycle when oestradiol and progesterone levels are lower (Butcher et al., 1974, Singletary et al., 2005). This may be considered a shortcoming because there are big hormonal changes from pro-oestrus to oestrus, especially in oestradiol levels, which are high in pro-oestrus and low in oestrus (Becker et al., 2005, Singletary et al., 2005). Testing had to be carried out over at least two days in order to obtain reliable results for most tests, therefore it was not possible to test rats in only one phase, for example in pro-oestrus. During the two days of testing, the oestrous cycle phase changed because the duration of the cycle in rats is only 4-5 days and pro-oestrus, for example, lasts only approximately $12 \mathrm{~h}$ (Becker et al., 2005, Singletary et al., 2005).

It should be noted that taking vaginal smears may affect behavioural parameters. It has been shown that repeated, but not acute, vaginal lavage decreases cocaine-stimulated behaviour, while behaviour without cocaine treatment was not affected by repeated vaginal lavage (Becker et al., 2005, Singletary et al., 2005). Furthermore, in the study by Becker et al. oestrous cycle phase influenced motor activity only in nonlavaged rats. In the present study, oestrous cycle did affect the behavioural response to ATD. During the period of behavioural tests, we took vaginal smears only in the morning before testing in the afternoon and not on non-testing days. Thus, vaginal smears were taken only twice in a week, which may not be considered as repeated vaginal manipulations. Although we used a different procedure of fixating the rats compared to Walker et al. and used vaginal 
smears and not lavage, we cannot exclude that our procedure of taking vaginal smears had an effect on behavioural parameters.

In conclusion, females in pro/oes showed stronger behavioural responses to ATD than males and females in met/di in fear/anxiety tests. Furthermore, these females showed a larger difference in TRP concentrations in the hippocampus between the TRP+ and TRP- condition, although treatment effects on plasma TRP/ $\Sigma$ LNAA concentrations were similar in both groups of females. An overall treatment effect was only found in the object recognition test. The disruption of object recognition after ATD did not appear to be limited to some vulnerable subgroup, but this may be due to the limited number of animals that were used and the limited sensitivity of the test. In the anxiety-related situations used in this study, females appear to be more active than males and this effect appeared to be enhanced by ATD on at least some behavioural tests. Sex and oestrous cycle phase affect several behavioural responses to ATD and in this respect the females in pro/oes may have higher SV than males and females in met/di. Interpretation of the results is complicated by the fact that the tests used here are mainly validated in male rats and may not be optimal to measure anxiety in female rats.

\section{References}

Agren, H., Mefford, I. N., Rudorfer, M. V., Linnoila, M. and Potter, W. Z., 1986. Interacting neurotransmitter systems. A non-experimental approach to the 5HIAA-HVA correlation in human CSF. J Psychiat Res. 20, 175-193.

Asberg, M., Bertilsson, L., Tuck, D., Cronholm, B. and Sjoqvist, F., 1973. Indoleamine metabolites in the cerebrospinal fluid of depressed patients before and during treatment with nortriptyline. Clin Pharmacol Ther. 14, 277-286.

Becker, J. B., Arnold, A. P., Berkley, K. J., Blaustein, J. D., Eckel, L. A., Hampson, E., Herman, J. P., Marts, S., Sadee, W., Steiner, M., Taylor, J. and Young, E., 2005. Strategies and methods for research on sex differences in brain and behavior. Endocrinology. 146, 1650-1673.

Bell, C., Abrams, J. and Nutt, D., 2001. Tryptophan depletion and its implications for psychiatry. Br J Psychiat. 178, 399-405.

Bethea, C. L., Gundlah, C. and Mirkes, S. J., 2000. Ovarian steroid action in the serotonin neural system of macaques. Novartis Found Symp. 230, 112-130; discussion 130-113.

Biggio, G., Fadda, F., Fanni, P., Tagliamonte, A. and Gessa, G. L., 1974. Rapid depletion of serum tryptophan, brain tryptophan, serotonin and 5 hydroxyindoletic acid by a tryptophan-free diet. Life Scie. 14, 13211329.

Blokland, A., 1998. Reaction time responding in rats. Neurosci Biobehav Rev. 22, 847-864.

Blokland, A., Lieben, C. and Deutz, N. E., 2002. Anxiogenic and depressive-like effects, but no cognitive deficits, after repeated moderate tryptophan depletion in the rat. J Psychopharmacol. 16, 39-49.

Blokland, A., Prickaerts, J. and Raaijmakers, W., 1992. Reduced level of anxiety in adult Lewis rats after chronic ethanol consumption. Physiol Behav. 51, 245-248.

Blokland, A., Şık, A. and Lieben, C., 2005. Evaluation of DOI, 8-OH-DPAT, eticlopride and amphetamine on impulsive responding in a reaction time task in rats. Behav Pharmacol. 16, 93-100.

Booij, L., Van der Does, W., Benkelfat, C., Bremner, J. D., Cowen, P. J., Fava, M., Gillin, C., Leyton, M., Moore, P., Smith, K. A. and Van der Kloot, W. A., 2002. Predictors of mood response to acute tryptophan depletion. A reanalysis. Neuropsychopharmacology. 27, 852-861. 
Brown, C. M., Fletcher, P. J. and Coscina, D. V., 1998. Acute amino acid loads that deplete brain serotonin fail to alter behavior. Pharmacol Biochem Behav. 59, 115-121.

Butcher, R. L., Collins, W. E. and Fugo, N. W., 1974. Plasma concentration of LH, FSH, prolactin, progesterone and estradiol-17beta throughout the 4-day estrous cycle of the rat. Endocrinology. 94, 1704-1708.

Carlsson, M. and Carlsson, A., 1988. A regional study of sex differences in rat brain serotonin. Prog Neuropsychopharmacol Biol Psychiat. 12, 53-61.

Contreras, C. M., Molina, M., Saavedra, M. and Martinez-Mota, L., 2000. Lateral septal neuronal firing rate increases during proestrus-estrus in the rat. Physiol Behav. 68, 279-284.

Dalla, C., Antoniou, K., Drossopoulou, G., Xagoraris, M., Kokras, N., Sfikakis, A. and Papadopoulou-Daifoti, Z., 2005. Chronic mild stress impact: are females more vulnerable? Neuroscience. 135, 703-714.

Dominguez, R., Cruz-Morales, S. E., Carvalho, M. C., Xavier, M. and Brandao, M. L., 2003. Sex differences in serotonergic activity in dorsal and median raphe nucleus. Physiol Behav. 80, 203-210.

Ellenbogen, M. A., Young, S. N., Dean, P., Palmour, R. M. and Benkelfat, C., 1996. Mood response to acute tryptophan depletion in healthy volunteers: sex differences and temporal stability. Neuropsychopharmacology. 15, 465-474.

Ennaceur, A. and Delacour, J., 1988. A new one-trial test for neurobiological studies of memory in rats. 1: Behavioral data. Behav Brain Res. 31, 47-59.

Fernandes, C., Gonzalez, M. I., Wilson, C. A. and File, S. E., 1999. Factor analysis shows that female rat behaviour is characterized primarily by activity, male rats are driven by sex and anxiety. Pharmacol Biochem Behav. 64, 731-738.

Fernstrom, J. D. and Wurtman, R. J., 1997. Brain serotonin content: physiological regulation by plasma neutral amino acids. Obes Res. 5, 377-380.

File, S. E. and Hyde, J. R., 1978. Can social interaction be used to measure anxiety? Br J Pharmacol. 62, 19-24.

File, S. E. and Seth, P., 2003. A review of 25 years of the social interaction test. Eur J Pharmacol. 463, 35-53.

Fink, G., Sumner, B. E., McQueen, J. K., Wilson, H. and Rosie, R., 1998. Sex steroid control of mood, mental state and memory. Clin Exp Pharmacol Physiol. 25, 764-775.

Fluttert, M., Dalm, S. and Oitzl, M. S., 2000. A refined method for sequential blood sampling by tail incision in rats. Lab Anim. 34, 372-378.

Gessa, G. L., Biggio, G., Fadda, F., Corsini, G. U. and Tagliamonte, A., 1974. Effect of the oral administration of tryptophan-free amino acid mixtures on serum tryptophan, brain tryptophan and serotonin metabolism. J Neurochem. 22, 869-870.

Gundlah, C., Simon, L. D. and Auerbach, S. B., 1998. Differences in hypothalamic serotonin between estrous phases and gender: an in vivo microdialysis study. Brain Res. 785, 91-96.

Haleem, D. J., Kennett, G. A. and Curzon, G., 1990. Hippocampal 5-hydroxytryptamine synthesis is greater in female rats than in males and more decreased by the 5-HT1A agonist 8-OH-DPAT. J Neural Transm Gen Sect. 79, 93-101.

Heninger, G. R., 1995. Indoleamines: The Role of Serotonin in Clinical Disorders. In: Bloom, F. E. and Kupfer, D. J. (Eds.), Psychopharmacology: The Fourth Generation of Progress. Raven Press, Ltd., New York, pp. 471-482.

Jacobs, B. L. and Fornal, C. A., 1995. Serotonin and Behavior. In: Bloom, F. E. and Kupfer, D. J. (Eds.), Psychopharmacology: The Fourth Generation of Progress. Raven Press, Ltd., New York, pp. 461-469.

Jans, L. A., Riedel, W. J., Markus, C. R. and Blokland, A., 2006. Serotonergic vulnerability and depression: assumptions, experimental evidence and implications. Mol Psychiat.

Joffe, H. and Cohen, L. S., 1998. Estrogen, serotonin, and mood disturbance: where is the therapeutic bridge? Biol Psychiat. 44, 798-811.

Johnston, A. L. and File, S. E., 1991. Sex differences in animal tests of anxiety. Physiol Behav. 49, 245-250.

Kennett, G. A., Chaouloff, F., Marcou, M. and Curzon, G., 1986. Female rats are more vulnerable than males in an animal model of depression: the possible role of serotonin. Brain Res. 382, 416-421.

Lieben, C. K., Blokland, A., Westerink, B. and Deutz, N. E., 2004a. Acute tryptophan and serotonin depletion using an optimized tryptophan-free protein-carbohydrate mixture in the adult rat. Neurochem Int. 44, $9-16$. 
Lieben, C. K., van Oorsouw, K., Deutz, N. E. and Blokland, A., 2004b. Acute tryptophan depletion induced by a gelatin-based mixture impairs object memory but not affective behavior and spatial learning in the rat. Behav Brain Res. 151, 53-64.

Lifschytz, T., Shalom, G., Lerer, B. and Newman, M. E., 2006. Sex-dependent effects of fluoxetine and triiodothyronine in the forced swim test in rats. Eur Neuropsychopharmacol. 16, 115-121.

Mann, J. J., Huang, Y. Y., Underwood, M. D., Kassir, S. A., Oppenheim, S., Kelly, T. M., Dwork, A. J. and Arango, V., 2000. A serotonin transporter gene promoter polymorphism (5-HTTLPR) and prefrontal cortical binding in major depression and suicide. Arch Gen Psychiat. 57, 729-738.

Maswood, S., Truitt, W., Hotema, M., Caldarola-Pastuszka, M. and Uphouse, L., 1999. Estrous cycle modulation of extracellular serotonin in mediobasal hypothalamus: role of the serotonin transporter and terminal autoreceptors. Brain Res. 831, 146-154.

McEwen, B. S. and Alves, S. E., 1999. Estrogen actions in the central nervous system. Endocr Rev. 20, 279307.

Moja, E. A., Cipolla, P., Castoldi, D. and Tofanetti, O., 1989. Dose-response decrease in plasma tryptophan and in brain tryptophan and serotonin after tryptophan-free amino acid mixtures in rats. Life Sci. 44, 971-976.

Moore, P., Landolt, H. P., Seifritz, E., Clark, C., Bhatti, T., Kelsoe, J., Rapaport, M. and Gillin, J. C., 2000. Clinical and physiological consequences of rapid tryptophan depletion. Neuropsychopharmacology. 23, 601-622.

Nishizawa, S., Benkelfat, C., Young, S. N., Leyton, M., Mzengeza, S., de Montigny, C., Blier, P. and Diksic, M., 1997. Differences between males and females in rates of serotonin synthesis in human brain. Proc Natl Acad Sci U S A. 94, 5308-5313.

Ossenkopp, K. P. and Mazmanian, D. S., 1985. The measurement and integration of behavioral variables: aggregation and complexity as important issues. Neurobehav Toxicol Teratol. 7, 95-100.

Osterlund, M. K. and Hurd, Y. L., 2001. Estrogen receptors in the human forebrain and the relation to neuropsychiatric disorders. Prog Neurobiol. 64, 251-267.

Palanza, P., 2001. Animal models of anxiety and depression: how are females different? Neurosci Biobehav Rev. 25, 219-233.

Piccinelli, M. and Wilkinson, G., 2000. Gender differences in depression. Critical review. Br J Psychiat. 177, 486-492.

Prickaerts, J., Raaijmakers, W. and Blokland, A., 1996. Effects of myocardial infarction and captopril therapy on anxiety-related behaviors in the rat. Physiol Behav. 60, 43-50.

Prickaerts, J., van Staveren, W. C., Şık, A., Markerink-van Ittersum, M., Niewohner, U., van der Staay, F. J., Blokland, A. and de Vente, J., 2002. Effects of two selective phosphodiesterase type 5 inhibitors, sildenafil and vardenafil, on object recognition memory and hippocampal cyclic GMP levels in the rat. Neuroscience. 113, 351-361.

Riedel, W. J., Klaassen, T., Deutz, N. E., van Someren, A. and van Praag, H. M., 1999. Tryptophan depletion in normal volunteers produces selective impairment in memory consolidation. Psychopharmacology (Berl). 141, 362-369.

Riedel, W. J., Klaassen, T. and Schmitt, J. A., 2002. Tryptophan, mood, and cognitive function. Brain Behav Immun. 16, 581-589.

Rosencrans, J. A., 1970. Differences in brain area 5-hydroxytryptamine turnover and rearing behavior in rats and mice of both sexes. Eur J of Pharmacol. 9, 379-382.

Sambeth, A., Blokland, A., Harmer, C. J., Kilkens, T. O. C., Nathan, P. J., Porter, R. J., Schmitt, J. A. J., Scholtissen, B., Sobczak, S., Young, A. H. and Riedel, W. J., In press. Sex differences in the effect of acute tryptophan depletion on declarative episodic memory: a pooled analysis of nine studies. Neurosci Biobehav Rev.

Schmitt, J. A., Jorissen, B. L., Sobczak, S., van Boxtel, M. P., Hogervorst, E., Deutz, N. E. and Riedel, W. J., 2000. Tryptophan depletion impairs memory consolidation but improves focussed attention in healthy young volunteers. J Psychopharmacol. 14, 21-29.

Schoemaker, R. G. and Smits, J. F., 1994. Behavioral changes following chronic myocardial infarction in rats. Physiol Behav. 56, 585-589. 
Selmanoff, M. K., Pramik-Holdaway, M. J. and Weiner, R. I., 1976. Concentrations of dopamine and norepinephrine in discrete hypothalamic nuclei during the rat estrous cycle. Endocrinology. 99, 326-329.

Shors, T. J. and Miesegaes, G., 2002. Testosterone in utero and at birth dictates how stressful experience will affect learning in adulthood. Proc Natl Acad Sci U S A. 99, 13955-13960.

Singletary, S. J., Kirsch, A. J., Watson, J., Karim, B. O., Huso, D. L., Hurn, P. D. and Murphy, S. J., 2005. Lack of correlation of vaginal impedance measurements with hormone levels in the rat. Contemp Top Lab Anim Sci. 44, 37-42.

Smith, K. A., Fairburn, C. G. and Cowen, P. J., 1997. Relapse of depression after rapid depletion of tryptophan. Lancet. 349, 915-919.

Stancampiano, R., Melis, F., Sarais, L., Cocco, S., Cugusi, C. and Fadda, F., 1997. Acute administration of a tryptophan-free amino acid mixture decreases 5-HT release in rat hippocampus in vivo. Am J Physiol. 272, R991-994.

Sumner, B. E. and Fink, G., 1998. Testosterone as well as estrogen increases serotonin2A receptor mRNA and binding site densities in the male rat brain. Brain Res Mol Brain Res. 59, 205-214.

van der Staay, F. J. and Blokland, A., 1996. Behavioral differences between outbred Wistar, inbred Fischer 344, brown Norway, and hybrid Fischer 344 x brown Norway rats. Physiol Behav. 60, 97-109.

van der Staay, F. J., Kerbusch, S. and Raaijmakers, W., 1990. Genetic correlations in validating emotionality. Behav Genet. 20, 51-62.

van Eijk, H. M., Rooyakkers, D. R. and Deutz, N. E., 1993. Rapid routine determination of amino acids in plasma by high-performance liquid chromatography with a 2-3 microns Spherisorb ODS II column. J Chromatogr. 620, 143-148.

Watts, A. G. and Stanley, H. F., 1984. Indoleamines in the hypothalamus and area of the midbrain raphe nuclei of male and female rats throughout postnatal development. Neuroendocrinology. 38, 461-466.

Weigel, N. L., 1996. Steroid hormone receptors and their regulation by phosphorylation. Biochem J. 319 ( Pt 3), 657-667.

Weinstock, M., Matlina, E., Maor, G. I., Rosen, H. and McEwen, B. S., 1992. Prenatal stress selectively alters the reactivity of the hypothalamic-pituitary adrenal system in the female rat. Brain Res. 595, 195-200.

Weiss, E. L., Longhurst, J. G. and Mazure, C. M., 1999. Childhood sexual abuse as a risk factor for depression in women: psychosocial and neurobiological correlates. Am J Psychiat. 156, 816-828.

Weissman, M. M., Bland, R. C., Canino, G. J., Faravelli, C., Greenwald, S., Hwu, H. G., Joyce, P. R., Karam, E. G., Lee, C. K., Lellouch, J., Lepine, J. P., Newman, S. C., Rubio-Stipec, M., Wells, J. E., Wickramaratne, P. J., Wittchen, H. and Yeh, E. K., 1996. Cross-national epidemiology of major depression and bipolar disorder. JAMA. 276, 293-299.

Young, S. N., 1996. Behavioral Effects of Dietary Neurotransmitter Precursors: Basic and Clinical Aspects. Neurosci Biobehav Rev. 20, 313-323.

Young, S. N., Gauthier, S., Anderson, G. M. and Purdy, W. C., 1980. Tryptophan, 5-hydroxyindolacetic acid and indoleacetic acid in human cerebrospinal fluid: interrelationship and the influence of age, sex, epilepsy and anticonvulsant drugs. J Neurol Neurosurg Psychiat. 43, 438-445. 
The effects of acute tryptophan depletion on affective behaviour and cognition in Brown Norway and Sprague Dawley rats

L. A. W. Jans, G. A. H. Korte-Bouws, S. M. Korte, A. Blokland Submitted for publication 


\begin{abstract}
Several lines of research suggest that the development of depression-related symptoms may be related to a selective vulnerability of the serotonergic system. Serotonergic vulnerability (SV) suggests that differences between people in the regulation of serotonin (5-hydroxytryptamine, 5-HT) determine the vulnerability of an individual to develop depression or other 5HT related disorders. Here, a stronger behavioural response to acute tryptophan depletion (ATD) was assumed to reflect SV. The aim of the present experiment was to evaluate whether there are strain differences in SV. For this study Sprague Dawley (SD) and Brown Norway (BN) rats were chosen based on phenotypical characteristics, including normal activity in behavioural tests used in this study. Twenty-four SD and $24 \mathrm{BN}$ rats were repeatedly subjected to treatment with a gelatin-based protein-carbohydrate mixture, either with L-tryptophan (TRP+; control condition) or without L-tryptophan (TRP-; experimental condition). SD rats appeared to have higher serotonergic vulnerability than $\mathrm{BN}$ rats, as they showed an increase in anxiety- and depression- related behaviour and impaired object recognition after ATD. We found a striking dissociation between plasma TRP levels, central 5-HT concentrations and 5-HIAA/5-HT turnover. Plasma TRP/ $\Sigma$ LNAA depletion was similar in both strains, but hippocampal 5HT levels were decreased in $\mathrm{BN}$ rats but not in SD rats. Conversely, 5HIAA/5-HT turnover, reflecting 5-HT neurotransmission, was decreased in SD but not in $\mathrm{BN}$ rats. It is concluded that ATD revealed a difference in serotonergic vulnerability between $\mathrm{SD}$ and $\mathrm{BN}$ rats, and that this $\mathrm{SV}$ might be mediated by decreased 5-HIAA/5-HT turnover after ATD.
\end{abstract}




\section{Introduction}

The neurotransmitter serotonin (5-Hydroxytryptamine, 5-HT) is known to be involved in many physiological and behavioural processes, including mood, appetite, sleep, activity, sexual behaviour, and cognition. Although the mechanisms underlying depression are not yet fully understood, there is general consensus that 5-HT is involved in depression. The original hypothesis that low serotonin has a direct role in depression has been through several modifications and low 5-HTergic neurotransmission is now thought to operate as a biological risk factor, that may play an important role in the triggering and maintenance of mood disorders (Maes and Meltzer, 1995). Recently, serotonergic functioning has been proposed as a vulnerability factor in the development of depression and other 5-HT related symptoms and disorders (Jans et al., 2007b). According to this view, the serotonergic functioning of an individual determines the vulnerability of that individual to develop 5-HT related disorders. This implies that there are differences in the 5HT functioning between individuals and that the development of depression, anxiety, or other 5-HT related disorders is associated with the presence of a priori abnormalities in the functioning of this system. There are various factors that may interfere with 5-HTergic functioning, such as genetic factors, a family history of depression, the female gender, stress, and drug use. Each of these factor may disrupt the 5-HT system, resulting in serotonergic vulnerability, but psychopathology symptoms do not occur until a threshold is reached where the system can no longer compensate (Jans et al., 2007b). Vulnerability of the serotonergic system (serotonergic vulnerability, SV) means that there is a vulnerability or sensitivity to alterations or dysregulations in the serotonergic system, hence SV can be demonstrated by challenging the 5-HT system; vulnerable and non-vulnerable subjects will react differently to these manipulations (Jans et al., 2007b).

Family studies show a familial aggregation of depression (Sullivan et al., 1996, Kendler et al., 1997, Sullivan et al., 2000). The presence of one depressed first-degree relative increases the relative risk for major depression by twofold (Sullivan et al., 2000). It is interesting that in many cases subjects with a family history of depression also report other disorders in their family members, including affective psychosis, obsessivecompulsive phenomena, panic attacks, eating disorders, and alcoholism/substance abuse (Cadoret et al., 1996, Stallings et al., 1997, Michalak et al., 2002). There might be a general vulnerability factor involved in these disorders. Because the serotonergic system is involved in all these disorders (Heninger, 1995), serotonergic functioning might be a good candidate. The inheritability of liability to depression in most twin studies ranges from 31 to $42 \%$ (Sullivan et al., 2000). It has been shown that genetics can affect serotonergic activity, since CSF 5-HIAA levels are heritable in nonhuman primates (Higley et al., 1993, Clarke et al., 1995). Thus, alterations in the serotonergic system that are associated with psychiatric disorders may be inheritable and could represent heritable vulnerability factors for developing psychopathology. 
Based on these findings it is likely that different rat strains differ in vulnerability to develop psychopathology and in serotonergic parameters, and hence in SV. SV can be demonstrated by challenging the 5-HT system; vulnerable and non-vulnerable subjects will react differently to these manipulations. A stronger behavioural response to acute tryptophan depletion (ATD) is assumed to reflect SV. ATD is a way to challenge the 5HT system in which tryptophan (TRP) -the essential amino acid that is the precursor of 5-HT- is depleted, resulting in reduced systemic TRP levels and consequently lower central 5-HT concentrations (Biggio et al., 1974, Gessa et al., 1974, Moja et al., 1989, Fernstrom and Wurtman, 1997). ATD is a non-intrusive and reversible method that can be applied to investigate the role of 5-HT in behavioural functions (e.g., mood, anxiety, sleep, aggression, memory, impulsivity) in humans as well as in animals (Young, 1996, Moore et al., 2000, Bell et al., 2001). The TRP lacking amino acid mixture has been shown to reduce plasma TRP and tissue 5-HT levels in overall brain tissue and more selective brain structures (e.g., hippocampus) in the rat (Biggio et al., 1974, Gessa et al., 1974, Moja et al., 1989, Brown et al., 1998).

Previous studies in our lab using a gelatin-based protein-carbohydrate mixture showed a robust reduction in plasma TRP (about 70\%) and central tissue 5-HT (about 40-45\%) concentrations in adult male Wistar rats (Lieben et al., 2004a). This ATD procedure resulted in impaired object recognition memory, but did not influence affective behaviour (Lieben et al., 2004b). In healthy human volunteers ATD generally results in memory impairments, whereas other effects of ATD, such as mood effects, are only found in vulnerable subjects (Riedel et al., 1999, Schmitt et al., 2000, Riedel et al., 2002, Booij and Van der Does, 2007).

In this study we examined the effects of this TRP-free gelatin-based protein-carbohydrate mixture on affective behaviour and cognition in different rat strains. Since we would like to test whether one genotype is more sensitive to ATD treatment, rat strains should be selected that do not differ with respect to behaviour but only differ with respect to a serotonergic sensitivity. On basis of these ideal conditions we selected adult male Sprague Dawley (SD) and Brown Norway (BN) rats. Both BN and SD showed reduced immobility in the forced swim test in response to acute treatment with the tricyclic antidepressant (TCA) desipramine and the $5-\mathrm{HT}_{1 \mathrm{~A}}$ receptor agonist 8-OH-DPAT (Lahmame and Armario, 1996), suggesting a responsive 5-HT system. Furthermore, both BN and SD rats show normal activity in the open field test (van der Staay and Blokland, 1996), although BN rats are more active in a novel environment than SD rats (Lahmame and Armario, 1996, Ferguson and Holson, 1997). In addition, both strains show normal activity in the forced swim test (Lahmame et al., 1997), although BNs show higher levels of immobility (Armario et al., 1995, Lahmame and Armario, 1996, Lahmame et al., 1997). SD rats are known to more sensitive then Wistars to treatment with paracloroamphetamine (PCA) (Zhou et al., 1996), suggesting higher SV in SDs compared to Wistars. BNs show a certain degree of resistance in terms of the suppressive effect of dexamethasone on the HPA axis (Gomez et al., 1998), suggesting a lower responsiveness of the serotonergic 
system. Thus, BNs and SDs appear to be comparable in their behavioural performance on several tests, although there are some indications of higher SV in SDs than in BNs.

All animals were repeatedly treated with the protein-carbohydrate mixture either with (TRP+) or without (TRP-) L-tryptophan, and tested in animal tests of anxiety-related behaviour (open field test, home cage emergence test, social interaction test), depression-related behaviour (forced swim test) and cognition (object recognition test). The magnitude of TRP depletion was determined by measuring plasma amino acid concentrations and brain 5-HT and 5-HIAA concentrations.

\section{Materials and methods}

\section{Animals}

All experimental procedures were approved by the ethical committee of the Maastricht University for animal experiments and met governmental guidelines. Subjects were twenty-four 3-month-old male SD rats weighing between 421 and 515g at arrival and 24 male BN rats of the same age, weighing between 202 and $235 \mathrm{~g}$ at their arrival (Charles River, Germany). The rats were housed two of the same strain per cage in standard Macrolon cages on sawdust bedding in an air-conditioned room $\left( \pm 21^{\circ} \mathrm{C}\right)$. Only during training and testing in the object recognition test, the rats were housed individually. The animals had access to food and water ad libitum. They were kept under a reversed 12/12-h light/dark cycle. The lights were on from 17.00-5.00 h. A radio, which was playing softly, provided background noise.

\section{Drugs and chemicals}

The Gelatin hydrolysate (Solugel P') was obtained from PB Gelatins (Tessenderlo, Belgium). Glucodry 210 was obtained from the Amylumgroup (Koog aan de Zaan, The Netherlands). Kaliumchloride $(\mathrm{KCl})$ and calciumchloride-dihydrate $\left(\mathrm{CaCl}_{2} \cdot 2 \mathrm{H}_{2} \mathrm{O}\right)$ were purchased from Merck (Darmstadt, Germany). Tryptophan was obtained from Sigma (Zwijndrecht, The Netherlands).

\section{Treatment}

During a period of two weeks preceding the experiment, the rats were handled and habituated to oral injections with normal tap water (up to $10 \mathrm{ml} / \mathrm{kg}$ ). On testing days the rats were treated with a protein-carbohydrate mixture containing TRP (TRP+ group, $0.30 \%$ TRP of the total protein) or lacking TRP (TRP- group). The rats received two doses of $10 \mathrm{ml} / \mathrm{kg}$ with a 90 -minute interval. Each administration contained $4.0 \mathrm{~g}$ Solugel $\mathrm{P} / \mathrm{kg}$ and $2.0 \mathrm{~g}$ Glucodry $210 / \mathrm{kg}$ body weight. The composition of the nutritional mixture is shown in Table 1. 
Table 1: Composition of the treatment mixture.

\begin{tabular}{|c|c|c|}
\hline Protein $\left(\right.$ Solugel $\left.{ }^{\odot}\right)$ in $100 \mathrm{ml}$ water & & $100 \mathrm{~g}$ \\
\hline Alanine & 8.4 & \\
\hline Arginine & 7.7 & \\
\hline Aspartic Acid/Asparagine & 4.5 & \\
\hline Glutamic Acid/Glutamine & 10.0 & \\
\hline Glycine & 23.3 & \\
\hline Histidine & 0.9 & \\
\hline Hydroxylysine & 1.5 & \\
\hline Hydroxyproline & 12.3 & \\
\hline Isoleucine & 1.2 & \\
\hline Leucine & 2.6 & \\
\hline Lysine & 3.3 & \\
\hline Methionine & 0.9 & \\
\hline Phenylalanine & 1.6 & \\
\hline Proline & 13.7 & \\
\hline Serine & 3.4 & \\
\hline Threonine & 1.9 & \\
\hline Tryptophan & 0.0 & \\
\hline Tyrosine & 0.6 & \\
\hline Valine & 2.2 & \\
\hline Carbohydrate (Glucodry 210) in $80 \mathrm{ml}$ water & & 50 \\
\hline KCL & & 0.094 \\
\hline $\mathrm{CaCl}_{2} \cdot 2 \mathrm{H}_{2} \mathrm{O}$ & & 2.32 \\
\hline L-tryptophan (TRP- group) & & 0 \\
\hline L-tryptophan (TRP+ group) & & 0.28 \\
\hline
\end{tabular}

Table 2: Order of the different behavioural experiments and the number of days treatment was given for each of the separate testing groups.

\begin{tabular}{ccc}
\hline Week & Test & Treatment \\
\hline 1,2 & Handling & 1 \\
3 & Blood sampling & 1 \\
4 & Open field test & $3^{*}$ \\
5 & Home cage emergence test & $3^{*}$ \\
6 & Social interaction test & $2^{*}$ \\
7 & Forced swim test & $3^{*}$ \\
$8,9,10$ & Object recognition test & $2^{*}$ \\
11 & Blood and brain sampling & 1 \\
\hline
\end{tabular}

${ }^{*}$ Rats were treated with either TRP+ or TRP-. \# Rats were treated with TRP+ and TRP- on different testing days

The rats were fasted from $15 \mathrm{~h}$ prior to treatment until the testing period was completed. This was done to minimize the availability of TRP from food. Behavioural testing was conducted $4 \mathrm{~h}$ after the first oral administration. Treatment always began at $9.00 \mathrm{~h}$ and behavioural testing at $13.00 \mathrm{~h}$. At the end of each testing day, the animals had access to food for at least 3 hours. The rats were randomly assigned to treatment with TRP+ or 
TRP- for each test separately, except for the object recognition test, where all rats were treated with both TRP+ and TRP- on different days. An overview of the order of testing and the number of times the rats were treated with the mixture is given in Table 2.

\section{Biochemistry}

For the determination of plasma amino acid levels blood samples were taken at resting values (baseline; i.e., $10 \mathrm{~min}$ before the first oral administration; T0) and repeated two (T2) and four (T4) hours after the first administration. Blood sampling was done via a tailincision method (Fluttert et al., 2000). Promptly after collection of blood in a sodium heparin tube (Microvette ${ }^{\varpi}$ CB 300, Sarstedt, Germany), the samples were kept on ice. After centrifugation of the blood samples (at $4^{\circ} \mathrm{C}$ for $15 \mathrm{~min}$ at $3000 \mathrm{~g}$ in a Hettich EBA 12 centrifuge), plasma samples were frozen in liquid nitrogen and stored at $-80^{\circ} \mathrm{C}$. Before analysis, samples were thawed at $4^{\circ} \mathrm{C}$, vortex-mixed vigorously and centrifuged at 50,000 $\mathrm{g}$ in a Hereaus Model Biofuge Stratos for $10 \mathrm{~min}$ at $4^{\circ} \mathrm{C}$. From the clear supernatant $20 \mu \mathrm{l}$ was mixed with $1960 \mu \mathrm{l}$ water and $20 \mu \mathrm{l}$ norvaline and stored in the cooled $\left(7^{\circ} \mathrm{C}\right)$ sample compartment until analysis. Plasma amino acid concentrations were determined with a fully automated high-performance liquid chromatography (HPLC) system after precolumn derivatization with o-phthaldialdehyde (OPA) (van Eijk et al., 1993). OPA-AA derivates were quantified with fluorescence detection. The concentrations of the total plasma amino acids were expressed as $\mu \mathrm{mol} / \mathrm{l}$.

For brain samples of the frontal cortex and hippocampus, rats were decapitated four hours after the first administration of treatment and the heads were immersed in liquid nitrogen for $6 \mathrm{~s}$. Brain structures were rapidly dissected and then stored at $-80^{\circ} \mathrm{C}$ until further use. The tissue samples were homogenized in $250 \mu \mathrm{l}$ of an ice-cold solution containing $5 \mu \mathrm{M}$ clorgyline, $5 \mu \mathrm{g} / \mathrm{ml}$ glutathione and $0.6 \mu \mathrm{M} \mathrm{N} \omega$-methylserotonin (NMET, internal standard), using a potter tube. To $100 \mu \mathrm{l}$ homogenate, $25 \mu \mathrm{l} 2 \mathrm{M} \mathrm{HClO} 4$ was added and mixed. Then $20 \mu \mathrm{l} 2.5 \mathrm{M}$ potassium acetate was added and again mixed. After $15 \mathrm{~min}$ in ice water, the homogenates were centrifuged during $15 \mathrm{~min}$ at $15000 \mathrm{~g}\left(4^{\circ} \mathrm{C}\right)$. The supernatants were diluted 10 times with water before HPLC analysis. The concentration of 5-HT and 5-HIAA in the tissue extracts were measured by HPLC with ECD. The HPLC system consisted of a pump model P100, an autosampler model AS300 (both from Thermo Separation Products, Waltham, MA, USA), A ERC-3113 degasser (Erma CR. Inc. Tokyo, Japan), an ESA Coulochem II detector with 5011 analytical cell set at potential $+450 \mathrm{mV}$ (ESA Inc. Bedford MA, USA), a BD 41 chart recorder (Kipp \& zn, The Netherlands) and a column (150 $\mathrm{mm} \times 4.6 \mathrm{~mm}$ i.d.) packed with Hypersil BDS C18, $5 \mu \mathrm{m}$ particle size (Alltech Associates, USA). The mobile phase solution consisted of $50 \mathrm{mM}$ citric acid, $50 \mathrm{mM}$ phosphoric acid, $0.1 \mathrm{mM}$ EDTA, $45 \mu \mathrm{l} / \mathrm{L}$ dibutylamine, $77 \mathrm{mg} / \mathrm{L}$ 1-octanesulfonic acid sodium salt, $10 \%$ methanol; the $\mathrm{pH}$ of the buffer was adjusted to 3.4 with $\mathrm{NaOH}$. Separation was performed at room temperature using a flow rate of $0.7 \mathrm{ml} / \mathrm{min}$. The concentration of each compound was calculated by comparison with both the internal and the external standards. The limit 
of detection (signal/noise ratio 3:1) was $0.3 \mathrm{nM}$. Concentrations were expressed as $\mathrm{nmol} / \mathrm{g}$. From concentrations of 5-HT and 5-HIAA, the 5-HIAA/5-HT turnover was calculated.

\section{Behaviour}

Open field test The open field test was conducted in a square, clear Plexiglas box $(100 \times 100 \times 40 \mathrm{~cm})$, with an open top and a dark (SD) or grey $(\mathrm{BN})$ floor. The same apparatus was used for both strains, but a different flour colour was required for computer tracking of the rats. The arena of the open field was subdivided in 'corner' (four squares each $16 \times 16 \mathrm{~cm}$ ), 'wall' (four rectangles each $16 \times 64 \mathrm{~cm}$ ) and 'center' (one square $64 \times 64 \mathrm{~cm}$ ) zones. Testing was carried out in dimmed white light. A camera was installed above the center of the field. Immediately after a rat was placed in the center of the open field, the movements and position of the animals were recorded and registered automatically by a computerized system (EthoVision, Noldus Information Technology, Wageningen, The Netherlands). Reported are the time spent in the center and the corner zones of the open field and the total distance moved. Testing was carried out on three consecutive days, with one 5-minute trial a day for all rats. The floor of the open field was cleaned with a $10 \%$ ethanol solution between trials to prevent transmission of olfactory cues.

Home cage emergence test In the home cage emergence test the home cage was placed in an arena and the lid of the home cage was removed (Prickaerts et al., 1996). During the testing of one rat, its cage mate was placed in another cage for the duration of the trial. A grid was placed over the edge of the cage to make it easier for the rats to leave the home cage. Testing was carried out in dimmed white light. A stopwatch was used to measure the latency to leave the cage. The experimenter measured the time it took for the rat to climb out of its cage into the arena. A criterion was set to determine the escape time: time was stopped and the trial ended when all four paws of the rat were over the edge of the cage. If the rat did not emerge from its home cage within 300s, the trial was ended, the home cage was closed again and the rat was given a score of 300 . Between trials the grid was cleaned with a $10 \%$ ethanol solution to prevent transmission of olfactory cues. This test was carried out on three consecutive days.

Social interaction test In the social interaction test (File and Hyde, 1978, File and Seth, 2003) two rats were placed in closed part of the open field, $50 \times 50 \times 40 \mathrm{~cm}$ with two black and two transparent walls. The two animals that were tested together were weight matched and of the same strain, and had received the same treatment (both TRP- or both TRP+). The animals were placed in the test area at the same time and spend 10 minutes together, which were videotaped for later offline analysis by an observer who was blind to the treatment of the rats. Per interaction duo, total time of social interaction was measured, subdivided into active social interaction and passive body contact. Active social interaction comprised sniffing, grooming, exploring, following, biting, etc the other rat. During passive body contact, the rats touched each other, but did not explore, i.e. sitting or lying 
together. Social interaction was tested twice, rats received the same treatment on both trials, but were paired with an unfamiliar rat each trial.

Forced swim test Four cylindrical transparent plastic tanks $(40 \mathrm{~cm}$ tall $\times 17 \mathrm{~cm} \mathrm{di-}$ ameter), filled to a depth of $30 \mathrm{~cm}$ with about $22^{\circ} \mathrm{C}$ water, were used in the forced swim test. Testing was carried out over three consecutive days. When the animals were placed in the water, their movements and position were recorded and registered automatically by a computerized system (EthoVision, Noldus Information Technology, Wageningen, The Netherlands). Reported are the time the rats spent in behavioural immobility, which was defined as follows: making no movements or only making those movements that were necessary to keep the nose above the water. It was allowed for the rats to move their forepaws or support themselves by pressing their paws against the wall of the cylinder. Active climbing and swimming along the wall were categorized as strong mobility.

Object recognition test The object recognition test was performed as described in detail elsewhere (Ennaceur and Delacour, 1988, Prickaerts et al., 2002). During training and testing, the rats were housed individually. The apparatus consisted of a circular arena, $83 \mathrm{~cm}$ in diameter. Half of the $40-\mathrm{cm}$-high wall was made of grey polyvinyl chloride, the other half of transparent polyvinyl chloride. Testing was carried out in dimmed white light. We used four different sets of objects that could not be displaced by a rat. Each object was available in triplicate. The different objects were: 1) a cone consisted of a grey polyvinyl chloride base (maximal diameter $18 \mathrm{~cm}$ ) with collar on top made of brass (total height $16 \mathrm{~cm}$ ), 2) a standard 11 transparent glass bottle (diameter $10 \mathrm{~cm}$, height $22 \mathrm{~cm}$ ) filled with water, 3$)$ a massive metal cube $(10 \times 5 \times 7.5 \mathrm{~cm})$ with two holes (diameter $1.9 \mathrm{~cm})$, and 4$)$ a massive aluminium cube with a tapering top $(13 \times 8 \times 8 \mathrm{~cm})$.

On the day preceding testing, the animals were adapted to the procedure, i.e., they were allowed to explore the apparatus (without any objects) twice for 3 minutes. In the following days, the rats were trained until a stable discrimination performance was shown. A testing session comprised two trials. The duration of each trial was $3 \mathrm{~min}$. Two objects were placed in a symmetrical position about $10 \mathrm{~cm}$ away from the grey wall. A rat was always placed in the apparatus facing the wall at the middle of the front (transparent) segment. During the first trial the apparatus contained two identical objects. After the first exploration period the rat was put back in its home cage. One hour later the rat was put back in the apparatus for the second trial, but now with dissimilar objects, a familiar one and a new one. The duration of exploring each object in both trials was recorded manually with a personal computer. Exploration was defined as directing the nose to the object at a distance of no more than $2 \mathrm{~cm}$ and/or touching the object with the nose. Sitting on the object was not considered as exploratory behaviour. In order to avoid transmission of olfactory trails, the objects were cleaned with a $10 \%$ ethanol solution between trials. Moreover, each object was available in triplicate so that none of the two objects from the first trial had to be used as the familiar object in the second trial. In 
addition, all combinations and locations of objects were used in a balanced manner to reduce potential biases due to preferences for particular locations or objects.

After the rats were familiarized to the procedures of the task and showed stable baseline performance, testing with treatment began. The first trial was given four hours after the first oral administration. The delay interval of one hour between trial 1 and trial 2 was preferable since during this time, plasma TRP levels remain low. The basic measures in the object recognition test were the times spent by rats exploring an object during trial 1 and trial 2 ( $e 1$ and $e 2$ respectively). The discrimination index $d 2$ ((exploration new object trial 2 - exploration familiar object trial 2)/total exploration time during trial 2) was calculated for each treatment condition (Rutten et al., 2007). $d 2$ is a relative index of discrimination between new and familiar object, because it corrects for total exploration time in trial 2 (Sik et al., 2003). Rats that explored less than $5 \mathrm{~s}$ in any of the trials or explored only one of the objects were removed from analysis to avoid possible erroneous conclusions (Sik et al., 2003).

\section{Statistical analysis}

For all variables, treatment and strain effects were analysed using parametric statistics (ANOVA). Plasma amino acid concentrations were analysed with repeated measures ANOVA to include the time factor. Data of the open field test, home cage emergence test and forced swim test were aggregated over the three trial to enhance reliability (Ossenkopp and Mazmanian, 1985). In the open field, for example, these aggregated data strongly correlate with definitions of anxiety in other models, such as the plus maze and the light dark box (Blokland et al., 1992, Prickaerts et al., 1996, van der Staay and Blokland, 1996). The mean scores over the three testing days were used in statistical analysis, as was done in comparable studies (Blokland et al., 2002, Lieben et al., 2004b, Jans et al., 2007a). Because the data of the home cage emergence test was not normally distributed, rank scores were calculated and used for statistical testing. Data from the two trials of the social interaction test were treated as independent observations because the testing partner differed in the two trials. In order to test our specific hypotheses, we also analysed the effects of treatment on behaviour in each strain separately. Differences were statistically significant when $\mathrm{p}<0.05$.

\section{Results}

\section{Biochemistry}

Plasma amino acid concentrations of TRP and five other large neutral amino acids (LNAAs: valine, leucine, isoleucine, phenylalanine, tyrosine) were measured in the beginning and at the end of the study, i.e. before and after the period of behavioural testing. The ratio of TRP over the sum of the other LNAAs (TRP/ $\Sigma$ LNAA ratio) was calculated for each measurement, treatment and strain. As there was no difference in plasma TRP/ $\Sigma$ LNAA 
ratio between the two blood sampling measurements (before and after the period of behavioural testing), data from both blood sampling measurements were pooled together. Treatment and strain effects on plasma TRP/ LLNAA ratio are shown in Figure 1.

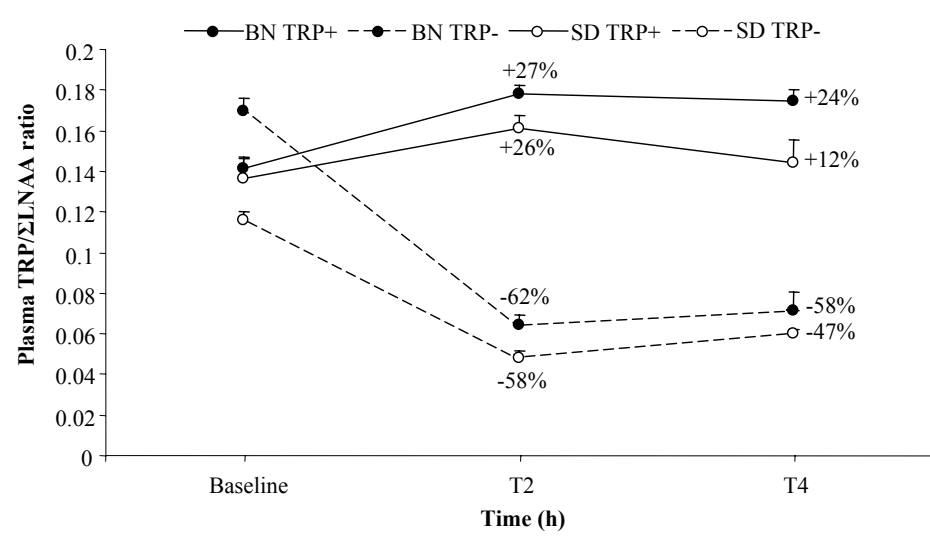

Figure 1. Effects of acute tryptophan depletion on the plasma TRP/ $/$ LNAA ratio in Sprague Dawley and Brown Norway rats. Percentages indicate changes from baseline.

At baseline, BNs had higher levels of TRP $[\mathrm{F}(1,46)=174.62, \mathrm{p}<0.001]$ and TRP/ $\Sigma$ LNAA ratio $[\mathrm{F}(1,46)=14.56, \mathrm{p}<0.001]$ than SDs. Plasma TRP levels [Time: $\mathrm{F}(2,86)=4.92$, $\mathrm{p}<0.01]$ and the plasma TRP $/ \Sigma$ LNAA ratio $[\mathrm{F}(2,86)=27.37, \mathrm{p}<0.001]$ decreased over the four hours. In the TRP- condition, plasma TRP levels [Treatment: $F(1,43)=296.39$, $\mathrm{p}<0.001$ ] and the plasma TRP/ $\Sigma$ LNAA ratio [Treatment: $\mathrm{F}(1,43)=205.64, \mathrm{p}<0.001$ ] were lower than in the TRP+ condition. There was a Time $\times$ Treatment interaction effect on plasma TRP concentration $[\mathrm{F}(2,86)=123.97, \mathrm{p}<0.001]$ and on the plasma TRP/ $\Sigma$ LNAA ratio $\mathrm{F}(2,86)=103.90, \mathrm{p}<0.001$ ]. In $\mathrm{BN}$ rats, plasma TRP levels [Strain: $\mathrm{F}(1,43)=108.50$, $\mathrm{p}<0.001$ ] and plasma TRP/ $\Sigma$ LNAA ratio [Strain: $\mathrm{F}(1,43)=22.77, \mathrm{p}<0.001$ ] were higher than in SD rats. There was a Time $\times$ Strain interaction effect $[F(2,86)=11.99, \mathrm{p}<0.001]$ on plasma TRP and a Time $\times$ Strain $\times$ Treat interaction effect on plasma TRP $[F(2,86)=5.59$, $\mathrm{p}<0.01]$ and on the plasma TRP $/ \Sigma$ LNAA ratio $[\mathrm{F}(2,86)=8.39, \mathrm{p}<0.001]$.

In the frontal cortex there was a Strain $\times$ Treatment interaction effect on 5-HT concentration $[\mathrm{F}(1,26)=8.28, \mathrm{p}<0.01]$, but this interaction was not found in the hippocampus. In both frontal cortex and hippocampus, 5 -HT concentrations were lower in the TRP- condition than in the TRP+ condition [Treatment: frontal cortex: $\mathrm{F}(1,26)=63.67, \mathrm{p}<0.001$; hippocampus: $\mathrm{F}(1,28)=10.02$, $\mathrm{p}<0.01]$. In the frontal cortex 5 -HT concentration was higher in $\mathrm{BN}$ than in SD rats [Strain: $\mathrm{F}(1,26)=14.08, \mathrm{p}<0.001$ ], whereas in the hippocampus this effect was only marginally significant [Strain: $F(1,28)=3.35, \mathrm{p}<0.08$ ]. When treatment effects were analysed within each strain, lower 5-HT in the TRP- condition was found for both strains in the frontal cortex [BN: $\mathrm{F}(1,12)=138.68, \mathrm{p}<0.001$; $\mathrm{SD}: \mathrm{F}(1,14)=9.20, \mathrm{p}<0.01]$. In the hip- 

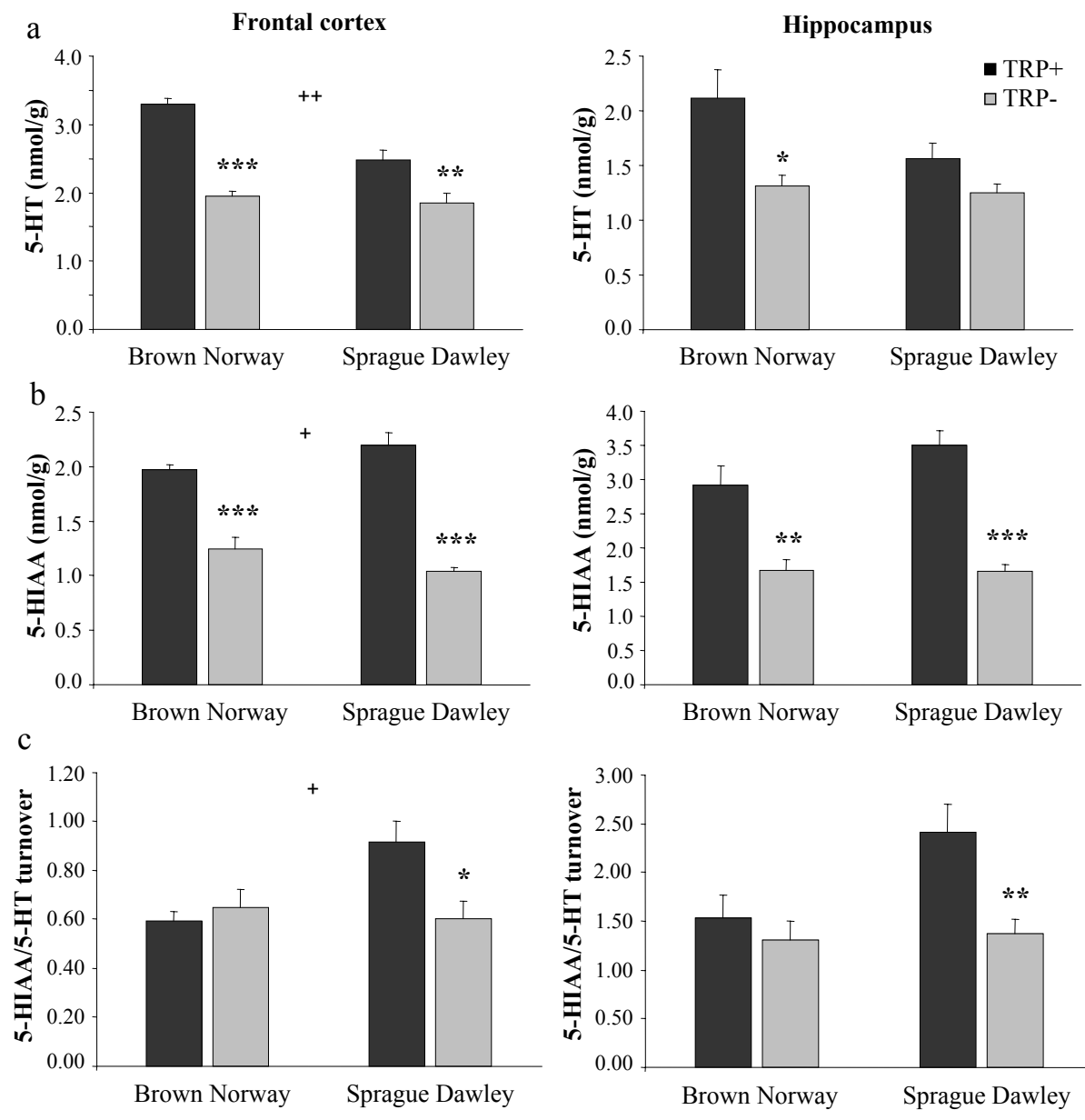

Figure 2. Effects of acute tryptophan depletion on 5-HT (2a), 5-HIAA (2b) and 5-HIAA/5-HT turnover (2c) in the frontal cortex and in the hippocampus in BN and SD rats. Strain $\times$ Treatment effect ${ }^{+} \mathrm{p}<0.05 ;{ }^{++} \mathrm{p}<0.01$; Treatment effect; ${ }^{*} \mathrm{p}<0.05 ;{ }^{* *} \mathrm{p}<0.01 ;{ }^{* * *} \mathrm{p}<0.001$.

pocampus, 5-HT was lower after TRP- compared to TRP+ treatment in $\mathrm{BN}[\mathrm{F}(1,13)=7.18$, $\mathrm{p}<0.05]$ but not in SD rats $[\mathrm{F}(1,14=3.26, \mathrm{~ns}]$. Strain and treatment effects on 5 -HT in the frontal cortex and hippocampus are shown in Figure 2.

Concentrations of 5-HIAA were lower after TRP- treatment compared to $\mathrm{TRP}+$ treatment in both frontal cortex $[\mathrm{F}(1,25)=108.56, \mathrm{p}<0.001]$ and hippocampus $[\mathrm{F}(1,29)=55.23, \mathrm{p}<0.001]$ (data not shown). There were no effects of strain on 5-HIAA concentrations and a Strain $\times$ Treatment interaction effect was found in the frontal cortex $[\mathrm{F}(1,25)=5.84, \mathrm{p}<0.05]$ but not in the hippocampus. When treatment effects were analysed within each strain, 5-HIAA concentrations were found to be lower after TRPtreatment compared with TRP+ treatment in both strains and brain structures [BN: 
frontal cortex: $\mathrm{F}(1,11)=33.38, \mathrm{p}<0.001 ; \mathrm{BN}$ : hippocampus: $\mathrm{F}(1,14)=14.43, \mathrm{p}<0.01$; SD: frontal cortex: $\mathrm{F}(1,14)=83.48, \mathrm{p}<0.001$; SD: hippocampus: $\mathrm{F}(1,14)=57.86, \mathrm{p}<0.001]$.

There was a Strain $\times$ Treatment interaction effect on the 5-HIAA/5-HT turnover $[\mathrm{F}(1,24)=5.68, \mathrm{p}<0.05]$ in the frontal cortex, but not in the hippocampus (data not shown). In the hippocampus 5-HIAA/5-HT turnover was lower after TRP-compared with TRP+ treatment [Treatment: $\mathrm{F}(1,28)=7.34, \mathrm{p}<0.05$ ], but this effect was not found in the frontal cortex. Furthermore, there was no strain effect in the frontal cortex, but in the hippocampus 5-HIAA/5-HT turnover was found to be higher in SD than in BN rats [Strain: $\mathrm{F}(1,28)=4.22, \mathrm{p}<0.05$ ]. When treatment effects were analysed within each strain, turnover was found to be lower in the TRP- than in the TRP+ condition in SD [frontal cortex: $\mathrm{F}(1,14)=7.47, \mathrm{p}<0.05$; hippocampus: $\mathrm{F}(1,14)=9.95, \mathrm{p}<0.01$ ] but not in $\mathrm{BN}$ rats. There were no treatment effects on concentrations of dopamine, DOPAC, or homovanillic acid (data not shown).

\section{Behaviour}

Open field test Aggregated data of the time spent in the corners of the open field and the total distance moved are shown in Figure 3 . There were no Treatment $\times$ Strain interaction effects on any of the outcome measures. SD rats spent less time in the center [Strain: $\mathrm{F}(1,41)=27.31, \mathrm{p}<0.001]$ and spent more time in corners [Strain: $\mathrm{F}(1,41)=5.72$, $\mathrm{p}<0.05$ ] of the open field than BN rats, independent of treatment. Independent of strain, TRP- treated rats spent less time in the center of the open field than TRP+ treated rats [Treatment: $\mathrm{F}(1.41)=4.12, \mathrm{p}<0.05]$. TRP- treated rats showed a trend towards spending more time in the corners than TRP+ treated rats [Treatment: $F(1,41)=3.41, \mathrm{p}<0.08$ ]. There were no effects of treatment or strain on the total distance the rats moved in the open field. When treatment effects were analysed within each strain there were no effects of treatment on any of the open field measures in $\mathrm{BN}$ rats, whereas $\mathrm{SD}$ rats spent more time in corners [Treatment: $\mathrm{F}(1,19)=5.51, \mathrm{p}<0.05$ ] and moved a shorter distance [Treatment $\mathrm{F}(1,19)=4.52, \mathrm{p}<0.05]$ in the TRP- condition compared to the TRP+ condition.
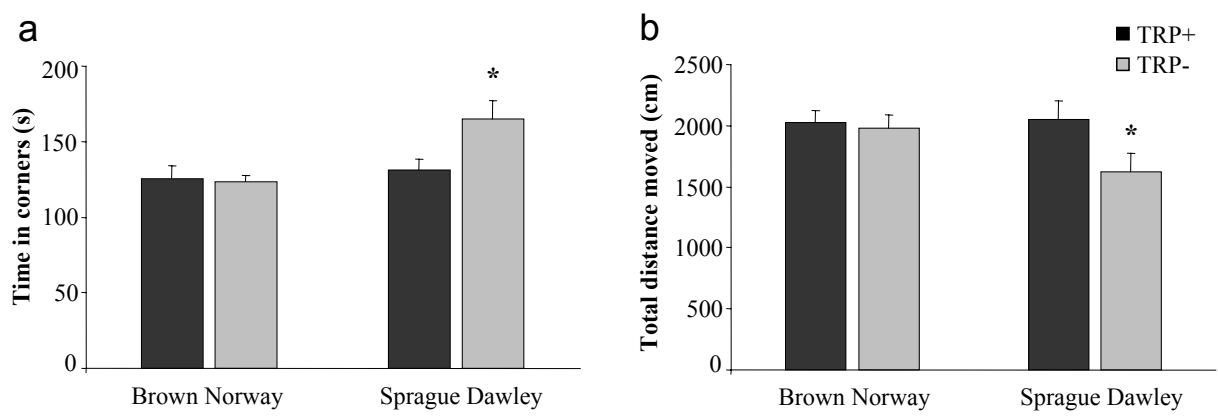

Figure 3. Open field test. Effects of ATD on time spent in the corners of the open field (3a) and the total distance moved ( $3 b)$ of $B N$ and SD rats. Treatment effect ${ }^{*} \mathrm{p}<0.05$. 
Home cage emergence test As the escape latency scores were not normally distributed, rank scores were calculated. Aggregated data of the escape latency are shown in Figure 4. Rats treated with TRP- escaped from the home cage faster than rats treated with $\mathrm{TRP}+[$ Treat: $\mathrm{F}(1,43=6.70, \mathrm{p}<0.05]$. There was no effect of strain or a Treatment $\times$ Strain interaction effect on rank scores of escape latency. When treatment effects were analysed within each strain, SD rats were found to escape faster in the TRP-condition than in the TRP+ condition [Treat: $\mathrm{F}(1,20)=4.68, \mathrm{p}<0.05$ ], but this treatment effect was not found in $\mathrm{BN}$ rats.

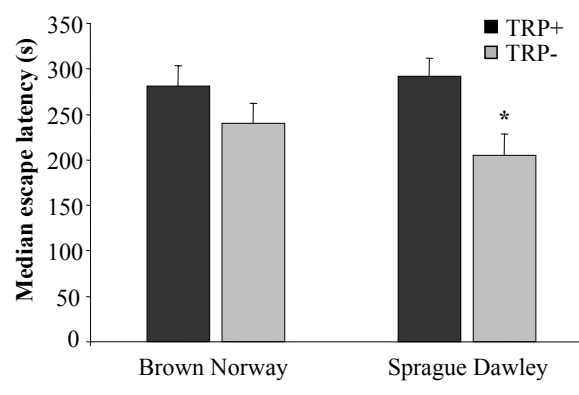

Figure 4. Home cage emergence test. Effects of ATD on median escape latency in the home cage emergence test. Treatment effect ${ }^{*} \mathrm{p}<0.05$.

Social interaction test There were no effects of treatment or strain on the duration of social interaction and active social interaction. BN rats showed more passive body contact than SD rats [Strain: $\mathrm{F}(1,20)=4.88, \mathrm{p}<0.05$ ] and spent a larger percentage of their social interaction in passive body contact [Strain: $F(1,20)=5.93, p<0.05$ ] independent of treatment. There were no significant Treatment $\times$ Strain interaction effects. When treatment were analysed within each strain, there were no significant effects in either strain on any of the variables (F's $<3.04$, ns). Effects on active and passive body contact are shown in Figure 5.
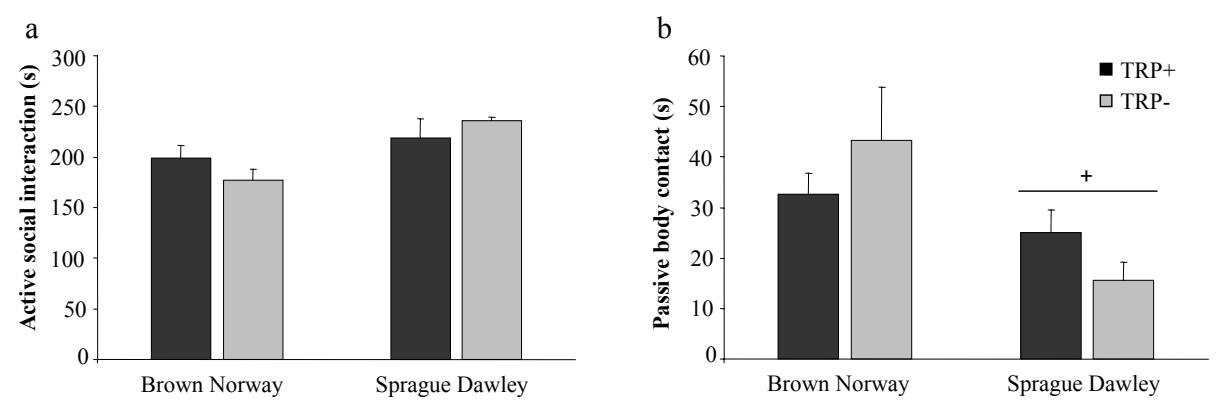

Figure 5. Social interaction test. Effects of ATD on active social interaction (5a) and passive body contact (5b). Strain effect ${ }^{+} \mathrm{p}<0.05$. 
Forced swim test There was a Treatment $\times$ Strain interaction effect on immobility in the forced swim test $[\mathrm{F}(1,41)=4.22, \mathrm{p}<0.05]$, caused by opposite behavioural responses to ATD in BN and SD. Furthermore, the SD rats showed a longer total duration of immobility than the $\mathrm{BN}$ rats [Strain: $\mathrm{F}(1,41)=43.73$, $\mathrm{p}<0.001$ ]. There was no effect of treatment on the total duration of immobility. Analysing treatment effects within each strain revealed a trend towards a longer immobility duration in the TRP- condition compared to the TRP+ condition in SD rats [Treatment: $\mathrm{F}(1,20)=3.51, \mathrm{p}<0.08$ ], whereas no treatment effect was found on immobility in $\mathrm{BN}$ rats.

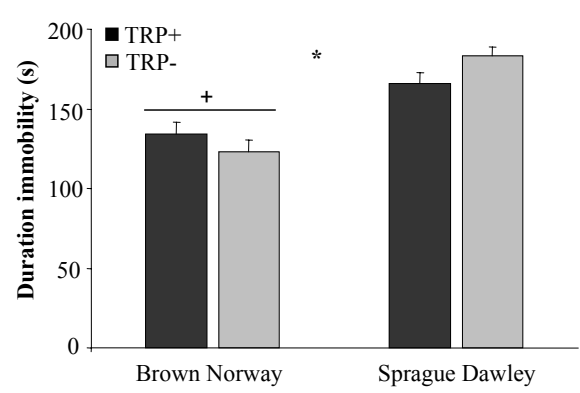

Figure 6. Forced swim test. Effects of ATD on immobility in the forced swim test. Strain $\times$ Treatment interaction effect * $\mathrm{p}<0.05$; Strain effect ${ }^{+} \mathrm{p}<0.05$.

Object recognition test In both trials of the object recognition test, SDs had higher exploration times than BNs $[e 1: \mathrm{F}(1,89)=6.22, \mathrm{p}<0.05 ; e 2: \mathrm{F}(1,88)=18.00$, $\mathrm{p}<0.001]$. There were no treatment effects on exploration times in $e 1$ and $e 2$. There was a Strain $\times$ Treatment interaction effect on $e 2[\mathrm{~F}(1,88)=5.34, \mathrm{p}<0.05]$ but not on $e 1$. Discrimination index $d 2$ was lower in the TRP- than in the TRP+ condition [Treatment: $\mathrm{F}(1,88)=20.07, \mathrm{p}<0.001$ ] and BNs had higher $d 2$ than SDs [Strain: $\mathrm{F}(1,88)=10.01$, $\mathrm{p}<0.01]$. There was a Strain $\times$ Treatment interaction effect on $d 2[\mathrm{~F}(1,88)=4.70, \mathrm{p}<0.05]$. When treatment effects on $d 2$ were analysed within each strain, $d 2$ was found to be lower in the TRP- condition than in the TRP+ condition in $\operatorname{SDs}[F(1,43)=19.59, \mathrm{p}<0.001]$, but not in BNs. $e 1, e 2$, and $d 2$ scores are shown in Table 3.

Table 3. Effects of treatment and strain on the measures of the object recognition test.

\begin{tabular}{cccc}
\hline \multirow{2}{*}{$\begin{array}{c}\text { Outcome } \\
\text { measure }\end{array}$} & \multirow{2}{*}{ Treatment condition } & \multicolumn{2}{c}{ Experimental group } \\
\cline { 3 - 4 }$e 1^{+}$ & & Brown Norway & Sprague Dawley \\
& TRP+ & $277.67(15.63)$ & $279.65(20.99)$ \\
\multirow{2}{*}{$e 2^{+++}$} & TRP- & $243.58(14.52)$ & $331.13(20.64)$ \\
& TRP+ & $306.54(13.21)$ & $341.39(26.66)$ \\
\multirow{2}{*}{$d 2^{*+*}$} & TRP- & $289.00(18.41)$ & $428.70(27.40)$ \\
& TRP+ & $0.32(0.04)$ & $0.27(0.06)$ \\
& TRP- & $0.21(0.04)$ & $-0.04(0.04)$ \\
\hline
\end{tabular}

Data represent mean (SEM). Treatment effect ${ }^{* * *} p<0.001$; Strain effect $+++p<0.001 ;+p<0.05$. 


\section{Discussion}

In this study, Sprague Dawley and Brown Norway rats were repeatedly treated with a gelatin-based protein-carbohydrate mixture either with or without TRP, to evaluate whether there is a difference in SV in these strains. Depletion effects on plasma TRP and the TRP/ $\Sigma$ LNAA ratio were similar in both strains. In the frontal cortex 5-HT depletion was similar in both strains, but in the hippocampus, there was a significant treatment effect on 5-HT only in BN rats. In the open field test, SD rats spent more time in the corners and moved a shorter distance after TRP- treatment compared to TRP+ treatment, whereas these effects were not found in BNs. These data suggest that ATD resulted in more anxious behaviour in SD. In the home cage emergence test as well, SD rats showed the strongest behavioural response to ATD. In this test however, SDs appeared to be less anxious after ATD, as they escaped from the home cage faster. There were no treatment effects on social interaction. In the forced swim test, SD showed a trend towards increased immobility in the TRPcondition, indicating an increase in depression-related behaviour, which was not found in BN rats. Furthermore, SD rats showed impaired object recognition after TRP- treatment, whereas the $\mathrm{BN}$ rats did not. In general, $\mathrm{SD}$ rats showed stronger behavioural responses to ATD than $\mathrm{BN}$ rats. These findings suggest that SD rats have higher SV than $\mathrm{BN}$ rats.

ATD had different behavioural effects on behaviour in the open field test and the home cage emergence test, two test of fear/anxiety-related behaviour. While SDs showed increased anxiety-related behaviour after TRP- in the open field test (i.e. more time spent in the corners and shorter distance moved), they showed less anxiety-related behaviour after TRP- in the home cage emergence test (i.e. shorter escape latency). These tests may measure different types of fear/anxiety; in the open field test the rat is placed in an unfamiliar environment without the possibility of escape, whereas in the home cage emergence test the rat can choose either to leave the home cage and enter an unfamiliar environment or to stay in the home cage. Nevertheless, this finding was unexpected, because previous studies have shown effects in similar directions on these tests (Van den Hove et al., 2005, Jans et al., 2007a).

Perhaps the most striking finding in this study is the dissociation between 5-HT depletion in the hippocampus and behavioural effects of ATD. BN rats showed significant 5-HT depletion in both the frontal cortex and the hippocampus after ATD, but no treatment effects on anxiety- and depression- related behaviour. Moreover, object recognition memory was not significantly impaired in BNs, although the $d 2$ was lower than in untreated sessions. SD rats on the other hand, showed significant ATD-induced 5 -HT depletion in the frontal cortex, but not in the hippocampus; and increased indices of anxiety- and depression- related behaviour and impaired object recognition. In SD rats, decreased 5-HIAA/5-HT turnover was found in both the frontal cortex and hippocampus after ATD, whereas these effects were not found in BN rats. Thus, this decrease in 5-HIAA/5-HT may be the critical parameter for the occurrence of ATD effects on affective behaviour and cognition. The finding of no significant decrease in 5-HT, but 
significantly lower 5-HIAA and 5-HIAA/5-HT turnover may suggest that after TRP- less 5-HT is metabolized into 5-HIAA in the hippocampus of SDs. Apparently however, this lack of significant 5-HT depletion in the hippocampus did not prevent the occurrence of behavioural effects after ATD. These results suggest that decreased 5-HIAA/5-HT turnover, perhaps due to diminished 5-HT neurotransmission, in frontal cortex and hippocampus may be more important in causing behavioural effects of ATD than reduced hippocampal 5-HT, but further research is required to resolve this issue.

Another possibility is that 5-HT depletion in brain regions not measured in this study are more important for the occurrence of ATD effects of ATD on anxiety-and depression- related behaviour than 5-HT or 5-HIAA/5-HT turnover depletion in the hippocampus. Although the hippocampus is involved in emotion, it is possible that 5HT depletion in other brain structures has stronger effects on affective behaviour. For example, increased regional cerebral glucose utilization in the orbitofrontal cortex, medial thalamus, anterior and posterior cingulate cortices, and ventral striatum have been found in remitted depressed patients with no medication, but not in healthy volunteers (Neumeister et al., 2004). The possible role of ATD effects in these structures on affective behaviour and cognition cannot be excluded here, because we only measured 5-HT and 5-HIAA in frontal cortex and hippocampus. In terms of the object recognition test, it is possible that 5-HT depletion in the perirhinal cortex of the temporal lobe, which was not measured in the present study, is involved in the ATD effect. In BNs, neither depletion of plasma TRP/ $\Sigma$ LNAA ratio nor 5-HT depletion in the hippocampus caused impaired object recognition. There is evidence to suggest that this region is more important for object recognition than the hippocampus (Winters et al., 2004, Forwood et al., 2005, Winters and Bussey, 2005). This might explain the dissociation between hippocampal 5-HT and object recognition reported in the present study.

Previously, several non-serotonergic explanations of impaired object recognition after ATD have been suggested (Riedel et al., 2002, Blokland et al., 2004, Lieben et al., 2004a). TRP is not only the precursor of 5-HT, but also of the kynurenine (KYN) pathway, which is quantitatively the most prominent metabolism pathway of tryptophan.

ATD may affect N-methyl-D-asparate (NMDA) receptor functioning via the KYN pathway. It is likely that ATD also decreases the amount of KYN, the primary degradation product of TRP, which is further converted to several metabolites, such as KYN acid (KYNA) and quinolinic acid (QUIN). Independent of each other, these metabolites are connected with NMDA receptors (Perkins and Stone, 1982), which can inhibit long term potentiation and lead to memory impairments (Morris et al., 1986, Saucier and Cain, 1995). KYNA has an antagonising effect on NMDA receptors and has a neuroprotective role, but QUIN can result in overstimulation of NMDA receptors and result in neurotoxic effects. Increased activity in the glutamatergic system and NMDA-receptor agonism have been hypothesized to be associated with depressed mood (Muller and Schwarz, 2007), and an increase of QUIN is strongly associated with several prominent features of depression, including cognitive deficits, in particular difficulties in learning (Heyes et al., 
1998). It is also possible that decreased 5-HTergic activity affects glutamatergic functioning and NMDA receptor activity more directly, as 5-HT may inhibit glutamatergic neurotransmission (Maura et al., 2000, Shutoh et al., 2000).

Furthermore, ATD has been reported to decrease citrulline (CIT) in the brain without affecting peripheral levels (Lieben et al., 2004a). It is known that arginine (ARG) is catalysed into CIT and nitric oxide (NO). ATD can affect CIT in the brain without affecting its precursor ARG, which could indicate that ATD might decrease NO synthesis, and in this way affect learning and memory (Prast and Philippu, 2001).

Another possible explanation is that ATD results in memory impairment through a general decrease in protein synthesis, as drug-induced inhibition of protein synthesis in the brain is an animal model of memory disorders (Sarter et al., 1992). However, (Klaassen et al., 1999) showed that depletion of the essential amino acid lysine, which is not related to cognition or behaviour but was assumed to result in decreased protein synthesis, did not affect memory. Likewise, Harrison et al. (Harrison et al., 2004), when comparing ATD and acute tyrosine/phenylalanine depletion (ATPD) effects on memory, reported that indeed the memory consolidation effect was specific for ATD.

In this study, SD rats showed 50-60\% depletion of plasma TRP and significant depletion of central 5-HT in the frontal cortex, but not in the hippocampus. In a study applying a different ATD method, SDs showed $89 \%$ depletion of plasma TRP and significant depletion of central 5-HT in frontal cortex, hippocampus, and cortex. Furthermore, $5-\mathrm{HT}_{1 \mathrm{~A}}$ receptor binding was decreased only in the dorsal raphe (Cahir et al., 2007). Perhaps in the present study the plasma TRP depletion level was not sufficient to result in significant hippocampal 5-HT depletion.

Several strain differences in behaviour were found in this study. BN rats showed more passive body contact than SD rats, and spent a larger percentage of their social interaction in passive body contact. SD rats showed more immobility in the forced swim test than BNs. Not all strain effects reported in the present study, however, are necessarily genuine. For example, the strain difference that was found in the forced swim test may be at least partly explained by the size difference between the strains. As the SD were bigger, they were able to rest on their tail more easily and support themselves by spreading their paws across the walls of the cylindrical tanks. Therefore, it may have been easier for the SDs to show immobility behaviour than for the BNs. This might also explain our finding of lower immobility in BN rats compared to SDs, whereas other studies have reported passive behaviour of the BN in the forced swim test (Armario et al., 1995, Gomez et al., 1996, Lahmame et al., 1997). The size of the rats may have been a factor in other tests as well, because larger animals may tend to be less inclined to show active behaviours. The effects of body size and strain could not be studied separately because all SDs were bigger and had a higher body weight than the BNs.

This study has several other possible shortcomings and limitations. First, the same group of rats was frequently subjected to the treatment, although the treatment condition varied between tests. The tests used in this study required multiple testing trials 
to obtain valid indices of anxiety and depression. Therefore it is important to note that there were no differences in the treatment effect on the plasma TRP/ $\Sigma$ LNAA ratio when comparing the data of the blood sampling at the beginning and at the end of the study. Apparently, the treatment effect after the second exposure to the treatment was the same as after the thirteenth exposure. We therefore assume that the treatment has had comparable biochemical effects throughout the entire study.

Second, the repeated testing of the rats in the successive tests (Table 2) might have affected the performance from one test to the other. Because all rats were subjected to the same series of tests, we may assume that the effects of repeated testing were similar in all groups. Furthermore, there were always at least three days between tests during which the rats were left undisturbed and provided with food ad libitum. However, it cannot be excluded that this successive testing could have interfered with treatment effects. This can only be tested if naïve rats are used for each individual test.

In conclusion, SD rats appear to have higher serotonergic vulnerability than BN rats, as they showed an increase in anxiety- and depression- related behaviour and impaired object recognition after ATD. The higher SV in SDs may be related to the ATDinduced decrease in 5-HIAA/5-HT turnover in the frontal cortex and hippocampus, which was not found in BNs. It appeared that depletion of plasma TRP/ 2 LNAA was not predictive of 5-HT depletion in the hippocampus, and that plasma TRP/ 2 LNAA and central 5-HT depletion did not necessarily result in decreased 5-HIAA/5-HT turnover. BNs and SDs showed similar plasma TRP/ $/$ LNAA depletion, but central 5-HT and 5-HIAA/5-HT depletion were different: only BNs showed significant 5-HT depletion in the hippocampus, and only SDs showed decreased 5-HIAA/5-HT depletion in frontal cortex and hippocampus. Behavioural effects of ATD were found only in SD rats.

\section{References}

Armario, A., Gavalda, A. and Marti, J., 1995. Comparison of the behavioural and endocrine response to forced swimming stress in five inbred strains of rats. Psychoneuroendocrinology. 20, 879-890.

Bell, C., Abrams, J. and Nutt, D., 2001. Tryptophan depletion and its implications for psychiatry. Br J Psychiatry. 178, 399-405.

Biggio, G., Fadda, F., Fanni, P., Tagliamonte, A. and Gessa, G. L., 1974. Rapid depletion of serum tryptophan, brain tryptophan, serotonin and 5-hydroxyindoleacetic acid by a tryptophan-free diet. Life Sci. 14, 1321-1329.

Blokland, A., Lieben, C. and Deutz, N. E., 2002. Anxiogenic and depressive-like effects, but no cognitive deficits, after repeated moderate tryptophan depletion in the rat. J Psychopharmacol. 16, 39-49.

Blokland, A., Lieben, C., Deutz, N. E. P. and Schmitt, J., 2004. Acute tryptophan depletion: comparing the effects of an amino acid mixture with a gelatin-based protein in man and rat. Current Topics in Nutraceutical Research. 2, 161-169.

Blokland, A., Prickaerts, J. and Raaijmakers, W., 1992. Reduced level of anxiety in adult Lewis rats after chronic ethanol consumption. Physiol Behav. 51, 245-248.

Booij, L. and Van der Does, A. J., 2007. Cognitive and serotonergic vulnerability to depression: convergent findings. J Abnorm Psychol. 116, 86-94. 
Brown, C. M., Fletcher, P. J. and Coscina, D. V., 1998. Acute amino acid loads that deplete brain serotonin fail to alter behavior. Pharmacol Biochem Behav. 59, 115-121.

Cadoret, R. J., Winokur, G., Langbehn, D., Troughton, E., Yates, W. R. and Stewart, M. A., 1996. Depression spectrum disease, I: The role of gene-environment interaction. Am J Psychiatry. 153, 892-899.

Cahir, M., Ardis, T., Reynolds, G. P. and Cooper, S. J., 2007. Acute and chronic tryptophan depletion differentially regulate central 5-HT1A and 5-HT 2A receptor binding in the rat. Psychopharmacology (Berl). 190, 497-506.

Clarke, A. S., Kammerer, C. M., George, K. P., Kupfer, D. J., McKinney, W. T., Spence, M. A. and Kraemer, G. W., 1995. Evidence for heritability of biogenic amine levels in the cerebrospinal fluid of rhesus monkeys. Biol Psychiatry. 38, 572-577.

Ennaceur, A. and Delacour, J., 1988. A new one-trial test for neurobiological studies of memory in rats. 1 : Behavioral data. Behav Brain Res. 31, 47-59.

Ferguson, S. A. and Holson, R. R., 1997. Methylazoxymethanol-induced micrencephaly in the brown Norway strain: behavior and brain weight. Int J Dev Neurosci. 15, 75-86.

Fernstrom, J. D. and Wurtman, R. J., 1997. Brain serotonin content: physiological regulation by plasma neutral amino acids. 1971. Obes Res. 5, 377-380.

File, S. E. and Hyde, J. R., 1978. Can social interaction be used to measure anxiety? Br J Pharmacol. 62, 19-24.

File, S. E. and Seth, P., 2003. A review of 25 years of the social interaction test. Eur J Pharmacol. 463, 35-53.

Fluttert, M., Dalm, S. and Oitzl, M. S., 2000. A refined method for sequential blood sampling by tail incision in rats. Lab Anim. 34, 372-378.

Forwood, S. E., Winters, B. D. and Bussey, T. J., 2005. Hippocampal lesions that abolish spatial maze performance spare object recognition memory at delays of up to 48 hours. Hippocampus. 15, 347-355.

Gessa, G. L., Biggio, G., Fadda, F., Corsini, G. U. and Tagliamonte, A., 1974. Effect of the oral administration of tryptophan-free amino acid mixtures on serum tryptophan, brain tryptophan and serotonin metabolism. J Neurochem. 22, 869-870.

Gomez, F., De Kloet, E. R. and Armario, A., 1998. Glucocorticoid negative feedback on the HPA axis in five inbred rat strains. Am J Physiol. 274, R420-427.

Gomez, F., Lahmame, A., de Kloet, E. R. and Armario, A., 1996. Hypothalamic-pituitary-adrenal response to chronic stress in five inbred rat strains: differential responses are mainly located at the adrenocortical level. Neuroendocrinology. 63, 327-337.

Harrison, B. J., Olver, J. S., Norman, T. R., Burrows, G. D., Wesnes, K. A. and Nathan, P. J., 2004. Selective effects of acute serotonin and catecholamine depletion on memory in healthy women. J Psychopharmacol. 18, 32-40.

Heninger, G. R., 1995. Indoleamines: The Role of Serotonin in Clinical Disorders. In: Bloom, F. E. and Kupfer, D. J. (Eds.), Psychopharmacology: The Fourth Generation of Progress. Raven Press, Ltd., New York, pp. 471-482.

Heyes, M. P., Saito, K., Lackner, A., Wiley, C. A., Achim, C. L. and Markey, S. P., 1998. Sources of the neurotoxin quinolinic acid in the brain of HIV-1-infected patients and retrovirus-infected macaques. Faseb J. 12, 881-896.

Higley, J. D., Thompson, W. W., Champoux, M., Goldman, D., Hasert, M. F., Kraemer, G. W., Scanlan, J. M., Suomi, S. J. and Linnoila, M., 1993. Paternal and maternal genetic and environmental contributions to cerebrospinal fluid monoamine metabolites in rhesus monkeys (Macaca mulatta). Arch Gen Psychiatry. 50, 615-623.

Jans, L. A., Lieben, C. K. and Blokland, A., 2007a. Influence of sex and estrous cycle on the effects of acute tryptophan depletion induced by a gelatin-based mixture in adult Wistar rats. Neuroscience. 147, 304-317.

Jans, L. A., Riedel, W. J., Markus, C. R. and Blokland, A., 2007b. Serotonergic vulnerability and depression: assumptions, experimental evidence and implications. Mol Psychiatry. 12, 522-543.

Kendler, K. S., Davis, C. G. and Kessler, R. C., 1997. The familial aggregation of common psychiatric and substance use disorders in the National Comorbidity Survey: a family history study. Br J Psychiatry. 170, 541-548. 
Klaassen, T., Riedel, W. J., Deutz, N. E., van Someren, A. and van Praag, H. M., 1999. Specificity of the tryptophan depletion method. Psychopharmacology (Berl). 141, 279-286.

Lahmame, A. and Armario, A., 1996. Differential responsiveness of inbred strains of rats to antidepressants in the forced swimming test: are Wistar Kyoto rats an animal model of subsensitivity to antidepressants? Psychopharmacology (Berl). 123, 191-198.

Lahmame, A., Grigoriadis, D. E., De Souza, E. B. and Armario, A., 1997. Brain corticotropin-releasing factor immunoreactivity and receptors in five inbred rat strains: relationship to forced swimming behaviour. Brain Res. 750, 285-292.

Lieben, C. K., Blokland, A., Westerink, B. and Deutz, N. E., 2004a. Acute tryptophan and serotonin depletion using an optimized tryptophan-free protein-carbohydrate mixture in the adult rat. Neurochem Int. 44, 9-16.

Lieben, C. K., van Oorsouw, K., Deutz, N. E. and Blokland, A., 2004b. Acute tryptophan depletion induced by a gelatin-based mixture impairs object memory but not affective behavior and spatial learning in the rat. Behav Brain Res. 151, 53-64.

Maes, M. and Meltzer, H. Y., 1995. The Serotonin Hypothesis of Major Depression. In: Bloom, F. E. and Kupfer, D. J. (Eds.), Psychopharmacology: The Fourth Generation of Progress. Raven Press, Ltd., New York, pp. 933-944.

Maura, G., Marcoli, M., Pepicelli, O., Rosu, C., Viola, C. and Raiteri, M., 2000. Serotonin inhibition of the NMDA receptor/nitric oxide/cyclic GMP pathway in human neocortex slices: involvement of 5-HT(2C) and 5-HT(1A) receptors. Br J Pharmacol. 130, 1853-1858.

Michalak, E. E., Wilkinson, C., Hood, K. and Dowrick, C., 2002. Seasonal and nonseasonal depression: how do they differ? Symptom profile, clinical and family history in a general population sample. J Affect Disord. 69, 185-192.

Moja, E. A., Cipolla, P., Castoldi, D. and Tofanetti, O., 1989. Dose-response decrease in plasma tryptophan and in brain tryptophan and serotonin after tryptophan-free amino acid mixtures in rats. Life Sci. 44, 971-976.

Moore, P., Landolt, H. P., Seifritz, E., Clark, C., Bhatti, T., Kelsoe, J., Rapaport, M. and Gillin, J. C., 2000. Clinical and physiological consequences of rapid tryptophan depletion. Neuropsychopharmacology. 23, 601-622.

Morris, R. G., Anderson, E., Lynch, G. S. and Baudry, M., 1986. Selective impairment of learning and blockade of long-term potentiation by an N-methyl-D-aspartate receptor antagonist, AP5. Nature. 319, 774-776.

Muller, N. and Schwarz, M. J., 2007. The immune-mediated alteration of serotonin and glutamate: towards an integrated view of depression. Mol Psychiatry. 12, 988-1000.

Neumeister, A., Nugent, A. C., Waldeck, T., Geraci, M., Schwarz, M., Bonne, O., Bain, E. E., Luckenbaugh, D. A., Herscovitch, P., Charney, D. S. and Drevets, W. C., 2004. Neural and behavioral responses to tryptophan depletion in unmedicated patients with remitted major depressive disorder and controls. Arch Gen Psychiatry. 61, 765-773.

Ossenkopp, K. P. and Mazmanian, D. S., 1985. The measurement and integration of behavioral variables: aggregation and complexity as important issues. Neurobehav Toxicol Teratol. 7, 95-100.

Perkins, M. N. and Stone, T. W., 1982. An iontophoretic investigation of the actions of convulsant kynurenines and their interaction with the endogenous excitant quinolinic acid. Brain Res. 247, 184-187.

Prast, H. and Philippu, A., 2001. Nitric oxide as modulator of neuronal function. Prog Neurobiol. 64, 51-68.

Prickaerts, J., Raaijmakers, W. and Blokland, A., 1996. Effects of myocardial infarction and captopril therapy on anxiety-related behaviors in the rat. Physiol Behav. 60, 43-50.

Prickaerts, J., van Staveren, W. C., Sik, A., Markerink-van Ittersum, M., Niewohner, U., van der Staay, F. J., Blokland, A. and de Vente, J., 2002. Effects of two selective phosphodiesterase type 5 inhibitors, sildenafil and vardenafil, on object recognition memory and hippocampal cyclic GMP levels in the rat. Neuroscience. 113, 351-361.

Riedel, W. J., Klaassen, T., Deutz, N. E., van Someren, A. and van Praag, H. M., 1999. Tryptophan depletion in normal volunteers produces selective impairment in memory consolidation. Psychopharmacology (Berl). 141, 362-369. 
Riedel, W. J., Klaassen, T. and Schmitt, J. A., 2002. Tryptophan, mood, and cognitive function. Brain Behav Immun. 16, 581-589.

Rutten, K., Lieben, C., Smits, L. and Blokland, A., 2007. The PDE4 inhibitor rolipram reverses object memory impairment induced by acute tryptophan depletion in the rat. Psychopharmacology (Berl). 192, 275-282.

Sarter, M., Hagan, J. and Dudchenko, P., 1992. Behavioral screening for cognition enhancers: from indiscriminate to valid testing: Part I. Psychopharmacology (Berl). 107, 144-159.

Saucier, D. and Cain, D. P., 1995. Spatial learning without NMDA receptor-dependent long-term potentiation. Nature. 378, 186-189.

Schmitt, J. A., Jorissen, B. L., Sobczak, S., van Boxtel, M. P., Hogervorst, E., Deutz, N. E. and Riedel, W. J., 2000. Tryptophan depletion impairs memory consolidation but improves focussed attention in healthy young volunteers. J Psychopharmacol. 14, 21-29.

Shutoh, F., Hamada, S., Shibata, M., Narita, M., Shiga, T., Azmitia, E. C. and Okado, N., 2000. Long term depletion of serotonin leads to selective changes in glutamate receptor subunits. Neurosci Res. 38, 365-371.

Sik, A., van Nieuwehuyzen, P., Prickaerts, J. and Blokland, A., 2003. Performance of different mouse strains in an object recognition task. Behav Brain Res. 147, 49-54.

Stallings, M. C., Cherny, S. S., Young, S. E., Miles, D. R., Hewitt, J. K. and Fulker, D. W., 1997. The familial aggregation of depressive symptoms, antisocial behavior, and alcohol abuse. Am J Med Genet. 74, 183-191.

Sullivan, P. F., Neale, M. C. and Kendler, K. S., 2000. Genetic epidemiology of major depression: review and meta-analysis. Am J Psychiatry. 157, 1552-1562.

Sullivan, P. F., Wells, J. E., Joyce, P. R., Bushnell, J. A., Mulder, R. T. and Oakley-Browne, M. A., 1996. Family history of depression in clinic and community samples. J Affect Disord. 40, 159-168.

Van den Hove, D. L., Blanco, C. E., Aendekerk, B., Desbonnet, L., Bruschettini, M., Steinbusch, H. P., Prickaerts, J. and Steinbusch, H. W., 2005. Prenatal restraint stress and long-term affective consequences. Dev Neurosci. 27, 313-320.

van der Staay, F. J. and Blokland, A., 1996. Behavioral differences between outbred Wistar, inbred Fischer 344, brown Norway, and hybrid Fischer 344 x brown Norway rats. Physiol Behav. 60, 97-109.

van Eijk, H. M., Rooyakkers, D. R. and Deutz, N. E., 1993. Rapid routine determination of amino acids in plasma by high-performance liquid chromatography with a 2-3 microns Spherisorb ODS II column. J Chromatogr. 620, 143-148.

Winters, B. D. and Bussey, T. J., 2005. Removal of cholinergic input to perirhinal cortex disrupts object recognition but not spatial working memory in the rat. Eur J Neurosci. 21, 2263-2270.

Winters, B. D., Forwood, S. E., Cowell, R. A., Saksida, L. M. and Bussey, T. J., 2004. Double dissociation between the effects of peri-postrhinal cortex and hippocampal lesions on tests of object recognition and spatial memory: heterogeneity of function within the temporal lobe. J Neurosci. 24, 5901-5908.

Young, S. N., 1996. Behavioral effects of dietary neurotransmitter precursors: basic and clinical aspects. Neurosci Biobehav Rev. 20, 313-323.

Zhou, D., Schreinert, M., Pilz, J. and Huether, G., 1996. Rat strain differences in the vulnerability of serotonergic nerve endings to neurotoxic damage by p-chloroamphetamine. J Neural Transm. 103, 1381-1395. 
The influence of chronic mild stress on the behavioural effects of acute tryptophan depletion induced by a gelatinbased mixture

L. A. W. Jans, A. Blokland Submitted for publication 


\section{Abstract}

Several types of stress can increase the vulnerability to develop depression. This may be caused by stress effects on the serotonergic system that make the system more vulnerable. Serotonergic vulnerability entails that differences between people in the regulation of serotonin determine the vulnerability of an individual to develop depression or other serotonin-related disorders. The aim of the present experiment was to evaluate whether chronic mild stress (CMS) results in chronic or long-lasting serotonergic vulnerability, reflected by a stronger behavioural response to ATD several weeks after the CMS had ended. Wistar rats were exposed to three weeks of CMS followed by a two-week resting period. Subsequently the rats were repeatedly subjected to treatment with a gelatin-based protein-carbohydrate mixture, either with or without L-tryptophan. The CMS caused anhedonia, blunted weight gain and lower corticosterone levels. As expected, after the two-week resting period CMS had no effects on behaviour, except an increased escape latency in the home cage emergence test in CMS rats. There were no CMS $\times$ ATD interaction effects on behaviour. Acute tryptophan depletion also had some effects on behaviour, such as reduced time spent in the open zones of the zero maze and increased aggressive behaviour in the social interaction test in controls and impaired object memory in all rats. The CMS did not result in increased sensitivity to ATD, only on the social interaction test did the CMS rats react stronger to ATD than the controls. CMS TRP- rats showed less passive body contact than CMS $\mathrm{TRP}+$ rats. Overall, we conclude that CMS did not result in long-lasting vulnerability of the 5-HTergic system, as measured by the behavioural response to ATD two weeks and longer after the CMS had ended. 


\section{Introduction}

Depression results from a combination of innate and environmental factors that each modify the risk of an individual to develop symptoms. Stress is one of the most potent environmental factors (Markus 2003). Depression is often preceded by stressors (van Praag 2004) and chances to develop a depressive episode are increased five or six fold after stressful life events (Connor and Leonard 1998). There is also evidence to indicate that exposure to chronic low grade stress may predispose to depression (Willner 1990). Stress consists of a threatening of homeostasis to which the organism reacts with biological changes that are probably an adaptive response, serving to sustain well-being (Anisman and Merali 2003; Markus 2003). During stress, activity of the brain serotonin (5-Hydroxytryptamine, 5-HT) system and hypothalamic-pituitary-adrenal (HPA) axis rises. Acutely, increased corticosteroid levels cause higher CNS 5-HT turnover by increasing tryptophan availability and stimulation of tryptophan hydroxylase activity (Davis et al. 1995; Maccari et al. 2003) and increased responsivity of the $5 \mathrm{HT}_{1 \mathrm{~A}}$ receptor system (Meijer and de Kloet 1994; Young et al. 1994).

A person may adapt to the stressor by responding in a way that reduces the impact of the stressor (Prickaerts and Steckler 2005). If this coping fails, stress can result in a long-lasting state of distress, which is reflected in abnormal HPA axis activity and altered limbic function. When cortisol/corticosterone levels remain high, this will in time result in decreased 5-HT turnover and 5- $\mathrm{HT}_{1 \mathrm{~A}}$ responsivity and increasing the risk of developing depression (de Kloet et al. 2005; van Praag 2004).

5 -HT is known to be involved in many physiological and behavioural processes, including mood, appetite, sleep, activity, sexual behaviour, and cognition. Although the mechanisms underlying depression are not yet fully understood, there is general consensus that 5-HT is involved in depression. The original hypothesis that low serotonin has a direct role in depression has been through several modifications and low 5-HTergic neurotransmission is now thought to operate as a biological risk factor, that may play an important role in the triggering and maintenance of mood disorders (Maes and Meltzer 1995). Recently, serotonergic functioning has been proposed as a vulnerability factor in the development of depression and other 5-HT related symptoms and disorders (Jans et al. 2007b). Vulnerability of the serotonergic system (serotonergic vulnerability, SV) means that there is a vulnerability or increased sensitivity to alterations or dysregulations in the serotonergic system, hence SV can be demonstrated by challenging the 5-HT system; vulnerable and non-vulnerable subjects will react differently to these manipulations (Jans et al. 2007b).

According to this view, the serotonergic functioning of an individual determines the vulnerability of that individual to develop 5 -HT related disorders. This implies that there are differences in the 5-HT functioning between individuals and that the development of depression, anxiety, or other 5-HT related disorders is associated with the presence of a priori abnormalities in the functioning of this system. There are various factors that may interfere with 5-HTergic functioning and stress is one of these factors. 
Stress may disrupt the 5-HT system, resulting in serotonergic vulnerability, but psychopathological symptoms do not occur until a threshold is reached where the system can no longer compensate for the disrupted 5-HTergic functioning (Jans et al. 2007b). This implies that stress alone may result in vulnerability of the 5-HT system, but may not be enough to cause symptoms. A further challenge of the 5-HT system may then elicit symptoms such as increased anxiety- and depression- related behaviour. As stress influences several physiological processes and neurotransmitter systems including the 5 -HT system, and predisposes to depression, the question is whether stress can cause increased vulnerability to a challenge of the 5-HTergic system, indicating SV.

In an attempt to answer this question, rats were exposed to pretreatment with chronic mild stress (CMS) and, at a later stage, treatment with acute tryptophan depletion (ATD) in order to challenge the 5-HTergic system in order to reveal possible SV. CMS induces anhedonia (Willner et al. 1992), a core symptom of depression that is defined as "the decreased capacity to experience pleasure of any sort" (Fawcett et al. 1983). CMS models anhedonia by inducing a decrease in responsiveness to reward, generally reflected by decreased intake or preference of a sucrose-solution (Willner 2005; Willner et al. 1992). The reduction in sucrose intake by CMS is a robust effect that can be returned to normal by chronic antidepressant treatment, including treatment with several SSRIs (Grippo et al. 2006; Muscat et al. 1992; Papp et al. 2002; Przegalinski et al. 1995). CMS also causes behavioural changes in animals that resemble symptoms of depression, including decreased sexual and aggressive behaviour and decreased anxiety in the elevated plus maze, whereas social interaction was not affected (D'Aquila et al. 1994). Increased immobility in the forced swim test has been reported repeatedly (Bielajew et al. 2003; Garcia-Marquez and Armario 1987; Molina et al. 1994). Rats exposed to CMS gain weight more slowly than control rats (Muscat and Willner 1992) and show corticosterone hypersecretion (Ayensu et al. 1995) indicating increased HPA axis activity. CMS causes changes in the binding properties of neuroreceptor systems, including decreases in $\mathrm{D}_{2} / \mathrm{D}_{3}$ receptors in the nucleus accumbens and increases in cortical beta-adrenergic, hippocampal 5- $\mathrm{HT}_{1 \mathrm{~A}}$ and cortical 5- $\mathrm{HT}_{2 \mathrm{~A}}$ receptors (Dziedzicka-Wasylewska et al. 1997; Klimek and Papp 1994; Papp et al. 1994a; b; Papp et al. 2002; Papp et al. 1994c).

In order to reveal possible SV, we used ATD to challenge the 5-HT system. In ATD, L-tryptophan (TRP) - the essential amino acid that is the precursor of 5-HT - is depleted, resulting in lower central 5-HT levels. The method of ATD has been frequently used as a tool to reduce systemic TRP levels and consequently central 5-HT concentrations (Biggio et al. 1974; Fernstrom and Wurtman 1997; Gessa et al. 1974; Moja et al. 1989). ATD is a non-intrusive and reversible method that can be applied to investigate the role of 5-HT in behavioural functions (e.g., anxiety, sleep, aggression, memory, impulsivity) in humans as well as in animals (Bell et al. 2001; Moore et al. 2000; Young 1996). Previous studies in our lab using a gelatin-based-carbohydrate mixture showed a robust reduction in plasma TRP (about 70\%) and central tissue 5-HT (about 40-45\%) concentrations in male Wistar rats (Lieben et al. 2004a). In male Wistar rats, this ATD 
method has been reported to impair object memory, but not affective behaviour (Lieben et al. 2004b). In healthy human volunteers, ATD generally results in memory impairments, whereas other effects of ATD, such as effects on mood, are only found in vulnerable subjects, for example subjects with a personal or family history of depression and subjects with a genetic vulnerability (Booij et al. 2003; Riedel et al. 1999; Riedel et al. 2002a; Schmitt et al. 2000). Thus, vulnerable subjects are assumed to show a stronger behavioural response to this 5-HT challenge than non-vulnerable subjects, for example a stronger anxiety- or depression-like response on one of the behavioural tests.

In this study we examined the effects of this TRP-free protein-carbohydrate mixture on affective and cognitive behaviour in adult male Wistar rats that had previously been exposed to chronic mild stress (CMS pretreatment) or not (control pretreatment). All animals were tested in models of anxiety-related behaviour (open field test, home cage emergence test, elevated zero maze, social interaction test), depression-related behaviour (forced swim test) and cognition (object recognition test). The magnitude of TRP depletion was determined by measuring plasma amino acid concentrations. Because the aim of this study was to evaluate whether CMS caused chronic/long-lasting vulnerability of the serotonergic system, the CMS period was followed by a two-week resting period, before the effects of ATD on behaviour were tested. This period was applied since we intended to induce a difference in SV without $a$ priori behavioural differences between both experimental groups. This study design allows interpreting a stronger behavioural effect of ATD in the CMS group in terms a vulnerable 5-HT system.

\section{Experimental procedures}

\section{Animals}

All experimental procedures were approved by the local ethical committee of the Maastricht University for animal experiments and met governmental guidelines. Subjects were 48 two-month-old male Wistar rats weighing between 226 and $274 \mathrm{~g}$ at arrival (Charles River, The Netherlands). The rats were housed in standard Macrolon cages on sawdust bedding in an air-conditioned room $\left( \pm 21^{\circ} \mathrm{C}\right)$. They were housed individually during the CMS period and two per cage during the behavioural tests except for the object recognition test. The animals always had free access to water. They were kept under a reversed 12/12-h light/dark cycle. The lights were on from 17.00-05.00 h. A radio, which was playing softly, provided background noise.

\section{Drugs and chemicals}

The Gelatin hydrolysate (Solugel P') was obtained from PB Gelatins (Tessenderlo, Belgium). Glucodry 210 was obtained from Tate \& Lyle (Koog aan de Zaan, The Neth- 
erlands). Kaliumchloride (KCl), calciumchloride-dihydrate $\left(\mathrm{CaCl}_{2} \cdot 2 \mathrm{H}_{2} \mathrm{O}\right)$ and 5-sulfosalicylic acid dihydrate were purchased from Merck (Darmstadt, Germany). Tryptophan and sucrose were obtained from Sigma (Zwijndrecht, The Netherlands).

\section{Sucrose consumption}

The rats were habituated to drinking a $1 \%$ sucrose solution by replacing the normal water with the sucrose solution for $48 \mathrm{~h}$, while the rats had ad libitum access to food. On the next day, baseline sucrose consumption in the sucrose consumption test was measured. In this procedure, all rats were deprived of food and water for $14 \mathrm{~h}$, starting at the beginning of the dark phase of the light/dark cycle. After the $14 \mathrm{~h}$ deprivation period, the rats were provided with the sucrose-solution for one hour and the amount each rat drank was calculated in $\mathrm{ml} / \mathrm{kg}$, corrected for body weight. This procedure was repeated with all animals once a week during the CMS period and once more two weeks after the CMS.

\section{Chronic mild stress}

The rats were matched on baseline sucrose consumption and body weight and divided into the CMS-group and the control group, with $n=24$ in each group. The CMS period lasted three weeks. Stressors for the CMS were food and water deprivation, lights on and off every hour, housing in mouse cages, tilting the cages $45^{\circ}, 300 \mathrm{ml}$ cold water in the cage, stroboscopic light, housing in dirty cages (with excreta of another rat), and housing in empty cages without sawdust. On Monday to Friday rats in the CMS group were exposed to two stressors a day, each for the duration of two h. In order to maintain a low level of predictability, times and order of the CMS were not fixed, but one always took place in the morning and one in the afternoon. On Saturday all rats underwent the sucrose consumption test. On Sunday the CMS rats were exposed to two stressors simultaneously for a duration of $6 \mathrm{~h}$, one of the stressors always being lights on during the dark period or food deprivation. CMS rats were exposed to stressors in a different room than where the controls were housed. During the CMS period the rats in the control group were left undisturbed as much as possible, except for weekly measurement of body weight and sucrose consumption. At the end of the CMS period blood samples were taken to measure corticosterone levels. After the CMS period, there was a two-week resting period, in which all rats were left undisturbed except from weekly body weight measurements. After two weeks, sucrose consumption was measured again.

\section{Corticosterone measurement}

On the day after the CMS period, blood samples were taken for measuring corticosterone (CORT) levels between 12 and 15.30. Within $90 \mathrm{~s}$ of taking the rat from its home cage, a first blood samples was collected to determine baseline CORT levels. Immedi- 
ately after taking this first blood sample the rat was placed in a mouse cage with $500 \mathrm{ml}$ water of $25^{\circ} \mathrm{C}$ for 20 minutes, after which a second blood sample was taken. After this, the rat was returned to its home cage and left undisturbed for 40 minutes after which a third blood sample was taken. CORT was measured again, following the same procedure, after all behavioural tests were finished. In this measurement, effects of TRP+ and TRP- on CORT were studied. Baseline blood samples were collected $4 \mathrm{~h}$ after the first injection with TRP+ or TRP-.

Blood samples were kept on ice and subsequently centrifuged at $3000 \mathrm{~g}$ for $10 \mathrm{~min}$ utes at $4^{\circ} \mathrm{C}$ after which the plasma was frozen down at $-80^{\circ} \mathrm{C}$ for subsequent determination. For the determination of the plasma CORT concentrations, $50 \mu \mathrm{l}$ of plasma was extracted with $3 \mathrm{ml}$ dichloromethane and vortexed for $1 \mathrm{~min}$. The CORT was then measured directly on $1 \mathrm{ml}$ dried dichloromethane and extracted for radioimmunoassay using corticosterone- ${ }^{125}$ I. The radioimmunological reaction was performed overnight at $4^{\circ} \mathrm{C}$, after which a second antibody system was used to separate bound and unbound steroid as previously described in detail (Sulon et al. 1978).

\section{Acute tryptophan depletion}

During one week preceding the behavioural tests the rats were habituated to oral injections with normal tap water (up to $10 \mathrm{ml} / \mathrm{kg}$ ). On testing days the rats were treated with a protein-carbohydrate mixture containing TRP (TRP+ group, $0.30 \%$ TRP of the total protein) or lacking TRP (TRP- group). The rats received two doses of $10 \mathrm{ml} / \mathrm{kg}$ with a 90 -minute interval. Each administration contained $4.0 \mathrm{~g}$ Solugel P/kg and $2.0 \mathrm{~g}$ Glucodry $210 / \mathrm{kg}$ of the body weight. The composition of the nutritional mixture is shown in Table 1.

The rats were fasted from at least $12 \mathrm{~h}$ prior to treatment until the testing period was completed. This was done to minimize the availability of TRP from food. Behavioural testing was conducted $4 \mathrm{~h}$ after the first oral administration. At the end of each testing day, the animals had ad libitum access to food for at least 3 hours. The rats were randomly assigned to treatment with $\mathrm{TRP}+$ or TRP- for each test separately, except for the object recognition test, where all rats were treated with both TRP+ and TRP- on different days. An overview of the order of testing and the number of times the rats were treated with the mixture is given in Table 2.

For the determination of plasma amino acid levels blood samples were taken at resting values (T0; i.e., $10 \mathrm{~min}$ before the first oral administration) and repeated at $4 \mathrm{~h}$ after the first administration (T4). Blood sampling was done via a tail-incision method (Fluttert et al. 2000). Promptly after collection of blood in a sodium heparin tube (Microvette ${ }^{\varpi} \mathrm{CB}$ 300 , Sarstedt, Germany), the samples were kept on ice. After centrifugation of the blood samples (at $4^{\circ} \mathrm{C}$ for $15 \mathrm{~min}$ at $3000 \mathrm{~g}$ in a Hettich EBA 12 centrifuge), plasma was deproteinised with cups containing dry 5-sulfosalicylic acid ( $17 \mu \mathrm{l}$ of a $5 \mathrm{mg} / 10 \mathrm{ml}$ milliQ water solution with $100 \mu$ l plasma) and the protein was spun down. Samples were frozen in liquid nitrogen and stored at $-80^{\circ} \mathrm{C}$. Before analysis, samples were thawed at $4^{\circ} \mathrm{C}$, vor- 
tex-mixed vigorously and centrifuged at 50,000 g in a Hereaus Model Biofuge Stratos for $10 \mathrm{~min}$ at $4^{\circ} \mathrm{C}$. From the clear supernatant $20 \mu \mathrm{l}$ was mixed with $1960 \mu \mathrm{l}$ water and 20 $\mu \mathrm{l}$ norvaline and stored in the cooled $\left(7^{\circ} \mathrm{C}\right)$ sample compartment until analysis. Plasma amino acid concentrations were determined with a fully automated high-performance liquid chromatography (HPLC) system after precolumn derivatization with o-phthaldialdehyde (OPA) (van Eijk et al. 1993). OPA-AA derivates were quantified with fluorescence detection. The concentrations of the total plasma amino acids were expressed as $\mu \mathrm{mol} / \mathrm{l}$.

Table 1: Composition of the treatment mixture.

\begin{tabular}{|c|c|c|}
\hline Protein $\left(\right.$ Solugel $\left.{ }^{\star}\right)$ in $100 \mathrm{ml}$ water & & $100 \mathrm{~g}$ \\
\hline Alanine & 8.4 & \\
\hline Arginine & 7.7 & \\
\hline Aspartic Acid/Asparagine & 4.5 & \\
\hline Glutamic Acid/Glutamine & 10.0 & \\
\hline Glycine & 23.3 & \\
\hline Histidine & 0.9 & \\
\hline Hydroxylysine & 1.5 & \\
\hline Hydroxyproline & 12.3 & \\
\hline Isoleucine & 1.2 & \\
\hline Leucine & 2.6 & \\
\hline Lysine & 3.3 & \\
\hline Methionine & 0.9 & \\
\hline Phenylalanine & 1.6 & \\
\hline Proline & 13.7 & \\
\hline Serine & 3.4 & \\
\hline Threonine & 1.9 & \\
\hline Tryptophan & 0.0 & \\
\hline Tyrosine & 0.6 & \\
\hline Valine & 2.2 & \\
\hline Carbohydrate (Glucodry 210) in $80 \mathrm{ml}$ water & & 50 \\
\hline KCL & & 0.094 \\
\hline $\mathrm{CaCl}_{2} \cdot 2 \mathrm{H}_{2} \mathrm{O}$ & & 2.32 \\
\hline L-tryptophan (TRP- group) & & 0 \\
\hline L-tryptophan (TRP+ group) & & 0.28 \\
\hline
\end{tabular}

\section{Behaviour}

Open field test The open field test was conducted in a square, clear Plexiglas box $(100 \times 100 \times 40 \mathrm{~cm})$, with an open top and a dark floor. The arena of the open field was subdivided in 'corner' (four squares each $16 \times 16 \mathrm{~cm}$ ), 'wall' (four rectangles each $16 \times 64 \mathrm{~cm}$ ) and 'center' (one square $64 \times 64 \mathrm{~cm}$ ) zones. Testing was carried out in dimmed white light. A camera was installed above the center of the field. Immediately after a rat was placed in the center of the open field, the movements and position of the animals were recorded and registered automatically by a computerized system (Ethovi- 
sion, Noldus Information Technology, Wageningen, The Netherlands). Reported are the time spent in the center and the corner zones of the open field and the total distance moved. Testing was carried out on three consecutive days, with one 5-minute trial a day for all rats. Between trials, the open field was cleaned with water and ethanol to prevent transmission of olfactory cures. Open field behaviour was tested between $13.00 \mathrm{~h}$ and $16.30 \mathrm{~h}$. Data of the three trials were aggregated to enhance reliability (Ossenkopp and Mazmanian 1985). These aggregated data strongly correlate with definitions of anxiety in other models, such as the plus maze and the light dark box (Blokland et al. 1992; Prickaerts et al. 1996; van der Staay and Blokland 1996).

Table 2. Overview of the experiment, order of the different behavioural tests and the number of treatments the rats received.

\begin{tabular}{|c|c|c|c|}
\hline Week & Day & Control group & $\begin{array}{c}\text { ATD treatments } \\
\text { per rat }\end{array}$ \\
\hline \multirow[t]{3}{*}{1} & $1-2$ & Habituation sucrose solution & \\
\hline & 3 & Sucrose consumption test & \\
\hline & 4 & Group division CMS and control & \\
\hline \multirow[t]{3}{*}{2} & 1 & Body weight & \\
\hline & $1-6$ & CMS (undisturbed) & \\
\hline & 7 & Sucrose consumption test & \\
\hline \multirow[t]{3}{*}{3} & 1 & Body weight & \\
\hline & $1-6$ & CMS (undisturbed) & \\
\hline & 7 & Sucrose consumption test & \\
\hline \multirow[t]{3}{*}{4} & 1 & Body weight & \\
\hline & $1-6$ & CMS (undisturbed) & \\
\hline & 7 & Sucrose consumption test & \\
\hline \multirow[t]{3}{*}{5} & 1 & Collecting blood for corticosterone & \\
\hline & $2-6$ & Resting period (both groups undisturbed) & \\
\hline & 7 & Body weight & \\
\hline \multirow[t]{2}{*}{6} & $2-6$ & Resting period (undisturbed) & \\
\hline & 7 & Sucrose consumption test & \\
\hline 7 & $1-7$ & Habituation ATD & 1 \\
\hline 8 & 3,5 & Collecting blood samples AA & 1 \\
\hline 9 & $1-6$ & Open field test ${ }^{*}$ & 3 \\
\hline 10 & $1-6$ & Elevated zero maze ${ }^{\star}$ & 3 \\
\hline 11 & $1-6$ & Home cage emergence test ${ }^{\star}$ & 3 \\
\hline 12 & 2,5 & Social interaction test ${ }^{\star}$ & 2 \\
\hline 13 & $3-5$ & Forced swim test ${ }^{*}$ & 3 \\
\hline 14 & $1-6$ & Training Object recognition test & \\
\hline 15 & $1-4$ & Object recognition test ${ }^{\sharp}$ & 2 \\
\hline 16 & $2-3$ & Collecting blood for corticosterone & 1 \\
\hline 17 & $2-5$ & Collecting blood and brain samples AA & 1 \\
\hline
\end{tabular}


Elevated zero maze The zero-maze, originally described in Shepherd et al. (Shepherd et al. 1994), was made of black plastic that was transparent for infrared light. It consisted of a circular runway ( $98 \mathrm{~cm}$ in diameter, $10 \mathrm{~cm}$ path width, $14 \mathrm{~cm}$ above floor level) which was divided equally into two opposite open and two opposite parts enclosed with $50 \mathrm{~cm}$ high side walls. A $7 \mathrm{~mm}$ high edge surrounded the open parts to prevent rats from falling of the maze. A rat was placed into one of the open parts facing a closed part and allowed to explore the maze over a period of $5 \mathrm{~min}$. The duration a rat spent in the open and closed zones and the total distance moved in the maze were measured under low light conditions via an infrared video camera connected to a video tracking system (Ethovision, Noldus Information Technology, Wageningen, The Netherlands). Between trials, the zero maze was cleaned with water and ethanol to prevent transmission of olfactory cures. Testing was carried out between $13.00 \mathrm{~h}$ and $16.30 \mathrm{~h}$ on three consecutive days, with one trial a day for all rats. Data of the three trials were aggregated to enhance reliability.

Home cage emergence test In the home cage emergence test the home cage was placed in an arena and the lid of the cage was removed (Prickaerts et al. 1996). During the testing of one rat, its cage mate was placed in another cage for the duration of the trial. A grid was placed over the edge of the cage to make it easier for the rats to leave the home cage. Testing was carried out in dimmed white light. A stopwatch was used to measure the latency to leave the cage. The experimenter measured the time it took for the rat to climb out of its cage into the arena. A criterion was set to determine the escape time. Time was stopped and the trial ended when all four paws of the rat were over the edge of the cage. If the rat did not emerge from its home cage within $300 \mathrm{~s}$, the trial was ended, the home cage was closed again and the rat was given a score of 300 . This test was carried out on three consecutive days.

Social interaction test In the social interaction test (File and Hyde 1978; File and Seth 2003) two rats were placed in closed part of the open field, $50 \times 50 \times 40 \mathrm{~cm}$ with two black and two transparent walls. The two animals that were tested together were weight matched and of the same pretreatment (both CMS or both control), and had received the same treatment (both TRP- or both TRP+). The animals were placed in the test area at the same time and spend 10 minutes together, which were videotaped for later offline analysis by an observer who was blind to the treatment of the rats. Per interaction duo, the duration of general investigation, anogenital investigation, aggressive behaviour, passive body contact and rearing were measured. General investigation consisted of sniffing, grooming, etc the other rat, except for the anogenital region. Aggressive behaviour comprised mainly kicking the other rat. During passive body contact, the rats touch each other, but do not explore, i.e. sitting or lying together.

Forced swim test Three cylindrical transparent plastic tanks $(40 \mathrm{~cm}$ tall $\times 17 \mathrm{~cm}$ diameter), filled to a depth of $30 \mathrm{~cm}$ with $22( \pm 1)^{\circ} \mathrm{C}$ water, were used in the forced swim 
test. Testing was carried out over two consecutive days. When the animals were placed in the water, their movements and position were recorded and registered automatically by a computerized system (Ethovision, Noldus Information Technology, Wageningen, The Netherlands). Reported are the time the rats spent in behavioural immobility, mobility and strong mobility. The behavioural variable 'immobility' was defined as follows: making no movements or only making those movements that were necessary to keep the nose above the water. It was allowed for the rats to move their forepaws or support themselves by pressing their paws against the wall of the cylinder. Active climbing and swimming along the wall were categorized as strong mobility.

Object recognition test The object recognition test was performed as described in detail elsewhere (Ennaceur and Delacour 1988; Prickaerts et al. 2002). During training and testing, the rats were housed individually. The apparatus consisted of a circular arena, $83 \mathrm{~cm}$ in diameter. Half of the 40 -cm-high wall was made of grey polyvinyl chloride, the other half of transparent polyvinyl chloride. Testing was carried out in dimmed white light. We used four different sets of objects that could not be displaced by a rat. Each object was available in triplicate. The different objects were: 1) a cone consisted of a grey polyvinyl chloride base (maximal diameter $18 \mathrm{~cm}$ ) with collar on top made of brass (total height $16 \mathrm{~cm}$ ), 2) a standard 11 transparent glass bottle (diameter $10 \mathrm{~cm}$, height $22 \mathrm{~cm}$ ) filled with water, 3$)$ a massive metal cube $(10 \times 5 \times 7.5 \mathrm{~cm})$ with two holes (diameter $1.9 \mathrm{~cm})$, and 4) a massive aluminium cube with a tapering top $(13 \times 8 \times 8 \mathrm{~cm})$.

In the week preceding treatment, the animals were adapted to the procedure, i.e., they were allowed to explore the apparatus (without any objects) twice for 3 minutes. In the following days, the rats were tested until a stable discrimination performance was shown. A testing session comprised two trials. The duration of each trial was $3 \mathrm{~min}$. Two objects were placed in a symmetrical position about $10 \mathrm{~cm}$ away from the grey wall. A rat was always placed in the apparatus facing the wall at the middle of the front (transparent) segment. During the first trial the apparatus contained two identical objects. After the first exploration period the rat was put back in its home cage. One hour later the rat was put back in the apparatus for the second trial, but now with dissimilar objects, a familiar one and a new one. The duration of exploring each object in both trials was recorded manually with a personal computer. Exploration was defined as directing the nose to the object at a distance of no more than $2 \mathrm{~cm}$ and/or touching the object with the nose. Sitting on the object was not considered as exploratory behaviour. In order to avoid the presence of olfactory trails, the objects were always thoroughly cleaned. Moreover, each object was available in triplicate so that none of the two objects from the first trial had to be used as the familiar object in the second trial. In addition, all combinations and locations of objects were used in a balanced manner to reduce potential biases due to preferences for particular locations or objects.

After the rats were familiarized to the procedures of the task, testing with treatment began. The first trial was given $4 \mathrm{~h}$ after the first oral administration. The delay 
interval of one hour was preferable since during this time, we expected the plasma TRP levels to remain at low level. The basic measures were the total exploration time of both objects during trial 1 and trial 2, e1 and $e 2$, respectively. Rats that explored less than 10 seconds in any of the trials or explored only one of the objects were removed from analysis to avoid possible erroneous conclusions. A discrimination index $d 2(d 2=($ exploration new object - exploration familiar object $) /$ total exploration time during test trial) were calculated.

\section{Statistical analysis}

For all variables, treatment effects were analysed using parametric statistics (ANOVA). Data of the open field test, home cage emergence test and forced swim test were aggregated over the three trials to enhance reliability (Ossenkopp and Mazmanian 1985). The mean scores over the three testing days were used in statistical analysis, as was done in comparable studies (Blokland et al. 2002; Jans et al. 2007a; Lieben et al. 2004b). Data of the home cage emergence test were not normally distributed, therefore rank scores were calculated. Data from the two trials of the social interaction test were treated as independent observations because the testing partner differed on the two trials. Plasma amino acid concentrations and CORT levels were analysed with repeated measures ANOVA to include the time factor. In order to test our specific hypotheses, we also analysed the effects of ATD treatment on behaviour in each CMS pretreatment group separately.

\section{Results}

\section{Chronic mild stress}

Body weight The effects of CMS pretreatment are shown in Figure 1. At the beginning of the study there was no difference in body weight between the CMS group and the control group $[\mathrm{F}(1,46)=2.79$, ns]. During the 3 weeks of CMS rats in both groups gained weight [Time $\mathrm{F}(2,92)=773.93, \mathrm{p}<0.001$ ] but the controls gained significantly more weight than the CMS rats [CMS: $\mathrm{F}(1,46)=17.94, \mathrm{p}<0.001]$. Over the 12 measurements of the entire experiment, both groups gained weight [Time: $F(11,495)=1051.29$, $\mathrm{p}<0.001$ ] but the controls gained more weight than the CMS rats [CMS: $\mathrm{F}(1,45)=4.34$, $\mathrm{p}<0.05]$. Further analysis revealed that the difference in weight was different during the CMS and resting period (Figure 1a) and remained significant until 6 weeks after the CMS period (data not shown).

Sucrose consumption As the rats were matched on baseline sucrose intake, there was no difference between the CMS group and the control group in sucrose consumption 
at the beginning of the CMS period [CMS pretreatment: $F(1,46)=0.004$, ns]. Sucrose intake was then measured at the end of each of the three weeks of CMS. There was no Time $\times$ CMS pretreatment interaction effect. During the CMS period, sucrose intake decreased over time [Time: $\mathrm{F}(2,90)=11.20, \mathrm{p}<0.001$ ]. In the CMS pretreatment group, sucrose intake was significantly lower than in the control pretreatment group [CMS pretreatment: $\mathrm{F}(1,45)=16.50, \mathrm{p}<0.001]$. Further analysis showed that the difference in sucrose intake between the CMS and the control group was significant at the end of week 2 and week 3 of the CMS. Sucrose intake was measured again at the end of the 2 week resting period that followed CMS/control pretreatment. At this point there was no difference in sucrose intake [CMS pretreatment: $F(1,46)=0.15$, ns]. Sucrose consumption data are shown in Figure 1b.
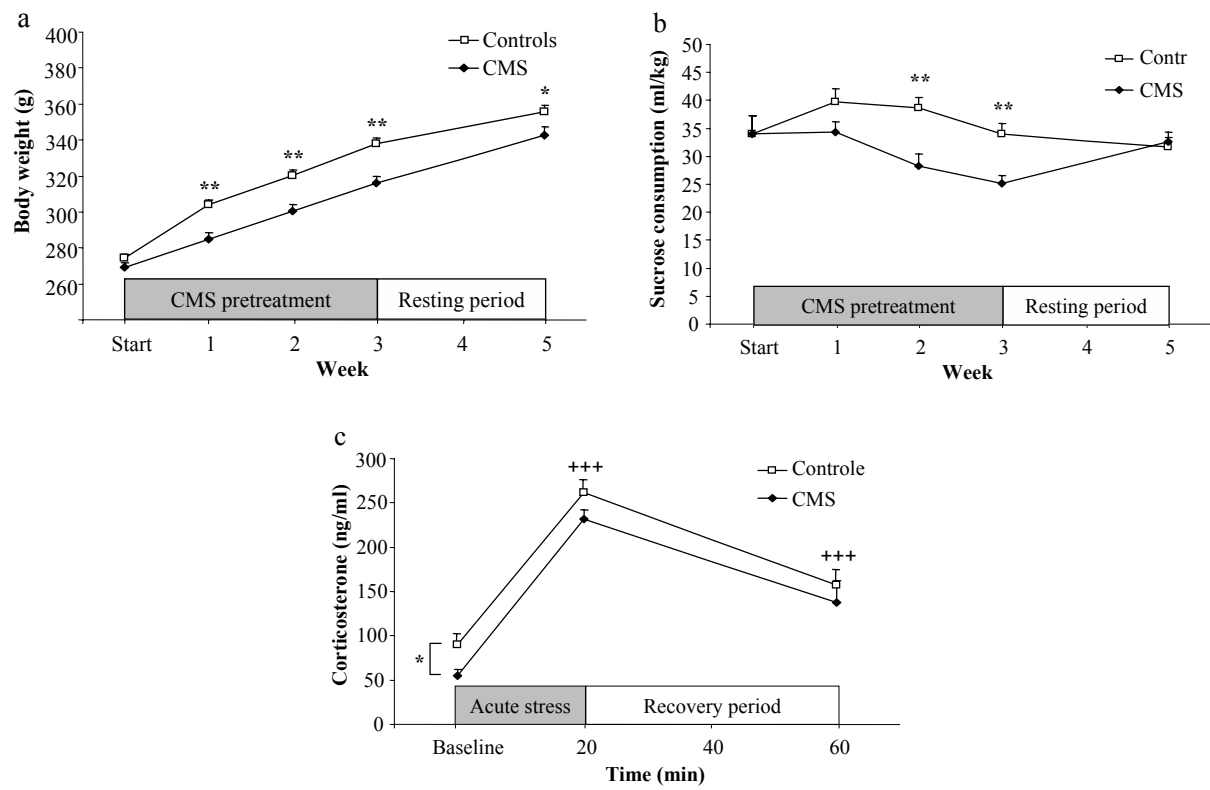

Figure 1. The effects of CMS on body weight (1a), sucrose consumption (1b), and corticosterone levels (1c). Data represent means and standard error bars. CMS effect ${ }^{*} \mathrm{p}<0.05$; Time effect ${ }^{+++} \mathrm{p}<0.001$.

Corticosterone levels CORT levels were measured for the first time after the CMS period (see table 2 ). There was no Time $\times$ CMS pretreatment interaction effect. CORT levels changed over the time of the three measurements (baseline, $20 \mathrm{~min}$, and $60 \mathrm{~min}$ after baseline; Figure 1c) [Time: $\mathrm{F}(2,30)=136.10, \mathrm{p}<0.001$ ]. There was a significant stress response $(\mathrm{T} 0-\mathrm{T} 20)[\mathrm{F}(1,15)=379.99, \mathrm{p}<0.001]$ and recovery $(\mathrm{T} 20-\mathrm{T} 60)[\mathrm{F}(1,15)=119.89$, $\mathrm{p}<0.001]$. CORT levels in the CMS pretreatment group were significantly lower than in the control condition [CMS pretreatment: $\mathrm{F}(1,15)=5.51, \mathrm{p}<0.05$ ]. 
When all behavioural tests were finished, blood samples were collected after TRP+ or TRP- treatment for the second CORT measurement (Figure 2). There was no CMS pretreatment $\times$ ATD treatment interaction effect and there were no effects of CMS pretreatment or ATD treatment individually on CORT levels [F's < 2.14]. In all groups, CORT levels changed over time in response to the acute stress and recovery from the stress [Time: $\mathrm{F}(2,56)=92.83, \mathrm{p}<0.001$ ].

During the stress response (baseline - T20), CORT levels increased significantly as a result of the acute stress $[F(1,28)=794.02, p<0.001]$. A Stress response $\times$ ATD treatment interaction effect was found $[\mathrm{F}(1,28)=5.16, \mathrm{p}<0.05]$, with $\mathrm{TRP}+$ treated rats showing a stronger CORT increase than the TRP- treated rats, irrespective of CMS pretreatment. When stress response effects were analysed within each CMS pretreatment and ATD treatment group, all groups showed a significant stress response [F's $>354.79$, p's $<0.001$. Within the TRP+ rats, the CMS rats showed lower CORT levels than the $\mathrm{TRP}+$ controls [CMS pretreatment: $\mathrm{F}(1,14)=8.46, \mathrm{p}<0.05$ ].

When looking at the recovery (T20 - T60), there was a general time effect $[\mathrm{F}(1,28)=27.03, \mathrm{p}<0.001]$ indicating that CORT levels were reduced after the recovery period. When recovery effects were analysed within each CMS pretreatment and ATD treatment group, it was found that TRP- treated rats did not show significant recovery of CORT levels from T20 to T60, whereas TRP+ treated rats did.

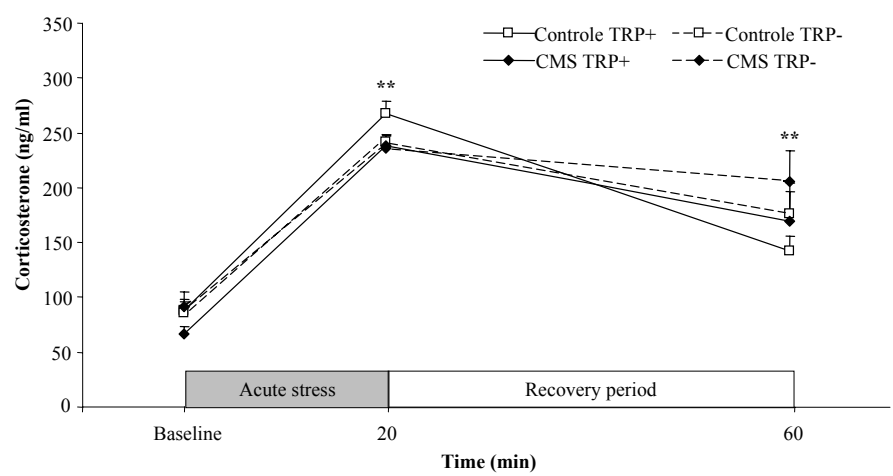

Figure 2. The effects of CMS pretreatment and ATD treatment on corticosterone levels at baseline, after acute stress and after recovery from acute stress. Data represent means and standard error bars. Time effect ${ }^{* *} \mathrm{p}<0.01$ (difference from baseline levels).

\section{Acute tryptophan depletion}

Plasma amino acid concentrations of TRP and the ratio of TRP over the sum of the other large neutral amino acids (TRP/ $\Sigma$ LNAA ratio) were calculated in the beginning and at 
the end of the study, i.e. before and after the period of behavioural testing. Data from both blood sampling measurements were pooled together, as there was no difference in treatment effects on TRP and the TRP/ $\Sigma$ LNAA ratio between the blood sampling measurements before and after the period of behavioural testing [F's $<1.78, \mathrm{~ns}]$.

Plasma levels of TRP and the TRP/ LLNAA ratio decreased over the four hours [Time: TRP $\mathrm{F}(1,56)=90.34, \mathrm{p}<0.001$; Ratio $\mathrm{F}(1,56)=185.55, \mathrm{p}<0.001]$. There was an ATD treatment effect on both TRP level $[\mathrm{F}(1,56)=24.68, \mathrm{p}<0.001]$ and the TRP $/ \Sigma$ LNAA ratio $[\mathrm{F}(1,56)=29.48, \mathrm{p}<0.001]$ and an interaction effect [Time $\times$ ATD Treatment: TRP $\mathrm{F}(1,56)=63.28, \mathrm{p}<0.001$; Ratio $\mathrm{F}(1,56)=83.38, \mathrm{p}<0.001]$ indicating that TRP and TRP/ $\Sigma$ LNAA ratio levels decreased much more in the TRP-condition compared to the TRP+ condition. Pretreatment with CMS did not affect baseline plasma TRP or the TRP/ $\Sigma$ LNAA ratio [F's $<1.26$, ns]. Treatment effects on the TRP/ $\Sigma$ LNAA ratio are shown in Figure 3.

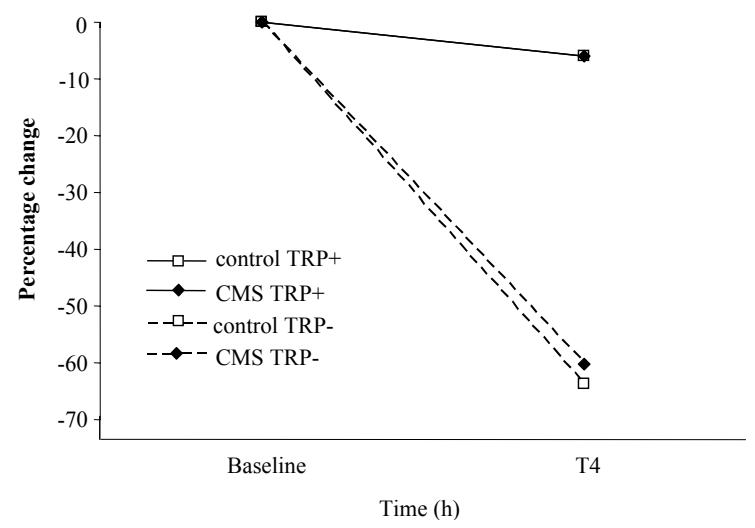

Figure 3. The effects of ATD treatment on the plasma TRP/ LLNAA ratio, shown as percentage decrease from baseline TRP/ $\Sigma$ LNAA ratio levels measured four hours after the first TRP+ or TRP-injection. Data represent means and standard error bars.

\section{Behaviour}

Open field test Aggregated data were calculated of the time spent in the center and corners of the open field and the total distance moved (Figure 4). There were no CMS Pretreatment $\times$ ATD Treatment interaction effects on any of the outcome measures. Neither pretreatment with CMS or control nor treatment with TRP+ or TRP- had any effect on any of the outcome parameters (all F's $<1.73$ ). When treatment effects were analysed within each pretreatment group there were no effects of treatment on any of the open field outcome parameters in the both the CMS group and the pretreatment control group. 

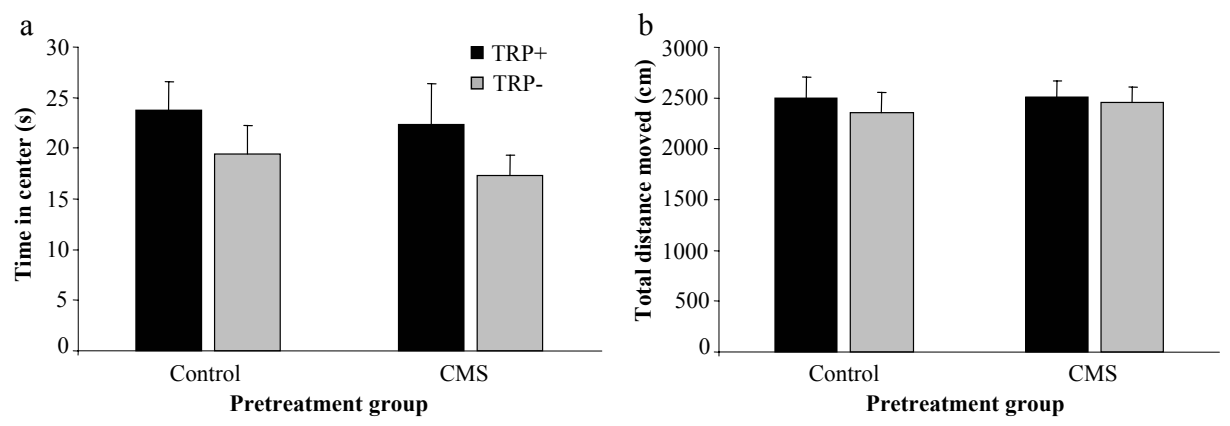

Figure 4. Open field test. The effects of CMS pretreatment and ATD treatment on time spent in the center (4a) and total distance moved (4b) in the open field test. Bars represent means and SEM.

Elevated zero maze There were no CMS Pretreatment $\times$ ATD Treatment interaction effects on the duration the rats spent in the closed and open zones of the zero maze or on the total distance moved (Figure 5). Neither were there any effects of pretreatment or treatment [All F's <2.66]. In the control group TRP+ treated rats spent more time in the open zones than in the closed zones whereas TRP- treated rats showed an opposite pattern [Treatment: $\mathrm{F}(1,19)=6.88, \mathrm{p}<0.05]$, an effect that was not found in the CMS group.
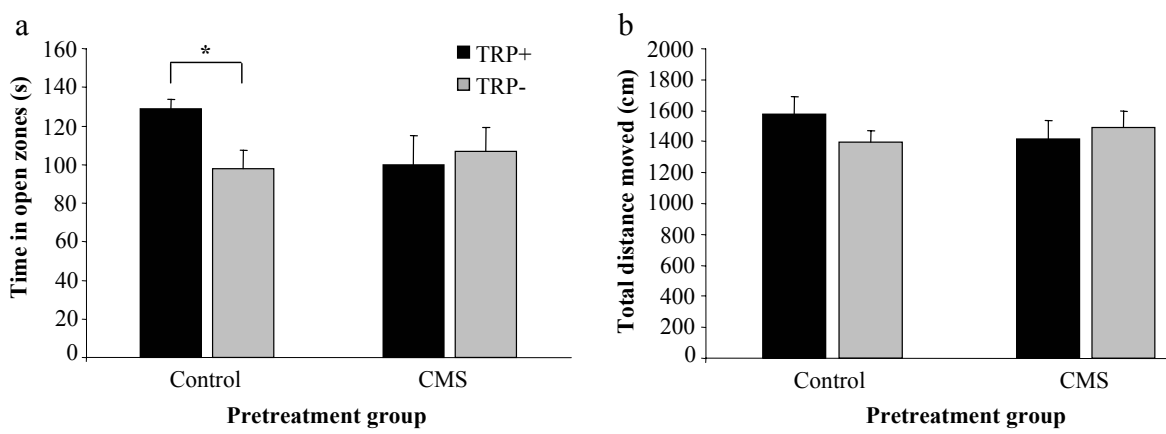

Figure 5. Elevated zero maze. The effects of CMS pretreatment and ATD treatment on time spent in the open zones (5a) and total distance moved (5b) in the zero maze. Bars represent means and SEM. ATD treatment effect ${ }^{*} \mathrm{p}<0.05$.

Home cage emergence test The aggregated data of the escape scores are shown in Figure 6. There was no CMS Pretreatment $\times$ ATD Treatment interaction effect and no treatment effect on escape latency. CMS Pretreatment did have an effect on escape latency, CMS rats had a longer escape latency compared to control rats $[F(1,39)=9.78, p<0.01]$. Further analysis showed that the CMS rats had a longer escape latency than the control rats in the TRP+ condition $[\mathrm{F}(1,20)=6.72, \mathrm{p}<0.05]$ but not in the TRP-condition. 


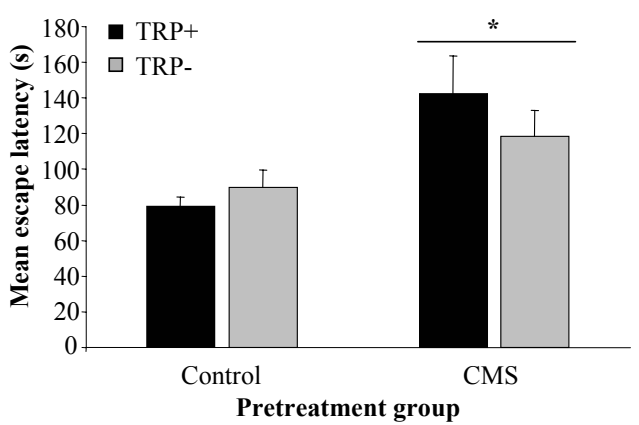

Figure 6. Home cage emergence test. Effects of CMS pretreatment and ATD treatment on escape latency in the home cage emergence test. Bars represent means and SEM. CMS pretreatment effect ${ }^{*} \mathrm{p}<0.05$.

Social interaction test There were no CMS Pretreatment $\times$ ATD Treatment interaction effects on the duration of general investigation, anogenital investigation, rearing, and passive body contact [F's < 3.35]. Pretreatment with CMS did not affect social interaction [F's $<1.03$ ]. TRP+ treated rats showed more passive body contact than TRPtreated rats (Figure 7a), irrespective of their pretreatment [Treatment: $F(1,38)=5.13$, $\mathrm{p}<0.05]$. Further analysis indicated that within the CMS group, TRP- treated rats showed less passive body contact than CMS TRP+ rats $[\mathrm{F}(1,20)=4.30, \mathrm{p}=0.05]$. For aggressive behaviour there was a trend towards a CMS Pretreatment $\times$ ATD Treatment interaction effect $[\mathrm{F}(1,37)=3.35, \mathrm{p}<0.08]$. When treatment effects were analysed within each pretreatment group, it was found that TRP- treated controls showed more aggressive behaviour that the TRP+ treated controls [Treatment: $\mathrm{F}(1,17)=4.57$, $\mathrm{p}<0.05$ ], whereas this treatment effect on aggressive behaviour was not found in the CMS pretreated rats (Figure $7 \mathrm{~b}$ ).
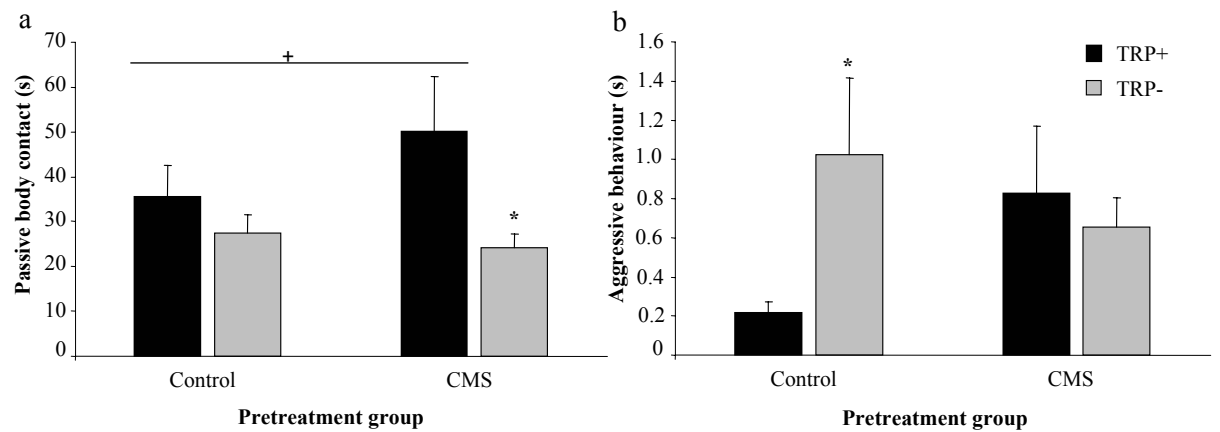

Figure 7. Social interaction test. Effects of CMS pretreatment and ATD treatment on passive body contact (7a) and aggressive behaviour (7b). Bars represent means and SEM. CMS pretreatment effect ${ }^{+} \mathrm{p}<0.05$; Treatment effect ${ }^{*} \mathrm{p}<0.05$. 
Forced swim test Data of the duration of immobility are shown in Figure 8. There was no significant interaction effect of CMS Pretreatment $\times$ ATD Treatment on the total duration of immobility and there were no effects of pretreatment or treatment [F's $<1.34, \mathrm{~ns}]$.

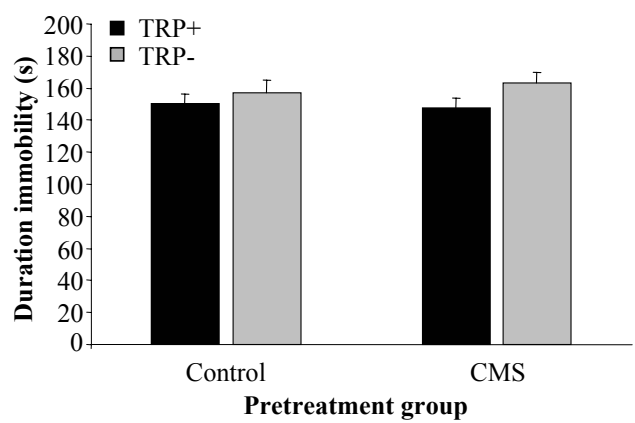

Figure 8. Forced swim test. The effects of CMS pretreatment and ATD treatment on the total duration of immobility. Bars represent means and SEM.

Object recognition test The effects of CMS pretreatment and ATD treatment on the performance in the object recognition test are summarized in Table 3. There were no CMS pretreatment $\times$ ATD treatment interaction effects on exploration time in trial 1 or trial 2 or on discrimination index $d 2$. Treatment did not affect the exploration time in trial 1 or trial 2. A clear treatment effect was found on $d 1[\mathrm{~F}(1,91)=11.31, \mathrm{p}<0.01]$ and on the discrimination index $(d 2)[\mathrm{F}(1,91)=9.89, \mathrm{p}<0.01]$, rats treated with TRP- did not discriminate between the novel and the known object in trial 2 after a one hour interval. In contrast, the rats treated with TRP+ showed a high preference to investigate the novel object. Pretreatment with CMS did not affect any of the outcome parameters of the object recognition test.

Table 3. Effects of treatment and experimental group on the measures of the object recognition test.

\begin{tabular}{cccr}
\hline \multirow{2}{*}{$\begin{array}{c}\text { Outcome } \\
\text { measure }\end{array}$} & \multirow{2}{*}{ Treatment condition } & \multicolumn{2}{c}{ Pretreatment group } \\
\cline { 3 - 4 }$e 1$ & TRP+ & Chronic mild stress & Control \\
\hline \multirow{2}{*}{$e$} & TRP- & $281.35(19.95)$ & $267.25(20.88)$ \\
& TRP+ & $270.83(13.98)$ & $276.04(16.95)$ \\
\multirow{2}{*}{$d 1^{* *}$} & TRP- & $391.91(22.52)$ & $389.63(35.69)$ \\
& TRP+ & $359.87(14.89)$ & $386.00(20.89)$ \\
\multirow{2}{*}{$d 2^{* *}$} & TRP- & $85.13(19.45)$ & $138.71(33.72)$ \\
& TRP+ & $33.61(23.01)$ & $20.92(21.90)$ \\
& TRP- & $0.22(0.05)$ & $0.32(0.07)$ \\
\hline
\end{tabular}

Values are mean (standard error). Treatment effect ${ }^{* *} p<0.01$. 


\section{Discussion}

In this study, rats were exposed to CMS and later treated with ATD to investigate whether the CMS procedure caused long-lasting SV. Immediately following the CMS rats were left undisturbed for two weeks, after which behavioural testing following TRP+ and/or TRPtreatment began. In this way we did not measure the direct effects of CMS on behaviour, but investigated whether CMS resulted in a long-lasting increase in vulnerability to show behavioural changes after ATD, reflecting SV.

During the CMS, rats in the CMS group consumed less of a sucrose solution and gained less weight than the controls. Immediately after the CMS, basal CORT levels were lower in CMS rats compared to controls, while both groups of rats showed a similar acute CORT response to stress and recovery from acute stress. After the resting period, sucrose consumption was back at baseline levels, but the CMS effect on body weight remained for six weeks after the CMS had ended. In conclusion, the CMS procedure was effective in that it resulted in anhedonia and other stress effects, and the subsequent resting period was effective in restoring some of these effects to normal values before ATD testing began.

Acute TRP depletion had similar effects on ratio TRP/ $\Sigma$ LNAA levels in CMS and control rats, TRP- treatment decreased this ratio with $60 \%$ and $64 \%$ respectively, compared to only $6 \%$ decrease in both groups after TRP+ treatment. There were no CMS pretreatment $\times$ ATD treatment effects or ATD treatment effects on behaviour in any of the tests. There were no effects of CMS pretreatment and ATD treatment on behaviour in the open field test and forced swim test. In the elevated zero maze, the control TRPrats spent less time in the open arms compared to control TRP+ treatment but the CMS rats did not show this effect. In the social interaction test there was an ATD treatment effect on passive body contact, which was higher in TRP+ rats than in TRP- rats, especially in the CMS pretreated rats. Furthermore, the control TRP- rats showed higher levels of aggressive behaviour compared to the control TRP+ treated rats. In the object recognition test it was found that TRP- treatment resulted in decreased object recognition, irrespective of CMS pretreatment.

After the behavioural tests, CORT was measured again. Whereas immediately after the CMS CORT levels had been lower in CMS rats, there was no difference after the behavioural tests. TRP- treatment appeared to blunt the acute CORT response to stress, irrespective of CMS pretreatment, similar to the effect that was seen in healthy humans (Riedel et al. 2002b). There was an overall recovery effect, with CORT levels decreasing after the acute stress had ended and the rat was returned to the home cage. Further analysis showed that the recovery effect was significant in TRP+ rats but not in TRP- rats. In other words, TRP- treatment appeared to blunt the acute CORT response to stress and the CORT recovery from acute stress, effects that were not found in an earlier study with a different ATD method that resulted in a plasma TRP depletion of about $40 \%$ (Blokland et al. 2002). Therefore it is likely that a stronger effect on TRP depletion is needed to affect the CORT response. 
As expected, after the two-week resting period CMS did not affect locomotor activity, social interaction, anxiety or immobility in the forced swim test. These type of behaviours were affected in other studies in which behavioural assessment was started directly after CMS (Bielajew et al. 2003; D’Aquila et al. 1994; Garcia-Marquez and Armario 1987). Sucrose consumption, which was decreased during the CMS period, was normal after the two-week resting period. Furthermore, corticosterone, which was altered by CMS before the resting period (week 5) was normal at the end of the study (week 16). However, CMS pretreatment increased the escape latency in the home cage emergence test (week 11), indicating that CMS had at least some effects on behaviour throughout the study. The general lack of CMS pretreatment effects on behaviour can be explained by the two-week resting period after the CMS, although other methodological differences, such as the duration of the CMS period and the strain of rats, may also play a role.

The aim of this study was to investigate whether CMS resulted in SV, reflected by a stronger behavioural response to ATD in the CMS rats, which in general was not found. There are several possible explanations for these findings. Perhaps the CMS was too mild or to short to result in long-lasting effects on the 5-HTergic system. Furthermore, the Wistar strain may not be the optimal strain for this study, because several studies have shown that Wistars do not show strong behavioural responses to ATD (Blokland et al. 2002; Jans et al. 2007a; Lieben et al. 2004b). A recent study by our group (Jans et al., submitted) showed that Sprague Dawley rats show stronger behavioural responses to ATD than Brown Norway rats. Thus, it cannot be excluded that the CMS procedure would have resulted in increased behavioural responses to ATD if another strain of rats was used.

Moreover, it is possible that the CMS did not result in SV because dopamine may be more important than 5-HT in regulating CMS-induced anhedonia. Although CMS has some effects on the 5-HT system (Klimek and Papp 1994; Papp et al. 1994a), the mesolimbic dopamine projections from the ventral tegmental area to the nucleus accumbens play a crucial role in mediating the behavioural effects of reward (Willner et al. 1992). Even though it has been shown that some SSRIs are effective in reversing CMS-induced anhedonia, it appeared that they do so via sensitisation of $\mathrm{D}_{2} / \mathrm{D}_{3}$ receptors in the nucleus accumbens, a final common pathway for the anti-anhedonic effects of antidepressant drugs, irrespective of their primary mechanism of action (Muscat et al. 1992). The involvement and interactions of neurotransmitters in the CMS effects appear to be complex, and perhaps, if vulnerability to develop psychiatric symptoms were to be caused by CMS, it might be, at least partly, related to other neurotransmitters than 5-HT, such as dopamine. ATD, apparently, does not challenge the CMS rat neurotransmitter systems in a way that compensation is no longer possible and behavioural effects occur. It cannot be concluded that stress does not result in SV. The CMS procedure that was used in the present study may not be a suitable model to study the incidence of stress-induced SV.

In this study CORT levels were lower in the CMS group than the control group, which was surprising because in general CMS results in higher CORT levels (Ayensu et 
al. 1995; Bielajew et al. 2002; Grippo et al. 2005) or no change in CORT levels (Stout et al. 2000; Willner et al. 1987). Lower CORT levels have been reported after prenatal stress (Gotz and Stefanski 2007). There are several possible explanations for the lower CORT levels after CMS that were found in the present study. In mice, for example, it has been shown that CMS caused an increase in CORT levels, but the CORT levels returned to normal values after three weeks despite continuing CMS (Silberman et al. 2004; Silberman et al. 2002); a similar pattern may have occurred in the present study. As we did not measure CORT after for example one week of CMS, this cannot be excluded.

It is also possible, however, that the present CMS procedure resulted in the equivalent of a specific subtype of depression that is characterized by lower cortisol levels: atypical depression. Whereas melancholic depression is characterised by a hyperactive stress system with high cortisol levels, anxiety, insomnia and lack of appetite; atypical depression is characterised by downregulated HPA axis activity, lethargy, hypersomnia and increased appetite (Association 1994; Gold and Chrousos 1999; Gold et al. 1988a; b). However, this does not explain the lack of significant effect on behavioural tests, especially the open field test, elevated zero maze and forced swim test.

Another possibility is that, instead of causing symptoms of depression, the CMS procedure resulted in posttraumatic stress disorder, an anxiety disorder that can develop after exposure to a severe stressful event. Post traumatic stress disorder is associated with increased avoidance, hyperarousal, and hypocortisolemia (Association 1994). Although an association between CMS and post traumatic stress disorder has not been reported before, the lower CORT levels after CMS in the present study might indicate such an association. It might be argued that the CMS procedure that was used in the present study may not have been that different from time-dependent sensitisation (TDS) (Harvey et al. 2003; Liberzon et al. 1997), a model for post traumatic stress disorder in which rats are exposed to three severe stressors on one day and again to one of those stressors eight days later. Behaviour and CORT are measured seven days after the last exposure to stress. This procedure appeared to result in increased anxiety and increased sensitivity to negative feedback (Harvey et al. 2006; Harvey et al. 2003; Liberzon et al. 1997), whereas CMS generally results in decreased sensitivity to fast feedback and hence higher CORT levels. This post traumatic stress theory would also explain the present finding that CMS rats took longer to climb out of their cage in the home cage emergence test, an indication of increased avoidance. On the other hand, the decrease in CORT after CMS reported here was no longer found at the end of the study, and besides the increased escape latency in the home cage emergence test, no other behavioural effects indicative of PTSD were found. Furthermore, it has been suggested that a stress-restress paradigm might be a better animal model for PTSD than chronic stress paradigms (Yehuda and Antelman 1993).

A possible shortcoming of this study is that the repeated testing of the rats in the successive tests (Table 2) might have affected the performance from one test to the other. Because all rats were subjected to the same series of tests, we may assume that the effects 
of repeated testing were similar in all groups but it is possible that CMS rats and control rats react differently to the stress experiences during tests. Furthermore, it is possible that the stress of the successive tests influences the control rats in a way that possible behavioural differences between CMS rats and controls become smaller as the controls are exposed to stress. There were always at least three days between tests during which the rats were left undisturbed and provided with food ad libitum. However, it cannot be excluded that this successive testing could have interfered with treatment effects. This can only be tested if naïve rats are used for each individual test.

In the present study CMS caused anhedonia, blunted weight gain and lower CORT levels. As expected, after a two-week resting period CMS had no effects on behaviour, except for an increased escape latency in the home cage emergence test in the CMS group. There were no CMS pretreatment $\times$ ATD treatment interaction effects on behaviour. ATD had some effects on behaviour, such as reduced time spent in the open zones of the zero maze and increased aggressive behaviour in the social interaction test in controls. In general, CMS did not result in increased sensitivity to ATD, only in the social interaction test did the CMS rats react stronger to ATD than the controls. CMS TRP- rats showed less passive body contact that CMS TRP+ rats. Overall, we conclude that the CMS procedure was effective in causing stress-related effects, but did not result in long-lasting vulnerability of the 5-HTergic system, measured by the behavioural response to ATD two weeks and longer after the CMS.

\section{References}

Anisman H, Merali Z (2003) Cytokines, stress and depressive illness: brain-immune interactions. Ann Med 35: $2-11$

Association AP (1994) Diagnostic and Statistical Manual of Mental Disorders, 4th edn. American Psychiatric Association, American Psychiatric Association

Ayensu WK, Pucilowski O, Mason GA, Overstreet DH, Rezvani AH, Janowsky DS (1995) Effects of chronic mild stress on serum complement activity, saccharin preference, and corticosterone levels in Flinders lines of rats. Physiol Behav 57: 165-9

Bell C, Abrams J, Nutt D (2001) Tryptophan depletion and its implications for psychiatry. Br J Psychiatry 178: 399-405

Bielajew C, Konkle AT, Kentner AC, Baker SL, Stewart A, Hutchins AA, Santa-Maria Barbagallo L, Fouriezos G (2003) Strain and gender specific effects in the forced swim test: effects of previous stress exposure. Stress 6: 269-80

Bielajew C, Konkle AT, Merali Z (2002) The effects of chronic mild stress on male Sprague-Dawley and Long Evans rats: I. Biochemical and physiological analyses. Behav Brain Res 136: 583-92

Biggio G, Fadda F, Fanni P, Tagliamonte A, Gessa GL (1974) Rapid depletion of serum tryptophan, brain tryptophan, serotonin and 5 hydroxyindoletic acid by a tryptophan-free diet. Life Sciences 14: 1321-1329

Blokland A, Lieben C, Deutz NE (2002) Anxiogenic and depressive-like effects, but no cognitive deficits, after repeated moderate tryptophan depletion in the rat. J Psychopharmacol 16: 39-49

Blokland A, Prickaerts J, Raaijmakers W (1992) Reduced level of anxiety in adult Lewis rats after chronic ethanol consumption. Physiol Behav 51: 245-8 
Booij L, Van der Does AJ, Riedel WJ (2003) Monoamine depletion in psychiatric and healthy populations: review. Mol Psychiatry 8: 951-73

Connor TJ, Leonard BE (1998) Depression, stress and immunological activation: the role of cytokines in depressive disorders. Life Sci 62: 583-606

D'Aquila PS, Brain P, Willner P (1994) Effects of chronic mild stress on performance in behavioural tests relevant to anxiety and depression. Physiol Behav 56: 861-7

Davis S, Heal DJ, Stanford SC (1995) Long-lasting effects of an acute stress on the neurochemistry and function of 5-hydroxytryptaminergic neurones in the mouse brain. Psychopharmacology (Berl) 118: 267-72

de Kloet ER, Joels M, Holsboer F (2005) Stress and the brain: from adaptation to disease. Nat Rev Neurosci 6: 463-75

Dziedzicka-Wasylewska M, Willner P, Papp M (1997) Changes in dopamine receptor mRNA expression following chronic mild stress and chronic antidepressant treatment. Behav Pharmacol 8: 607-18

Ennaceur A, Delacour J (1988) A new one-trial test for neurobiological studies of memory in rats. 1: Behavioral data. Behav Brain Res 31: 47-59

Fawcett J, Clark DC, Scheftner WA, Gibbons RD (1983) Assessing anhedonia in psychiatric patients. Arch Gen Psychiatry 40: 79-84

Fernstrom JD, Wurtman RJ (1997) Brain serotonin content: physiological regulation by plasma neutral amino acids. Obes Res 5: 377-80

File SE, Hyde JR (1978) Can social interaction be used to measure anxiety? Br J Pharmacol 62: 19-24

File SE, Seth P (2003) A review of 25 years of the social interaction test. Eur J Pharmacol 463: 35-53

Fluttert M, Dalm S, Oitzl MS (2000) A refined method for sequential blood sampling by tail incision in rats. Lab Anim 34: 372-8

Garcia-Marquez C, Armario A (1987) Chronic stress depresses exploratory activity and behavioral performance in the forced swimming test without altering ACTH response to a novel acute stressor. Physiol Behav 40: 33-8

Gessa GL, Biggio G, Fadda F, Corsini GU, Tagliamonte A (1974) Effect of the oral administration of tryptophan-free amino acid mixtures on serum tryptophan, brain tryptophan and serotonin metabolism. J Neurochem 22: 869-70

Gold PW, Chrousos GP (1999) The endocrinology of melancholic and atypical depression: relation to neurocircuitry and somatic consequences. Proc Assoc Am Physicians 111: 22-34

Gold PW, Goodwin FK, Chrousos GP (1988a) Clinical and biochemical manifestations of depression. Relation to the neurobiology of stress (1). N Engl J Med 319: 348-53

Gold PW, Goodwin FK, Chrousos GP (1988b) Clinical and biochemical manifestations of depression. Relation to the neurobiology of stress (2). N Engl J Med 319: 413-20

Gotz AA, Stefanski V (2007) Psychosocial maternal stress during pregnancy affects serum corticosterone, blood immune parameters and anxiety behaviour in adult male rat offspring. Physiol Behav 90: 108-15

Grippo AJ, Beltz TG, Weiss RM, Johnson AK (2006) The effects of chronic fluoxetine treatment on chronic mild stress-induced cardiovascular changes and anhedonia. Biol Psychiatry 59: 309-16

Grippo AJ, Francis J, Beltz TG, Felder RB, Johnson AK (2005) Neuroendocrine and cytokine profile of chronic mild stress-induced anhedonia. Physiol Behav 84: 697-706

Harvey BH, Brand L, Jeeva Z, Stein DJ (2006) Cortical/hippocampal monoamines, HPA-axis changes and aversive behavior following stress and restress in an animal model of post-traumatic stress disorder. Physiol Behav 87: 881-90

Harvey BH, Naciti C, Brand L, Stein DJ (2003) Endocrine, cognitive and hippocampal/cortical 5HT 1A/2A receptor changes evoked by a time-dependent sensitisation (TDS) stress model in rats. Brain Res 983: 97-107

Jans LA, Lieben CK, Blokland A (2007a) Influence of sex and estrous cycle on the effects of acute tryptophan depletion induced by a gelatin-based mixture in adult Wistar rats. Neuroscience 147: 304-17

Jans LA, Riedel WJ, Markus CR, Blokland A (2007b) Serotonergic vulnerability and depression: assumptions, experimental evidence and implications. Mol Psychiatry 12: 522-43 
Klimek V, Papp M (1994) The effect of MK-801 and imipramine on beta-adrenergic and 5-HT2 receptors in the chronic mild stress model of depression in rats. Pol J Pharmacol 46: 67-9

Liberzon I, Krstov M, Young EA (1997) Stress-restress: effects on ACTH and fast feedback. Psychoneuroendocrinology 22: 443-53

Lieben CK, Blokland A, Westerink B, Deutz NE (2004a) Acute tryptophan and serotonin depletion using an optimized tryptophan-free protein-carbohydrate mixture in the adult rat. Neurochem Int 44: 9-16

Lieben CK, van Oorsouw K, Deutz NE, Blokland A (2004b) Acute tryptophan depletion induced by a gelatinbased mixture impairs object memory but not affective behavior and spatial learning in the rat. Behav Brain Res 151: 53-64

Maccari S, Darnaudery M, Morley-Fletcher S, Zuena AR, Cinque C, Van Reeth O (2003) Prenatal stress and long-term consequences: implications of glucocorticoid hormones. Neurosci Biobehav Rev 27: 119-27

Maes M, Meltzer HY (1995) The Serotonin Hypothesis of Major Depression. In: Bloom FE, Kupfer DJ (eds) Psychopharmacology: The Fourth Generation of Progress. Raven Press, Ltd., New York, pp 933-944

Markus CR (2003) Interactions between stress, food and mood. In: Watson DaD, F (ed) Performance functional foods. Woodhead Publishing, Cambridge, pp 5-20

Meijer OC, de Kloet ER (1994) Corticosterone suppresses the expression of 5-HT1A receptor mRNA in rat dentate gyrus. Eur J Pharmacol 266: 255-61

Moja EA, Cipolla P, Castoldi D, Tofanetti O (1989) Dose-response decrease in plasma tryptophan and in brain tryptophan and serotonin after tryptophan-free amino acid mixtures in rats. Life Sci 44: 971-6

Molina VA, Heyser CJ, Spear LP (1994) Chronic variable stress or chronic morphine facilitates immobility in a forced swim test: reversal by naloxone. Psychopharmacology (Berl) 114: 433-40

Moore P, Landolt HP, Seifritz E, Clark C, Bhatti T, Kelsoe J, Rapaport M, Gillin JC (2000) Clinical and physiological consequences of rapid tryptophan depletion. Neuropsychopharmacology 23: 601-22

Muscat R, Papp M, Willner P (1992) Reversal of stress-induced anhedonia by the atypical antidepressants, fluoxetine and maprotiline. Psychopharmacology (Berl) 109: 433-8

Muscat R, Willner P (1992) Suppression of sucrose drinking by chronic mild unpredictable stress: a methodological analysis. Neurosci Biobehav Rev 16: 507-17

Ossenkopp KP, Mazmanian DS (1985) The measurement and integration of behavioral variables: aggregation and complexity as important issues. Neurobehav Toxicol Teratol 7: 95-100

Papp M, Klimek V, Willner P (1994a) Effects of imipramine on serotonergic and beta-adrenergic receptor binding in a realistic animal model of depression. Psychopharmacology (Berl) 114: 309-14

Papp M, Klimek V, Willner P (1994b) Parallel changes in dopamine D2 receptor binding in limbic forebrain associated with chronic mild stress-induced anhedonia and its reversal by imipramine. Psychopharmacology (Berl) 115: 441-6

Papp M, Nalepa I, Antkiewicz-Michaluk L, Sanchez C (2002) Behavioural and biochemical studies of citalopram and WAY 100635 in rat chronic mild stress model. Pharmacol Biochem Behav 72: 465-74

Papp M, Nalepa I, Vetulani J (1994c) Reversal by imipramine of beta-adrenoceptor up-regulation induced in a chronic mild stress model of depression. Eur J Pharmacol 261: 141-7

Prickaerts J, Raaijmakers W, Blokland A (1996) Effects of myocardial infarction and captopril therapy on anxiety-related behaviors in the rat. Physiol Behav 60: 43-50

Prickaerts J, Steckler T (2005) Effects of glucocorticoids on emotion and cognitive processes in animals. In: Steckler T, Kalin NH, Reul JMHM (eds) Handbook of Stress and the Brain. Elsevier, Amsterdam/London, pp 359-385

Prickaerts J, van Staveren WC, Şık A, Markerink-van Ittersum M, Niewohner U, van der Staay FJ, Blokland A, de Vente J (2002) Effects of two selective phosphodiesterase type 5 inhibitors, sildenafil and vardenafil, on object recognition memory and hippocampal cyclic GMP levels in the rat. Neuroscience 113: 351-61

Przegalinski E, Moryl E, Papp M (1995) The effect of 5-HT1A receptor ligands in a chronic mild stress model of depression. Neuropharmacology 34: 1305-10

Riedel WJ, Klaassen T, Deutz NE, van Someren A, van Praag HM (1999) Tryptophan depletion in normal volunteers produces selective impairment in memory consolidation. Psychopharmacology (Berl) 141: 362-9 
Riedel WJ, Klaassen T, Schmitt JA (2002a) Tryptophan, mood, and cognitive function. Brain Behav Immun 16: $581-9$

Riedel WJ, Sobczak S, Nicolson N, Honig A (2002b) Stress, cortisol and memory as markers of serotonergic vulnerability. Acta Neuropsychiatrica 14: 186-191

Schmitt JA, Jorissen BL, Sobczak S, van Boxtel MP, Hogervorst E, Deutz NE, Riedel WJ (2000) Tryptophan depletion impairs memory consolidation but improves focussed attention in healthy young volunteers. J Psychopharmacol 14: 21-9

Shepherd JK, Grewal SS, Fletcher A, Bill DJ, Dourish CT (1994) Behavioural and pharmacological characterisation of the elevated "zero-maze" as an animal model of anxiety. Psychopharmacology (Berl) 116: 56-64

Silberman DM, Ayelli-Edgar V, Zorrilla-Zubilete M, Zieher LM, Genaro AM (2004) Impaired T-cell dependent humoral response and its relationship with $\mathrm{T}$ lymphocyte sensitivity to stress hormones in a chronic mild stress model of depression. Brain Behav Immun 18: 81-90

Silberman DM, Wald M, Genaro AM (2002) Effects of chronic mild stress on lymphocyte proliferative response. Participation of serum thyroid hormones and corticosterone. Int Immunopharmacol 2: 487-97

Stout SC, Mortas P, Owens MJ, Nemeroff CB, Moreau J (2000) Increased corticotropin-releasing factor concentrations in the bed nucleus of the stria terminalis of anhedonic rats. Eur J Pharmacol 401: 39-46

Sulon J, Demey-Ponsart L, Beauduin P, Sodoyez JC (1978) Radioimmunoassay of corticosterone, cortisol and cortisone: their application to human cord and maternal plasma. J Steroid Biochem 9: 671-6

van der Staay FJ, Blokland A (1996) Behavioral differences between outbred Wistar, inbred Fischer 344, brown Norway, and hybrid Fischer $344 \times$ brown Norway rats. Physiol Behav 60: 97-109

van Eijk HM, Rooyakkers DR, Deutz NE (1993) Rapid routine determination of amino acids in plasma by high-performance liquid chromatography with a 2-3 microns Spherisorb ODS II column. J Chromatogr 620: 143-8

van Praag HM (2004) Can stress cause depression? Prog Neuropsychopharmacol Biol Psychiatry 28: 891-907

Willner P (1990) Animal models of depression: an overview. Pharmacol Ther 45: 425-55

Willner P (2005) Chronic mild stress (CMS) revisited: consistency and behavioural-neurobiological concordance in the effects of CMS. Neuropsychobiology 52: 90-110

Willner P, Muscat R, Papp M (1992) Chronic mild stress-induced anhedonia: a realistic animal model of depression. Neurosci Biobehav Rev 16: 525-34

Willner P, Towell A, Sampson D, Sophokleous S, Muscat R (1987) Reduction of sucrose preference by chronic unpredictable mild stress, and its restoration by a tricyclic antidepressant. Psychopharmacology (Berl) 93: 358-64

Yehuda R, Antelman SM (1993) Criteria for rationally evaluating animal models of posttraumatic stress disorder. Biol Psychiatry 33: 479-86

Young AH, Goodwin GM, Dick H, Fink G (1994) Effects of glucocorticoids on 5-HT1A presynaptic function in the mouse. Psychopharmacology (Berl) 114: 360-4

Young SN (1996) Behavioral Effects of Dietary Neurotransmitter Precursors: Basic and Clinical Aspects. Neuroscience and Biobehavioral Reviews 20: 313-323 



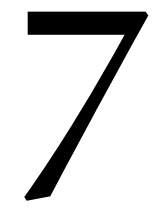

\section{The effects of acute tryptophan depletion in serotonin transporter knockout rats}

J. D. A. Olivier", L. A. W. Jans", G. A. H. Korte-Bouws,

S. M. Korte, P. M. T. Deen, B. A. Ellenbroek, A. Blokland

\# authors contributed equally 


\section{Abstract}

In humans, serotonin transporter (SERT) functioning is associated with depression. The aim of the present experiment was to investigate whether male wildtype $\left(\mathrm{SERT}^{+/+}\right)$, heterozygous $\left(\mathrm{SERT}^{+/}\right)$, and knockout $\left(\mathrm{SERT}^{-/}\right.$) serotonin transporter rats differ in serotonergic vulnerability, reflected by a stronger behavioural response to acute tryptophan depletion (ATD). Twenty-four male SERT ${ }^{+/+}, \mathrm{SERT}^{+/-}$and $\mathrm{SERT}^{-/-}$rats were repeatedly treated with a gelatin-based protein-carbohydrate mixture, either with $(\mathrm{TRP}+)$ or without L-tryptophan (TRP-) and subjected to several behavioural tests, including tests of anxiety- and depression- related behaviour, and cognition. In order to determine the magnitude of ATD, plasma amino acid concentrations and brain 5-HT and 5-HIAA concentrations were measured. Plasma TRP levels and brain 5-HT and 5-HIAA levels were decreased in all genotypes after ATD. Behaviourally, all rats showed low activity in anxiety-related situations. In the open field test, TRP- treated $\mathrm{SERT}^{+/+}$and $\mathrm{SERT}^{+/-}$rats spent more time in the center of the open field and moved a longer distance compared to their TRP+ treated controls. There were no treatment effects in SERT ${ }^{-/}$rats in the open field test. In the home cage emergence task, $\mathrm{SERT}^{+/-}$rats showed a higher escape latency after TRP-, but SERT ${ }^{+/+}$and SERT ${ }^{-/-}$rats had already reached a ceiling effect after treatment with TRP+. In the elevated plus maze, social interaction test and in the forced swim test no treatment effects were found. Only in an object recognition test, $\mathrm{SERT}^{-/-}$and to a lesser extent $\mathrm{SERT}^{+/-}$rats were more vulnerable to ATD than $\mathrm{SERT}^{+/+}$rats; they showed impaired object recognition after mild ATD whereas $\mathrm{SERT}^{+/+}$did not. In conclusion, different effects of ATD on behaviour in anxiety- and depression- related behaviour in $\mathrm{SERT}^{+/+}, \mathrm{SERT}^{+/-}$and $\mathrm{SERT}^{-/}$rats were not found. 


\section{Introduction}

The neurotransmitter serotonin (5-Hydroxytryptamine, 5-HT) is known to be involved in many physiological and behavioural processes, including mood, appetite, sleep, activity, impulsivity, suicide, sexual behaviour and cognition. Although the mechanisms underlying depression are not yet fully understood, there is general consensus that 5 -HT is involved in depression. The original hypothesis that low serotonin has a direct role in depression has been through several modifications and low 5-HTergic neurotransmission is now thought to operate as a biological risk factor, that may play an important role in the triggering and maintenance of mood disorders (Maes and Meltzer, 1995). Recently, serotonergic functioning has been proposed as a vulnerability factor in the development of depression and other 5-HT related symptoms and disorders (Jans et al., 2007b). According to this view, the serotonergic functioning of an individual determines the vulnerability of that individual to develop 5 -HT related disorders. This implies that there are differences in the 5-HT functioning between individuals and that the development of depression, anxiety, or other 5-HT related disorders is associated with the presence of $a$ priori abnormalities in the functioning of this system. There are various factors that may interfere with 5-HTergic functioning, such as genetic factors, a family history of depression, the female gender, stress, and drug use. Each of these factor may disrupt the 5-HT system, resulting in serotonergic vulnerability, but psychopathological symptoms do not occur until a threshold is reached where the system can no longer compensate (Jans et al., 2007b). Vulnerability of the serotonergic system (serotonergic vulnerability, SV) means that there is a vulnerability or sensitivity to alterations or dysregulations in the serotonergic system. Hence, SV can be demonstrated by challenging the 5-HT system; vulnerable and non-vulnerable subjects will react differently to these manipulations (Jans et al., 2007b).

Acute tryptophan depletion (ATD) is a way to challenge the 5-HT system in which L-tryptophan (TRP) - the essential amino acid that is the precursor of 5-HT - is depleted, resulting in lower peripheral and central 5-HT levels (Biggio et al., 1974, Gessa et al., 1974, Moja et al., 1989, Fernstrom and Wurtman, 1997). TRP depletion also lowered the extracellular levels of 5-HT in the hippocampus (Stancampiano et al., 1997). The nonintrusive and reversible ATD methodology has been applied to investigate the role of 5 -HT in behavioural functions (e.g., anxiety, sleep, aggression, memory, impulsivity) in humans as well as in animals (Young, 1996, Moore et al., 2000, Bell et al., 2001). Previous studies using a gelatin-based-carbohydrate mixture showed a robust reduction in plasma TRP (about 70\%) and central tissue 5-HT (about 40-45\%) concentrations in male Wistar rats (Lieben et al., 2004a). Moreover, this ATD method has been reported to impair object memory, but not affective behaviour (Lieben et al., 2004b). A stronger behavioural response to acute tryptophan depletion (ATD) is assumed to reflect SV. In healthy human volunteers, ATD generally results in memory impairments, whereas other effects of 
ATD, such as effects on mood, are only found in vulnerable subjects (Riedel et al., 1999, Schmitt et al., 2000, Riedel et al., 2002, Booij and Van der Does, 2007).

The serotonin transporter (SERT) is involved in the reuptake of 5-HT from the synapse, returning it to the presynaptic neuron where it can be degraded or retained for future release. In this way, the SERT determines the magnitude and duration of the 5-HT synaptic signal and thus plays an important role in the regulation of serotonergic neurotransmission. SERT abnormalities are widely reported in depression (Mann et al., 2000, Neumeister et al., 2002). Both functional imaging (Malison et al., 1998) and postmortem brain studies (Mann et al., 2000) have reported less SERT protein expression in the brain of depressed patients, indicating less SERT binding. Logically, genetic alterations in the SERT are associated with multiple neuropsychiatric disorders (Murphy et al., 1999, Gingrich and Hen, 2001, Holmes et al., 2003). In humans, the SERT gene transcription is modulated by a common polymorphism in its upstream regulatory region (5-HTTLPR). Two 5-HTTLPR alleles have been identified: a 484-base pair denoted as short, and a 528-base pair denoted as long. Studies in reporter gene constructs and in human lymphoblastic cell lines found that the short variant reduces the transcriptional efficiency of the SERT gene (Lesch et al., 1996, Heils et al., 1996, Heils et al., 1997). Carriers of this short version display significantly higher scores in neuroticism, an anxiety-related personality trait and exhibit more depressive symptoms, diagnosable depression, and suicidality in relation to stressful events compared to individuals with the long version of this polymorphism (Mann et al., 2000, Caspi et al., 2003, Dick et al., 2007, Schmitz et al., 2007). Furthermore, several studies have shown that 5-HTTLPR genotype can influence behavioural responses to ATD (Marsh et al., 2006, Neumeister et al., 2006, Roiser et al., 2006, Walderhaug et al., 2007).

We recently generated a SERT knockout rat $\left(\mathrm{SERT}^{-1}\right)$ by $\mathrm{N}$-ethyl-N-nitrosurea (ENU) driven mutagenesis (Smits et al., 2004, Smits et al., 2006). This animal has a premature stopcodon (TGC>TGA) introduced at position 3924 in the third exon encoding the second extracellular loop of the SERT protein. At a functional level, the 5-HT releaser d-fenfluramine (Homberg et al., 2007) and the full 5-HT ${ }_{1 \mathrm{~A}}$ agonist flesinoxan (Olivier et al., unpublished data) are unable to elicit hypothermia in SERT ${ }^{-/}$rats. Moreover, extracellular 5-HT levels in the hippocampus were nine-fold elevated and $[3 \mathrm{H}]$ citalopram (SSRI) binding to brain slices is completely absent in SERT ${ }^{-/}$rats (Homberg et al., 2007). In this study, we used homozygous serotonin transporter knockout rats (SERT ${ }^{-/-}$), heterozygous serotonin transporter knockout rats $\left(\mathrm{SERT}^{+-}\right)$and their wildtype littermates $\left(\mathrm{SERT}^{+/+}\right)$as a model to study SV. Since in humans low SERT activity has been associated with affective disorders (Mann et al., 2000, Neumeister et al., 2002, Caspi et al., 2003, Dick et al., 2007, Mossner et al., 2007), we hypothesized that $\mathrm{SERT}^{-/}$and $\mathrm{SERT}^{+/-}$rats may have higher SV than $\mathrm{SERT}^{+/+}$rats.

In this study $\mathrm{SERT}^{+/}$, $\mathrm{SERT}^{+/-}$and $\mathrm{SERT}^{-/-}$rats were repeatedly treated with ATD to investigate whether the SERT is associated with SV, reflected by an increased behavioural response to ATD. The animals were repeatedly treated with ATD and tested in behavioural tests of anxiety-related behaviour (open field test, elevated plus maze, home 
cage emergence test, social interaction test), depression-related behaviour (forced swim test) and cognition (object recognition test). In order to determine the magnitude of ATD, plasma amino acid concentrations and brain 5-HT and 5-HIAA concentrations were measured. Animals with lower SERT function were hypothesized to have higher SV and therefore SERT ${ }^{+/-}$and SERT ${ }^{-/-}$rats were hypothesized to show stronger behavioural responses, i.e. more anxiety- and depression-related behaviour, in response to the ATD treatment on one or more behavioural tests compared to $\mathrm{SERT}^{+/+}$rats.

\section{Materials and methods}

\section{Animals}

All serotonin transporter knockout rats $\left(\mathrm{Slc6a} 4^{1 \mathrm{Hubr}}\right)$ have been generated, bred and reared in the Central Animal Laboratory of the Radboud University of Nijmegen. Experimental animals were derived from crossing SERT ${ }^{+/-}$rats that were outcrossed for 4 or 5 generations. In all experiments, male SERT ${ }^{++}, \mathrm{SERT}^{+/-}$and $\mathrm{SERT}^{-/-}$littermates were compared. After weaning at the age of 21 days, ear cuts were taken for genotyping. Genotyping was performed at the Hubrecht Institute (Utrecht, the Netherlands). During the experiment, all animals were housed two per cage in standard Macrolon type 3 cages $(42 \times 26 \times 20 \mathrm{~cm})$ in temperature-controlled rooms $\left(21^{\circ} \mathrm{C} \pm 1^{\circ} \mathrm{C}\right)$ with standard $12 / 12$ $\mathrm{h}$ day/night-cycle (lights on at $7.00 \mathrm{am}$ ) and food (Sniff, long cut pellet, Bio Services, Uden, The Netherlands) and water available ad libitum. The behavioural experiments were performed between 12.30 and $17.00 \mathrm{~h}$. For the telemetry measurements a different group of $8 \mathrm{SERT}^{+/+}$and $8 \mathrm{SERT}^{-/-}$rats were used. All experiments were carried out in accordance with institutional, national and international guidelines for animal care and the Dutch law concerning welfare.

\section{Drugs and chemicals}

The Gelatin hydrolysate (Solugel P') was obtained from PB Gelatins (Tessenderlo, Belgium). Glucodry 210 was obtained from Tate \& Lyle (Koog aan de Zaan, The Netherlands). Kaliumchloride $(\mathrm{KCl})$ and calciumchloride-dihydrate $\left(\mathrm{CaCl}_{2} \cdot 2 \mathrm{H}_{2} \mathrm{O}\right)$ were purchased from Merck (Darmstadt, Germany). L-Tryptophan was obtained from Sigma (Zwijndrecht, The Netherlands).

\section{Treatment}

During a period of two weeks preceding the experiment, the rats were handled and habituated to oral injections with normal tap water (up to $10 \mathrm{ml} / \mathrm{kg}$ ). On testing days the rats were treated with a protein-carbohydrate mixture containing L-TRP (TRP+ group, 
$0.30 \%$ TRP of the total protein) or lacking L-TRP (TRP- group). The rats received two doses of $10 \mathrm{ml} / \mathrm{kg}$ with a 90 -minute interval. Each administration contained $4.0 \mathrm{~g}$ Solugel $\mathrm{P} / \mathrm{kg}$ and $2.0 \mathrm{~g}$ Glucodry $210 / \mathrm{kg}$ of the body weight. The composition of the nutritional mixture is shown in Table 1.

Table 1: Composition of the treatment mixture.

\begin{tabular}{|c|c|c|}
\hline Protein $\left(\right.$ Solugel $\left.{ }^{\star}\right)$ in $100 \mathrm{ml}$ water & & $100 \mathrm{~g}$ \\
\hline Alanine & 8.4 & \\
\hline Arginine & 7.7 & \\
\hline Aspartic Acid/Asparagine & 4.5 & \\
\hline Glutamic Acid/Glutamine & 10.0 & \\
\hline Glycine & 23.3 & \\
\hline Histidine & 0.9 & \\
\hline Hydroxylysine & 1.5 & \\
\hline Hydroxyproline & 12.3 & \\
\hline Isoleucine & 1.2 & \\
\hline Leucine & 2.6 & \\
\hline Lysine & 3.3 & \\
\hline Methionine & 0.9 & \\
\hline Phenylalanine & 1.6 & \\
\hline Proline & 13.7 & \\
\hline Serine & 3.4 & \\
\hline Threonine & 1.9 & \\
\hline Tryptophan & 0.0 & \\
\hline Tyrosine & 0.6 & \\
\hline Valine & 2.2 & \\
\hline Carbohydrate (Glucodry 210) in $80 \mathrm{ml}$ water & & 50 \\
\hline KCL & & 0.094 \\
\hline $\mathrm{CaCl}_{2} \cdot 2 \mathrm{H}_{2} \mathrm{O}$ & & 2.32 \\
\hline L-tryptophan (TRP- group) & & 0 \\
\hline L-tryptophan (TRP+ group) & & 0.28 \\
\hline
\end{tabular}

The rats were fasted from $14 \mathrm{~h}$ prior to treatment until the testing period was completed. This was done to minimize the availability of TRP from food. Behavioural testing was conducted $4 \mathrm{~h}$ after the first oral administration. At the end of each testing day, the animals had ad libitum access to food for at least $2 \mathrm{~h}$. An overview of the order of testing and the number of times the rats were treated with the mixture is given in Table 2. Rats were randomly assigned to treatment with TRP+ or TRP- for each test separately. In this way the treatment condition for each rat varied between tests, but not within one test.

\section{Biochemistry}

Plasma amino acid levels. For the determination of plasma amino acid levels blood samples were taken at resting values (T0; i.e., $10 \mathrm{~min}$ before the first oral administration) 
and repeated $4 \mathrm{~h}$ after the first administration (T4). Blood sampling was done via a tailincision method (Fluttert et al., 2000). Promptly after collection of blood in a sodium heparin tube (Microvette CB 300, Sarstedt, Germany), the samples were kept on ice. After centrifugation of the blood samples (at $4^{\circ} \mathrm{C}$ for $15 \mathrm{~min}$ at $3000 \mathrm{~g}$ ), plasma samples were stored at $-70^{\circ} \mathrm{C}$. Plasma amino acid concentrations were determined with a fully automated high-performance liquid chromatography (HPLC). The concentrations of the total plasma amino acids were expressed as $\mu \mathrm{mol} / \mathrm{L}$.

Table 2: Order of the different behavioural experiments and the number of days treatment was given.

\begin{tabular}{llc}
\hline Week & \multicolumn{1}{c}{ Test } & Treatment \\
\hline 1,2 & Handling & 1 \\
3 & Blood sampling & $1^{*}$ \\
4 & Open field test & $3^{*}$ \\
5 & Elevated plus maze & $3^{*}$ \\
6 & Home cage emergence test & $3^{*}$ \\
7 & Social interaction test & $2^{*}$ \\
8 & Forced swim test & $3^{*}$ \\
$9,10,11$ & Object recognition test & $3^{*}$ \\
12 & Brain sampling & 1 \\
\hline
\end{tabular}

* Rats were treated with either TRP+ or TRP-.

\# Rats were treated with TRP+, TRP-, and TRP- $40 \mathrm{~g}$ on different testing days

Brain 5-HT and 5-HIAA levels. Animals were decapitated and tissue samples (frontal cortex and hippocampus) were dissected from the brain, weighed and stored at $-80^{\circ} \mathrm{C}$ until further use. The tissue samples were homogenized in $250 \mu \mathrm{l}$ of an ice-cold solution containing $5 \mu \mathrm{M}$ clorgyline, $5 \mu \mathrm{g} / \mathrm{ml}$ glutathione and $0.6 \mu \mathrm{M} \mathrm{N} \omega$-methylserotonin (NMET, internal standard), using a potter tube. To $100 \mu \mathrm{l}$ homogenate, $25 \mu \mathrm{l} 2 \mathrm{M} \mathrm{HClO}_{4}$ was added and mixed. Then $20 \mu \mathrm{l} 2.5 \mathrm{M}$ potassium acetate was added and again mixed. After 15 minutes in ice water, the homogenates were centrifuged during 15 minutes at $15000 \mathrm{~g}\left(4^{\circ} \mathrm{C}\right)$. The supernatants were diluted 10 times with water before HPLC analysis. The concentration of 5-HT and 5-HIAA in the tissue extracts were measured by HPLC with ECD. The HPLC system consisted of a pump model P100, an autosampler model AS300 (both from Thermo Separation Products, Waltham, MA, USA), A ERC-3113 degasser (Erma CR. Inc. Tokyo, Japan), an ESA Coulochem II detector with 5011 analytical cell set at potential $+450 \mathrm{mV}$ (ESA Inc. Bedford MA, USA), a BD 41 chart recorder (Kipp \& $\mathrm{zn}$, The Netherlands) and a column $(150 \mathrm{~mm} \times 4.6 \mathrm{~mm}$ i.d.) packed with Hypersil BDS C18, $5 \mu \mathrm{m}$ particle size (Alltech Associates, USA)

The mobile phase solution consisted of $50 \mathrm{mM}$ citric acid, $50 \mathrm{mM}$ phosphoric acid, $0.1 \mathrm{mM}$ EDTA, $45 \mu \mathrm{l} / \mathrm{L}$ dibutylamine, $77 \mathrm{mg} / \mathrm{L}$ 1-octanesulfonic acid sodium salt, $10 \%$ methanol; the $\mathrm{pH}$ of the buffer was adjusted to 3.4 with $\mathrm{NaOH}$. Separation was performed at room temperature using a flow rate of $0.7 \mathrm{ml} / \mathrm{min}$. The concentration of each com- 
pound was calculated by comparison with both the internal and the external standards. The limit of detection (signal/noise ratio 3:1) was $0.3 \mathrm{nM}$. Concentrations were expressed as nmol/g. The 5-HIAA/5-HT turnover was calculated, which can be used as an index of 5-HT system activity.

\section{Behaviour}

Open field test The open field test is based on an exploration-conflict and an increase in time spent in the central part of the open field is considered to be an indication of anxiolytic behaviour (Prut and Belzung, 2003). The test was conducted in a square arena $(100 \times 100 \times 40 \mathrm{~cm})$, with an open top, dark walls and a dark floor. The arena of the open field was subdivided in 'corner' (four squares each $16 \times 16 \mathrm{~cm}$ ), 'wall' (four rectangles each $16 \times 64 \mathrm{~cm}$ ) and 'center' (one square $64 \times 64 \mathrm{~cm}$ ) zones. Testing was carried out in dimmed white light. A camera was installed above the center of the field. Immediately after a rat was placed in a corner of the open field, the movements and position of the animals were recorded and registered automatically by a computerized system (EthoVision, Noldus Information Technology, Wageningen, The Netherlands). Reported are the time a rat spent in the center and the corner zones of the open field and the total distance moved. Testing was carried out on three consecutive days, with one 5-minute trial a day for all rats. The floor of the open field was cleaned with a $70 \%$ ethanol solution between trials to prevent transmission of olfactory cues.

Elevated plus maze The elevated plus maze is based upon the idea that elevated open alleys arouse greater avoidance responses than elevated closed alleys. Voluntary passage onto the open arms of an elevated, plus-shaped maze is associated with neurobiological changes indicative of a decreased anxiety (Hogg, 1996). The test was performed as described previously (de Jong et al., 2006). The apparatus was made of polyvinylchloride and was elevated to a height of $50 \mathrm{~cm}$. The maze consisted of two open $(50 \times 10)$ and two enclosed arms $(50 \times 10 \times 40)$ arranged in a way that the arms of the same type were opposite to each other. The illumination intensity measured in the center was 440 Lux. Rats were placed in the center of the maze, facing one of the open arms, for a 5 minute period of free exploration. The movements and position of the animals were recorded and scored by the observer. Between trial, the apparatus was cleaned with a $70 \%$ ethanol solution to prevent transmission of olfactory cues. Testing was carried out on three consecutive days. Results were expressed as the mean of time spent (s) in open and closed arms.

Home cage emergence test The home cage emergence test was used to assess the level of fear/anxiety. An increase in fear/anxiety results in an increased latency to leave the home cage (Prickaerts et al., 1996). In this test the home cage was placed in an arena and the lid of the home cage was removed (Prickaerts et al., 1996). During the testing 
of one rat, its cage mate was placed in another cage for the duration of the trial. A grid was placed over the edge of the cage to make it easier for the rats to leave the home cage. Testing was carried out in dimmed white light. A stopwatch was used to measure the latency to leave the cage. The experimenter measured the time it took for the rat to climb out of its cage into the arena. A criterion was set to determine the escape time. Time was stopped and the trial ended when all four paws of the rat were over the edge of the cage. If the rat did not emerge from its home cage within $300 \mathrm{~s}$, the trial was ended, the home cage was closed again and the rat was given a score of 300 . Between trials, the grid was cleaned with a $70 \%$ ethanol solution to prevent transmission of olfactory cues. This test was carried out on three consecutive days.

Social interaction test The social interaction test was used as a last assay to assess the level of anxiety in SERT with or without acute TRP depletion. The inhibition of social behaviour was assumed to reflect an increase in anxiety (File and Hyde, 1978, File and Seth, 2003). In the social interaction test (File and Hyde, 1978, File and Seth, 2003), two rats were placed in a closed part of the open field, $50 \times 50 \times 50 \mathrm{~cm}$ with four black walls. The two animals that were tested together were weight- and genotype-matched, and had received the same treatment (both TRP- or both TRP+). The animals were placed in the test area at the same time and spent 10 minutes together, which were videotaped for later offline analysis by an observer who was blind to the treatment and genotype of the rats. Per interaction duo, total time of social interaction was measured, subdivided into active social interaction and passive body contact. Active social interaction comprised sniffing, grooming, exploring, following, biting, etc the other rat. During passive body contact, the rats touch each other but do not explore, i.e. sitting or lying together. Between trials, the apparatus was cleaned with a $70 \%$ ethanol solution to prevent transmission of olfactory cues. In order to increase the number of observations, all rats were tested twice. They received the same treatment on both trials, but were exposed to a different unfamiliar testing partner on each trial.

Forced swim test When rats are forced to swim in an inescapable situation, they typically display an immobile posture, which is considered to reflect a state of behavioural despair. Antidepressant treatments are known to reduce immobility time in the forced swim test (Connor et al., 2000) and it is assumed that a procedure that produced depressive-like effects should have the opposite effect, as has been reported repeatedly after chronic mild stress (Molina et al., 1994, Willner, 2005, Huang and Lin, 2006). The forced swim test was conducted as reported previously (Jans et al., 2007). In short, cylindrical glass tanks $\left(50 \mathrm{~cm}\right.$ tall $\times 18 \mathrm{~cm}$ diameter), filled to a depth of $30 \mathrm{~cm}$ with $22( \pm 1)^{\circ} \mathrm{C}$ water, were used in the forced swim test. Testing was carried out over three consecutive days. When a rat was placed in the water, its movements were videotaped in 5-min test trials for off-line measurement of the duration of immobility (s). The behavioural variable 'immobility' was defined as follows: making no movements for at least 2 seconds 
or making only those movements that were necessary to keep the nose above the water. The rats were allowed to slightly move their forepaws or support themselves by pressing their paws against the wall of the cylinder. Active climbing, diving and swimming along the wall were scored as mobility (s). Between trials the cylinders were cleaned and filled with clean water. This test was carried out on three consecutive days.

Object recognition test The object recognition test was performed as described in detail elsewhere (Ennaceur and Delacour, 1988, Prickaerts et al., 2002). During training and testing, the rats were housed individually. The apparatus consisted of a square arena $(100 \times 100 \times 40 \mathrm{~cm})$, with an open top, dark walls and a dark floor. Testing was carried out in dimmed white light. We used four different sets of objects that could not be displaced by a rat. Each object was available in triplicate. The different objects were: 1) a bowl with handle made of green china (maximal diameter $15 \mathrm{~cm}$ and a height of $9 \mathrm{~cm}$ ), 2) a cubic box $(12 \times 12 \times 7 \mathrm{~cm})$ made of polyvinyl, with a coloured topping (pink), 3) a china trapezium cylinder (with a maximal diameter of $12 \mathrm{~cm}$ and a minimum diameter of $10.5 \mathrm{~cm}$ ) with a dish on top (diameter $12 \mathrm{~cm}$ ), and 4) a brown tinned cylinder (with a diameter of $9.5 \mathrm{~cm}$ and a height of $15 \mathrm{~cm}$ ).

One day preceding testing, the animals were adapted to the procedure, i.e. they were allowed to explore the apparatus (without any objects) for $3 \mathrm{~min}$. In the following days, the rats were tested twice. A testing session comprised two trials with a 1-h interval between trials. The duration of each trial was $3 \mathrm{~min}$. Two objects were placed in a symmetrical position about $10 \mathrm{~cm}$ away from the black wall. A rat was always placed in the apparatus facing the corner. During the first trial the apparatus contained two identical objects. After the first exploration period the rat was put back in its home cage. One hour later the rat was put back in the apparatus for the second trial, but now with dissimilar objects, a familiar one and a new one. The duration of exploring each object in both trials was recorded manually with a personal computer. Exploration was defined as directing the nose to the object at a distance of no more than $2 \mathrm{~cm}$ and/or touching the object with the nose. Sitting on the object was not considered as exploratory behaviour. In order to avoid the presence of olfactory trails, the objects were thoroughly cleaned between trials with a 70\% ethanol solution. Moreover, each object was available in triplicate so that none of the two objects from the first trial had to be used as the familiar object in the second trial. In addition, all combinations and locations of objects were used in a balanced manner to reduce potential biases due to preferences for particular locations or objects.

After the rats were familiarized to the procedures of the task, testing with treatment began. The first trial was given $4 \mathrm{~h}$ after the first oral administration. The delay interval of $1 \mathrm{~h}$ was preferable since during this time, we expected the plasma TRP levels to remain low. The basic measures in the object recognition test were the times spent by rats exploring an object during trial 1 and trial 2. The discrimination index $d 2$ ((exploration new object trial 2 - exploration familiar object trial 2)/total exploration time trial 2) was 
calculated for each treatment condition (see Rutten et al., 2007). $d 2$ is a relative index of discrimination between new and familiar object, because it corrects for total exploration time in trial 2 (see Şı et al., 2003). Rats that explored less than $5 \mathrm{~s}$ in any of the trials or explored only one of the objects were removed from analysis to avoid possible erroneous conclusions (see Şı et al., 2003).

The rats were tested without treatment (baseline), with TRP+, with TRP- and with TRP- $40 \mathrm{~g}$ on different days. In the TRP- $40 \mathrm{~g}$ condition, rats were treated with a mixture that contained $40 \mathrm{~g}$ instead of the normal $100 \mathrm{~g}$ of Solugel protein per $100 \mathrm{ml}$. Because TRP was absent and the amino acids were given in a lesser concentration this resulted in milder tryptophan depletion. Previous research showed that lowering the concentration of Solugel protein in the TRP- mixture had dose-dependent effects on the plasma TRP/ $\Sigma$ LNAA ratio, and that there was a positive correlation between the plasma TRP/ $\Sigma$ LNAA ratio and performance in the object recognition test (Lieben et al., unpublished data). The TRP- 40g condition was included because the standard TRP- treatment is known to impair object recognition in all experimental groups, suggesting this treatment results in a floor effect (Lieben et al., 2004b, Jans et al., 2007a).

\section{Statistical analysis}

For all variables, treatment effects were analysed using parametric statistics (ANOVA). The effect of TRP depletion on BT was analysed using three-way repeated measures ANOVA with the factors genotype, treatment and time. In case of statistical significance a two-way repeated measure ANOVA with the factors treatment and time was performed. Where appropriate, group differences were further analysed using an independent sample T-test. Plasma amino acid concentrations were analysed with repeated measures ANOVA. Data of the open field test, elevated plus maze, home cage emergence test and forced swim test were aggregated over the three trials to enhance reliability (Ossenkopp and Mazmanian, 1985). It is known, for example, that the aggregated data of the open field test strongly correlate with indices of anxiety in other models, such as the plus maze and the light dark box (Blokland et al., 1992, Prickaerts et al., 1996, van der Staay and Blokland, 1996). The mean scores over the three testing days were used in statistical analysis, as was done in comparable studies (Blokland et al., 2002, Lieben et al., 2004b, Jans et al., 2007a). Because the data of the home cage emergence test was not normally distributed, Z-scores were calculated and used for statistical testing. Data from the two trials of the social interaction test were treated as independent observations because the testing partner differed in the two trials. To further characterize the differences between groups, post-hoc Bonferroni t-test was used $(\mathrm{p}<0.05)$. In order to test our specific hypotheses, we also analysed the effects of treatment on behaviour in each experimental group separately.

In the object recognition test, we compared the $d 2$ values of the baseline and different treatment conditions with $d 2$ values of a virtual control group. The virtual 
control group had a $d 2$ of zero, meaning there was no object recognition. The number of animals and SEM were similar to those of our treatment groups. Comparison with this virtual control group is used to evaluate more reliably whether discrimination performance differs from zero in a certain treatment condition. The $d 2$ values were compared with ANOVA and a one-sided Dunnett post-hoc test was used to test whether $d 2$ in a treatment condition was higher than in the virtual control group, which would indicate that the rats are able to discriminate the objects.

\section{Results}

\section{Biochemistry}

Plasma levels. The effects of treatment and genotype on the plasma TRP/ $L$ LNAA ratio levels are shown in Figure 1. Plasma TRP levels and the plasma TRP/ $L$ LNAA ratio decreased over the four hours [Time: TRP: $F(1,29)=45.20, p<0.001$; Ratio: $F(1,29)=31.43$, $\mathrm{p}<0.001]$. Plasma TRP levels and the TRP/ $\Sigma$ LNAA ratio were lower in the TRP- group compared to the TRP+ group [Treatment: TRP: $F(1,29)=77.46, \mathrm{p}<0.001$; Ratio: $\mathrm{F}(1,29)=84.91$, $\mathrm{p}<0.001]$. There was no Time $\times$ Genotype $\times$ Treatment interaction effect on TRP or on the ratio $(F ' s<0.4)$. There was no Genotype $\times$ Treatment interaction effect on TRP or on the ratio $(F ' s<2.15)$. There was a Time $\times$ Treatment interaction effect on $\operatorname{TRP}[F(1,29)=206.17$, $\mathrm{p}<0.001]$ and on the TRP $/ \Sigma \mathrm{LNAA}$ ratio $[\mathrm{F}(1,29)=181.17, \mathrm{p}<0.001]$. Further analysis showed that in the TRP+ condition there was a significant increase of TRP and the TRP/ $L$ LNAA ratio over the four hours [TRP: $F(1,13)=26.26, p<0.001$; Ratio: $F(1,13)=23.01, p<0.001$ ], whereas in the TRP- condition these were significantly decreased [TRP: $(1,14)=223.26$,

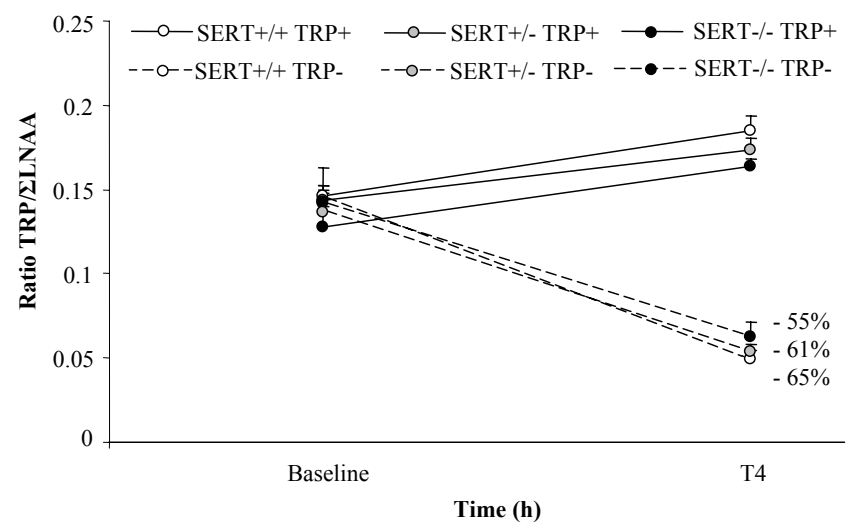

Figure 1. Treatment effects in $\mathrm{SERT}^{+/}$, $\mathrm{SERT}^{+/}$, and $\mathrm{SERT}^{-/}$on the plasma TRP/LLNAA ratio. Percentages indicate depletion from baseline levels. 
$\mathrm{p}<0.001$; Ratio: $\mathrm{F}(1,14)=222.13, \mathrm{p}<0.001]$. There was no Time $\times$ Genotype effect and no effect of genotype on TRP levels and on the TRP/ $\Sigma$ LNAA ratio.

Brain levels. As shown in Figure 2, there was a treatment effect on 5-HT in the frontal cortex $[\mathrm{F}(2,66)=41.46, \mathrm{p}<0.001]$ and in the hippocampus $[\mathrm{F}(2,66)=17.85, \mathrm{p}<0.001]$. Posthoc testing showed that in both structures, 5-HT levels were lower in the TRP- condition than in the untreated and TRP+ conditions. Furthermore, in both structures, 5-HT concentrations in the $\mathrm{TRP}+$ condition were higher than in the untreated rats. There was a genotype effect on 5 -HT in the frontal cortex $[\mathrm{F}(2,66)=73.76, \mathrm{p}<0.001]$ and in the hippocampus $[\mathrm{F}(2,66)=67.25, \mathrm{p}<0.001]$. Posthoc analysis showed that in both structures, 5 -HT levels in $\mathrm{SERT}^{-/-}$were lower than in $\mathrm{SERT}^{+/-}$and $\mathrm{SERT}^{+/+}$rats. There were no Treatment $\times$Genotype interaction effects on 5-HT in the frontal cortex and the hippocampus.

When treatment effects were analysed within each genotype, it was found that in the frontal cortex there was a treatment effect on 5 -HT in all genotypes $\left[\mathrm{SERT}^{+/+}\right.$: $\mathrm{F}(2,20)=9.80, \mathrm{p}<0.001 ; \mathrm{SERT}^{+/-}: \mathrm{F}(2,21)=12.75, \mathrm{p}<0.001 ; \mathrm{SERT}^{-/}: \mathrm{F}(2,21)=27.88$, $\mathrm{p}<0.001]$. In all genotypes, 5-HT levels in the TRP- group were significantly lower than in the TRP+ group. In the SERT ${ }^{+/+}$and the SERT ${ }^{+/} 5-\mathrm{HT}$ was higher in the TRP+ group than in the untreated rats, which was not the case in SERT ${ }^{-1-}$ rats. In SERT ${ }^{-1-}$ rats 5-HT was lower in the TRP- condition than in untreated rats, which was not the case in $\mathrm{SERT}^{+/+}$and $\mathrm{SERT}^{+/-}$rats. In the hippocampus, there was a treatment effect on 5-HT in $\mathrm{SERT}^{+-}[\mathrm{F}(2,21)=9.29, \mathrm{p}<0.001]$ and in $\mathrm{SERT}^{-/-}$rats $[\mathrm{F}(2,21)=20.88, \mathrm{p}<0.001]$, but not in $\mathrm{SERT}^{+/+}$rats. In $\mathrm{SERT}^{+/-}$rats, 5 -HT levels in the TRP+ condition were higher than in untreated and TRP- treated rats. In SERT ${ }^{-1}$ rats, 5-HT levels in the TRP- condition were lower than in the TRP+ condition and in untreated rats.

There was a treatment effect on 5-HIAA in the frontal cortex $[\mathrm{F}(2,66)=23.98$, $\mathrm{p}<0.001]$ and in the hippocampus $[\mathrm{F}(2,66)=34.35, \mathrm{p}<0.001]$. Posthoc testing showed that in both structures, concentrations in the TRP- condition were lower than in the untreated rats and in the TRP+ condition. In the hippocampus, 5-HIAA was higher in untreated rats than in TRP+ treated rats. There was a genotype effect on 5-HIAA in the frontal cortex $[\mathrm{F}(2,66)=34.03, \mathrm{p}<0.001]$ and in the hippocampus $[\mathrm{F}(2,66)=35.30$, $\mathrm{p}<0.001]$. Posthoc analysis showed that in both structures, 5-HIAA levels in SERT ${ }^{/-}$were lower than in $\mathrm{SERT}^{+/-}$and SERT ${ }^{+/+}$rats. There were no Treatment $\times$Genotype interaction effects on 5-HT in the frontal cortex and the hippocampus. In all genotypes, there was a treatment effect on 5-HIAA in the frontal cortex $\left[\mathrm{SERT}^{+/+}: \mathrm{F}(2,20)=18.69, \mathrm{p}<0.001\right.$; SERT $^{+/}: \mathrm{F}(2,21)=4.29, \mathrm{p}<0.05 ;$ SERT $\left.^{-1}: \mathrm{F}(2,21)=10.66, \mathrm{p}<0.001\right]$. Posthoc testing showed that in $\mathrm{SERT}^{+/+} 5$-HIAA was lower in the TRP- group compared to the TRP+ group $(\mathrm{p}<0.01)$ and the untreated group $(\mathrm{p}<0.001)$. In SERT ${ }^{+/-}$and $\mathrm{SERT}^{-/-}$rats, 5-HIAA levels were lower in TRP- compared to untreated rats $\left(\mathrm{SERT}^{+/-}: \mathrm{p}<0.05 ; \mathrm{SERT}^{-/}: \mathrm{p}<0.001\right)$. In all genotypes, there was a treatment effect in the hippocampus as well [SERT ${ }^{+/+}$: $\mathrm{F}(2,20)=28.19, \mathrm{p}<0.001 ; \mathrm{SERT}^{+/-}: \mathrm{F}(2,21)=7.16, \mathrm{p}<0.001 ; \mathrm{SERT}^{-1-}: \mathrm{F}(2,21)=11.91$, $\mathrm{p}<0.001]$. Posthoc testing showed that in $\mathrm{SERT}^{+/+}$and $\mathrm{SERT}^{+/-}$rats 5-HIAA was lower 

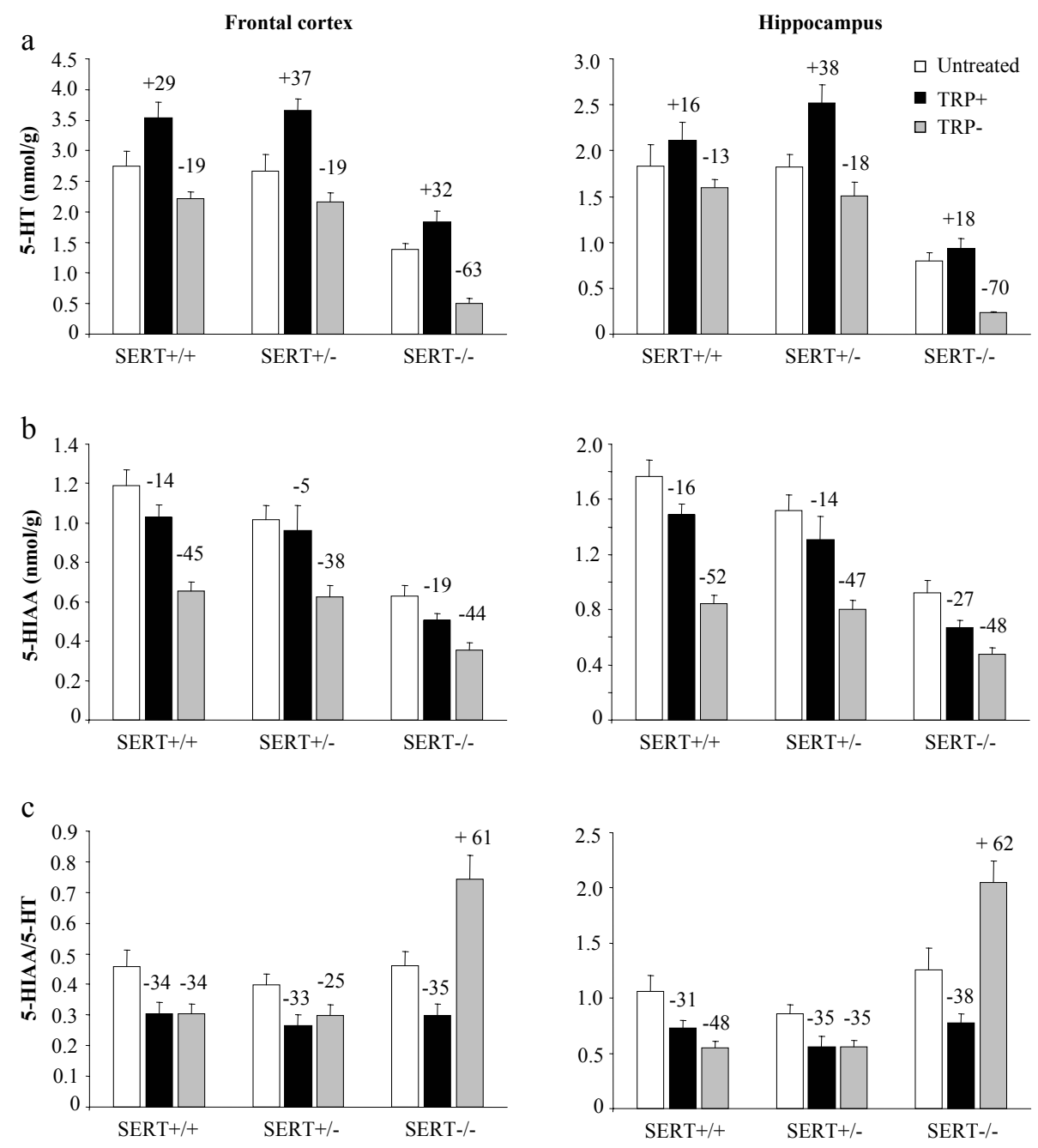

Figure 2. Effect of treatment with TRP+ or TRP- on basal brain 5-HT (2a), 5-HIAA (2b) and 5-HIAA/5-HT turnover (2c) levels in the frontal cortex and hippocampus. Bars represent mean and standard error. Numbers above the bars represent percentage difference from the untreated condition.

in the TRP- group compared to the TRP+ $\left(\mathrm{SERT}^{+/+}: \mathrm{p}<0.001 ; \mathrm{SERT}^{+/-}: \mathrm{p}<0.05\right)$ and untreated group $\left(\mathrm{SERT}^{+/+}: \mathrm{p}<0.001 ; \mathrm{SERT}^{+-}: \mathrm{p}<0.01\right)$. In SERT ${ }^{-/-}$rats, 5-HIAA was higher in the untreated rats compared to rats treated with TRP+ $(\mathrm{p}<0.05)$ and TRP- $(\mathrm{p}<0.001)$.

There was a Treatment $\times$ Genotype interaction effect on the 5-HIAA/5-HT turnover in the frontal cortex $[\mathrm{F}(4,62)=9.628, \mathrm{p}<0.001]$ and in the hippocampus 
$[\mathrm{F}(4,62)=12.60, \mathrm{p}<0.001]$. There was a treatment effect on the turnover in the frontal cortex $[\mathrm{F}(2,62)=11.60, \mathrm{p}<0.001]$ and in the hippocampus $[\mathrm{F}(2,62)=9.02, \mathrm{p}<0.001]$. Posthoc testing showed that in both structures, the turnover was lower in the TRP+ condition than in the untreated rats and in the TRP- condition. There was a genotype effect on 5-HIAA in the frontal cortex $[\mathrm{F}(2,62)=13.64, \mathrm{p}<0.001]$ and in the hippocampus $[\mathrm{F}(2,62)=28.62, \mathrm{p}<0.001]$. Posthoc analysis showed that in both structures, the turnover was higher in $\mathrm{SERT}^{/-}$rats than in $\mathrm{SERT}^{+/}$and $\mathrm{SERT}^{+/+}$rats. In all genotypes, there was a treatment effect on 5-HIAA/5-HT turnover in the frontal cortex [SERT ${ }^{+/+}$: $\mathrm{F}(2,20)=4.64, \mathrm{p}<0.05 ; \quad \mathrm{SERT}^{+/-}: \mathrm{F}(2,21)=3.78, \mathrm{p}<0.05 ; \quad \mathrm{SERT}^{-1-}: \mathrm{F}(2,21)=16.37$, $\mathrm{p}<0.001]$. Posthoc testing showed that in $\mathrm{SERT}^{+/+} 5$-HIAA/5-HT was lower in the TRPgroup compared to the untreated group $(\mathrm{p}<0.05)$. In $\mathrm{SERT}^{+/-} 5$-HIAA/5-HT was lower in $\mathrm{TRP}+$ rats than in untreated rats $(\mathrm{p}<0.05) . \mathrm{In} \mathrm{SERT}^{-/}$rats 5 -HIAA/5-HT was higher in TRP- compared to untreated rats $(\mathrm{p}<0.001)$ and TRP+ rats $(\mathrm{p}<0.001)$. In all genotypes, there was a treatment effect in the hippocampus as well [ $\mathrm{SERT}^{+/+}: \mathrm{F}(2,20)=7.31$, $\mathrm{p}<0.01 ;$ SERT $^{+/-}: \mathrm{F}(2,21)=4.10, \mathrm{p}<0.05 ;$ SERT $\left.^{-/}: \mathrm{F}(2,21)=15.12, \mathrm{p}<0.001\right]$. Posthoc testing showed that in SERT $^{+/+}$rats 5-HIAA/5-HT was lower in the TRP- group compared to the untreated group $(\mathrm{p}<0.01)$. In $\mathrm{SERT}^{-/-}$rats, 5-HIAA/5-HT was higher in the TRPrats compared to untreated $(\mathrm{p}<0.01)$ and $\mathrm{TRP}+$ treated rats $(\mathrm{p}<0.001)$.

\section{Behavioural Tests}

Open field test There was a trend towards a Genotype $\times$ Treatment interaction effect $[F(2,66)=2.76, p<0.08]$ on time spent in the center of the open field (Figure 3 ). There was no effect of genotype, but rats treated with TRP- spent more time in the center of the open field [Treatment: $\mathrm{F}(1,68)=8.38, \mathrm{p}<0.01$ ] . There was no Genotype $\times$ Treatment interaction effect and no effect of genotype on time spent in the corners of the open field, but the TRP- rats spent less time in the corners than the rats treated with TRP+ [Treatment: $\mathrm{F}(1,68)=4.97, \mathrm{p}<0.05]$. There was a Genotype $\times$ Treatment interaction effect on the distance the rats moved in the open field $[\mathrm{F}(2,66)=5.17, \mathrm{p}<0.01]$. Genotype had no effect on the distance moved, whereas TRP- treated rats moved a longer distance compared to TRP+ treated rats [Treatment: $\mathrm{F}(1,66)=5.41, \mathrm{p}<0.05$ ].

When treatment effects were analysed within each genotype, it was found that both SERT ${ }^{+/+}$and SERT $^{+/-}$rats treated with TRP- spent more time in the center [Treatment: SERT $\left.^{+/+} \mathrm{F}(1,23)=7.07, \mathrm{p}<0.05 ; \mathrm{SERT}^{+/-} \mathrm{F}(1,21)=4.80, \mathrm{p}<0.05\right]$, and moved a longer distance [Treatment: $\operatorname{SERT}^{+/+} \mathrm{F}(1,23)=7.28, \mathrm{p}<0.05 ; \mathrm{SERT}^{+/-} \mathrm{F}(1,21)=6.55$, $\mathrm{p}<0.05$ ] compared to their TRP+ controls. SERT ${ }^{+/+}$, but not SERT ${ }^{+/-}$and SERT ${ }^{-/}$, TRPtreated rats spent less time in the corners [Treatment: $F(1,23)=7.45, p<0.05$ ] than $\mathrm{TRP}+$ treated $\mathrm{SERT}^{+/+}$rats. There were no treatment effects on any of the outcome parameters in $\mathrm{SERT}^{-/-}$rats. 


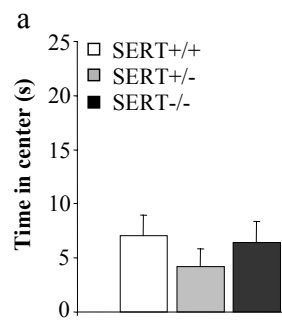

TRP+

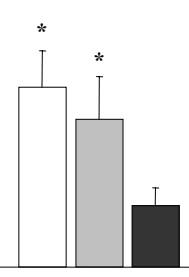

TRP-

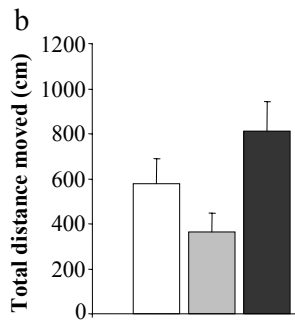

TRP+

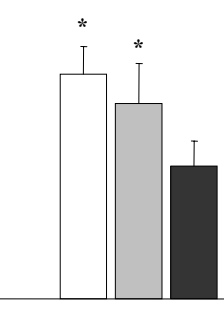

TRP-

Figure 3. Open field test. Treatment effects in $\mathrm{SERT}^{+/+}, \mathrm{SERT}^{+/}$, and $\mathrm{SERT}^{-/}$on time spent in the center (3a) and total distance moved (3b) in the open field. Treatment effect ${ }^{*} \mathrm{p}<0.05$.

Elevated plus maze Data of the time spent in the closed and open zones of the elevated plus maze are shown in Figure 4. Due to technical problems, data of 21 rats were lost. There were no Genotype $\times$ Treatment interaction effect on the time spent in the open or closed zones of the elevated plus maze [F's $(2,45)<0.72$, ns]. Besides a tendency of shorter time spent in the closed zones after ATD $[F(1,47)=3.70, \mathrm{p}<0.08]$, there were no significant effects of Genotype or Treatment on the time the rats spent in the open and closed zones [F’s $(2,47)<1.88, \mathrm{~ns}]$.
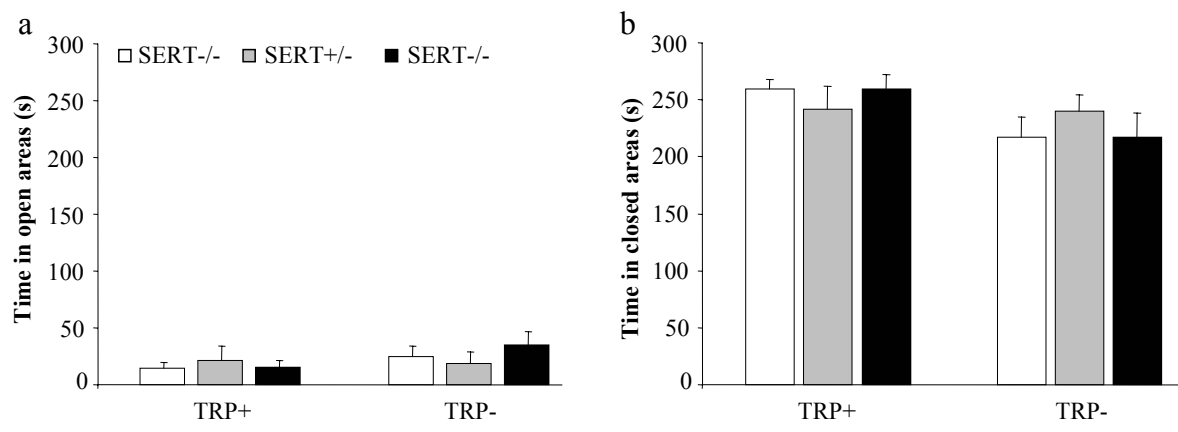

Figure 4. Elevated plus maze. Treatment effects in $\mathrm{SERT}^{+/+}, \mathrm{SERT}^{+/-}$, and $\mathrm{SERT}^{-/}$on time spent in the open (4a) and in the closed areas $(4 \mathrm{~b})$ of the elevated plus maze.

Home cage emergence test Due to methodological issues we could use the home cage emergence data of only half of the animals. Median escape latency data of the home cage emergence test are depicted in Figure 5. There was a Treatment $\times$ Genotype interaction effect on mean escape latency $[\mathrm{F}(2,30)=4.14, \mathrm{p}<0.05]$. Genotype and treatment did not affect escape latency. When treatment effects were analysed within each genotype, the TRP- treated SERT ${ }^{+-}$rats showed a trend towards a longer escape latency 
compared to their TRP+ controls $[\mathrm{F}(1,10)=4.74, \mathrm{p}<0.06]$. Treatment did not affect escape latency in $\mathrm{SERT}^{+/+}$and $\mathrm{SERT}^{-/-}$rats.

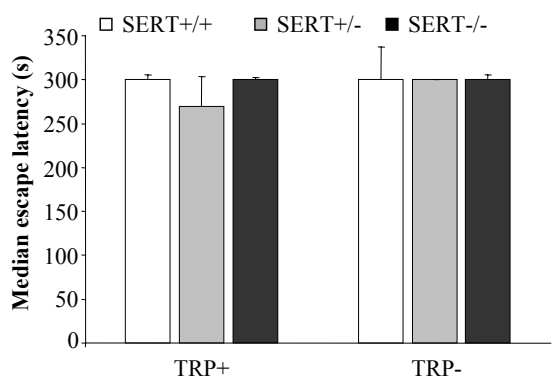

Figure 5. Home cage emergence test. Treatment effects in $\mathrm{SERT}^{+/+}, \mathrm{SERT}^{+/}$, and $\mathrm{SERT}^{-/}$on escape latency.

Social interaction test There were no Genotype $\times$ Treatment interaction effects, Genotype effects, or Treatment effects on the total time the rats spent in social interaction, the frequency of active social interaction, the duration of active social interaction, the duration of passive interaction or the percentage of active social interaction (Figure 6). There was a genotype effect on the frequency of passive body contact $[\mathrm{F}(2,65)=3.88$, $\mathrm{p}<0.05]$. Post-hoc analysis revealed that the SERT ${ }^{+/+}$rats showed more episodes of passive body contact than the SERT ${ }^{-/-}$rats $(\mathrm{p}<0.05)$. No treatment effects were found when treatment effects were analysed within each genotype.

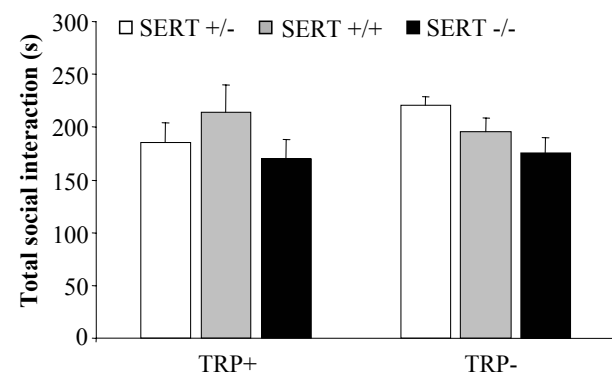

Figure 6. Social interaction test. Treatment effects in $\mathrm{SERT}^{+/+}$, $\mathrm{SERT}^{+/}$, and $\mathrm{SERT}^{-/-}$on the total duration of social interaction.

Forced swim test There was no Genotype $\times$ Treatment interaction effect on immobility in the forced swim test $[\mathrm{F}(2,55)=1.82, \mathrm{~ns}]$ and no Treatment or Genotype effects $\left[F^{\prime} s<0.94, n s\right]$. Data are shown in Figure 7. 


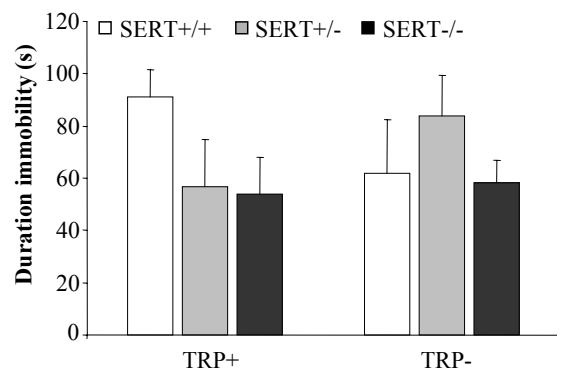

Figure 7. Forced swim test. Treatment effects in $\mathrm{SERT}^{+/+}, \mathrm{SERT}^{+/}$, and $\mathrm{SERT}^{-/-}$on immobility

Object recognition test The effects of Treatment and Genotype on discrimination index $d 2$ in the object recognition test are shown in Figure 8. There was no Genotype $\times$ Treatment interaction effect $[\mathrm{F}(8,138)=1.28$, ns $]$ and no effect of Genotype on discrimination index $d 2[\mathrm{~F}(2,138)=2.31, \mathrm{~ns}]$. A treatment effect was found on the discrimination index $d 2[\mathrm{~F}(4,146)=21.65, \mathrm{p}<0.001]$, post-hoc analysis showed that the baseline $d 2$ and the $d 2$ in the TRP+ and TRP- $40 \mathrm{~g}$ condition differed from the virtual control group. Only in the TRP-conditions rats were unable to discriminate between the new and familiar object after a one-hour interval. When treatment effects were analysed within each genotype group, there was a treatment effect on $d 2 \mathrm{in}$ all genotypes [SERT ${ }^{+/+}$ $\mathrm{F}(4,50)=17.61, \mathrm{p}<0.001 ; \mathrm{SERT}^{+/-} \mathrm{F}(4,43)=6.00, \mathrm{p}<0.01 ;$ SERT $\left.^{-/-} \mathrm{F}(4,45)=4.92, \mathrm{p}<0.01\right]$. In the SERT ${ }^{+/+}$baseline, TRP- and TRP- $40 \mathrm{~g}$ were different from the virtual controls, but TRP- was not. In the SERT ${ }^{+/}$only baseline and TRP+ treatment were different from the virtual controls, but TRP- and TRP- $40 \mathrm{~g}$ were not. In the SERT ${ }^{-/-}$rats only baseline was different from the virtual controls, whereas TRP+, TRP- and TRP- 40g were not.

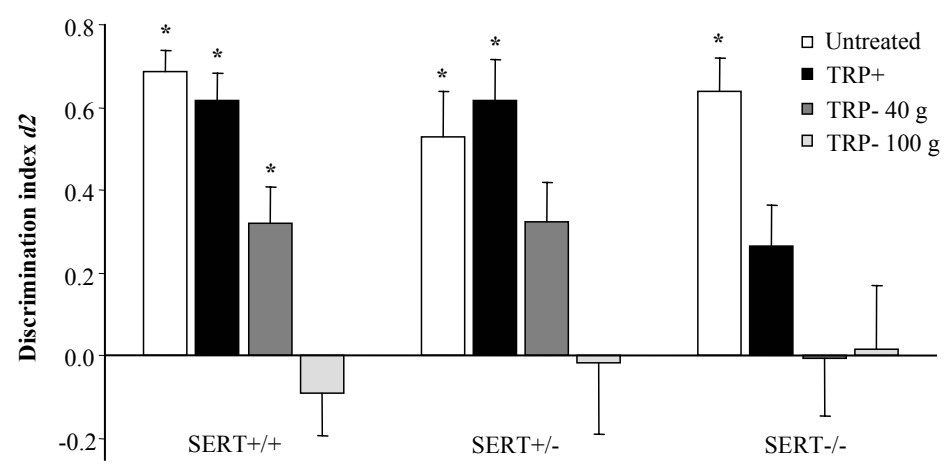

Figure 8. Object recognition test. Treatment effects in SERT ${ }^{+/+}, \mathrm{SERT}^{+/}$, and SERT ${ }^{-/-}$on discrimination index $d 2$. Treatment effect ${ }^{\star} \mathrm{p}<0.05$ difference from virtual control group with no object recognition. 


\section{Discussion}

In the present study, the effects of acute TRP depletion using a gelatin-based proteincarbohydrate mixture were examined in $\mathrm{SERT}^{+/}, \mathrm{SERT}^{+/-}$and $\mathrm{SERT}^{-/}$rats. The rats were tested in animal behavioural tests of anxiety- and depression- related behaviour and cognition to investigate whether the rats' genotype influenced the behavioural response to ATD. On tests of anxiety- and depression- related behaviour there were no, or only small, effects of genotype and treatment. The effects of ATD on brain 5-HT and object recognition were stronger in $\mathrm{SERT}^{-/-}$rats than in $\mathrm{SERT}^{+/+}$and $\mathrm{SERT}^{+/-}$rats.

The biochemical data showed strong depletion of plasma TRP levels in the TRPcondition. Four hours after the first injection a depletion of $65 \%$ in SERT ${ }^{+/+}, 61 \%$ in SERT $^{+/-}$and 55\% in SERT ${ }^{-/}$rats was found. Moreover 5-HT and 5-HIAA levels in frontal cortex were decreased after TRP- treatment compared to TRP+ treatment. SERT ${ }^{-1-}$ rats showed stronger depletion of 5-HT in the frontal cortex $(63 \%)$ compared to SERT ${ }^{+/+}$and SERT $^{+/-}$rats (both 19\%); and in the hippocampus, (70\%) compared to SERT ${ }^{+/}$rats $(18 \%)$ and $\mathrm{SERT}^{+/+}$rats (13\%). In both the frontal cortex and hippocampus, 5-HIAA decreased to a similar extent in all genotypes. In both structures, 5-HIAA was lower after TRPtreatment than after TRP+ treatment. Whereas 5-HIAA/5-HT turnover is a bit lower in TRP+ and TRP- treated rats in SERT ${ }^{+/+}$and $\mathrm{SERT}^{+/-}$rats, in $\mathrm{SERT}^{-/-}$rats, the turnover ratio is highly increased after TRP- compared to TRP+ and untreated rats as a result of strong decrease in 5-HT. In SERT ${ }^{-/}$rats, ATD results in a stronger reduction of 5-HT in both brain structures than in $\mathrm{SERT}^{+/-}$and $\mathrm{SERT}^{+/+}$rats, while de decrease in 5-HIAA is similar in all genotypes, suggesting similar breakdown of 5-HT in all genotypes. Because in $\mathrm{SERT}^{-/}$rats released 5-HT cannot be transported back into the presynaptic neuron, the presynaptic 5-HT storage may be lower in SERT ${ }^{-/-}$than in the other genotypes and therefore their 5-HT levels may decrease more strongly after ATD.

At a behavioural level, ATD impaired object recognition memory, but did not influence affective behaviour. Healthy human subjects show impaired cognitive performance after ATD (Riedel et al., 1999, Riedel et al., 2002, Sambeth et al., 2007) and impaired object recognition in rats has been found in male and female Wistar rats (Lieben et al., 2004b, Jans et al., 2007a). In this test all genotypes showed impaired object recognition after ATD. The relatively mild depletion of the TRP- 40g treatment impaired object recognition in SERT ${ }^{+/-}$and especially in SERT ${ }^{-/}$rats but not in $\mathrm{SERT}^{+/+}$rats where the $d 2$ was lower than at baseline, but still different from the virtual control group with impaired object recognition. The stronger effects of the TRP- $40 \mathrm{~g}$ treatment in $\mathrm{SERT}^{-/}$rats may be related to the stronger effects of TRP- treatment on central 5-HT levels. The same dose of TRP- appeared to have a stronger effect on central 5-HT levels in SERT ${ }^{-/-}$rats compared to $\mathrm{SERT}^{+-}$and $\mathrm{SERT}^{-1-}$ rats. Notably, $\mathrm{SERT}^{-1-}$ rats showed impaired object recognition after TRP+ treatment as well, although their baseline discrimination index $d 2$ indicated normal object recognition when untreated. 
The open field test and the elevated plus maze are generally accepted animal models for measuring exploration-conflict anxiety-related behaviour (Hogg, 1996, Prut and Belzung, 2003). In the open field test, TRP- treated SERT ${ }^{+/+}$and $\mathrm{SERT}^{+/}$rats spent more time in the center of the open field and had a longer distance moved compared to their TRP+ treated controls. These effects were not found in SERT ${ }^{-/}$rats. ATD was hypothesized to increase anxiety-related behaviour in vulnerable subjects, but here a decrease in anxiety-related behaviour was found in $\mathrm{SERT}^{+/+}$and SERT ${ }^{+/-}$rats. In the elevated plus maze and the social interaction test, no effects of treatment and genotype were found on the behaviour of the animals. Time spent in the open zones of the elevated plus maze was very low, which might indicate a ceiling effect. In the home cage emergence test TRP- treated SERT ${ }^{+/}$rats had a longer escape latency than $\mathrm{SERT}^{+/-} \mathrm{TRP}+$ rats, but there were no treatment effects on escape latency in the SERT ${ }^{+/+}$and $\mathrm{SERT}^{-{ }^{--}}$rats. In the $\mathrm{SERT}^{+/+}$and $\mathrm{SERT}^{-/}$rats the escape latency in the home cage emergence was almost maximal in the TRP+ condition, making it impossible to increase the escape latency after TRP- treatment. Perhaps treatment effects would have been observed if the maximal escape latency had been set differently.

The forced swim test was performed to assess depression-related behaviour in response to ATD in $\mathrm{SERT}^{+/+}, \mathrm{SERT}^{+/}$, and $\mathrm{SERT}^{-/-}$rats. Chronic mild stress and maternal separation increase the immobility in the forced swim test (Molina et al., 1994, Huang and Lin, 2006), indicating that an increased immobility is related to a higher 'depressive'-like state in rats. If the rats are vulnerable to ATD, their immobility will increase. No treatment or genotype effects were found in the forced swim test. Indicating that the depression-related behaviour seen in the forced swim test was not affected by TRP depletion. This is in line with previous results, where ATD had no effect on male and female rats in the forced swim test (Lieben et al., 2004b, Jans et al., 2007a). At basal levels in the Porsolt forced swim test, where rats are forced to swim for 15 minutes on day one, and subsequently tested for immobility on day 2 for 5 minutes, SERT ${ }^{-/}$rats showed a significantly higher immobility time compared to $\mathrm{SERT}^{+/+}$rats (Olivier et al., unpublished data). However, when SERT ${ }^{-/}$rats are tested repeatedly in the forced swim test this difference between SERT ${ }^{+/+}$and SERT ${ }^{-/-}$disappears (Olivier et al., unpublished data). Taken together, these results might suggest an impaired stress coping in SERT ${ }^{-}$ 1- rats, which disappears after repeated testing of the forced swim test. And apparently, ATD does not affect this behaviour.

Most indices of anxiety-related behaviour in this study were high even in the TRP+ condition. Activity levels were generally low in all behavioural tests, including the object recognition test in which the duration of exploration was low. This may indicate that the rats in general had low levels of activity and exploration, which might suggest high levels of anxiety in these rats. Furthermore it is possible that these behaviours are related to the light-dark cycle the rats were on, with behavioural testing during the day in the light period which is the inactive period for rats. Naïve anxiety levels have been measured in previous studies during the light-period, where SERT ${ }^{-/-}$rats showed an increased anxi- 
ety-like behaviour compared to $\mathrm{SERT}^{+/+}$rats (Olivier et al, unpublished data). However, exploration time in the test used here was very low and could have been increased by testing the rats during their active period.

The TRP+ treatment resulted in increased levels of plasma TRP and brain 5-HT, suggesting an active control. Essentially this means that we compared TRP depletion and mild TRP suppletion in SERT rats. This may have affected behaviour in the TRP+ condition. However, these effects were similar in all genotypes. Both this genotype difference in the central effects of ATD and the treatment effect in the TRP+ condition complicate the interpretation of the behavioural data.

Other possible shortcomings and limitations are the fact that the same group of rats was frequently subjected to the treatment, although the treatment condition varied between tests. The tests used in this study required multiple testing trials to obtain valid indices of anxiety and depression. In previous studies with a similar design (Jans et al., 2007a) it has been shown that there were no differences in the treatment effect on the plasma TRP/ $\Sigma$ LNAA ratio when comparing the data of the blood sampling at the beginning and at the end of the study. Apparently, the treatment effect after the second exposure to the treatment was the same as after the thirteenth exposure. We therefore assume that the treatment has had comparable biochemical effects throughout the entire study although it cannot be excluded that repeated treatment had the same effects in all genotypes. It is possible that $\mathrm{SERT}^{+/-}$and $\mathrm{SERT}^{-/-}$rats were differently affected by repeated treatment compared to SERT ${ }^{+/+}$rats.

Furthermore, the repeated testing of the rats in the successive tests (Table 2) might have affected the performance from one test to the other. Because all rats were subjected to the same series of tests, we may assume that the effects of repeated testing were similar in all groups. However, it is possible that the different genotypes were differently affected by exposure to the behavioural test. It cannot be excluded that this successive testing could have interfered with treatment effects. This can only be tested if naïve rats are used for each individual test.

It should also be noted that due to some technical and methodological issues on some tests, data of several rats had been lost. Hence, the groups and the power may have been too small to detect group differences.

The aim of the present experiment was to investigate whether male $\mathrm{SERT}^{+/+}, \mathrm{SERT}^{+/-}$, and SERT $^{-/}$serotonin transporter rats differ in serotonergic vulnerability. In humans, ATD impairs memory, but effects on mood are only seen in vulnerable subjects. In the present study, there were no strong indications of higher SV in $\mathrm{SERT}^{-/-}$and SERT ${ }^{+-}$rats. Results of the open field test do not indicate higher SV in SERT ${ }^{+-}$and $\mathrm{SERT}^{-/-}$compared to $\mathrm{SERT}^{+/+}$rats. In the elevated plus maze and home cage emergence test there were probably ceiling effects, although the SERT ${ }^{+/}$showed increased anxiety-like behaviour after ATD. In the social interaction tests and forced swim test there were no indications of SV in any genotype. Only in the object recognition test, $\mathrm{SERT}^{+/-}$and SERT ${ }^{-/}$showed signs of higher SV by showing impaired object recognition after the milder ATD treatment 
TRP- 40g. It is unsure however, whether this is just an effect of the stronger central 5-HT depletion in these rats, or whether these effects on memory can be interpreted as a sign of higher SV in $\mathrm{SERT}^{-/-}$and SERT ${ }^{+/-}$rats.

\section{References}

Bell, C., Abrams, J. and Nutt, D., 2001. Tryptophan depletion and its implications for psychiatry. Br J Psychiatry. 178, 399-405.

Biggio, G., Fadda, F., Fanni, P., Tagliamonte, A. and Gessa, G. L., 1974. Rapid depletion of serum tryptophan, brain tryptophan, serotonin and 5 hydroxyindoletic acid by a tryptophan-free diet. Life Sciences. 14, 1321-1329.

Blokland, A., Lieben, C. and Deutz, N. E., 2002. Anxiogenic and depressive-like effects, but no cognitive deficits, after repeated moderate tryptophan depletion in the rat. J Psychopharmacol. 16, 39-49.

Blokland, A., Prickaerts, J. and Raaijmakers, W., 1992. Reduced level of anxiety in adult Lewis rats after chronic ethanol consumption. Physiol Behav. 51, 245-248.

Booij, L. and Van der Does, A. J., 2007. Cognitive and serotonergic vulnerability to depression: convergent findings. J Abnorm Psychol. 116, 86-94.

Caspi, A., Sugden, K., Moffitt, T. E., Taylor, A., Craig, I. W., Harrington, H., McClay, J., Mill, J., Martin, J., Braithwaite, A. and Poulton, R., 2003. Influence of life stress on depression: moderation by a polymorphism in the 5-HTT gene. Science. 301, 386-389.

Connor, T. J., Kelliher, P., Shen, Y., Harkin, A., Kelly, J. P. and Leonard, B. E., 2000. Effect of subchronic antidepressant treatments on behavioral, neurochemical, and endocrine changes in the forced-swim test. Pharmacol Biochem Behav. 65, 591-597.

de Jong, T. R., Snaphaan, L. J., Pattij, T., Veening, J. G., Waldinger, M. D., Cools, A. R. and Olivier, B., 2006. Effects of chronic treatment with fluvoxamine and paroxetine during adolescence on serotonin-related behavior in adult male rats. Eur Neuropsychopharmacol. 16, 39-48.

Dick, D. M., Plunkett, J., Hamlin, D., Nurnberger, J., Jr., Kuperman, S., Schuckit, M., Hesselbrock, V., Edenberg, H. and Bierut, L., 2007. Association analyses of the serotonin transporter gene with lifetime depression and alcohol dependence in the Collaborative Study on the Genetics of Alcoholism (COGA) sample. Psychiatr Genet. 17, 35-38.

Ennaceur, A. and Delacour, J., 1988. A new one-trial test for neurobiological studies of memory in rats. 1: Behavioral data. Behav Brain Res. 31, 47-59.

Fernstrom, J. D. and Wurtman, R. J., 1997. Brain serotonin content: physiological regulation by plasma neutral amino acids. Obes Res. 5, 377-380.

File, S. E. and Hyde, J. R., 1978. Can social interaction be used to measure anxiety? Br J Pharmacol. 62, 19-24.

File, S. E. and Seth, P., 2003. A review of 25 years of the social interaction test. Eur J Pharmacol. 463, 35-53.

Fluttert, M., Dalm, S. and Oitzl, M. S., 2000. A refined method for sequential blood sampling by tail incision in rats. Lab Anim. 34, 372-378.

Gessa, G. L., Biggio, G., Fadda, F., Corsini, G. U. and Tagliamonte, A., 1974. Effect of the oral administration of tryptophan-free amino acid mixtures on serum tryptophan, brain tryptophan and serotonin metabolism. J Neurochem. 22, 869-870.

Gingrich, J. A. and Hen, R., 2001. Dissecting the role of the serotonin system in neuropsychiatric disorders using knockout mice. Psychopharmacology (Berl). 155, 1-10.

Hogg, S., 1996. A review of the validity and variability of the elevated plus-maze as an animal model of anxiety. Pharmacol Biochem Behav. 54, 21-30.

Holmes, A., Murphy, D. L. and Crawley, J. N., 2003. Abnormal behavioral phenotypes of serotonin transporter knockout mice: parallels with human anxiety and depression. Biol Psychiatry. 54, 953-959. 
Homberg, J. R., Olivier, J. D., Smits, B. M., Mul, J. D., Mudde, J., Verheul, M., Nieuwenhuizen, O. F., Cools, A. R., Ronken, E., Cremers, T., Schoffelmeer, A. N., Ellenbroek, B. A. and Cuppen, E., 2007. Characterization of the serotonin transporter knockout rat: a selective change in the functioning of the serotonergic system. Neuroscience. 146, 1662-1676.

Huang, T. Y. and Lin, C. H., 2006. Role of amygdala MAPK activation on immobility behavior of forced swim rats. Behav Brain Res. 173, 104-111.

Jans, L. A., Lieben, C. K. and Blokland, A., 2007a. Influence of sex and estrous cycle on the effects of acute tryptophan depletion induced by a gelatin-based mixture in adult Wistar rats. Neuroscience. 147, 304-317.

Jans, L. A., Riedel, W. J., Markus, C. R. and Blokland, A., 2007b. Serotonergic vulnerability and depression: assumptions, experimental evidence and implications. Mol Psychiatry. 12, 522-543.

Lieben, C. K., Blokland, A., Westerink, B. and Deutz, N. E., 2004a. Acute tryptophan and serotonin depletion using an optimized tryptophan-free protein-carbohydrate mixture in the adult rat. Neurochem Int. 44, 9-16.

Lieben, C. K., van Oorsouw, K., Deutz, N. E. and Blokland, A., 2004b. Acute tryptophan depletion induced by a gelatin-based mixture impairs object memory but not affective behavior and spatial learning in the rat. Behav Brain Res. 151, 53-64.

Maes, M. and Meltzer, H. Y., 1995. The Serotonin Hypothesis of Major Depression. In: Bloom, F. E. and Kupfer, D. J. (Eds.), Psychopharmacology: The Fourth Generation of Progress. Raven Press, Ltd., New York, pp. 933-944.

Malison, R. T., Price, L. H., Berman, R., van Dyck, C. H., Pelton, G. H., Carpenter, L., Sanacora, G., Owens, M. J., Nemeroff, C. B., Rajeevan, N., Baldwin, R. M., Seibyl, J. P., Innis, R. B. and Charney, D. S., 1998. Reduced brain serotonin transporter availability in major depression as measured by [123I]-2 betacarbomethoxy-3 beta-(4-iodophenyl)tropane and single photon emission computed tomography. Biol Psychiatry. 44, 1090-1098.

Mann, J. J., Huang, Y. Y., Underwood, M. D., Kassir, S. A., Oppenheim, S., Kelly, T. M., Dwork, A. J. and Arango, V., 2000. A serotonin transporter gene promoter polymorphism (5-HTTLPR) and prefrontal cortical binding in major depression and suicide. Arch Gen Psychiatry. 57, 729-738.

Marsh, A. A., Finger, E. C., Buzas, B., Soliman, N., Richell, R. A., Vythilingham, M., Pine, D. S., Goldman, D. and Blair, R. J., 2006. Impaired recognition of fear facial expressions in 5-HTTLPR S-polymorphism carriers following tryptophan depletion. Psychopharmacology (Berl). 189, 387-394.

Moja, E. A., Cipolla, P., Castoldi, D. and Tofanetti, O., 1989. Dose-response decrease in plasma tryptophan and in brain tryptophan and serotonin after tryptophan-free amino acid mixtures in rats. Life Sci. 44, 971-976.

Molina, V. A., Heyser, C. J. and Spear, L. P., 1994. Chronic variable stress or chronic morphine facilitates immobility in a forced swim test: reversal by naloxone. Psychopharmacology (Berl). 114, 433-440.

Moore, P., Landolt, H. P., Seifritz, E., Clark, C., Bhatti, T., Kelsoe, J., Rapaport, M. and Gillin, J. C., 2000. Clinical and physiological consequences of rapid tryptophan depletion. Neuropsychopharmacology. 23, 601-622.

Mossner, R., Mikova, O., Koutsilieri, E., Saoud, M., Ehlis, A. C., Muller, N., Fallgatter, A. J. and Riederer, P., 2007. Consensus paper of the WFSBP Task Force on Biological Markers: biological markers in depression. World J Biol Psychiatry. 8, 141-174.

Murphy, D. L., Wichems, C., Li, Q. and Heils, A., 1999. Molecular manipulations as tools for enhancing our understanding of 5-HT neurotransmission. Trends Pharmacol Sci. 20, 246-252.

Neumeister, A., Hu, X. Z., Luckenbaugh, D. A., Schwarz, M., Nugent, A. C., Bonne, O., Herscovitch, P., Goldman, D., Drevets, W. C. and Charney, D. S., 2006. Differential effects of 5-HTTLPR genotypes on the behavioral and neural responses to tryptophan depletion in patients with major depression and controls. Arch Gen Psychiatry. 63, 978-986.

Neumeister, A., Konstantinidis, A., Stastny, J., Schwarz, M. J., Vitouch, O., Willeit, M., Praschak-Rieder, N., Zach, J., de Zwaan, M., Bondy, B., Ackenheil, M. and Kasper, S., 2002. Association between serotonin transporter gene promoter polymorphism (5HTTLPR) and behavioral responses to tryptophan depletion in healthy women with and without family history of depression. Arch Gen Psychiatry. 59, 613-620. 
Ossenkopp, K. P. and Mazmanian, D. S., 1985. The measurement and integration of behavioral variables: aggregation and complexity as important issues. Neurobehav Toxicol Teratol. 7, 95-100.

Prickaerts, J., Raaijmakers, W. and Blokland, A., 1996. Effects of myocardial infarction and captopril therapy on anxiety-related behaviors in the rat. Physiol Behav. 60, 43-50.

Prickaerts, J., van Staveren, W. C., Şık, A., Markerink-van Ittersum, M., Niewohner, U., van der Staay, F. J., Blokland, A. and de Vente, J., 2002. Effects of two selective phosphodiesterase type 5 inhibitors, sildenafil and vardenafil, on object recognition memory and hippocampal cyclic GMP levels in the rat. Neuroscience. 113, 351-361.

Prut, L. and Belzung, C., 2003. The open field as a paradigm to measure the effects of drugs on anxiety-like behaviors: a review. Eur J Pharmacol. 463, 3-33.

Riedel, W. J., Klaassen, T., Deutz, N. E., van Someren, A. and van Praag, H. M., 1999. Tryptophan depletion in normal volunteers produces selective impairment in memory consolidation. Psychopharmacology (Berl). 141, 362-369.

Riedel, W. J., Klaassen, T. and Schmitt, J. A., 2002. Tryptophan, mood, and cognitive function. Brain Behav Immun. 16, 581-589.

Roiser, J. P., Blackwell, A. D., Cools, R., Clark, L., Rubinsztein, D. C., Robbins, T. W. and Sahakian, B. J., 2006. Serotonin transporter polymorphism mediates vulnerability to loss of incentive motivation following acute tryptophan depletion. Neuropsychopharmacology. 31, 2264-2272.

Rutten, K., Lieben, C., Smits, L. and Blokland, A., 2007. The PDE4 inhibitor rolipram reverses object memory impairment induced by acute tryptophan depletion in the rat. Psychopharmacology (Berl). 192, 275282.

Sambeth, A., Blokland, A., Harmer, C. J., Kilkens, T. O., Nathan, P. J., Porter, R. J., Schmitt, J. A., Scholtissen, B., Sobczak, S., Young, A. H. and Riedel, W. J., 2007. Sex differences in the effect of acute tryptophan depletion on declarative episodic memory: a pooled analysis of nine studies. Neurosci Biobehav Rev. 31, 516-529.

Schmitt, J. A., Jorissen, B. L., Sobczak, S., van Boxtel, M. P., Hogervorst, E., Deutz, N. E. and Riedel, W. J., 2000. Tryptophan depletion impairs memory consolidation but improves focussed attention in healthy young volunteers. J Psychopharmacol. 14, 21-29.

Schmitz, A., Hennig, J., Kuepper, Y. and Reuter, M., 2007. The association between neurotism and the serotonin transporter polymorphism depends on structural differences between personality measures. Pers ind dif. 42.

Şık, A., van Nieuwehuyzen, P., Prickaerts, J. and Blokland, A., 2003. Performance of different mouse strains in an object recognition task. Behav Brain Res. 147, 49-54.

Smits, B. M., Mudde, J., Plasterk, R. H. and Cuppen, E., 2004. Target-selected mutagenesis of the rat. Genomics. 83, 332-334.

Smits, B. M., Mudde, J. B., van de Belt, J., Verheul, M., Olivier, J., Homberg, J., Guryev, V., Cools, A. R., Ellenbroek, B. A., Plasterk, R. H. and Cuppen, E., 2006. Generation of gene knockouts and mutant models in the laboratory rat by ENU-driven target-selected mutagenesis. Pharmacogenet Genomics. 16, 159-169.

Stancampiano, R., Melis, F., Sarais, L., Cocco, S., Cugusi, C. and Fadda, F., 1997. Acute administration of a tryptophan-free amino acid mixture decreases 5-HT release in rat hippocampus in vivo. Am J Physiol. 272, R991-994.

van der Staay, F. J. and Blokland, A., 1996. Behavioral differences between outbred Wistar, inbred Fischer 344, brown Norway, and hybrid Fischer $344 \times$ brown Norway rats. Physiol Behav. 60, 97-109.

Walderhaug, E., Magnusson, A., Neumeister, A., Lappalainen, J., Lunde, H., Refsum, H. and Landro, N. I., 2007. Interactive effects of sex and 5-HTTLPR on mood and impulsivity during tryptophan depletion in healthy people. Biol Psychiatry. 62, 593-599.

Willner, P., 2005. Chronic mild stress (CMS) revisited: consistency and behavioural-neurobiological concordance in the effects of CMS. Neuropsychobiology. 52, 90-110.

Young, S. N., 1996. Behavioral Effects of Dietary Neurotransmitter Precursors: Basic and Clinical Aspects. Neuroscience and Biobehavioral Reviews. 20, 313-323. 


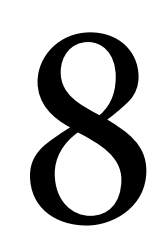

General discussion and conclusion 


\section{General discussion and conclusion}

Although the mechanisms underlying depression are not yet fully understood, there is general consensus that 5 -HT is involved in depression. The first monoamine theories of depression proposed that depression was caused by monoamine deficiency. By now, however, the model of a deficit in 5-HTergic neurotransmission being primary in the aetiology of depressive disorders, and predictive of therapeutic response to drugs enhancing 5-HTergic neurotransmission has become obsolete: not all depressed patients present with 5-HT abnormalities, not all patients benefit from drugs enhancing 5-HTergic neurotransmission, and several drugs that are devoid of major effects on 5-HTergic neurotransmission are known to be effective antidepressants. Furthermore, the absence of robust mood effects in healthy controls after ATD indicates that mood is not a direct correlate of 5-HT functioning in the brain. In depressed patients, ATD does not result in a further decrease of mood. This could indicate a ceiling effect, or it could indicate there is no simple relation between 5-HT deficiency and depressed mood (Ruhe et al., 2007). Hence, the thinking has progressively evolved from an absolute deficit to a high-risk model: low 5-HTergic neurotransmission is now thought to operate as a biological risk factor, resulting from innate and/or environmental factors, neither sufficient nor necessary, yet when combined may play an important role in the triggering and maintenance of mood disorders (Maes and Meltzer, 1995). Moreover, the categorical view -low 5-HT is specific for depression- has gradually been replaced by a dimensional approach: low 5-HT explains in part the vulnerability to mood liability across diagnoses, rather than depression per se.

The aim of this thesis was to find evidence for the concept of serotonergic vulnerability in animal studies applying the method of acute TRP depletion. Serotonergic vulnerability was described and several possible causes were discussed (Chapter 2). Next, the presence of SV was studied experimentally by exposing rats to acute TRP depletion. Several possible vulnerability factors were studied: the female sex (chapter 4), different rat strains (chapter 5), stress (chapter 6), and absence or diminished functionality of the serotonin transporter (chapter 7).

\section{Serotonergic vulnerability}

As was proposed in Chapter 2, serotonergic vulnerability means that the there is a vulnerability or sensitivity to natural or experimental alterations or dysregulations in the serotonergic system (based upon Maes and Meltzer, 1995, van Praag, 1996, Aberg-Wistedt et al., 1998, Bhagwagar et al., 2002, Booij et al., 2002, Neumeister et al., 2002, Riedel et al., 2002, Sobczak et al., 2002a, Sobczak et al., 2002b). There are various factors that may interfere with 5-HTergic functioning, such as genetic factors, a family history of depression, the female gender, stress, and drug use. The proposed model was one in 
which each factor disrupts the 5-HT system, resulting in serotonergic vulnerability, but psychopathology symptoms do not occur until a threshold is reached where the system can no longer compensate.

The female gender was proposed as a factor that may cause SV, based upon the higher prevalence of depression and anxiety in women compared to men (for review see Piccinelli and Wilkinson, 2000), the presence of several sex differences in serotonergic indices and interactions between oestrogen and 5-HT. Furthermore, in human ATD studies mood effects are more prevalent in women than in men. We studied the effects of ATD in male and female rats (Chapter 4) and found that the effects of ATD on both brain TRP and behaviour in anxiety-related test situations depended on sex and the oestrous cycle phase of the females. Females in the pro-oestrus and oestrus phase of the oestrous cycle showed a stronger response to acute TRP depletion compared to male rats and females in met-oestrus and di-oestrus.

Furthermore, we evaluated whether Sprague Dawley and Brown Norway rats differed in SV (Chapter 5) and concluded that Sprague Dawley rats showed a stronger behavioural response to ATD on almost all behavioural tests and thus appear to have higher SV, although biochemical effects were more pronounced in Brown Norways.

The role of stress as a possible cause of SV was assessed in an experiment in which male Wistars were exposed to chronic mild stress, followed by a two-week resting period, after which they were treated with ATD and behaviour and cognition were tested (Chapter 6). Although the chronic mild stress procedure was effective in causing an anhedonia-related reduction in sucrose consumption and blunted weight gain and lower corticosterone levels, it did not result in increased SV; in general the stressed group did not show stronger behavioural responses to ATD.

In order to investigate the role of the serotonin transporter in serotonergic vulnerability, the effects of ATD were examined in SERT ${ }^{+/+}$, SERT ${ }^{+-}$and SERT ${ }^{-1-}$ rats (Chapter 7). SERT ${ }^{-/}$rats showed the strongest brain 5 -HT reduction and was more sensitive to ATD effects on object recognition memory. $\mathrm{SERT}^{+/-}$showed intermediate sensitivity to ATD in the object recognition test. In other behavioural tests there was in general no indication of higher SV in SERT ${ }^{-/-}$and/or $\mathrm{SERT}^{+/-}$rats compared to $\mathrm{SERT}^{+/+}$rats.

\section{Acute tryptophan depletion as a method to study SV}

From the definition of SV, it is a logical consequence that SV can be demonstrated by challenging the 5-HT system. Several methods can be applied to challenge the serotonergic system and study the effect of serotonin on behaviour in animal experiments. These include challenging the serotonergic system with a serotonergic probe, such as 5-HT releasing agents, SSRIs, receptor agonists or antagonists, and methods that challenge the 5-HT system by reducing serotonergic functioning. Serotonergic challenge tests, involving the administration of a 5-HTergic probe and the subsequent assessment of one or more anterior pituitary hormones, such as cortisol, ACTH, growth hormone 
and prolactin, can be used to measure serotonergic responsivity in human and animal studies. A blunted neuroendocrine response to serotonergic agonists has been found in depressed patients, but it is unclear whether this abnormality persists following clinical recovery (Bhagwagar et al., 2002). More research is needed to evaluate the use of serotonergic drug challenges as a tool for studying SV.

Selective neurotoxins such as 5,7-dihydroxytryptamine (5,7-DHT) (Harrison et al., 1997, Hall et al., 1999), or the tryptophan hydroxylase inhibitor p-chlorophenylalanine (PCPA) (Mazer et al., 1997) can be used to study the chronic effects of selective reductions of 5-HT. These methods may be valuable tools for studying the role of serotonin in behaviour, but because these methods have permanent consequences they are, at least is their current form, not ideal for studying SV. Due to their toxicity, these methods cannot be applied in human studies. Acute tryptophan depletion on the other hand, results in a transient reduction in peripheral and central TRP and central 5-HT. The method of acute tryptophan depletion has been described as a way to identify a subgroup of patients with a specific serotonergic 'vulnerability' (Aberg-Wistedt et al., 1998) and as a suitable model of vulnerability to depression (Booij et al., 2005). The mood response to ATD in healthy controls with a family history of depression might indicate a biological vulnerability, which is revealed by the depletion (Ruhe et al., 2007). A relapse of depressive symptoms in remitted patients after ATD probably reflects a biological vulnerability of the 5-HT system (Booij et al., 2002, Booij et al., 2003, Bell et al., 2005, Ruhe et al., 2007), which increases their risk to become depressed. In two prospective studies, the mood response to ATD in remitted patients was used to predict later relapse/recurrence (Neumeister et al., 1999, Moreno et al., 2000). ATD may disclose a trait vulnerability rather than a pure state dependent change due to depletion (Ruhe et al., 2007). From Chapter 4, 5, 6 and 7 of this thesis it appears that ATD functions as a method to reveal SV in rats as well.

\section{Specificity of acute tryptophan depletion}

Whether ATD can be used to study SV depends on the selectivity and specificity of the ATD method on 5-HT. ATD is theorized to result in reduced synthesis of 5-HT (Gessa et al., 1974, Moja et al., 1989) and reduced synthesis of proteins in general (Blazek and Shaw, 1978, Cortamira et al., 1991). The latter effect is a non-specific effect that occurs after the depletion of any amino acid. In order to test the specificity of the ATD method, (Klaassen et al., 1999) treated healthy volunteers with an amino acid either lacking TRP or lacking the essential amino acid lysine, or a balanced control mixture. They found that the ATD effects on mood and memory are specific for TRP depletion and are not caused by the depletion of an amino acid per se. This supports the hypothesis that ATD affects brain serotonin metabolism and not just brain protein metabolism in general. These results make general effects on protein synthesis an unlikely explanation for the ATD effects on mood and memory. 
Our ATD procedure appears to selectively lower plasma and central TRP and central 5-HT and 5-HIAA. There were no considerable treatment effects on other plasma (chapter 3, Lieben et al., 2004a) and brain amino acids (Chapter 4, Lieben et al., 2004a). Although plasma concentrations of several amino acids changed over the four hours after treatment, these effects were generally similar in the TRP+ and the TRP- condition (Chapter 3). Although at the time of behavioural testing, several plasma amino acid concentrations differed between treatment conditions, these differences were small compared to the difference in TRP (Chapter 3). In male Wistars (Lieben et al., 2004a), Sprague Dawley and Brown Norway rats (Chapter 5) concentrations of DA, DOPAC, and HVA have been shown to be unaffected by ATD.

In this thesis, the most consistent finding was the ATD-induced impairment of object recognition. Previously, several non-serotonergic explanations of impaired object recognition after ATD have been suggested by our group (Riedel et al., 1999, Blokland et al., 2004, Lieben et al., 2004a). For example, ATD may affect N-methyl-D-asparate (NMDA) receptor functioning via the kynurenine (KYN) pathway. It is likely that ATD also decreases the amount of KYN, the primary degradation product of TRP, which is further converted to several metabolites, such as KYN acid (KYNA) and quinolinic acid (QUIN). Independent of each other, these metabolites are connected with NMDA receptors (Perkins and Stone, 1982), which can inhibit long term potentiation and lead to memory impairments (Morris et al., 1986, Saucier and Cain, 1995). KYNA has an antagonising effect on NMDA receptors and has a neuroprotective role, but QUIN can result in overstimulation of NMDA receptors and result in neurotoxic effects. Based on these facts it can be speculated that changes in the KYN pathway can affect cognitive function. Furthermore, ATD has been reported to decrease citrulline (CIT) in the brain without affecting peripheral levels (Lieben et al., 2004a). It is known that arginine (ARG) is catalysed into CIT and nitric oxide (NO). ATD can affect CIT in the brain without affecting its precursor ARG, which could indicate that ATD might decrease NO synthesis, and in this way affect learning and memory (Prast and Philippu, 2001). Another possible explanation is that ATD results in memory impairment through a general decrease in protein synthesis, as drug-induced inhibition of protein synthesis in the brain is an animal model of memory disorders (Sarter et al., 1992). However, (Klaassen et al., 1999) showed that depletion of the essential amino acid lysine, which is not related to cognition or behaviour but was assumed to result in decreased protein synthesis, did not affect memory.

Our TRP+ condition was designed to be a balanced control, but may have had some influence on peripheral and central AA concentrations. From the results presented in chapter 3, it appeared that a slight increase in TRP in the TRP+ condition could maintain a stable plasma TRP $/ \Sigma$ LNAA ratio over the four hours after treatment. Therefore, an additional $0.02 \mathrm{mg}$ TRP of TRP was added to the TRP+ mixture in subsequent experiments (Chapters 5, 6, and 7). However, this slight increase resulted in a small increase in the plasma TRP and the TRP/ $\Sigma$ LNAA ratio in the TRP+ condition in Sprague Dawley 
and Brown Norway rats (Chapter 5) and in SERT ${ }^{+/+}, \mathrm{SERT}^{+/-}$and $\mathrm{SERT}^{-/-}$rats (Chapter 7). In the latter rats, brain 5-HT was increased in the TRP+ condition. Whether this was also the case in the Sprague Dawley and Brown Norway rats is not known, as there were no brain samples of untreated rats available in that study. Thus, in some experiments our $\mathrm{TRP}+$ condition may have resulted in mild TRP suppletion instead of being a balanced control. In other experiments a slight decrease in the plasma TRP/ $\Sigma$ LNAA ratio has been reported (Chapters 4 and 6).

In both human and rat studies, ATD can be used to reveal SV. In humans, the female gender, a family history of depression, serotonin transporter polymorphism genotype, and drug use can influence the response to ATD. In this thesis, female oestrous cycle phase (Chapter 4), rat strain (Chapter 5) and serotonin transporter genotype (Chapter 7) influenced the response to ATD.

\section{Effects of ATD on TRP and 5-HT levels}

Effects of ATD on plasma TRP and the TRP/ $L$ LNAA ratio were similar in all groups. Within some experiments, there were differences in the central effects of ATD. In Chapter 4 , females in pro-oestrus and oestrus show stronger central ATD reduction than females in met-/di-oestrus. This group of females also showed stronger behavioural effects of ATD. In Chapter 5, there was a dissociation between strong 5-HT depletion in the frontal cortex and hippocampus to ATD and strong behavioural effects. Brown Norway rats showed strong central 5-HT depletion in the absence of behavioural effects, while Sprague Dawley rats showed strong behavioural effects of ATD in the absence of strong central 5-HT depletion. However, ATD decreased 5-HIAA/5-HT turnover in Sprague Dawleys, but not Brown Norways, which may have been more important than 5-HT depletion in the occurrence of behavioural effects of ATD. This decreased turnover may indicate that 5-HT neurotransmission was decreased in Sprague Dawley rats.

In Chapter 7, $\mathrm{SERT}^{-/-}$rats showed much stronger brain 5-HT reduction compared to $\mathrm{SERT}^{+/+}$and $\mathrm{SERT}^{+/-}$rats. However, $\mathrm{SERT}^{-/-}$did not show increased anxiety- and depression- related behaviour after ATD, again suggesting that decreased central 5-HT does not necessarily cause behavioural effects. A different behavioural response to ATD was found only in the object recognition task, after mild depletion. SERT ${ }^{-/-}$rats not only showed strong depletion of central 5-HT, they also showed strong increases in central 5HIAA/5-HT turnover. It is unclear whether either of these findings is related to the ATD effect on object recognition memory. It should be noted that SERT ${ }^{+/-}$rats showed object recognition impairment after mild depletion that was intermediate between $\mathrm{SERT}^{+/+}$and $\mathrm{SERT}^{-/}$rats, a pattern that was not found in either central 5-HT depletion or 5-HIAA/5HT turnover. However, these data are not available in the TRP- $40 \mathrm{~g}$ condition, in which the differences in object recognition memory were found.

In conclusion, ATD results in decreases plasma TRP and central TRP and 5-HT, but there is no straightforward relationship between peripheral or central ATD effects and 
behavioural effects. It appeared that strong depletion of plasma TRP/ $\Sigma$ LNAA does not always predict strong 5-HT depletion, especially in the hippocampus, and that plasma TRP/ $\Sigma$ LNAA and central 5-HT depletion are not necessarily accompanied by decreased 5-HIAA/5-HT turnover. In some cases, stronger behavioural and/or cognitive responses were associated with stronger TRP and/or 5-HT depletion effects in the brain. Lowering of the 5-HIAA/5-HT turnover may be important for the occurrence of behavioural effects, but more research is needed in this area.

\section{Effects of ATD on affective behaviour}

In human studies, ATD does not lower mood in currently depressed patients, but it can cause mild effects on mood in remitted depressed patients, especially those treated with SSRIs, in euthymic untreated remitted depressed patients and in healthy volunteers. ATD has been found to result in mild, subclinical mood effects in vulnerable groups; mood lowering effects have been reported in subjects with higher baseline depression scores, in females, in subjects with a personal history of depression, in subjects with a history of suicide attempts in subjects with a family history of depression and in carriers of the sallele of the serotonin transporter promoter region polymorphism (see Bell et al., 2005). Results are generally mixed and even in the group of SSRI treated recovered patients only 50-60\% reported clinical worsening of mood in response to ATD (Booij et al., 2002). ATD, either combined with a pharmacological panicogenic challenge or not, generally does not result in increased anxiety in healthy volunteers, although small increases in anxiety and nervousness have been reported (Goddard et al., 1995, Klaassen et al., 1998). Similar to results in depression, ATD does not increase anxiety in untreated panic disorder patients, but combined with a panicogenic challenge ATD increased anxiety and the rate of panic attacks (Miller et al., 2000, Schruers et al., 2000). This was also found in SSRI treated remitted anxiety disorder patients (Bell et al., 2005). However, lowered 5-HT has also been reported to have anxiolytic effects, such as impaired recognition of fearful facial expressions in women (Harmer et al., 2003) and reduced anxiety behaviour as measured by an inhibitory anxiety response during exposure to novel stimuli in rats (Bechtholt et al., 2007).

In this thesis, anxiety-related behaviour was tested using the open field test, home cage emergence test, elevated zero or plus maze and social interaction test and depressionrelated behaviour was evaluated using the forced swim test.

Anxiety-related behaviour In the open field test, ATD resulted in increased anxietyrelated behaviour only in Sprague Dawley rats, they spent more time in the corners and moved a shorter distance after ATD (Chapter 5). Although females in the pro-oestrus and oestrus phase of the oestrous cycle showed a stronger response to ATD in the open field test compared to male rats and females in met-oestrus and di-oestrus, this response 
was anxiolytic in nature: they spent less time in the corners and moved a longer distance (Chapter 4). In SERT ${ }^{+/+}$and SERT ${ }^{+/}$rats, TRP- treatment resulted in the anxiolytic effects of increased time spent in the center and increased distance moved compared to TRP+ treatment, but these effects were not found in SERT ${ }^{-/-}$rats (Chapter 7). In the chronic mild stress study, ATD did not have any effect on behaviour in the open field in any of the groups (Chapter 6).

In the home cage emergence test, females in pro/oes showed a stronger behavioural response to ATD than females in met/di and men, and again this response was anxiolytic in nature: after ATD they escaped from the home cage after a shorter time (Chapter 4). A similar ATD effect was found in Sprague Dawley rats (Chapter 5). CMS pretreatment did not influence the ATD response on escape latency, but CMS rats showed higher escape latency, suggesting an anxiogenic effect of exposure to the CMS procedure (Chapter 6). SERT $^{+/+}$and SERT ${ }^{-/}$rats showed ceiling effects, but SERT ${ }^{+/}$rats had a higher escape latency after TRP- compared to TRP+ treatment, suggesting an anxiogenic response of ATD in these rats (Chapter 7).

In the elevated zero maze, time spent in the open zones of the zero maze was decreased after TRP- treatment only the control rats of the CMS study (Chapter 6). In $\mathrm{SERT}^{+/+}, \mathrm{SERT}^{/-}$, and SERT ${ }^{+/}$rats, ATD did not influence behaviour on the elevated plus maze (Chapter 7), although marginal decrease of time spent in the closed zones after ATD suggests a decrease of anxiety- related behaviour after ATD.

In the social interaction test, ATD reduced the duration of passive body contact in males and females in pro/oes, but increased passive body contact was found in females in met/di. An increase in the percentage of active social interaction was found only in females in pro/oes (Chapter 4). In the CMS study, ATD resulted in a shorter duration of passive body contact (Chapter 6). Furthermore, TRP- treatment resulted in more aggressive behaviour compared to TRP+ treatment in the control rats of the CMS study. In Sprague Dawley and Brown Norway rats, and in SERT ${ }^{+/+}$, SERT ${ }^{--}$, and $\mathrm{SERT}^{+/-}$rats, ATD did not affect behaviour in the social interaction test (Chapters 5 and 7). Effects of ATD on the total duration of social interaction were not found in any of the studies.

In summary, The effects of ATD on anxiety-related behaviour are inconsistent. Decreased, increased, and unchanged indices of anxiety were found after ATD, and results were different in the various tests of anxiety-related behaviour. Females in pro/oes showed a stronger behavioural effect on anxiety- related behaviour after ATD compared to males and females in met/di. Sprague Dawley rats showed ATD effects on anxietyrelated behaviour whereas no effects were found in Brown Norway rats. This may reflect higher SV in these groups. The ATD response on behaviour in the open field test and home cage emergence test was qualitatively different in Sprague Dawley rats and in $\mathrm{SERT}^{+/-}$rats, indicating that the open field test and the home cage emergence test measure different aspects of the anxiety domain. This is in accordance with previous reports suggesting that escape behaviour, as measured in the home cage emergence test, may 
reflect a different anxiety-related trait than the activity and time spent in the different zones of the open field test and plus maze (Prickaerts et al., 1996).

Depression-related behaviour When rats are forced to swim in an inescapable situation, they typically display an immobile posture, which is considered to reflect a state of behavioural despair. Antidepressant treatments are known to reduce immobility time in the forced swim test (Connor et al., 2000) and it is assumed that a procedure that produced depressive-like effects should have the opposite effect, as has been reported repeatedly after chronic mild stress (Molina et al., 1994, Willner, 2005, Huang and Lin, 2006). Previous ATD studies showed mixed results (Blokland et al., 2002, Lieben et al., 2004b). In this thesis, immobility was found to be higher in males than in females in all oestrous cycle phases (Chapter 4) and in Sprague Dawley rats compared to Brown Norway rats (Chapter 5). ATD did not result in increased immobility in study described in this thesis, although the Strain $\times$ Treatment interaction effect on immobility that was reported in Chapter 6 indicated opposite effects of ATD on immobility in Sprague Dawley and Brown Norway rats. Thus, the only group that showed signs of SV in the forced swim test was the Sprague Dawley strain. Perhaps the forced swim test is not very sensitive in detecting effects of ATD.

\section{Effects of ATD on memory}

In healthy subjects ATD impairs consolidation of newly learned information/material (Klaassen et al., 1999, Riedel et al., 1999, Schmitt et al., 2000, Riedel et al., 2002, Sambeth et al., 2007). In general, these affects are found independent of SV factors and show some similarity to symptoms of depression. In the experiments described in this thesis, ATD affected memory in the object recognition test. Usually, there was no difference in object recognition after TRP- treatment between assumed SV and non-SV subjects, all groups show impaired object recognition. This effect was found in male and female Wistar rats, in male Sprague Dawley rats and in male SERT ${ }^{++}, \mathrm{SERT}^{+-}$, and SERT ${ }^{-/-}$rats. The only group that did not show this effect were the Brown Norways. These rats did show lower discrimination after TRP- treatment, but the effect was not significant. Thus in general, rats respond with impaired object recognition after two full doses of ATD, similar to the ATD-induced memory effects in humans.

However, at a lower ATD dose, the object recognition test may be sensitive enough to detect differences between SV and non-SV groups. This was shown in SERT ${ }^{+/+}$, $\mathrm{SERT}^{+-}$, and $\mathrm{SERT}^{-/-}$rats after a TRP- dose with only $40 \mathrm{~g}$ of the TRP free protein instead of the normal $100 \mathrm{~g}$. After this relatively mild depletion treatment impaired object recognition was found in $\mathrm{SERT}^{+/-}$and especially in $\mathrm{SERT}^{-/}$rats but not in $\mathrm{SERT}^{+/+}$. Furthermore, it was found in a mega-analysis that the ATD-induced memory impairments were larger in females than in males (Sambeth et al., 2007), which is generally not found in individual studies, probably because these smaller studies lack the statistical power to 
pick up small effects. Thus, it appears that ATD-induced memory effects may be stronger in hypothesized SV subjects, provided that the statistical power is high enough and the memory test is sensitive enough to detect differences in impairment in the applied ATD procedure. The question remains whether these effects might represent mild first symptoms of depression or the starting symptoms of a cascade of altered brain function leading to depression (Ruhe et al., 2007), or whether the effects on cognition occur relatively separate from the mood effects.

\section{Final evaluation}

Several studies in humans suggest that factors such as the female gender and genetic factors can cause SV, reflected by a mood response to ATD. In this thesis, we investigated several factors that could cause SV separately, in a controlled setting in an animal model. ATD elicited different behavioural effects in different groups of rats, suggesting ATD can be used in rats to study SV. Most of the factors tested, however, did not result in SV as reflected by an increased behavioural response to ATD on tests of anxiety-and depression-related behaviour. It appeared that oestrous cycle phase, rat strain and serotonin transporter genotype can influence the biochemical and behavioural response to ATD, whereas the female sex in general and exposure to chronic mild stress did not affect the behavioural response to ATD. Taken together, it could be argued that the presence of one factor may not be sufficient to cause SV. In human studies it is not always possible to separately study different factors that may influence the 5-HT system, which can explain the mixed results that are generally found in human studies. Although it is considered an advantage that animal studies allow for a more separate investigation of different factors, in this thesis it appeared that most of the separate factors did not result in SV or at least not in a level of SV that was revealed by ATD in these models.

A stronger effect of ATD on cognition may be associated with SV, just as the mood response to SV. ATD impairs object recognition memory in almost all groups of rats. However, when low-dose ATD was used, SERT rats showed a genotype dependent impairment of object memory; SERT ${ }^{+/+}$showed the least and SERT ${ }^{-/-}$the most impairment. This interesting finding indicated that the effects of ATD on memory may be a promising area of further study. The results described in this thesis indicate that the effects on memory are relatively straightforward and uncomplicated to study in animal models compared to effects on 'mood'. Hence, if a stronger memory impairment after ATD is able to discriminate between serotonergically vulnerable and non-vulnerable or less vulnerable populations, this would be an interesting model to further study of SV in rats.

Several questions remain that might be interesting for future studies. In this thesis, genetic influences (different strains, Chapter 5; SERT, Chapter 7) were associated with the strongest behavioural responses to ATD. This raises the question whether the Wistar is the optimal strain to investigate SV in. Because it appears that the presence of a single factor that can affect the 5-HT system is not enough to cause SV, future studies investi- 
gating the effect of a factor that may cause SV (e.g., stress) may require the use of a rats train with already higher SV than the Wistar. At this point, it cannot be excluded that, for example, stronger Sex $\times$ ATD or CMS $\times$ ATD interaction effects would have been found when a strain with higher baseline SV had been used. The Sprague Dawley may be a good candidate, because this strain showed the strongest effect of ATD in the strains that have been tested thus far. It should be noted though, that Sprague Dawleys were not directly compared with Wistars in the same experiment, making it difficult to draw conclusions regarding the level of SV in Sprague Dawleys compared to Wistars. Furthermore, it is unclear why the Sprague Dawleys showed higher SV than Brown Norways. It would be interesting to further examine the differences in serotonergic functioning between these two strains, and what it is that makes the Brown Norways unresponsive to ATD. The influence of central 5-HT lowering in different brain structures, as well as the ATD effects on 5-HIAA and 5-HIAA/5-HT turnover require further investigation. Finally, the cognitive effects of ATD appear promising for further investigation; groups that are hypothesized to differ in SV should be tested in the object recognition test (and perhaps other cognitive tests) with different doses of ATD and/or varying inter-trial interval to evaluate whether impaired object recognition after ATD can be used to study SV.

\section{References}

Aberg-Wistedt, A., Hasselmark, L., Stain-Malmgren, R., Aperia, B., Kjellman, B. F. and Mathe, A. A., 1998. Serotonergic 'vulnerability' in affective disorder: a study of the tryptophan depletion test and relationships between peripheral and central serotonin indexes in citalopram-responders. Acta Psychiatr Scand. 97, 374-380.

Bechtholt, A. J., Hill, T. E. and Lucki, I., 2007. Anxiolytic effect of serotonin depletion in the novelty-induced hypophagia test. Psychopharmacology (Berl). 190, 531-540.

Bell, C. J., Hood, S. D. and Nutt, D. J., 2005. Acute tryptophan depletion. Part II: clinical effects and implications. Aust N Z J Psychiatry. 39, 565-574.

Bhagwagar, Z., Whale, R. and Cowen, P. J., 2002. State and trait abnormalities in serotonin function in major depression. Br J Psychiatry. 180, 24-28.

Blazek, R. and Shaw, D. M., 1978. Tryptophan availability and brain protein synthesis. Neuropharmacology. 17, 1065-1068.

Blokland, A., Lieben, C. and Deutz, N. E., 2002. Anxiogenic and depressive-like effects, but no cognitive deficits, after repeated moderate tryptophan depletion in the rat. J Psychopharmacol. 16, 39-49.

Blokland, A., Lieben, C., Deutz, N. E. P. and Schmitt, J., 2004. Acute tryptophan depletion: comparing the effects of an amino acid mixture with a gelatin-based protein in man and rat. Current Topics in Nutraceutical Research. 2, 161-169.

Booij, L., van der Does, A. J., Haffmans, P. M., Spinhoven, P. and McNally, R. J., 2005. Acute tryptophan depletion as a model of depressive relapse: behavioural specificity and ethical considerations. Br J Psychiatry. $187,148-154$.

Booij, L., Van der Does, A. J. and Riedel, W. J., 2003. Monoamine depletion in psychiatric and healthy populations: review. Mol Psychiatry. 8, 951-973.

Booij, L., Van der Does, W., Benkelfat, C., Bremner, J. D., Cowen, P. J., Fava, M., Gillin, C., Leyton, M., Moore, P., Smith, K. A. and Van der Kloot, W. A., 2002. Predictors of mood response to acute tryptophan depletion. A reanalysis. Neuropsychopharmacology. 27, 852-861. 
Connor, T. J., Kelliher, P., Shen, Y., Harkin, A., Kelly, J. P. and Leonard, B. E., 2000. Effect of subchronic antidepressant treatments on behavioral, neurochemical, and endocrine changes in the forced-swim test. Pharmacol Biochem Behav. 65, 591-597.

Cortamira, N. O., Seve, B., Lebreton, Y. and Ganier, P., 1991. Effect of dietary tryptophan on muscle, liver and whole-body protein synthesis in weaned piglets: relationship to plasma insulin. Br J Nutr. 66, 423-435.

Gessa, G. L., Biggio, G., Fadda, F., Corsini, G. U. and Tagliamonte, A., 1974. Effect of the oral administration of tryptophan-free amino acid mixtures on serum tryptophan, brain tryptophan and serotonin metabolism. J Neurochem. 22, 869-870.

Goddard, A. W., Charney, D. S., Germine, M., Woods, S. W., Heninger, G. R., Krystal, J. H., Goodman, W. K. and Price, L. H., 1995. Effects of tryptophan depletion on responses to yohimbine in healthy human subjects. Biol Psychiatry. 38, 74-85.

Hall, F. S., Devries, A. C., Fong, G. W., Huang, S. and Pert, A., 1999. Effects of 5,7-dihydroxytryptamine depletion of tissue serotonin levels on extracellular serotonin in the striatum assessed with in vivo microdialysis: relationship to behavior. Synapse. 33, 16-25.

Harmer, C. J., Rogers, R. D., Tunbridge, E., Cowen, P. J. and Goodwin, G. M., 2003. Tryptophan depletion decreases the recognition of fear in female volunteers. Psychopharmacology (Berl). 167, 411-417.

Harrison, A. A., Everitt, B. J. and Robbins, T. W., 1997. Central 5-HT depletion enhances impulsive responding without affecting the accuracy of attentional performance: interactions with dopaminergic mechanisms. Psychopharmacology (Berl). 133, 329-342.

Huang, T. Y. and Lin, C. H., 2006. Role of amygdala MAPK activation on immobility behavior of forced swim rats. Behav Brain Res. 173, 104-111.

Klaassen, T., Klumperbeek, J., Deutz, N. E., van Praag, H. M. and Griez, E., 1998. Effects of tryptophan depletion on anxiety and on panic provoked by carbon dioxide challenge. Psychiatry Res. 77, 167-174.

Klaassen, T., Riedel, W. J., Deutz, N. E., van Someren, A. and van Praag, H. M., 1999. Specificity of the tryptophan depletion method. Psychopharmacology (Berl). 141, 279-286.

Lieben, C. K., Blokland, A., Westerink, B. and Deutz, N. E., 2004a. Acute tryptophan and serotonin depletion using an optimized tryptophan-free protein-carbohydrate mixture in the adult rat. Neurochem Int. 44, 9-16.

Lieben, C. K., van Oorsouw, K., Deutz, N. E. and Blokland, A., 2004b. Acute tryptophan depletion induced by a gelatin-based mixture impairs object memory but not affective behavior and spatial learning in the rat. Behav Brain Res. 151, 53-64.

Maes, M. and Meltzer, H. Y., 1995. The Serotonin Hypothesis of Major Depression. In: Bloom, F. E. and Kupfer, D. J. (Eds.), Psychopharmacology: The Fourth Generation of Progress. Raven Press, Ltd., New York, pp. 933-944.

Mazer, C., Muneyyirci, J., Taheny, K., Raio, N., Borella, A. and Whitaker-Azmitia, P., 1997. Serotonin depletion during synaptogenesis leads to decreased synaptic density and learning deficits in the adult rat: a possible model of neurodevelopmental disorders with cognitive deficits. Brain Res. 760, 68-73.

Miller, H. E., Deakin, J. F. and Anderson, I. M., 2000. Effect of acute tryptophan depletion on CO2-induced anxiety in patients with panic disorder and normal volunteers. Br J Psychiatry. 176, 182-188.

Moja, E. A., Cipolla, P., Castoldi, D. and Tofanetti, O., 1989. Dose-response decrease in plasma tryptophan and in brain tryptophan and serotonin after tryptophan-free amino acid mixtures in rats. Life Sci. 44, 971-976.

Molina, V. A., Heyser, C. J. and Spear, L. P., 1994. Chronic variable stress or chronic morphine facilitates immobility in a forced swim test: reversal by naloxone. Psychopharmacology (Berl). 114, 433-440.

Moreno, F. A., Heninger, G. R., McGahuey, C. A. and Delgado, P. L., 2000. Tryptophan depletion and risk of depression relapse: a prospective study of tryptophan depletion as a potential predictor of depressive episodes. Biol Psychiatry. 48, 327-329.

Morris, R. G., Anderson, E., Lynch, G. S. and Baudry, M., 1986. Selective impairment of learning and blockade of long-term potentiation by an N-methyl-D-aspartate receptor antagonist, AP5. Nature. 319, 774-776.

Neumeister, A., Habeler, A., Praschak-Rieder, N., Willeit, M. and Kasper, S., 1999. Tryptophan depletion: a predictor of future depressive episodes in seasonal affective disorder? Int Clin Psychopharmacol. 14, 313-315. 
Neumeister, A., Konstantinidis, A., Stastny, J., Schwarz, M. J., Vitouch, O., Willeit, M., Praschak-Rieder, N., Zach, J., de Zwaan, M., Bondy, B., Ackenheil, M. and Kasper, S., 2002. Association between serotonin transporter gene promoter polymorphism (5HTTLPR) and behavioral responses to tryptophan depletion in healthy women with and without family history of depression. Arch Gen Psychiatry. 59, 613-620.

Perkins, M. N. and Stone, T. W., 1982. An iontophoretic investigation of the actions of convulsant kynurenines and their interaction with the endogenous excitant quinolinic acid. Brain Res. 247, 184-187.

Piccinelli, M. and Wilkinson, G., 2000. Gender differences in depression. Critical review. Br J Psychiatry. 177, 486-492.

Prast, H. and Philippu, A., 2001. Nitric oxide as modulator of neuronal function. Prog Neurobiol. 64, 51-68.

Prickaerts, J., Raaijmakers, W. and Blokland, A., 1996. Effects of myocardial infarction and captopril therapy on anxiety-related behaviors in the rat. Physiol Behav. 60, 43-50.

Riedel, W. J., Klaassen, T., Deutz, N. E., van Someren, A. and van Praag, H. M., 1999. Tryptophan depletion in normal volunteers produces selective impairment in memory consolidation. Psychopharmacology (Berl). 141, 362-369.

Riedel, W. J., Klaassen, T. and Schmitt, J. A., 2002. Tryptophan, mood, and cognitive function. Brain Behav Immun. 16, 581-589.

Ruhe, H. G., Mason, N. S. and Schene, A. H., 2007. Mood is indirectly related to serotonin, norepinephrine and dopamine levels in humans: a meta-analysis of monoamine depletion studies. Mol Psychiatry. 12, 331-359.

Sambeth, A., Blokland, A., Harmer, C. J., Kilkens, T. O., Nathan, P. J., Porter, R. J., Schmitt, J. A., Scholtissen, B., Sobczak, S., Young, A. H. and Riedel, W. J., 2007. Sex differences in the effect of acute tryptophan depletion on declarative episodic memory: a pooled analysis of nine studies. Neurosci Biobehav Rev. 31, 516-529.

Sarter, M., Hagan, J. and Dudchenko, P., 1992. Behavioral screening for cognition enhancers: from indiscriminate to valid testing: Part I. Psychopharmacology (Berl). 107, 144-159.

Saucier, D. and Cain, D. P., 1995. Spatial learning without NMDA receptor-dependent long-term potentiation. Nature. 378, 186-189.

Schmitt, J. A., Jorissen, B. L., Sobczak, S., van Boxtel, M. P., Hogervorst, E., Deutz, N. E. and Riedel, W. J., 2000. Tryptophan depletion impairs memory consolidation but improves focussed attention in healthy young volunteers. J Psychopharmacol. 14, 21-29.

Schruers, K., Klaassen, T., Pols, H., Overbeek, T., Deutz, N. E. and Griez, E., 2000. Effects of tryptophan depletion on carbon dioxide provoked panic in panic disorder patients. Psychiatry Res. 93, 179-187.

Sobczak, S., Honig, A., Nicolson, N. A. and Riedel, W. J., 2002a. Effects of acute tryptophan depletion on mood and cortisol release in first-degree relatives of type I and type II bipolar patients and healthy matched controls. Neuropsychopharmacology. 27, 834-842.

Sobczak, S., Riedel, W. J., Booij, I., Aan Het Rot, M., Deutz, N. E. and Honig, A., 2002b. Cognition following acute tryptophan depletion: difference between first-degree relatives of bipolar disorder patients and matched healthy control volunteers. Psychol Med. 32, 503-515.

van Praag, H. M., 1996. Faulty cortisol/serotonin interplay. Psychopathological and biological characterisation of a new, hypothetical depression subtype (SeCA depression). Psychiatry Res. 65, 143-157.

Willner, P., 2005. Chronic mild stress (CMS) revisited: consistency and behavioural-neurobiological concordance in the effects of CMS. Neuropsychobiology. 52, 90-110. 



\section{Summary}

In this thesis a model is proposed in which serotonin is a vulnerability factor for the development of depression and other forms of psychopathology. Furthermore, the concept of serotonergic vulnerability was evaluated in animal studies applying the method of acute TRP depletion. Groups of rats that were hypothesized to differ in SV were repeatedly treated with the gelatin-based protein-carbohydrate mixture and the effects of this method of acute TRP depletion on depression- and anxiety- related behaviour and cognition were evaluated by testing the rats in several behavioural tests. A stronger behavioural response to ATD on tests of anxiety- and depression- related behaviour was assumed to reflect SV.

Chapter 1: An introduction is provided in which the synthesis of serotonin from tryptophan is described and the role of serotonin in depression and other forms of psychopathology is discussed, which points to serotonin as a vulnerability factor.

Chapter 2: The concept of serotonergic vulnerability is outlined. In recent years, the term 'serotonergic vulnerability' has been used in scientific literature, but so far it has not been explicitly defined. In this chapter an attempt is made to elucidate the SV concept. SV can be defined as increased sensitivity to natural or experimental alterations of the serotonergic system. Several factors that may disrupt the serotonergic system and hence contribute to SV are discussed, including genetic factors, female gender, personality characteristics, several types of stress and drug use. It is explained that SV can be demonstrated by means of manipulations of the serotonergic (5-HTergic) system, such as 5-HT challenges or acute tryptophan depletion (ATD). Results of 5-HT challenge studies and ATD studies are discussed in terms of their implications for the concept of SV. The proposed model is one in which each factor disrupts the 5-HT system, until a threshold is reached where the system can no longer compensate and pathology occurs. In this way, a combination of the factors described may result in depression or other 5-HT related disorders. 
Chapter 3: To further investigate the pharmacokinetic effects of acute TRP depletion, several experiments were carried out in which dose and treatment effects of acute tryptophan depletion using a gelatin-based protein-carbohydrate mixture are studied in male and female Wistar rats. A protocol with two injections with 90 minutes interval or one with three injections with 60 minutes interval resulted in depletion of peripheral TRP levels of about $65-70 \%$ two to four hours after the first treatment. Object recognition was impaired two, four, and six hours after the first of two doses acute tryptophan depletion, suggesting that the central effects occurred rapidly and continued until at least six hours after the first of two doses, in spite of decreasing treatment effects on plasma TRP levels at that time point. The method of acute tryptophan depletion described here can be used to temporarily lower peripheral tryptophan levels and consequently affect 5-HT levels, to study the relationship between serotonin and behaviour by temporarily lowering brain tryptophan in male and female rats.

Chapter 4: Women are more vulnerable to develop depression and anxiety disorders than men. This may be related to higher serotonergic vulnerability in women. In this experiment it was evaluated whether male and female Wistar rats differ in serotonergic vulnerability. Female oestrous cycle phase was determined by means of vaginal smears and the females were divided into two groups based on their oestrous cycle phase: pro-oestrus/oestrus and met-oestrus/di-oestrus. Blood samples showed stronger TRP depletion in males than females. In contrast to plasma concentrations, treatment effects on some brain TRP concentrations were influenced by oestrous cycle phase, females in pro-oestrus/oestrus showed the strongest response to TRP depletion. In tests of anxiety- related behaviour, females in pro-oestrus/oestrus also showed the strongest behavioural response to acute TRP depletion. Acute TRP depletion affected object recognition, but did not affect behaviour in the forced swim test and a reaction time task. It is concluded that sex and oestrous cycle phase can influence several behavioural responses to ATD, and that females in pro-oestrus/oestrus show the strongest behavioural response to acute TRP depletion.

Chapter 5: It is known that genetic factors and a family history of depression are can increase the risk to develop depression. To test the hypothesis that different rat strains may differ in serotonergic vulnerability, Sprague Dawley and Brown Norway rats were treated with acute TRP depletion. These strains were chosen based on phenotypical characteristics, including normal activity in behavioural tests used in this study. SD rats appeared to have higher serotonergic vulnerability than BN rats, as they showed an increase in anxiety- and depression- related behaviour and impaired object recognition after ATD. We found a striking dissociation between ATD effects on hippocampal 5-HT concentrations and on behaviour; hippocampal 5-HT was significantly lower after ATD in BN, but not in SD rats. The higher SV in SDs may be related to the ATD-induced decrease in 5HIAA/5-HT turnover, reflecting decreased neurotransmission, in the frontal cortex and hippocampus, which were not found in BNs. 
Chapter 6: There is an obvious association between stress and depression. Depression is often preceded by stressful life events and stress can increase the vulnerability to develop depression, this may be caused by stress effects on the serotonergic system which make the system more vulnerable. To investigate whether stress can increase serotonergic vulnerability, we studied the influence of exposure to chronic mild stress on the effects of ATD. The CMS caused anhedonia, blunted weight gain and lower corticosterone levels. CMS was followed by a two-week resting period, after which CMS and ATD both influenced behaviour on some tests, but overall the CMS procedure did not result in serotonergic vulnerability, as the CMS rats in general did not show stronger behavioural responses to ATD than controls.

Chapter 7: During the last decade the serotonin transporter has been a major focus of attention in the genetic factors involved in depression. In humans, a form of a serotonin transporter polymorphism resulting in less transporter efficiency has been associated with an increased risk to develop depression. The aim of this experiment was to investigate whether male wildtype $\left(\mathrm{SERT}^{+/+}\right)$, heterozygous $\left(\mathrm{SERT}^{+-}\right)$, and knockout $\left(\mathrm{SERT}^{-/-}\right.$) serotonin transporter rats differ in serotonergic vulnerability. Plasma TRP levels and brain 5-HT and 5-HIAA levels were decreased in all genotypes after ATD, but the strongest effects were seen in SERT ${ }^{-/-}$rats. Results of most tests of anxiety- and depressionrelated behaviour did not indicate higher SV in SERT ${ }^{+/-}$and $\mathrm{SERT}^{-/-}$compared to $\mathrm{SERT}^{+/+}$ rats. In the object recognition test however, a SERT gene-dose effect was found on object recognition memory after a relatively mild ATD protocol, which may reveal an increased vulnerability to serotonin-related disorders.

Chapter 8: In the final chapter a general discussion is presented of the findings that were described in this thesis. Oestrous cycle phase, rat strain and serotonin transporter genotype can influence the biochemical and behavioural response to ATD, whereas the female sex in general and exposure to chronic mild stress were not associated with SV. In some cases, stronger behavioural and/or cognitive response was associated with stronger central depletion effects in the brain. In general it appeared that most of the separate factors did not result in SV or at least not in a level of SV that was revealed by ATD in these models. A stronger memory response to ATD may be associated with SV, just as the mood response to SV. ATD impairs object recognition memory in almost all groups of rats. However, when low-dose ATD was used, SERT rats showed a genotype dependent impairment of object memory; SERT ${ }^{+/+}$showed the least and SERT ${ }^{-1-}$ the most impairment. This interesting finding indicated that the effects of ATD on memory may be a promising area of further study. The use of ATD to study SV and the specificity of the ATD method are discussed, as well as directions for future research. 



\section{Samenvatting}

In dit proefschrift getiteld "Serotonerge kwetsbaarheid - experimenten in ratten waarin de methode van acute tryptofaan depletie wordt toegepast" wordt een model beschreven waarin serotonine (5-HT) wordt voorgesteld als een kwetsbaarheidfactor voor het ontstaan van depressie en andere 5-HT-gerelateerde stoornissen. Het concept 'serotonerge kwetsbaarheid' wordt geëvalueerd in experimenten waarin ratten werden behandeld met acute tryptofaan depletie. Verschillende groepen ratten, die verondersteld werden te verschillen in serotonerge kwetsbaarheid, zijn herhaaldelijk behandeld met een eiwit-koolhydraat mengsel op basis van gelatine, met of zonder tryptofaan, en de effecten van deze behandeling op angst- en depressie-gerelateerd gedrag en geheugen werden gemeten. Sterkere effecten van ATD op gedrag zouden een hogere serotonerge kwetsbaarheid reflecteren.

Hoofdstuk 1: Inleiding waarin de synthese van 5-HT uit tryptofaan wordt beschreven en de rol van 5-HT in depressie wordt geëvalueerd, wat uitmondt in een beschrijving van de rol van 5-HT als kwetsbaarheidfactor voor het ontstaan van depressie en andere stoornissen.

Hoofdstuk 2: Het concept 'serotonerge kwetsbaarheid' wordt beschreven. De laatste jaren wordt de term serotonerge kwetsbaarheid (SK) gebruikt in de wetenschappelijke literatuur, maar niet expliciet gedefinieerd. In dit hoofdstuk wordt SK gedefinieerd als toegenomen gevoeligheid voor natuurlijke of experimentele veranderingen in het serotonerge systeem. Verschillende factoren worden besproken die het serotonerge systeem kunnen beïnvloeden en zo SK kunnen veroorzaken, zoals genetische factoren, het vrouwelijke geslacht, persoonlijkheidsfactoren, verschillende soorten stress en drugsgebruik. Er wordt uitgelegd dat SK kan worden aangetoond door het serotonerge systeem te manipuleren, zoals wordt gedaan met 5-HT challenges en acute tryptofaan depletie (ATD). Uitkomsten van experimenten met 5-HT challenges en ATD worden besproken met betrekking tot de implicaties voor de SK hypothese. Er wordt een model voorgesteld waarin verschillende factoren het 5-HT systeem beïnvloeden, tot er een drempel wordt bereikt waarin het systeem niet meer kan compenseren en psychopathologie ontstaat. Op deze manier kan een combinatie van de beschreven factoren resulteren in depressie of andere 5-HT gerelateerde stoornissen. 
Hoofdstuk 3: Om de farmacokinetische effecten van acute tryptofaan depletie verder in kaart te brengen, zijn verschillende experimenten gedaan waarin doserings- en behandelingseffecten van ATD, door middel van eiwit-koolhydraat mengsel op basis van gelatine, zijn onderzocht in mannetjes en vrouwtjes Wistar ratten. Een protocol met 2 injecties met 90 minuten interval of een protocol met 3 injecties met 60 minuten interval leidde tot een daling van plasma TRP van ongeveer $65-70 \% 2$ tot 4 uur na de eerste behandeling. Twee, vier en zes uur na de eerste behandeling was object herkenning verslechterd, waaruit blijkt dat de centrale effecten van ATD snel optreden en lang aanhouden, terwijl het effect op plasma TRP concentratie na 6 uur al sterk is afgenomen. Acute tryptofaan depletie kan gebruikt worden om tijdelijk de concentraties van plasma TRP en dus centraal TRP en 5-HT te verlagen, om zo de relatie tussen serotonine en gedrag te bestuderen in mannelijke en vrouwelijke ratten.

Hoofdstuk 4: Depressie en angststoornissen komen meer voor bij vrouwen dan bij mannen. Dit kan komen door een grotere SK bij vrouwen. In dit experiment werd gekeken of mannelijke en vrouwelijke Wistar ratten verschillen in SK door gedrag te meten na behandeling met acute tryptofaan depletie. Bij vrouwtjes werd fase van de hormonale cyclus bepaald door middel van uitstrijkjes en de vrouwtjes werden verdeeld in twee groepen: vrouwtjes in pro-oestrus/oestrus en vrouwtjes in met-oestrus/di-oestrus. ATD leidde tot een sterkere daling van plasma TRP bij mannetjes. De centrale effecten bleken echter afhankelijk te zijn van de cyclusfase en waren het grootst in vrouwtjes in pro-oestrus/oestrus. In tests van angst- en depressie-gerelateerd gedrag vertoonden vrouwtjes in pro-oestrus/oestrus ook de grootste gedragseffecten als gevolg van de ATD behandeling. ATD verstoorde object herkenning in alle groepen, maar had geen invloed op gedrag in de forced swim test en een reactietijd test. Er wordt geconcludeerd dat sekse en fase van de hormonale cyclus invloed kunnen hebben op gedragsresponse op ATD, en dat vrouwtjes in pro-oestrus/oestrus de grootste gedragseffecten laten zien.

Hoofdstuk 5: Genetische factoren en het voorkomen van depressie in de familie verhogen het risico op een depressie. Om de hypothese te testen dat rattenstammen verschillen in SK, werden Sprague Dawley (SD) en Brown Norway (BN) ratten herhaaldelijk behandeld met ATD. Deze stammen waren voornamelijk gekozen op basis van fenotypische kenmerken, zoals normaal gedrag in de tests die in dit experiment werden gebruikt. SD ratten bleken een grotere SK te hebben dan $\mathrm{BN}$ ratten, want ze toonden een toename in angst- en depressie-gerelateerd gedrag en verslechterde object herkenning na ATD. Er was een dissociatie tussen 5-HT verlaging in de hippocampus en gedragseffecten van ATD, aangezien 5-HT in de hippocampus was verlaagd in $\mathrm{BN}$ ratten, maar niet in SDs. De hogere SV in SD rats kan gerelateerd zijn aan een gevonden daling in 5-HIAA/5-HT turnover na ATD, duidend op afgenomen 5-HT neurotransmissie, in de frontale cortex en hippocampus. Deze daling werd niet gevonden bij BN ratten. 
Hoofdstuk 6: Er is een duidelijke relatie tussen stress en depressie: depressie wordt vaak voorafgegaan door stressvolle gebeurtenissen en stress kan de kans op een depressie doen toenemen. Dit laatste kan veroorzaakt worden door de effecten van stress op het serotonerge systeem, waardoor dit systeem meer kwetsbaar kan worden. Om te onderzoeken of stress kan leiden tot toegenomen SK, werden mannetjes Wistars gedurende drie weken blootgesteld aan chronische milde stress. De stress leidde tot anhedonia, afname van de groei en lagere corticosteron concentraties. Na de stress volgde en herstelperiode van twee weken, waarna de ratten werden behandeld met ATD om te kijken of de stress had geleid tot langdurige kwetsbaarheid van het serotonerge systeem. Hoewel de stress en de ATD allebei invloed hadden op het gedrag in sommige tests, leidde blootstelling aan chronische milde stress niet tot een toegenomen SK, want de ratten in de stress groep vertoonden over het algemeen geen grotere gedragseffecten van ATD dan de ratten in de controlegroep.

Hoofdstuk 7: Binnen de genetische factoren die ten grondslag liggen aan depressie is de laatste jaren veel aandacht besteed aan de 5-HT transporter. Bij mensen leidt een vorm van een polymorfisme in de 5-HT transporter tot verminderde effectiviteit van deze transporter en een toegenomen risico op depressie. In dit experiment werd bestudeerd in hoeverre mannelijke wildtype $\left(\mathrm{SERT}^{+/+}\right)$, heterozygote $\left(\mathrm{SERT}^{+/}\right)$, and knockout $\left(\mathrm{SERT}^{-/}\right)$5-HT transporter ratten verschillen in SK.Plasma TRP en centrale 5-HT en 5-HIAA concentraties waren afgenomen in alle genotypes na ATD, maar de sterkste effecten werden gevonden in $\mathrm{SERT}^{-/-}$rats. Hoewel resultaten van de meeste tests op het gebied van angst- en depressie-gerelateerd gedrag niet wezen op hogere SK in SERT ${ }^{+/-}$ en SERT ${ }^{-/-}$ratten dan in SERT ${ }^{+/+}$rats, werd er in de object herkenningstaak een grotere gevoeligheid voor milde ATD gevonden in $\mathrm{SERT}^{+/}$en vooral SERT ${ }^{-/}$ratten .

Hoofdstuk 8: In het laatste hoofdstuk worden alle bevindingen bediscussieerd die in dit proefschrift besproken zijn. Fase van de hormonale cyclus, rattenstam en 5-HT transporter genotype kunnen de biochemische en gedragsmatige effecten van ATD beïnvloeden, terwijl het vrouwelijke geslacht in het algemeen en blootstelling aan chronische milde stress niet hebben geleid tot grotere SK. In sommige gevallen waren sterkere veranderingen in gedrag en cognitie geassocieerd met sterkere centrale depletie effecten. Over het algemeen kan worden geconcludeerd dat de meeste bestudeerde factoren niet hebben geleid tot duidelijke SK, tenminste niet tot een niveau van SK dat aan het licht te brengen was met ATD in de gebruikte tests. Een sterkere verstoring van geheugen na ATD is mogelijk geassocieerd met SV, net als een toename in angst- en depressie-gerelateerd gedrag. ATD verstoord object herkenning in bijna alle onderzochte groepen ratten. Een mildere ATD behandeling, die leidt tot minder sterke daling van plasma TRP, veroorzaakte een verstoring van object herkenning die afhankelijk was van het SERT genotype: $\mathrm{SERT}^{+/+}$ vertoonden de minste verstoring en SERT ${ }^{-/-}$de meeste. Deze interessante bevinding in de effecten van ATD op geheugen nodigen uit tot verder onderzoek. Het gebruik van ATD om SV te bestuderen en de specificiteit van de ATD methode worden bediscussieerd. 



\section{Appendix}

\section{The effects of sex and oestrous cycle on object recognition memory}

L.A.W. Jans, A. Blokland 


\begin{abstract}
Substantial differences in cognitive function between men and women have been recognized for well over 50 years, and there is increasing evidence that fluctuations in sex hormones in are associated with changes in cognitive pattern. In this experiment the effects of sex and oestrous cycle phase on object recognition memory were studied in Wistar rats. Females were divided into two groups based upon oestrous cycle phase as determined by vaginal cytology; the first group consisted of females in pro-oestrus and oestrus, and the second group was composed of females in met-oestrus and di-oestrus. No sex difference was found, but within the group of females, oestrous cycle phase significantly affected object recognition memory. Females in pro-oestrus/oestrus showed better object recognition memory compared to females in met-oestrus/di-oestrus. These results suggest that oestrous cycle can influence behaviour and cognition and hence should be taken into account in experiments that include female subjects.
\end{abstract}




\section{Introduction}

Sex differences have been observed in many behavioural tests in both humans and laboratory rats and sex differences in cognitive processes are well known. In general, women perform better than men on verbal and memory tasks, whereas men excel in spatial tasks (Delgado and Prieto, 1996, Collins and Kimura, 1997). Rodents are commonly used to study cognitive functions, and they also show sex differences: males tend to perform better than females in spatial memory tasks (Jonasson, 2005), while females show a better performance in an object recognition test (Ghi et al., 1999). The object recognition test is a non-spatial memory test in which a familiar object is substituted by a novel one. The object recognition test is ethologically relevant, because it relies on the animals natural exploratory behaviour. Rats typically respond to environmental changes by preferential exploration of novel objects over those that are familiar, and this preference indicates the consolidation of information regarding the identity of the object.

Because of the fluctuations of female hormone levels observed during the oestrous cycle, oestrous cycle stage is emerging as an important consideration when working with female animals (Singletary et al., 2005). If females differ from males on some, but not all, days of the oestrous or menstrual cycle and when females are selected randomly, they may not be randomly distributed across the cycle, and a sex difference could be missed.

By 2 months of age, young female rats are reproductively mature and exhibit oestrous cycles and ovulation every 4 to 5 days. This is one of the most rapid ovarian cycles among mammals, and its is made possible by truncating the cycle after ovulation. In other female mammals, ovulation is followed by a luteal phase, which is maintained by hormones produced by the corpus luteum (a transient endocrine gland comprising the residual components of the follicle that remain after ovulation). In rats, the corpus luteum becomes functional only when the female engages in sexual behaviours that activate a progestational reflex that prolongs the secretion of progesterone from the corpus luteum. Female rats exhibit regular cyclicity until middle age, when animals then undergo a transition to irregular cyclicity and finally to acyclicity by 12 to 18 months of age. Generally, by 10 to 12 months of age, animals lose the ability to conceive and are considered to be 'reproductively senescent' (Becker et al., 2005, Singletary et al., 2005).

The rat oestrous cycle can be divided into four stages: pro-oestrus, oestrus, metoestrus, and di-oestrus. The ovarian cycle begins with the development of follicles in the ovary. Low concentrations of FSH from the pituitary stimulate follicular development. Oestradiol secretion increases gradually during this phase. In the rat, this stage is 2 days long. The first day is called met-oestrus, and the second day is di-oestrus. This is the follicular phase, which is followed by the preovulatory period, pro-oestrus in rats. Oestradiol increases dramatically, acting on the brain to trigger $\mathrm{GnRH}$ release, which induces a surge of LH from the pituitary that induces ovulation. Progesterone rises a few hours before ovulation and contributes to this process. Once $\mathrm{LH}$ and progesterone are released 
into the circulation, ovulation occurs 10-12 hours later. Oestrus is the period of sexual receptivity and the actual day of ovulation (Becker et al., 2005, Singletary et al., 2005).

Ovarian steroid action in the brain is not limited to reproductive effects and behaviours. In rats, as well as other species, these effects produce transient changes in behaviour. Measuring a trait in gonadally intact males and females is important because it gives information on the trait measured under natural conditions, with all endocrine feedback systems operating and all natural gonadal secretions operating (Becker et al., 2005). Research during the pas decade confirms that gonadal steroids have the ability to influence the structural properties of the brain regions that subserve learning and memory (Sutcliffe et al., 2007). In order to investigate the effects of the female oestrous cycle on object recognition memory, the group of females were subdivided in females in the pro-oestrus/ oestrus phase (pro/oes; characterized by higher levels of oestradiol and progesterone) and females in the met-oestrus/di-oestrus phase (met/di; characterized by lower levels of oestradiol and progesterone) of the oestrous cycle. This resulted in a total of three different experimental groups: males, females in pro/oes, and females in met/di.

\section{Materials and methods}

\section{Animals}

All experimental procedures were approved by the local ethical committee of the Maastricht University for animal experiments and met governmental guidelines. Subjects were twelve 4-month-old male Wistar rats weighing between 330 and $390 \mathrm{~g}$ at arrival and twenty-four female Wistar rats of the same age, weighing between 160 and $235 \mathrm{~g}$ at their arrival (Charles River, the Netherlands). All rats were singly housed in standard Macrolon cages on sawdust bedding in an air-conditioned room $\left( \pm 21^{\circ} \mathrm{C}\right)$. The animals always had free access to food and water. They were kept under a reversed 12/12-h light/ dark cycle. The lights were on from $17.00-05.00 \mathrm{~h}$. A radio, which was playing softly, provided background noise.

\section{Oestrous cycle}

To determine the oestrous cycle phase of each female, vaginal smears were taken between 7.00 and 10.00 am on all testing days. A plastic smear loop was inserted in the vaginal opening, gently rotated and withdrawn. The smear loop was immediately rolled onto a glass slide and allowed to air dry. Slides were examined under a light microscope for the presence of nucleated epithelial cells, cornified epithelial cells, leukocytes, and mucus. Oestrous cycle stage was determined using the following criteria: 1) pro-oestrus: predominantly nucleated epithelial cells; 2) oestrus: predominantly cornified epithelial cells; 3) met-oestrus: cornified epithelial cells and leukocytes; 4) di-oestrus: predomi- 
nantly leukocytes, some nucleated epithelial cells and mucus (Singletary et al., 2005). Female sex steroids vary with oestrous cycle phase. Plasma oestradiol levels peak during pro-oestrus and decrease during oestrus and met-oestrus, whereas the highest plasma progesterone levels have been observed during pro-oestrus and oestrus with lower levels during met-oestrus and di-oestrus (Butcher et al., 1974). Based on these plasma levels of sex steroids, we subdivided the group of females into two groups based on oestrous cycle phase. Females in pro-oestrus and oestrus formed one group, and the other group consisted of females in met-oestrus and di-oestrus. Similar subdivisions of cycling females have been made in other studies measuring behaviour and oestrous cycle (Contreras et al., 2000). In short, there were three experimental groups in this study: males, females in pro-oestrus and oestrus (pro/oes), and females in met-oestrus and di-oestrus (met/di).

\section{Object recognition test}

The object recognition test was performed as described in detail elsewhere (Ennaceur and Delacour, 1988, Prickaerts et al., 2002). The apparatus consisted of a circular arena, $83 \mathrm{~cm}$ in diameter. Half of the $40-\mathrm{cm}$-high wall was made of grey polyvinyl chloride, the other half of transparent polyvinyl chloride. Testing was carried out in dimmed white light. We used four different sets of objects that could not be displaced by a rat. Each object was available in triplicate. The different objects were: 1) a cone consisted of a grey polyvinyl chloride base (maximal diameter $18 \mathrm{~cm}$ ) with collar on top made of brass (total height $16 \mathrm{~cm}$ ), 2) a standard 11 transparent glass bottle (diameter $10 \mathrm{~cm}$, height $22 \mathrm{~cm}$ ) filled with water, 3) a massive metal cube $(10 \times 5 \times 7.5 \mathrm{~cm})$ with two holes (diameter $1.9 \mathrm{~cm}$ ), and 4$)$ a massive aluminium cube with a tapering top $(13 \times 8 \times 8 \mathrm{~cm})$.

In the week preceding testing, the animals were adapted to the procedure, i.e., they were allowed to explore the apparatus (without any objects) twice for $3 \mathrm{~min}$. In the following days, the rats were trained until a stable discrimination performance was shown. A testing session comprised two trials. The duration of each trial was $3 \mathrm{~min}$. Two objects were placed in a symmetrical position about $10 \mathrm{~cm}$ away from the grey wall. A rat was always placed in the apparatus facing the wall at the middle of the front (transparent) segment. During the first trial the apparatus contained two identical objects. After the first exploration period the rat was put back in its home cage. One hour later the rat was put back in the apparatus for the second trial, but now with dissimilar objects, a familiar one and a new one. The duration of exploring each object in both trials was recorded manually with a personal computer. Exploration was defined as directing the nose to the object at a distance of no more than $2 \mathrm{~cm}$ and/or touching the object with the nose. Sitting on the object was not considered as exploratory behaviour. In order to avoid the presence of olfactory trails, the objects were always thoroughly cleaned. Moreover, each object was available in triplicate so that none of the two objects from the first trial had to be used as the familiar object in the second trial. In addition, all combinations and locations of objects were used in a balanced manner to reduce potential biases due to preferences for particular locations or objects. 


\section{Statistical analysis}

The basic measures in the object recognition test were the times spent by rats exploring an object during trial 1 and trial 2. The discrimination index $d 2$ ((exploration new object trial 2 - exploration familiar object trial 2)/total exploration time during trial 2) was calculated for each group (Rutten et al., 2007). $d 2$ is a relative index of discrimination between new and familiar object, because it corrects for total exploration time in trial 2 (Şık et al., 2003). Effects of experimental group on object recognition were analysed with univariate ANOVA.

\section{Results}

There was no effect of experimental group on exploration times in trial 1 or trial 2 [Trial 1: $\mathrm{F}(2,32)=0.54$, ns; Trial 2: $\mathrm{F}(2,32)=1.53, \mathrm{~ns}]$. Exploration times are shown in Table 1. There was no effect of sex on discrimination index $d 2[\mathrm{~F}(1,33)-0.039$, ns]. However, there was an effect of experimental group on $d 2[\mathrm{~F}(2,32)=5.85, \mathrm{p}<0.01]$. Posthoc Bonferroni $(\mathrm{p}<0.01)$ showed that $d 2$ was significantly higher in females pro/oes compared to females met/di $[\mathrm{p}<0.01]$ (Figure 1).

Table 1. Exploration times in both trials of the object recognition test

\begin{tabular}{cccc}
\hline Exploration time & Male & Female pro/oes & Female met/di \\
\hline Trial 1 & $286.92(26.01)$ & $320.82(27.17)$ & $286.83(26.01)$ \\
Trial 2 & $393.25(30.75)$ & $425.18(32.12)$ & $347.92(30.75)$ \\
\hline
\end{tabular}

Mean exploration times (s) and SEM.

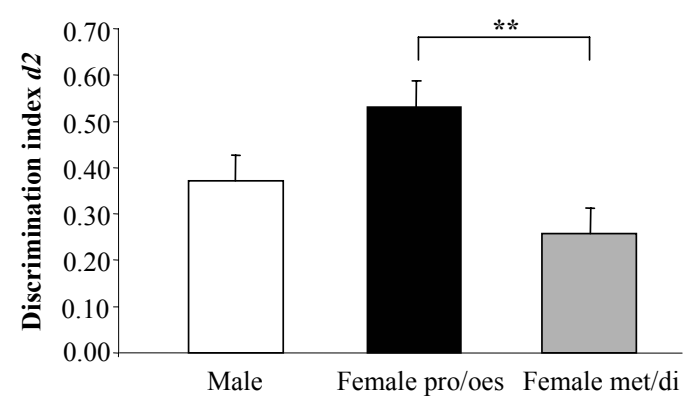

Figure 1. Object recognition test. Effects of experimental group on discrimination index $d 2 .{ }^{* *} \mathrm{p}<0.01$. 


\section{Discussion}

In the present study, male and female Wistar rats were tested in an object recognition test to study the effects of sex and oestrous cycle phase on object recognition memory. After the one-hour interval, all experimental groups spent a longer time exploring the novel object than the familiar object, indicating intact object recognition. No sex effect on object recognition was found, but females in pro-oestrus/oestrus had significantly better object recognition compared to females in met-oestrus/di-oestrus.

Previous studies have found normal object recognition memory after a one-hour interval in male (Lieben et al., 2005, Lieben et al., 2006, Rutten et al., 2007) and female Wistar rats (Jans et al., 2007). In the present study there was no sex effect on object recognition, whereas better object recognition in females compared to males has been reported previously (Ghi et al., 1999, Sutcliffe et al., 2007). However, in these studies longer lasting memory retrieval in females compared to males was found when the inter-trial interval was increased, an aspect that was not examined in the present study.

The finding of a significant oestrous cycle phase effect on object recognition, whereas there is no sex difference could be an important one. This could mean that in studies with a larger subject sample, females could show either better or worse object recognition, or there could be no sex difference, depending on the oestrous cycle phase that the majority of females were in during testing. Usually, female rodents and other mammals that spend a lot of time together synchronise their oestrous cycles, making it more likely that the females in one experiment are not evenly distributed across all oestrous cycle phases. Even if females in one experiment are in different phases, a sex difference could be missed because of the high variability in responses among the females.

In the present study, vaginal cytology was used to determine the oestrous cycle phase of the females and there were no blood samples taken to verify the oestrous cycle phase by measuring blood hormone levels. Vaginal smears are a reliable method of determining oestrous cycle phase, but inferring hormone levels from vaginal smears may not be as reliable. Although hormonal fluctuations during the oestrous cycle have been reported before (Becker et al., 2005, Singletary et al., 2005), having both hormonal and cytology data from the same rats could have increased the reliability of the results.

Another shortcoming of this study may be the rough division of oestrous cycle phases we made, by grouping pro-oestrus and oestrus together, and met-oestrus and dioestrus in another group. We made this division based on the follicular (i.e., met-oestrus and di-oestrus) when oestradiol and progesterone are low, and pro-oestrus/oestrus when levels are high. This may be considered a shortcoming, because there are big hormonal changes from pro-oestrus to oestrus, especially in oestradiol levels, which are high in pro-oestrus and low in oestrus (Becker et al., 2005, Singletary et al., 2005).

Furthermore, the females may have been exposed to higher levels of stress than the males, because of the vaginal smears that were taken several times throughout the study. Although there may not have been a direct effect of the stress on behaviour on the tests 
because the smears were taken at least three hours before testing, the presumably higher levels of stress in the females may nevertheless have influenced the results.

In conclusion, the present study showed no sex difference in the object recognition test with a one-hour interval between trials. Within the females, however, oestrous cycle phase significantly affected object recognition memory. These results suggest that oestrous cycle phase can influence behaviour and cognition and hence should be taken into account in experiments that include female subjects.

\section{References}

Becker, J. B., Arnold, A. P., Berkley, K. J., Blaustein, J. D., Eckel, L. A., Hampson, E., Herman, J. P., Marts, S., Sadee, W., Steiner, M., Taylor, J. and Young, E., 2005. Strategies and methods for research on sex differences in brain and behavior. Endocrinology. 146, 1650-1673.

Butcher, R. L., Collins, W. E. and Fugo, N. W., 1974. Plasma concentration of LH, FSH, prolactin, progesterone and estradiol-17beta throughout the 4-day estrous cycle of the rat. Endocrinology. 94, 1704-1708.

Collins, D. W. and Kimura, D., 1997. A large sex difference on a two-dimensional mental rotation task. Behav Neurosci. 111, 845-849.

Contreras, C. M., Molina, M., Saavedra, M. and Martinez-Mota, L., 2000. Lateral septal neuronal firing rate increases during proestrus-estrus in the rat. Physiol Behav. 68, 279-284.

Delgado, A. R. and Prieto, G., 1996. Sex differences in visuospatial ability: do performance factors play such an important role? Mem Cognit. 24, 504-510.

Ennaceur, A. and Delacour, J., 1988. A new one-trial test for neurobiological studies of memory in rats. 1: Behavioral data. Behav Brain Res. 31, 47-59.

Ghi, P., Orsetti, M., Gamalero, S. R. and Ferretti, C., 1999. Sex differences in memory performance in the object recognition test. Possible role of histamine receptors. Pharmacol Biochem Behav. 64, 761-766.

Jans, L. A., Lieben, C. K. and Blokland, A., 2007. Influence of sex and estrous cycle on the effects of acute tryptophan depletion induced by a gelatin-based mixture in adult Wistar rats. Neuroscience. 147, 304-317.

Jonasson, Z., 2005. Meta-analysis of sex differences in rodent models of learning and memory: a review of behavioral and biological data. Neurosci Biobehav Rev. 28, 811-825.

Lieben, C. K., Blokland, A., Şık, A., Sung, E., van Nieuwenhuizen, P. and Schreiber, R., 2005. The selective 5-HT6 receptor antagonist Ro4368554 restores memory performance in cholinergic and serotonergic models of memory deficiency in the rat. Neuropsychopharmacology. 30, 2169-2179.

Lieben, C. K., Steinbusch, H. W. and Blokland, A., 2006. 5,7-DHT lesion of the dorsal raphe nuclei impairs object recognition but not affective behavior and corticosterone response to stressor in the rat. Behav Brain Res. 168, 197-207.

Prickaerts, J., van Staveren, W. C., Şık, A., Markerink-van Ittersum, M., Niewohner, U., van der Staay, F. J., Blokland, A. and de Vente, J., 2002. Effects of two selective phosphodiesterase type 5 inhibitors, sildenafil and vardenafil, on object recognition memory and hippocampal cyclic GMP levels in the rat. Neuroscience. 113, 351-361.

Rutten, K., Lieben, C., Smits, L. and Blokland, A., 2007. The PDE4 inhibitor rolipram reverses object memory impairment induced by acute tryptophan depletion in the rat. Psychopharmacology (Berl). 192, 275-282.

Şık, A., van Nieuwehuyzen, P., Prickaerts, J. and Blokland, A., 2003. Performance of different mouse strains in an object recognition task. Behav Brain Res. 147, 49-54.

Singletary, S. J., Kirsch, A. J., Watson, J., Karim, B. O., Huso, D. L., Hurn, P. D. and Murphy, S. J., 2005. Lack of correlation of vaginal impedance measurements with hormone levels in the rat. Contemp Top Lab Anim Sci. 44, 37-42.

Sutcliffe, J. S., Marshall, K. M. and Neill, J. C., 2007. Influence of gender on working and spatial memory in the novel object recognition task in the rat. Behav Brain Res. 177, 117-125. 


\section{Dankwoord [Acknowledgements]}

Tijdens mijn AIO periode heb ik wel eens uitgekeken naar dit moment: het schrijven van het dankwoord, de laatste hand aan mijn proefschrift. Nu het zover is kijk ik terug op een intensieve, leerzame en over het algemeen leuke periode. Er zijn verschillende mensen die ik wil bedanken voor hun steun, hulp, advies en vertrouwen bij het tot stand komen van dit proefschrift.

Ten eerste promotor Prof. Dr. W. J. Riedel en copromotor Dr. A. Blokland. Wim, bedankt voor al je goede raad met betrekking tot het project en het proefschrift in het algemeen en het review artikel in het bijzonder. Arjan, ik had me geen betere begeleider kunnen wensen. Bedankt voor alle kansen die je me hebt gegeven. Ik kon altijd bij je terecht als $\mathrm{ik}$ advies nodig had en ik waardeer de vrijheid die je me hebt gegeven bij het uitvoeren van de experimenten en het schrijven van het proefschrift.

Van de capaciteitsgroep Neuropsychology and Psychopharmacology, Psychologie, wil ik Dr. C. R. Markus bedanken voor de prettige samenwerking aan het review artikel, en Anke voor het zijn van "contactpersoon" in de Uns 40 en natuurlijk voor de gezelligheid.

Verder dank aan Prof. Dr. H. W. M. Steinbusch van de afdeling Psychiatry and Neuropsychology, waar mijn werkplek was. Dr J. Prickaerts, Jos, bedankt voor je hulp en goede adviezen bij de uitvoering van de experimenten. Naast je ruime ervaring met gedragsexperimenten in het algemeen heeft vooral jouw expertise op het gebied van chronic mild stress me erg geholpen. Veel dank ben ik ook verschuldigd aan Marjanne Markerink en Helen Steinbusch, die mij hebben begeleid bij mijn eerste stapjes in het lab. Dankzij jullie kreeg ik snel de nodige labvaardigheden onder de knie. Helen, bedankt voor jouw hulp bij het interpreteren van uitstrijkes onder de micrsocoop - niet zelden in de zeer vroege ochtend. Voor de hulp bij de uitvoering van de experimenten -vele duizenden injecties- wil ik Laura Smits en Eva van Donkelaar bedanken. Daarnaast ook Kris, Marjo, en iedereen die wel eens een rat heeft vastgehouden voor een bloedafname. 
Dr C. K. J. Lieben, Cindy, dit proefschrift is gebaseerd op jouw eerdere werk, dus zonder jou was ook dit proefschrift er niet geweest. Je hulp en adviezen -vooral bij de eerste experimenten- hebben er aan bijgedragen dat de experimenten veelal soepel verliepen.

Prof. Dr. A. R. Cools en zo-goed-als-Dr. J. D. A. Olivier, bedankt voor de prettige samenwerking in het Psychoneurofarmacologie lab in Nijmegen. Ik ben erg blij dat jullie me de kans hebben gegeven om samen met jullie met de Serotonine transporter Knockout rat te werken. En het was ook nog eens erg gezellig! Jocelien, Rachel, Erik, Jesse en Michel bedankt voor de leuke tijd.

Mijn paranimfen, Monique van Mourik en Marjo van de Waarenburg. Monique, je bent al heel wat jaren mijn beste vriendinnetje en ik hoop dat dat nog lang zo blijft. Ook bedankt voor het beschikbaar stellen van Ramon voor het designen van de cover. Enorm bedankt Ramon! Marjo, we zijn jaren kamergenoten geweest en hebben veel gelachen, ook buiten het werk. Ondanks je superdrukke schema vond je altijd wel even tijd om te kletsen of om te helpen als dat nodig was. Leuk dat jullie beiden paranimf zijn!

Kris, ook jij was een super kamergenoot. Vooral in het begin, toen ik nog veel moest leren over de Limburgse taal en het p.o. injecteren van ratten, heb ik veel aan je gehad. Op een incidentele discutabele muziekkeuze (of beter: volume) na was je een ideale kamergenoot. Ook latere kamergenoten Laura en Olga: bedankt voor de leuke tijd die we hebben gehad, het was altijd erg gezellig bij ons op de kamer.

Dit proefschrift was er niet geweest zonder proefdieren. Ik wil dan ook alle snuitjes bedanken voor hun bijdrage aan de wetenschap. Ik heb altijd naar eer en geweten gehandeld met jullie en hoop dat jullie dat ook zo ervaren hebben. Ook de mensen van het CPV wil ik hier graag noemen: Allard, Richard, Nadine en de mensen die -vanuit onderzoekersoogpunt- meer achter de schermen werken.

Although the research in the Psychopharmacology lab at the University of Sydney ended up having nothing to do with this thesis, I think it was an essential part of my PhD period. I would like to thank Prof Iain McGregor for having me in the lab. Paul Callaghan, Petra van Nieuwenhuizen, and Rose Chesworth, I enjoyed working with you.

Papa, mama, Michiel en Margon, dank voor jullie interesse in wat ik doe (en de hulp bij het verhuizen). En natuurlijk Roel. Hoewel je regelmatig moest ervaren dat het werk altijd voorging, heb je me altijd gesteund. Daar kan ik je nooit genoeg voor bedanken.

Natuurlijk hebben er nog veel meer mensen een belangrijke rol gespeeld in mijn leven als AIO. Dank aan allen (collega's, vrienden, etc.) die op de een of andere manier een rol hebben gespeeld in het tot stand komen van dit boekje. 




\section{Curriculum vitae}

Linda Jans was born in Nijmegen on 14 September 1977 and grew up in Schaijk. She completed her secondary education (VWO) at the Mondriaan College in Oss in 1996. In that same year she started her study of Psychology at the Katholieke Universiteit Nijmegen (KUN), and in 2002 she graduated with honours in Biological Psychology. The following year she carried out a literature study and was engaged in teaching at the KUN. In 2004 she started her PhD project at the Faculty of Psychology, Maastricht University. The present dissertation is the result of her research conducted at Maastricht University. During her PhD project she had the opportunity to visit the Department of Cognitive Neuroscience, division Psychoneuropharmacology of the Radboud University Nijmegen. She also visited the Psychopharmacology Laboratory at the University of Sydney, Australia, for three months with a grant awarded by the Netherlands Organization for Scientific Research (NWO).

Linda Jans is geboren op 14 september 1977 in Nijmegen en groeide op in Schaijk. In 1996 behaalde ze haar VWO diploma aan het Mondriaan College te Oss en in datzelfde jaar begon ze met de studie Psychologie aan de Katholieke Universiteit Nijmegen (KUN). In 2002 behaalde ze haar doctoraal diploma Biologische Psychologie met genoegen. Daarna bleef ze korte tijd verbonden aan de KUN voor projectmatig literatuuronderzoek en het geven van onderwijs. In februari 2004 begon ze als promovendus (AIO) bij de Faculteit der Psychologie aan de Universiteit Maastricht. Dit proefschrift is het resultaat van het onderzoek aan de Universiteit Maastricht. Tijdens haar AIO periode kreeg ze de gelegenheid om de afdeling Cognitive Neuroscience, divisie Neuropsychofarmacologie van de Radboud Universiteit Nijmegen te bezoeken. Daarnaast bezocht ze gedurende drie maanden het Psychopharmacology Laboratory van de University of Sydney, Australië m.b.v. een beurs toegekend door de Nederlandse Organisatie voor Wetenschappelijk Onderzoek (NWO). 



\section{Publications}

\section{Journal articles}

Jans, L.A.W., Riedel, W.J., Markus, C.R., and Blokland, A. (2007). Serotonergic vulnerability and depression: assumptions, experimental evidence and implications. Molecular Psychiatry, 12, 522-543.

Jans, L.A.W., Lieben, C.K.J., and Blokland, A. (2007). Influence of sex and estrous cycle on the effects of acute tryptophan depletion induced by a gelatin-based mixture in adult Wistar rats. Neuroscience, 147, 304-317.

\section{Journal articles in progress}

Jans, L.A.W., Lieben, C.K.J., Smits. L.T., and Blokland, A. Pharmacokinetics of acute tryptophan depletion using a gelatin based protein in male and female Wistar rats. Submitted.

Jans, L.A.W., Korte-Bouws, G.A.H., Korte, S.M., and Blokland, A. The effects of acute tryptophan depletion on affective behavior and cognition in Brown Norway and Sprague Dawley rats. Submitted.

Jans, L.A.W., and Blokland, A. Influence of chronic mild stress on the behavioural effects of acute tryptophan depletion induced by a gelatin-based mixture. Submitted.

Olivier, J.D.A., Jans, L.A.W., Korte-Bouws, G.A.H., Korte, S.M., Deen, P.M.T., Cools, A.R., Ellenbroek, B.A., and Blokland, A. Acute tryptophan depletion dose-dependently impairs object memory in serotonin transporter knockout rats. Submitted. 


\section{Book chapter}

Jans, L.A.W., and Blokland, A. Women and serotonergic vulnerability. In: Women and Depression. New York: Nova Science Publishers, in press.

\section{Abstracts in international journals}

Olivier, J.D.A., Jans, L.A.W., van Swelm, R.P.L., Cuppen, E., Deen, P.M.T., Cools, A.R., Ellenbroek, B.A., and Blokland, A. (2007). Effects of acute tryptophan depletion in wildtype, heterozygous and knockout transporter rats. Behavioural Pharmacology 18, S108-S108.

Jans, L.A.W., Lieben, C.K.J., Deutz, N.E.P., and Blokland, A. (2005). The effects of acute tryptophan depletion on affective behaviour and cognition in male and female wistar rats. Behavioural Pharmacology 16, S89-S89.

Van Donkelaar, E.L., Jans, L.A.W., Blokland, A., Deutz, N.E.P., Kenis, G., Steinbusch, H.W.M., and Prickaerts, J. (2005). The effects of acute tryptophan depletion on BDNF protein levels in brain and serum of male and female rats. Behavioural Pharmacology 16, S89-S89. 